FACULTAD DE MEDICINA

\title{
"ESTUDIO CLÍNICO SOBRE EL COLOR DENTAL EN LA POBLACIÓN DE CASTILLA Y LEÓN"
}

TESIS DOCTORAL

CRISTINA GÓMEZ POLO

2012 



\section{"ESTUDIO CLÍNICO SOBRE EL COLOR DENTAL EN LA POBLACIÓN DE CASTILLA Y LEÓN"}

DIRECTORES:

Dr. Martínez Vázquez de Parga

Dra. Celemín Viñuela

Dr. Gómez Polo

TUTOR:

Dr. Herrero Payo

\section{TESIS DOCTORAL}

\section{CRISTINA GÓMEZ POLO}



Departamento de Cirugía

Universidad de Salamanca

PROF. CLEMENTE MURIEL VILLORIA. CATEDRÁTICO DE LA UNIVERSIDAD Y DIRECTOR DEL DEPARTAMENTO DE CIRUGÍA DE LA FACULTAD DE MEDICINA, EN LA UNIVERSIDAD DE SALAMANCA.

CERTIFICA:

Que el presente trabajo, titulado: "ESTUDIO CLínICO DEL COLOR DENTAL EN LA POBLACIÓN DE CASTILLA Y LEÓN" ha sido realizado por Doña Cristina Gómez Polo para optar al Grado de Doctor, cumpliendo todos los requisitos necesarios para su presentación y defensa ante el tribunal calificador.

Y para que así conste y obre los efectos oportunos, firmo el presente certificado en Salamanca a de de 2012.

Fdo.Prof. Clemente Muriel Villoria

Director de Departamento 

Departamento de Cirugía

Universidad de Salamanca

-PROF. DR. MARTINEZ VAZQUEZ DE PARGA, PROFESOR TITULAR DE LA FACULTAD DE ODONTOLOGÍA DE LA UNIVERSIDAD COMPLUTENSE DE MADRID. -PROF. DRA. CELEMÍN VIÑUELA, PROFESORA CONTRATADO DOCTOR DE LA FACULTAD DE ODONTOLOGÍA DE LA UNIVERSIDAD COMPLUTENSE DE MADRID. -PROF. DR. GÓMEZ POLO, PROFESOR ASOCIADO A LA FACULTAD DE ODONTOLOGÍA DE LA UNIVERSIDAD COMPLUTENSE DE MADRID.

-PROF. DR. HERRERO PAYO, PROFESOR ASOCIADO A LA FACULTAD DE MEDICINA DE LA UNIVERSIDAD DE SALAMANCA.

\section{HACEN CONSTAR:}

Que el presente estudio presentado por Doña Cristina Gómez Polo para optar al Grado de Doctor en Odontología con el título "ESTUDIO CLÍNICO DEL COLOR DENTAL EN LA POBLACIÓN DE CASTILLA Y LEÓN", es un trabajo original que sido realizado bajo nuestra supervisión y dirección.

Prof. Dr. Martínez Vazquez de Parga

Prof. Dra. Celemín Viñuela

Prof. Dr. Gómez Polo

Prof. Dr. Julio Herrero Payo 





\section{AGRADECIMIENTOS}

En primer lugar, me gustaría dar las gracias a la Dra. Celemín Viñuela, al Dr. Martínez Vázquez de Parga, al Dr. Gómez Polo y finalmente al Dr. Herrero Payo por aceptar la dirección de este trabajo. A todos ellos, por su colaboración, paciencia y dedicación, indispensable para desarrollar esta tesis doctoral.

A todos los compañeros de la Universidad de Salamanca, del departamento de Cirugía, especialidad de Odontoestomatología por animarme a seguir trabajando dentro de la carrera docente.

A Don Jorge Vizcaíno y a Doña Yolanda Oterino, por su información y apoyo constante en representación de la casa comercial Vita-Zahnfabrik (Alemania).

A Doña Carmen Bravo, del Centro de Proceso de Datos del Servicio Informático de Apoyo a la Investigación de la Universidad Complutense de Madrid, por su paciencia infinita durante la realización del estudio estadístico.

A todos y cada uno de los pacientes que de una manera desinteresada han aceptado participar en este estudio.

A mis compañeros de trabajo, Dr. Ramos García y Dr. Santos González por preocuparse de mi formación constante en el campo Odontológico.

A mis amigos, que siempre estuvieron a mi lado para ayudarme a no perder el ánimo.

Y gracias en definitiva, a todas aquellas personas que han hecho posible que este proyecto haya salido a la luz, a todas ellas, muchas gracias. 



\section{DEDICATORIA}

A mis padres y hermanos 

ÍNDICE 



\section{ÍNDICE}

1.- INTRODUCCIÓN. . . . . . . . . . . . . . . . . . . . . . 23

1.1.- GENERALIDADES SOBRE EL COLOR. . . . . . . . . . . 23

1.1.1.- Concepto de color 23

1.1.2.- Percepción del color 28

1.1.2.1.- Fuente de luz 29

1.1.2.2.- Objeto a observar 34

1.1.2.3.- Entorno 36

1.1.2.4.- Ojo humano 37

1.1.3.- Sistemas de Determinación del Color 41

1.1.3.1.- Tipos de colores 41

1.1.3.2.- Esfera cromática de Munsell 43

1.1.3.3.- CIE 1931 (x, y, z) 45

1.1.3.4.- CIE 1976 (CIELab) 47

1.1.4.- Umbrales de discriminación cromática 50

1.2.-COLOR EN OdONTOLOGíA. . . . . . . . . . . . . . . 52

1.2.1.- Características ópticas de los dientes 53

1.2.2.- Espacio cromático dental 60

1.2.3.- Medición del color en Odontología 61

1.2.3.1.- Métodos Subjetivos: Medición del color mediante guías dentales

1.2.3.2.- Métodos Objetivos: Medición del color mediante sistemas instrumentales

1.2.3.2.1.- Colorímetros 72

1.2.3.2.2.- Espectrofotómetros 77

1.2.4.- Condiciones óptimas en la selección del color 79

2.- JUSTIFICACIÓN. . . . . . . . . . . . . . . . . . . . . . 85

3.- HIPÓTESIS Y OBJETIVOS. . . . . . . . . . . . . . . . . 89

4.- MATERIAL Y MÉTODO. . . . . . . . . . . . . . . . . . . . . 93

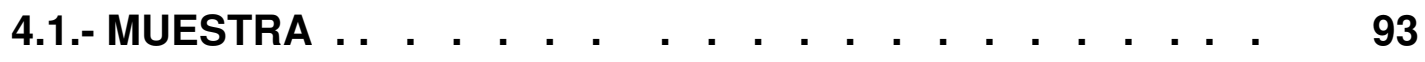

4.2.- MATERIAL. . . . . . . . . . . . . . . . . . . . . . . 96

4.3.- MÉTODO. . . . . . . . . . . . . . . . . . . . . . 106 
4.3.1.- Descripción de la toma de los registros del color

4.3.2.- Fórmulas de diferencia de color: Sistema CIELab y CIEDE2000

5.1.- ESTUDIO ESTADÍSTICO DESCRIPTIVO APLICADO A LAS

TRES DIMENSIONES DEL COLOR. . . . . . . . . . . . . 116

5.1.1.- Descriptiva de la muestra 116

5.1.2.- Descriptiva de variables cualitativas 117

5.1.2.1.- Subjetivas 117

5.1.2.2.- Objetivas 119

5.1.3.- Comparativa de las tres dimensiones del color en ambos métodos

5.2.- GRADO DE ACUERDO ENTRE EL MÉTODO OBJETIVO Y EL MÉTODO SUBJETIVO. . . . . . . . . . . . . . . . . . . 125

5.2.1.- Relativo a Coincidencias Absolutas 125

5.2.2.- Relativo a Coincidencias en Medios 130

5.3.- ASOCIACIÓN ENTRE VALOR, TINTE E INTENSIDAD

OBJETIVAS CON LOS GRUPOS DE EDAD Y EL GÉNERO. . . . . 133

5.3.1.- Valor (Luminosidad) 133

5.3.2.- Tinte 137

5.3.4.- Frecuencia de color de los dientes 141

5.4.- ANÁLISIS DE VARIABLES CONTINUAS ORDINALES $L, C, h$, ASOCIADAS A GRUPOS DE EDAD Y GÉNERO. . . . . . . . . 155

5.4.1.- Estudio estadístico descriptivo de variables continuas 155

5.4.2.- Estudio mediante el test de bondad de ajuste de

Kolmogorov-Smirnov

5.4.3.- Valor o Luminosidad (L) 160

5.4.4.- Intensidad (C) 166

5.4.5.- Tinte (h) 173

5.5.- EVOLUCIÓN DEL COLOR DENTAL CON EL ENVEJECIMIENTO DE LA POBLACIÓN. . . . . . . . . . . . 179

5.5.1.- Relación entre Valor o Luminosidad, Intensidad y Tinte con $L, C$ y $h$ respectivamente 
5.5.2.- Estudio de la evolución del color por décadas

5.6.- ESTUDIO DE LAS TABLILLAS DE COLOR DE LA GUÍA 3D

MASTER. . . . . . . . . . . . . . . . . . . 185

5.6.1.- Características descriptivas de las 26 tablillas de color 185

5.6.2.- Distancias de L, C, $h$, a y b entre las 26 tablillas de color

5.6.3.- Estudio de la ordenación de la guía $3 \mathrm{D}$ Master según las tres dimensiones del color

6.- DISCUSIÓN.

6.1.-COLOR DENTAL. . . . . . . . . . . . . . . . . . . . . 209

6.2.-FRECUENCIA DE COLORES. . . . . . . . . . . . . . 221

6.3.-MÉTODO SUBJETIVO. . . . . . . . . . . . . . . . . 222

6.4.-MÉTODO OBJETIVO. . . . . . . . . . . . . . . . . . 230

6.5.-COMPARATIVA ENTRE MÉTODO OBJETIVO Y MÉTODO

SUBJETIVO. . . . . . . . . . . . . . . . . . . . . . . . 236

6.6.- DISTRIBUCIÓN EN LA GUÍA 3D MASTER. . . . . . . . . . 240

7.- CONCLUSIONES. . . . . . . . . . . . . . . . . . . . . . . 249

8.- REFERENCIAS BIBLIOGRÁFICAS. . . . . . . . . . 253

9.-ANEXOS. . . . . . . . . . . . . . . . . . . . 271

9.1.- ANEXO I: ANÁLISIS DE CONGLOMERADOS. . . . . . . 271

9.1.1.-Análisis de todas las tablillas de color con peso $\quad 272$

9.1.2.-Análisis de todas las tablillas de color sin peso 279

9.1.3.-Análisis de las 26 tablillas de color de la guía 3D

Master con peso

284

9.1.4.-Análisis de las 26 tablillas de color de la guía 3D

Master sin peso

9.2.- ANEXO II: COMITÉ ÉTICO Y CONSENTIMIENTO

INFORMADO (CD Adjunto)

9.3.- ANEXO III: ESTUDIO ESTADÍSTICO (CD Adjunto) 



\section{1.- INTRODUCCIÓN}





\section{1.-INTRODUCCIÓN}

\section{1.- GENERALIDADES SOBRE EL COLOR}

\subsection{1.-Concepto de color}

Existen múltiples definiciones de color, entre algunas he seleccionado la de la Real Academia de la lengua Española que define, el color como "Sensación producida por los rayos luminosos que impresionan los órganos visuales y que depende de la longitud de onda" o también como, "Propiedad de la luz transmitida, reflejada o emitida por un objeto, que depende de su longitud de onda".

El color de los dientes es hoy día uno de los factores más importantes en la estética dentofacial. La Odontología Éstética comprende la integración armoniosa de las funciones fisiológicas orales, con la restauración o modificación de las estructuras dento-faciales para conseguir una armonía que lleve a una dentición ideal a través de la restauración del color, forma y función. Por este motivo vamos a desarrollar en profundidad los aspectos físicos que envuelven el fenómeno del color.

En las más remotas culturas, como la china, la bizantina, la eslava, la sudafricana o la maya, tan distintas entre sí y con rasgos propios tan peculiares, encontramos un factor común: la adoración al Sol. El Sol, en cuanto fuente de luz, es un dios, para ellos, reconociendo por esta creencia, su necesaria presencia en los ciclos de la vida.

En el mundo grecorromano, la influencia del Sol es tal, que es prácticamente imposible encontrar filósofo que no intente explicar el fenómeno de la visión, es decir, "explicar la luz", este es el caso de Pitágoras, Euclides, Ptolomeo, Heráclito,...

Con respecto al color, existen innumerables pruebas de su importancia en la Antigüedad. Sus templos, sus hogares e incluso sus tumbas, se adornan con colores que venciendo los embates del tiempo, aún causan admiración por su variedad y belleza. También en la Prehistoria, podemos encontrar la importancia del color en las pinturas rupestres de las cuevas de Altamira, como representación del arte paleolítico, y otro ejemplo relevante son las tumbas faraónicas de la sexta (2500 a C.) y duodécima (1900 a. JC) dinastías egipcias, con sus inigualables tonalidades de azules. 
Se podría decir que en el siglo $\mathrm{V}$ antes de Cristo hubo una afanosa búsqueda de la conexión entre el ojo y el objeto. De estas ideas se desarrollan, en el periodo helénico, tres corrientes teóricas:

La primera, la de la escuela pitagórica, que hace salir la luz del ojo. La segunda la de los atomistas de la escuela de Demócrito que estaban a favor de la emisión que partía de los cuerpos hacia el ojo. La tercera, la de la escuela platónica, Empédocles fue de los primeros en sostener una combinación de los dos flujos. Solamente, en el siglo siguiente, siglo IV a. C., la cuarta hipótesis se define en la obra de Aristóteles (384-322 aC), tal vez, como consecuencia de la insatisfacción por las otras ideas. Aristóteles consideraba la luz como movimiento entre el objeto y el ojo, por ello, parece pronunciarse por una teoría material en la que la luz, sea un fenómeno de naturaleza mecánica ${ }^{1}$.

Aristóteles identifica, junto al blanco y negro, cinco colores intermedios puros: blanco, amarillo, escarlata, violeta, verde, azul, negro (gris), formando una escala de siete colores, imitando la escala musical, que conocía bien, y que, por analogía, le proporcionaba el método de generar los colores intermedios, mediante proporciones numéricas. El resto de los colores son mezclas de los siete primarios (puros) de la escala. Los cinco colores básicos de Aristóteles son los "cinco colores estelares" en que Newton, veinte siglos después, descompone su Arco Iris.

Según Aristóteles, los colores no pueden estar contenidos en la luz, por ser más oscuros que ésta (pensamiento sostenido veinte siglos más tarde por Goëthe); pero, para verlos, necesitamos la luz, por eso escribió textualmente: "El color es visible a la luz".

La obra de Euclides (325-265 a. C) sobre Óptica es verdaderamente importante desde el punto de vista histórico, porque nos permite reconstruir la teoría de la luz que se estaba formando en la época. Euclides era un matemático, y su razonamiento tuvo una gran influencia sobre el desarrollo de la teoría de la luz.

Veamos los postulados básicos que Euclides exponía en su libro sobre Óptica.

1. El rayo emitido por el ojo va derecho. 
2. La figura comprendida por los rayos visuales es un cono que tiene el vértice en el ojo, y la base al margen del objeto mirado.

3. Se ven aquellos objetos a los cuales llegan los rayos visuales.

Euclides tiene el mérito de haber creado el modelo geométrico de la luz y el rayo luminoso rectilíneo y privado de estructura física, lo que ha servido a la construcción de la Óptica Geométrica actual.

En la Edad Media, una contribución decisiva se aportó con los descubrimientos fisiológicos y anatómicos del reconocido médico Galeno (129 dC - 200 dC), no solamente por haber descrito la estructura del ojo, sino por poner en evidencia la función del nervio óptico en la visión. Él lo consideraba como un canal a través del cual pasa el fluido visual proveniente del cerebro. Galeno se apunta a la idea platónica: un fluido externo hacia el ojo y uno interno que no sale del ojo, pero lo hace sensible y lo dispone para que sea impresionado por el fluido exterior.

Posteriormente, en 1630, el filósofo Descartes (1596-1650) atribuyó el color de los objetos al cambio experimentado en la luz cuando ésta se difunde desde aquellos. Hasta entonces, se creyó que la luz carecía de color, que éste pertenecía a los objetos y que la luz los hacía visibles ${ }^{2}$.

La idea que tenemos actualmente del color, podemos decir que es el resultado de aglutinar los esquemas de tres grandes pensadores de los siglos XVII, XVIII y XIX:

\begin{tabular}{|c|c|c|}
\hline ISAAC NEWTON & JOHANN GOËTHE & ARTHUR SCHOPENHAUER \\
\hline $1642-1727$ & $1749-1832$ & $1788-1860$ \\
\hline Finales del S. XVII & Finales del S. XVIII & Principios del S. XIX \\
\hline Física del color & Percepción del color & Sensación del color \\
\hline
\end{tabular}

Figura 1: Tabla resumen

El color se consideraba una entidad tridimensional en el siglo XIII. La concepción moderna del color nació con el descubrimiento de la naturaleza espectral de la luz que hizo Isaac Newton (1642-1727) en el siglo XVII. Newton fue quien en 1666 hizo pasar la luz a través de un prisma y observó que la luz se descomponía en un espectro de color. Demostró que la luz del día (blanca) se compone de muchos colores y que la combinación de ciertos colores de la luz da un resultado final blanco. 
Newton reemprende los trabajos sobre la luz sentando el "modelo corpuscular", que fue discutido desde un principio. Para Newton, la luz estaba constituida por partículas materiales que, lanzadas a gran velocidad por los cuerpos emisores, se propagaban en línea recta constituyendo los rayos de luz. Los colores, que hasta entonces se creían consecuencia de que la luz blanca se "contaminaba" al atravesar o chocar con los objetos coloreados, fueron interpretados por Newton después de descubrir la dispersión en el prisma. La luz era un complejo de ondas de longitud variable de 0,4 a 0,8 micras. Estas singulares ondas, de la más corta a la más larga, constituían la escala de los colores del arco iris desde el violeta hasta el rojo.

Como demostró Isaac Newton, la combinación de determinadas longitudes de onda en distintas proporciones en el intervalo emitido por el Sol da lugar a los colores que percibimos los seres humanos.

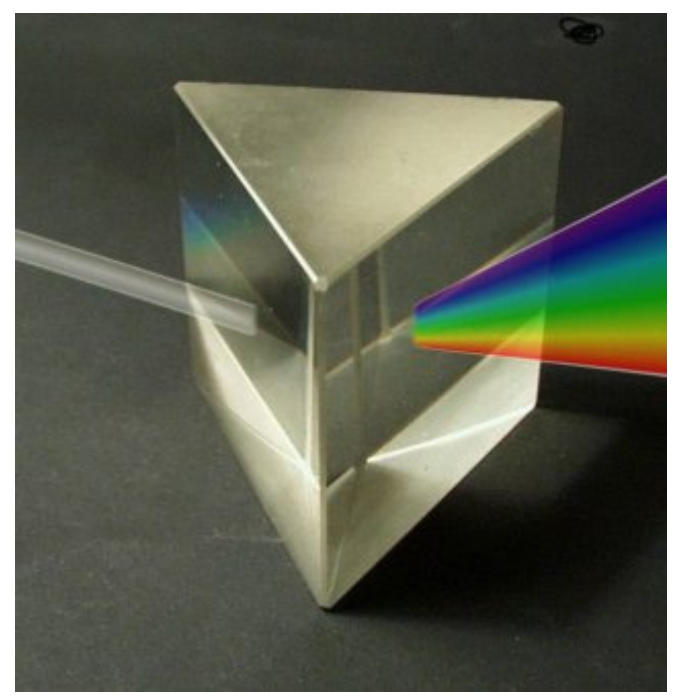

Figura 2: Experimiento de I. Newton ${ }^{3}$

Posteriormente, el filósofo Goëthe (1749-1832) afirmó que el color no existe en la luz que llega al objeto, siendo éste su verdadero creador.

Cuando Goëthe leyó a Newton, el poeta pudo completar aquello que el físico sólo había vislumbrado. La naturaleza, como ecuación, se vio así colmada por la naturaleza como comparación. La teoría de los colores de Goethe no es una óptica, sino una morfología de los colores.

La teoría de los colores de Goethe (1810) es un ejemplo de su opinión filosófica. Según esta opinión, nuestra psique dota al color de significado. Además, intentó deducir leyes sobre la armonía del color, incluyendo la forma en que nos afectan los 
colores y el fenómeno subjetivo de la visión. Las investigaciones de Goethe fueron la piedra angular de la actual psicología del color, ya que para él era fundamental entender la reacción humana a los colores.

Schopenhauer (1788-1860), ya a mediados del siglo XIX, convencido del aspecto subjetivo de las sensaciones escribió en 1810 "La Teoría de la visión y de los colores". Al estudiar los colores por indicación de su maestro Goëthe, va más allá que éste en su idea de la pureza del blanco y fiel a su pensamiento, coloca lo subjetivo por encima de lo objetivo. Para este autor las características de la imagen retiniana marcan el principio de la conversión de la energía exterior-luz- en la respuesta perceptual del color; idea de acorde con nuestros actuales conocimientos.

Y también la definición de color que en el año 2001, publica la Commission Internationale de I'Eclairage (C.I.E. $)^{4}:$ "Característica de la percepción visual que puede ser descrita por los atributos de Tinte o tono, Valor o luminosidad e Intensidad, saturación o croma".

De estas definiciones, se deduce, que el fenómeno del color es una respuesta psicosocial de la interacción física de la luz con un objeto, y la subjetiva experiencia del operador ${ }^{5}$. Además la percepción del color de un objeto es el resultado de una respuesta fisiológica a un estimulo fijo. Para que se produzca este fenómeno físico de la percepción del color es preciso que existan tres factores: la luz, un receptor u órgano de los sentidos que perciba dicho fenómeno y el objeto ${ }^{6}$.

Las ondas electromagnéticas que componen la luz inciden sobre el receptor, es decir, sobre el ojo humano en cuya retina se encuentran los conos y bastones, que son los receptores específicos de dichas ondas.

Un objeto varía de color dependiendo de la energía que ha sido absorbida o reflejada. Por ejemplo, un objeto parece rojo primariamente porque refleja una longitud de onda roja más que una longitud de onda azul o verde.

Grassmann comprobó en 1853 que las ecuaciones cromáticas gozan de las mismas propiedades que las identidades algebraicas. Este físico alemán sistematizó la teoría de la mezcla aditiva del color en una serie de conclusiones que se conocen como Leyes de Grassmann ${ }^{7}$ : 
1.-El ojo humano solo percibe tres atributos de luz: Valor o Luminosidad, Tinte o Tono, e Intensidad o Saturación o croma. Este postulado afirma que para definir una sensación de color es necesario y suficiente especificar tres magnitudes independientes.

2.- Si una luz varía de forma continua, la sensación de color de la mezcla aditiva con otra luz fija también varía de forma continua. Grassman, al contrario que Newton, asumió esta condición de continuidad de modo tan riguroso que llega a suponer que el púrpura tiene el mismo aspecto que el rojo extremo, de modo tal que el círculo se cierra definitivamente.

3.- El resultado de una mezcla aditiva de colores depende sólo de su aspecto y no de su composición física. El tercer postulado tiene gran importancia porque permite abstraer las características físicas de la luz y hablar simplemente de colores. Eso ha permitido a Grassmann interpretar los colores como vectores y la mezcla de dos colores como la suma de dos vectores.

4.- La intensidad luminosa de una mezcla aditiva de colores es la suma de la intensidad luminosa de los colores. Es decir, la intensidad de una mezcla es aditiva. Hoy día se sabe que esta afirmación sólo es verdad en algunos casos y el mismo Grassmann apuntaba que esta ley no está tan bien fundamentada como las precedentes, pero por las observaciones teóricas parece la más probable.

A partir de ahora y a lo largo de todo el texto se marcará con negrita y cursiva la palabra valor, cuando se refiera a luminosidad y así poder distinguirla de la misma palabra cuando se refiera a datos numéricos. De este modo, se señalarán las palabras tinte e intensidad como dimensiones del color. Con esta medida se pretende favorecer la comprensión y la lectura del presente trabajo de tesis doctoral.

\subsection{2.- Percepción del Color}

La percepción del color no es un fenómeno inexplicable, ya que debe considerarse como un concepto físico que puede ser medido y estudiado, pero que depende de varios factores que estudiaremos a continuación. Por eso debe ser analizado como un complejo interrelacionado en el que un cambio en alguno de los siguientes componentes se traduce en un cambio en la percepción del color ${ }^{8,9,10}$. 
El efecto cromático de un objeto, depende de tres elementos:

1.-la composición espectral de la fuente de luz;

2.- las propiedades físicas del objeto a observar.

3.- las propiedades sensitivas del aparato visual del observador.

Porque el ojo humano y en definitiva la visión o el proceso visual de cada observador no puede ser objetivo. El sistema del observador: ojo más cerebro afecta a la percepción del color ${ }^{10}$.

\subsubsection{1.- Fuente de luz}

Las primeras fuentes de luz empleadas por los hombres estuvieron basadas de alguna forma con la combustión, el fuego, las antorchas, las velas,...Posteriormente, los griegos y romanos fabricaron lámparas de arcilla o bronce con aceite de oliva u otros aceites vegetales como combustibles. La evolución del diseño de estas lámparas supuso añadir elementos reflectores para el mejor aprovechamiento de la luz producida. Alrededor del año 1800 las calles se alumbraban con lámparas de gas. Hacia el final del siglo XIX y principios del XX se inició el reemplazo de las lámparas de gas por lámparas eléctricas. Gracias a Edison que en el año 1879 inventó la lámpara incandescente transformándola en un éxito que aún perdura.

La luz es singular en la naturaleza. La radiación electromagnética puede describirse, considerando un modelo corpuscular, y/ o un modelo ondulatorio.

La luz es de naturaleza dual. Es tanto una partícula (fotón) como una onda; es decir, masa y energía. Es una forma de energía que consiste en radiaciones electromagnéticas que se extienden desde los rayos cósmicos a las ondas de radio más largas, con frecuencias desde tan solo unos pocos ciclos por minuto hasta $1 \times 10^{22}$ ciclos por segundo. Estas radiaciones electromagnéticas se propagan en línea recta con un movimiento ondulante en todas las direcciones a la velocidad de $299.792 \mathrm{~km}$ por segundo.

Las ondas del espectro electromagnético se pueden medir por tres parámetros: la frecuencia, la longitud de la onda, y la amplitud. 
La Frecuencia, se define como el número de ondas completas o ciclos por segundo. Ciclos por segundo también se expresa por hercios $(\mathrm{Hz})$.

La longitud de onda, se define como la distancia lineal ocupada por una onda completa o ciclo, medida horizontalmente. La longitud de onda de la luz se mide en nanómetros $(\mathrm{nm})$.

La amplitud es la diferencia entre el valor mínimo y el máximo de una onda; es decir, entre el valle y la cresta, distancia que se mide verticalmente. Longitud de onda y frecuencia no son independientes, ya que son inversamente proporcionales. Cuánto más pequeña sea la distancia entre las dos crestas de las ondas, tanto mayor será el número de ellas que entrarán en un espacio de un segundo de tiempo.

La luz es una forma de energía radiante electromagnética que puede detectar el ojo humano y que se propaga a través de ondas.

Nuestro sistema visual sólo es capaz de detectar una pequeña parte del espectro electromagnético y se le denomina "espectro visible". Así la retina humana sólo puede detectar longitudes de onda comprendidas entre los 380 (color violeta) y 780 (color rojo) $\mathrm{nm}$. El conjunto de radiaciones comprendidas entre estos valores constituye la luz solar percibida como luz blanca o incolora. En ambos lados del espectro visible están las longitudes de onda infrarrojas y ultravioletas, que son invisibles al ojo humano Es interesante destacar que un color de los que denominamos "caliente" como el rojo o naranja, está formado por radiaciones de longitud de onda larga y, por tanto, poseen menor energía que colores que son considerados "fríos" como el azul o el violeta.

\begin{tabular}{|c|c|c|}
\hline Color & Long. Onda (nanómetros) & Frecuencia \\
\hline Rojo & $800-650$ & $400-470$ \\
\hline Naranja & $640-590$ & $470-520$ \\
\hline Amarillo & $580-550$ & $520-590$ \\
\hline Verde & $530-490$ & $590-650$ \\
\hline Azul & $480-460$ & $650-700$ \\
\hline Añil & $450-440$ & $700-760$ \\
\hline Violeta & $430-390$ & $760-800$ \\
\hline
\end{tabular}

Figura 3: Tabla resumen que relaciona longitud de onda, frecuencia y color

La subdivisión en siete colores no es pura, pues el espectro presenta una serie continua de gradaciones entre un color y otro. Cada una de ellas constituye una 
tonalidad en sí misma determinada por mínimas modificaciones de la extensión de la onda y además no existen nombres específicos que nos permitan nombrar a todos los colores.

El contenido energético de una radiación electromagnética es proporcional a su frecuencia. La composición física de la atmósfera terrestre determina que sólo la pueden atravesar las radiaciones que van desde los 300 a los $1.100 \mathrm{~nm}$. de longitud de onda.

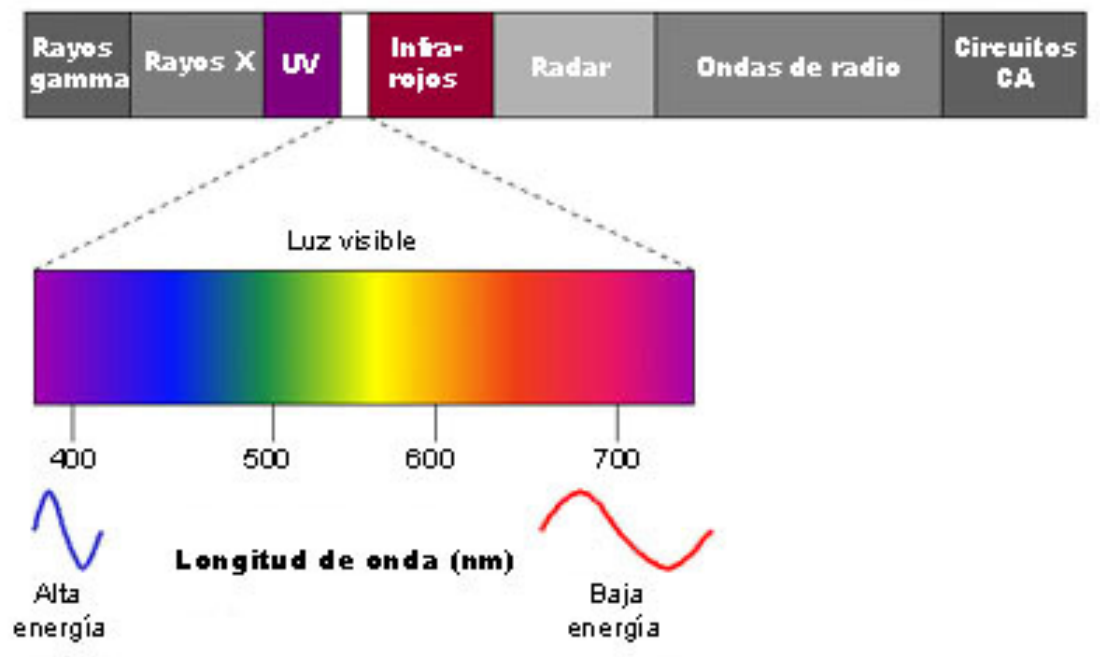

Figura 4: Espectro de luz visible ${ }^{11}$

La luz, es el elemento que más influye en el manejo del color, porque la luz al igual que el color, tiene calidad y cantidad. Calidad o temperatura de color, se mide en grados Kelvin y la cantidad se refiere a la intensidad y se mide en luxes.

La temperatura de color de una fuente de luz se define comparando su color dentro del espectro luminoso con el de la luz que emitiría un cuerpo negro calentado a una temperatura determinada. Por este motivo esta temperatura de color, aún siendo una temperatura relativa, se expresa en grados Kelvin.

Esta escala deriva del color de un cuerpo negro teórico (un objeto de metal que no tiene color en sí mismo, técnicamente conocido como un radiador Planckiano). Si lo calentamos hasta que esté incandescente, el cuerpo negro irradia luz y cambia de color según la temperatura. La temperatura de color es una cuantificación de términos, como rojo brillante, blanco brillante,... 
En honor de su descubrimiento, el primer científico británico del s. XX, Lord Kelvin, los grados de esta temperatura se denominan con su apeliido: Grados Kelvin. En la escala Celsius, el punto de congelación del agua es de 0ㅇ․ La escala de Kelvin toma el cero absoluto como punto cero. El cero absoluto es de -273ํㅡ Celsius y en la escala Kelvin, los 5.500 Kelvin son realmente $5.227^{\circ}$ Celsius. Los grados Kelvin se abrevian con la $\mathrm{K}$ y el símbolo de grados se omite. En esta tabla están algunas temperaturas de color, de las luminarias más habituales:

- Vela $1.500 \mathrm{~K}$

- Puesta de sol o amanecer $2.000 \mathrm{~K}$

- Tungsteno-halógeno $3.200 \mathrm{~K}$

- Lámparas fluorescente luz día $4.000 \mathrm{~K}$

- Sol mediodía $5.500 \mathrm{~K}$

- Mediodía luz del sol + luz del cielo $6.500 \mathrm{~K}$

- Cielo azul $10.000-20.000 \mathrm{~K}$

La temperatura de color ideal para la toma de color está entre los $5.500 \mathrm{~K}-6.500 \mathrm{~K}$. Es la considerada luz día blanca 6,10 . La lámpara incandescente de equipo dental promedio tiene una temperatura de color de $3.800 \mathrm{~K}^{12}$. No está recomendado la toma de color con la luz del equipo dental ya que la mayoría de ellas son incandescentes y emiten mucha luz en el espectro rojo-amarillo y poco en el extremo del azul ${ }^{13}$.

La intensidad luminosa es la cantidad de energía emitida bien por una fuente de luz natural (ejemplo el sol) o bien por una fuente de luz artificial. En fotometría, la intensidad luminosa se define como la cantidad de flujo luminoso que emite una fuente por unidad de ángulo sólido. Su unidad de medida en el Sistema Internacional de Unidades es la candela (cd).

El lux (símbolo Ix) es la unidad derivada del Sistema Internacional de Unidades para la iluminancia o nivel de iluminación. Equivale a un lumen $/ \mathrm{m}^{2}$. Se usa en fotometría como medida de la intensidad luminosa.

Una candela se define como la intensidad luminosa de una fuente de luz monocromática de $540 \mathrm{THz}$ que tiene una intensidad radiante de 1/683 vatios por estereorradián, o aproximadamente $1.464 \mathrm{~mW} / \mathrm{sr}$. La frecuencia de $540 \mathrm{THz}$ 
corresponde a una longitud de onda de $555 \mathrm{~nm}$, que se corresponde con la luz verde pálida cerca del límite de visión del ojo. Ya que hay aproximadamente 12.6 estereorradianes en una esfera, el flujo radiante total sería de aproximadamente $18.40 \mathrm{~mW}$, si la fuente emitiese de forma uniforme en todas las direcciones. Una vela corriente produce con poca precisión una candela de intensidad luminosa.

\begin{tabular}{|c|c|c|c|c|}
\hline Magnitud & Símbolo & $\begin{array}{c}\text { Unidad } \\
\text { del SI }\end{array}$ & Abrev. & Notas \\
\hline $\begin{array}{l}\text { Energía } \\
\text { luminosa }\end{array}$ & $Q_{v}$ & $\begin{array}{l}\text { lumen } \\
\text { segundo }\end{array}$ & $\mathrm{Im} \cdot \mathrm{s}$ & $\begin{array}{c}\text { A veces se usa la denominación } \\
\text { talbot, ajena al SI }\end{array}$ \\
\hline Flujo luminoso & $\mathrm{F}$ & $\begin{array}{l}\text { lumen } \\
(=\mathrm{cd} \cdot \mathrm{sr})\end{array}$ & Im & $\begin{array}{l}\text { Medida de la potencia luminosa } \\
\text { percibida }\end{array}$ \\
\hline $\begin{array}{l}\text { Intensidad } \\
\text { luminosa }\end{array}$ & $\mathrm{I}_{\mathrm{v}}$ & $\begin{array}{l}\text { candela } \\
(=\mathrm{Im} / \mathrm{sr})\end{array}$ & $c d$ & Una unidad básica del SI \\
\hline Iluminancia & $E_{v}$ & $\begin{aligned} \operatorname{lux} \\
\left(=\operatorname{lm} / \mathrm{m}^{2}\right)\end{aligned}$ & Ix & $\begin{array}{l}\text { Usado para medir la incidencia de la } \\
\text { luz sobre una superficie }\end{array}$ \\
\hline
\end{tabular}

Figura 5: Unidades de medida más frecuentes de la intensidad luminosa

Varios estudios han determinado que la intensidad de la luz ideal para el correcto registro de color es de 1.200-1.500 luxes ${ }^{10}$.

A continuación vamos a describir con más detalle el tipo de fuente de luz conocido como la "clase D" ya que ha sido el utilizado para este estudio de investigación. Este tipo de fuente de luz especifica unas distribuciones relativas de energía que se corresponden muy estrechamente con la radiación emitida por lo que se llama un "cuerpo negro" (black body). En un cuerpo negro, cuando se aumenta la temperatura, hay un cambio en la radiación que se emite hacia longitudes de onda más corta. Un iluminante de tipo $D$ se indica haciendo referencia a la temperatura absoluta, en grados Kelvin, del cuerpo negro al que más se aproxima: Un cuerpo negro a 6.500 grados Kelvin. 


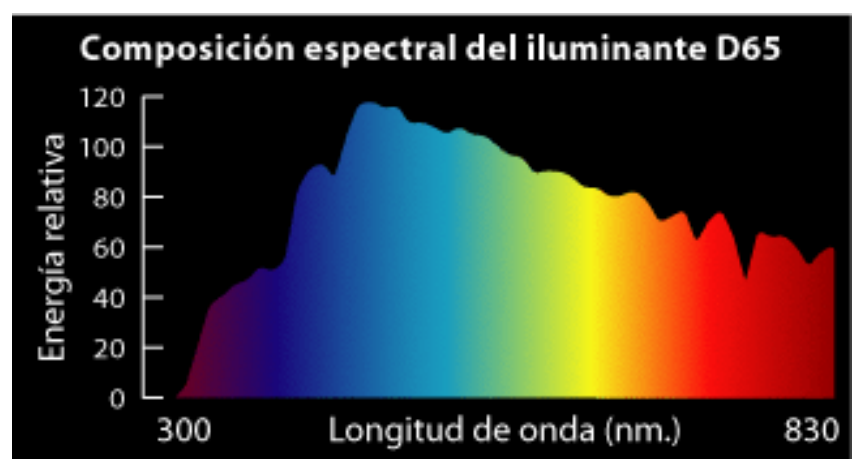

Figura 6: lluminante $D 65^{7}$

El iluminante D65 también se parece muy estrechamente a la distribución espacial relativa de energía de la luz del día en un cielo septentrional, por lo que es especialmente importante para definir colores en Europa Septentrional. Otros iluminantes, como el D55, son importantes en otras partes del mundo.

Algunos tubos fluorescentes tienen todos los colores y permiten la toma de color de forma más fiable ${ }^{13,14}$. La calidad de luz ambiental del gabinete debe mantenerse con iluminación artificial (varían las condiciones de luz ambiental), habitualmente se mide con la temperatura de color y el índice de toma de color (ITC). La temperatura de color es la longitud de onda promedio de la luz ambiental. La temperatura de color ideal para la toma de color es de $5500 \mathrm{~K}$, sensación de temperatura media y se considera "luz blanca" ${ }^{13}$. La lámpara incandescente del equipo dental promedio tiene un ITC de 75 y una media de $3800 \mathrm{~K}^{15}$.

\subsubsection{2.-Objeto a observar:}

Existen características estructurales de cada objeto que producen diversos fenómenos físicos, los cuales, a su vez, intervienen y modulan la apreciación visual de colores formas y tonalidades.

Los colores de los objetos tienen elementos diferentes que los hacen únicos y cuya importancia visual se basa en el tinte, valor, e intensidad.

El Tinte o Tono: es la primera dimensión del color y se asocia con las longitudes de onda de luz observadas. La longitud de onda dominante de un color es la longitud de onda de una luz monocromática. 
La longitud de onda más corta (380nm) es de color violeta, y la longitud de onda más larga (720nm) es roja. El tinte es la cualidad por la cual se distinguen las familias de colores, el rojo del amarillo el verde del azul o colores púrpuras. Munsell en su teoría establece diez tintes: rojo, amarillo, rojo, amarillo, verde-amarillo, verde, azul-verde, azul, púrpura-azul, púrpura, rojo y púrpura.

En términos dentales, el tinte se representa mediante las letras $A, B, C$ o $D$ según la guía de tonalidades Vita Classic utilizada comúnmente. Hasta un $80 \%$ de los dientes naturales encajan en la familia de los tintes $\mathrm{A}^{16}$. La fuente primaria del color dentario natural es la dentina y su tinte se encuentra en el intervalo del amarillo o amarillo-rojo.

Valor o Luminosidad: Esta dimensión es probablemente la más importante para el odontólogo. De acuerdo con Munsell es esa cualidad por la que se diferencia un color claro de otro oscuro. El valor de un color está determinado por la cantidad de blanco y negro en la escala de valores que se liga a la claridad/oscuridad. Es un indicador de la cantidad de luz.

- El valor se ve afectado sobre todo por la calidad y transparencia del esmalte.

- Los valores pueden determinarse clínicamente entornando los ojos y comprobando la cantidad de luz que llega a la retina. La visión escotópica de los bastones se pone en marcha.

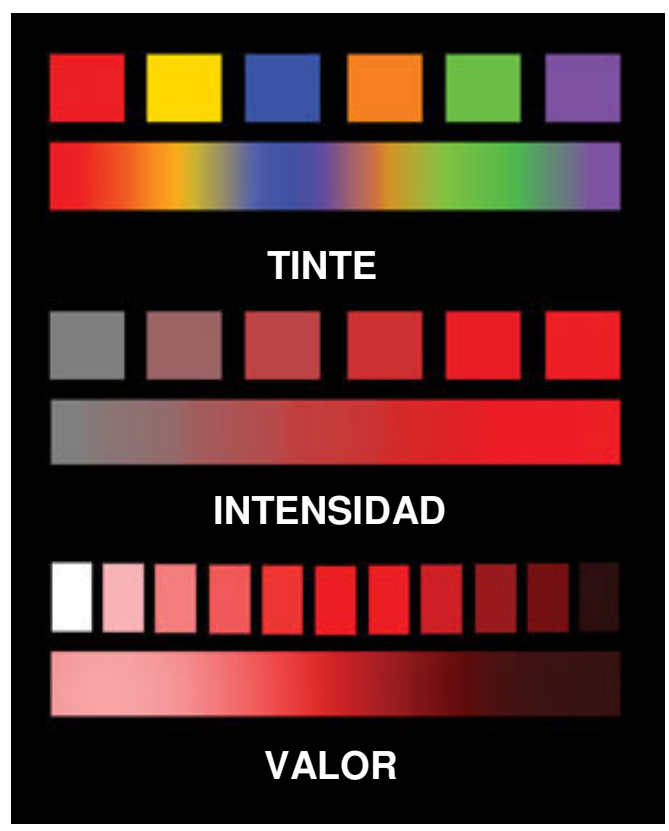

Figura 7: Esquema de tinte, intensidad y valor ${ }^{17}$ 
Intensidad o Croma: es la medición de la cantidad del color (cantidad de saturación del tinte de un color). La intensidad (croma) describe la cantidad de tinte que posee un determinado color. Esta tercera dimensión limita muy de cerca con la primera (tinte) y se confunde muy a menudo con la segunda (valor). Viene dictada y está influida por la translucidez y el espesor del esmalte. En los dientes las intensidades más elevadas están en la porción gingival mientras que las más bajas están en las regiones incisales.

La luz, dependiendo de las características del objeto con el que entra en contacto, en este caso el diente, puede dar lugar a diferentes fenómenos:

Transparencia: este término se aplica a aquel material que permite ser atravesado por la luz y también permite ver de forma clara los objetos situados detrás de él. Su superficie no refleja ninguna luz, ya que toda atraviesa el material.

Translucidez: caracteriza a aquellos materiales que dejan pasar la luz a su través pero los objetos situados detrás del no se ven de forma clara. Al presentar un aspecto más opaco, reflejan una parte de la luz incidente. Se trata de una de las características más importantes relacionadas con el color dentario. Para dar lugar a la translucidez debemos conseguir que haya una mínima absorción de luz y que la dispersión de luz sea máxima. Las diferentes regiones de los dientes humanos se caracterizan por los diversos grados de translucidez ${ }^{13}$.

Refracción: fenómeno por el cual se produce un cambio de dirección de una onda al pasar de un medio material a otro. Sólo se produce si la onda incide oblicuamente sobre la superficie de separación de los dos medios y si estos tienen índices de refracción distintos. La refracción se origina en el cambio de velocidad de propagación de la onda.

\subsubsection{3.-Entorno}

Entendemos por entorno el conjunto de elementos adyacentes al objeto a medir cuya presencia debido a la aportación de longitudes de onda diferentes, pudiera interferir con el registro del color verdadero del objeto: Modifica el tipo de luz que alcanza el objeto. 
Por ejemplo, una pared amarilla al absorber parte de la luz emitida por la fuente, impone un componente más amarillo a la iluminación resultante. Así también, el color de la ropa del paciente, del maquillaje, etc. influyen en la toma de color dental ${ }^{10,18}$.

- En la boca, el diente está rodeado óptimamente por tres segmentos cromáticos. El limite incisal está marcado por el fondo oscuro de la cavidad bucal, el limite proximal por los dientes colindantes rojizos y amarillentos, y el limite cervical por las papilas rojas y la encía. El color de las encías oscila entre el rojo claro y el rojo oscuro, en función de la concentración genética de melanina, y sangre. En algunas ocasiones, algunas zonas son de color violeta. Los labios influyen en la toma de color de los dientes a causa de su propio color y de la aportación de sombras.

- El efecto del contraste simultáneo del color de la encía sobre el cuello dental y el tercio superior del diente no se tienen en cuenta en la determinación convencional del color.

\subsubsection{4.- Ojo humano}

El ojo humano presenta la forma de una esfera con un diámetro transversal de cerca de $22 \mathrm{~mm}$ y anteroposterior de cerca de $26 \mathrm{~mm}$. Está constituido por una membrana externa llamada esclerótica. Es resistente, opaca, de color blanco y en su parte anterior, se transforma en otra transparente llamada córnea. La córnea, más convexa que la esclerótica, completa la envoltura del ojo y a través de ella penetran los rayos luminosos. Sobre la superficie interna de la esclerótica, se encuentra la coroides. Es rica en vasos sanguíneos que nutren la estructura del ojo y los pigmentos pardos, casi negros, que tiñendo el interior del ojo de negro desempeñan el papel de cámara oscura eliminando los reflejos inconvenientes de los rayos luminosos. La parte anterior de la coroides, provista de unos músculos llamados ciliares que sostienen el cristalino, termina en el iris. Este presenta una apertura circular, la pupila, que se muestra negra a causa del fondo oscuro del ojo. La esclerótica y la coroides son atravesadas en la parte posterior por el nervio óptico que comienza en la cavidad ocular de una membrana delicadísima: la retina. Ésta, que contiene las células receptoras, reviste a modo de copa los dos tercios posteriores de la coroides avanzando hasta la conjunción de esta última y el iris. Sobre la retina, frente a la pupila y muy cerca del nervio óptico, se encuentra una pequeña área de $2 \mathrm{~mm}$ de diámetro denominada mácula lútea (mancha amarilla) que rodea una depresión ovalada, la fóvea central, que es la parte más sensible de la retina: en ella se tiene la visión distinta. La parte 
donde las fibras nerviosas de las células retínicas confluyen para formar el origen del nervio óptico, al estar privada de fotorreceptores, se denomina punto ciego o también papila del nervio óptico. Los rayos luminosos, antes de alcanzar la retina, atraviesan sucesivamente la córnea, el humor acuoso, el cristalino y el humor vítreo; cada uno de estos medios posee una diferente densidad, siempre más elevada que la del aire, que influye sobre la velocidad de la luz aumentando la convergencia de los rayos sobre la retina.

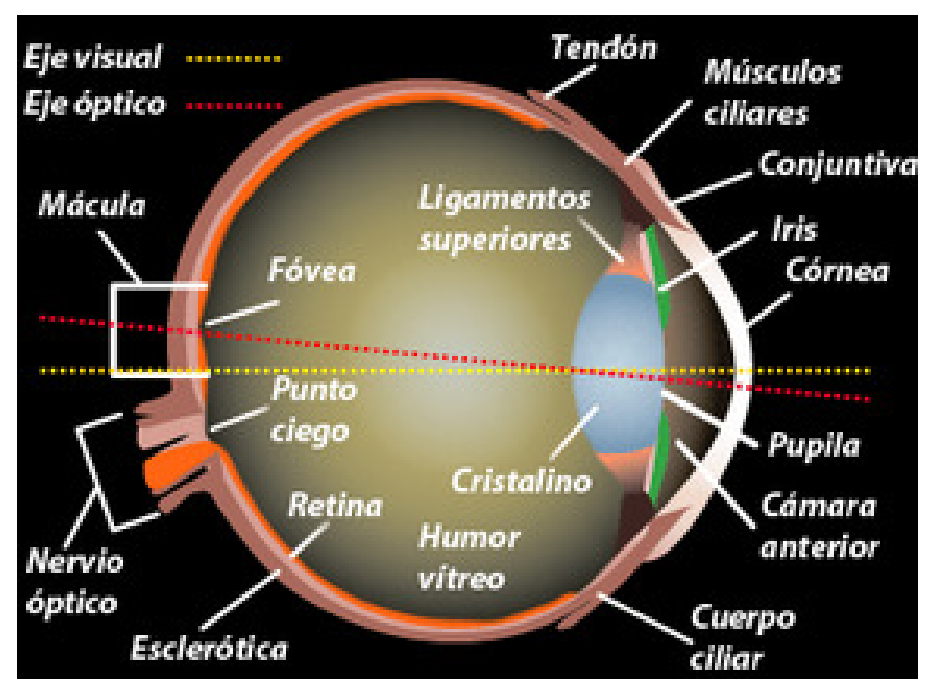

Figura 8: Corte sagital del globo ocular ${ }^{19}$

El humor acuoso ocupa la cámara anterior del ojo situada entre la córnea y el cristalino. El líquido es límpido e incoloro y se renueva cada cuatro horas.

El cristalino que es transparente y tiene forma de lente biconvexa, al presentar una mayor convexidad sobre la superficie posterior, está colocado verticalmente y separa los otros dos medios refringentes del ojo: el humor vítreo y el humor acuoso. La membrana elástica que lo contiene está fijada a los músculos ciliares. La convexidad de la lente varía según las contracciones de los músculos ciliares: así se modifica la distancia focal con la finalidad de tener imágenes nítidas sobre la retina cualquiera que sea la distancia de los objetos observados. Con el paso de los años la lente pierde elasticidad a causa del creciente endurecimiento de las células que la componen y consecuentemente aumenta la dificultad de enfocar las imágenes.

El humor vítreo es un líquido gelatinoso contenido en una cápsula delgadísima denominada membrana amarillenta unida por los músculos ciliares; ocupa la cámara posterior del ojo que es la más amplia. Así, constituyen el sistema óptico del ojo. 


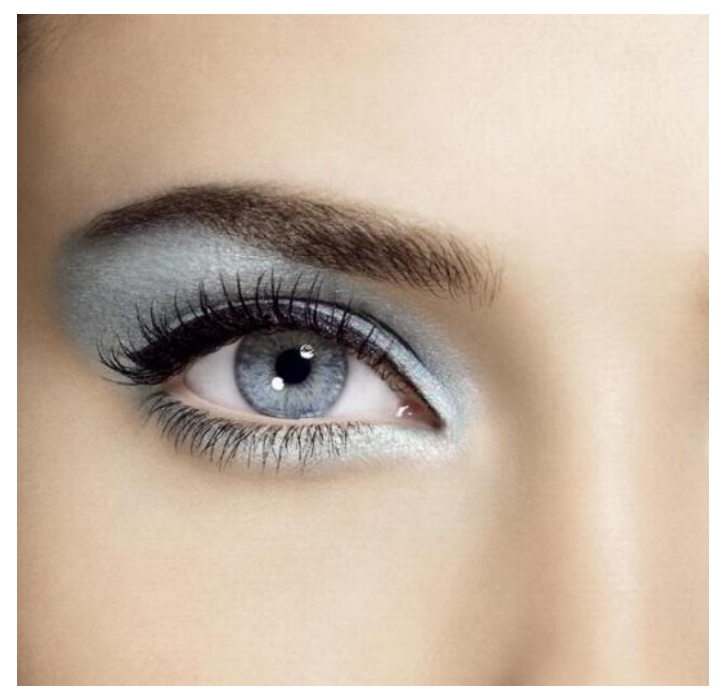

Figura 9: Ejemplo de ojo humano ${ }^{20}$

El ojo enfoca la imagen de un objeto visto en un área pequeña al fondo del ojo: la retina. La retina está compuesta por dos tipos de receptores: bastones y conos. Los bastones son mucho más sensibles a la luz, pero no pueden percibir el color. Son insensibles al color excepto al azul del final del espectro. Los conos están concentrados en una pequeña área de la retina llamada fóvea. Son menos numerosos que los bastones y menos sensibles a la luz pero mucho mejores a la hora de discernir el detalle, el color, la forma y la posición del objeto.

Los conos están divididos en tres tipos según su sensibilidad al color: unos responden al azul / violeta, otros al verde / amarillo y otros al rojo / naranja, con gamas más o menos centradas en $480 \mathrm{~nm}, 540 \mathrm{~nm}$ y $610 \mathrm{~nm}$ respectivamente. Por ejemplo, la luz amarilla de $570 \mathrm{~nm}$ genera una respuesta más o menos igual en los conos de sensibilidad rojo y verde, con una respuesta mucho más pequeña en los conos azules, mezclando la luz roja y verde producimos amarillo.

El ojo funciona de manera análoga: si dos longitudes de onda distintas alcanzan los conos pongamos $550 \mathrm{~nm}$ (verde) y $640 \mathrm{~nm}$ (rojo), esto produce la misma respuesta que una luz de $570 \mathrm{~nm}$ (amarillo).

Cuando la intensidad de la fuente de luz es suficiente, los responsables de la visión en color son los conos responsables de la visión diurna y cromática (visión fototópica). En la oscuridad todo el proceso de la visión está controlado por los bastones de la retina (visión escotópica) y solo permite distinguir los diferentes grados del gris que son útiles 
para la visión nocturna y acromática. Los pioneros trabajos anatómicos de Schultze (1825-1874), pusieron de manifiesto la existencia de estos dos tipos fotoreceptores en animales vertebrados. Son células de forma alargada, polarizadas en cuanto su forma y función, y segmentadas en subregiones con diferente papel.

El $90 \%$ de los axones retinianos en la especie humana terminan en el cuerpo geniculado lateral, la porción visual del tálamo. Esta estructura subcortical se encarga de transportar la información visual a la corteza cerebral.

Las respuestas visuales, incluso del mismo estímulo, varían de un individuo a otro.

- La percepción humana es susceptible de ilusiones ópticas, los colores adyacentes influyen en la interpretación.

- Una vez que percibimos el color transmitimos dicha imagen al cerebro, el cual elabora la imagen subjetiva del objeto, que posee el color que hemos percibido. Una vez confeccionada expresamos la idea que tenemos del objeto observado. Este razonamiento hace que la coloración percibida por los diferentes sujetos pueda ser parecida o bien dispar.

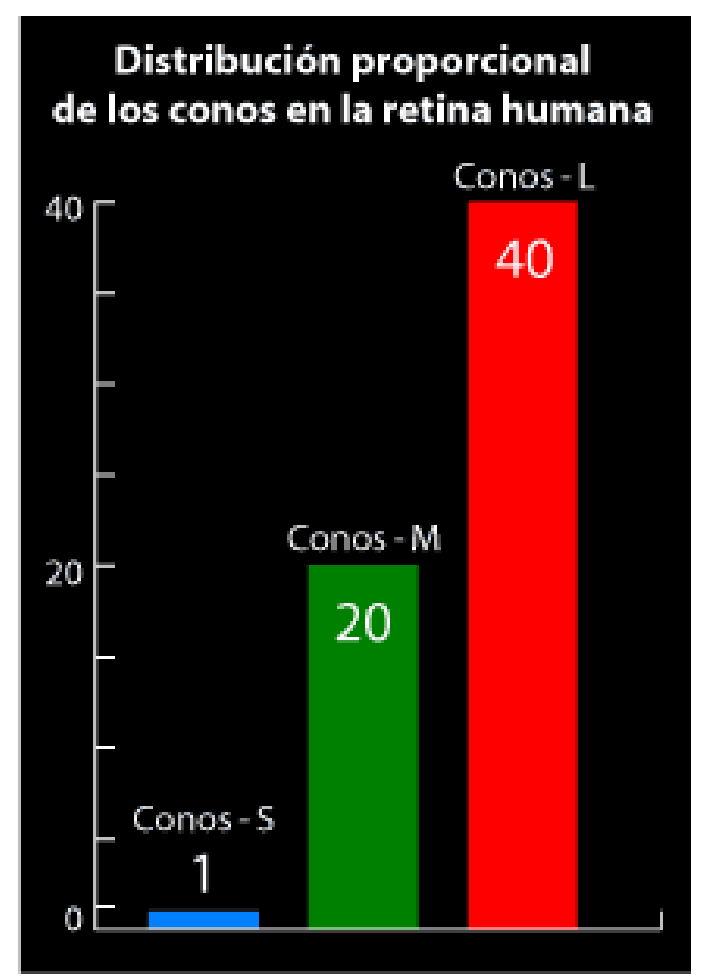

Figura 10: Distribución de conos y bastones ${ }^{7}$ 


\subsection{3.- Sistemas de Determinación del Color}

Un sistema de color es un sistema tridimensional para la definición del color, empleando el tinte, el valor y la intensidad, como coordenadas. Un color se define por las tres coordenadas distintas correspondientes.

Existen varias metodologías que sirven para la valoración y definición cuantitativa y cualitativa del color.

\subsubsection{1.- Tipos de colores}

Se considera color básico o primario al color que no se puede obtener mediante la mezcla de ningún otro. Son los colores que se clasifican según los conos que nuestros ojos pueden captar. Existen conos de 3 tipos, unos que detectan Rojos (sobre longitudes de onda de 700-600 nm), otros para los Verdes (Longitudes de onda de 550 $\mathrm{nm}$ ) y otros para los azules (que detectan radiaciones de 450-400 nm) De la combinación de dos de ellos salen los colores primarios de la pigmentación (Cyan, Magenta y Amarillo), siempre que se utilicen dos, ya que la unión de los tres colores en proporciones iguales forma el blanco, y la ausencia de los mismos forma el negro, ya que el negro es lo contrario a luz, oscuridad.

La obtención del resto de los colores implica dos métodos diferentes, el método aditivo y el método sustractivo.

- Método aditivo: Es el utilizado en física y trabaja con luz emitida por los objetos, en forma de longitudes de onda emitidas. En este método el rojo el verde y el azul son los colores primarios que forman conjuntamente la luz blanca. El negro es la ausencia de color. Los colores secundarios, azul cian magenta y amarillo, se forman por combinación de los colores primarios. El sistema aditivo solo es aplicable a la luz y no a los pigmentos. Método utilizado en la televisión.

- Método sustractivo: Bajo el nombre de mezcla sustractiva de colores, se entiende un fenómeno de absorción física. Por ejemplo, si un filtro azul y otro amarillo (cuyas luces en mezcla aditiva adecuada darían el blanco) son atravesados sucesivamente por una fuente luminosa de luz blanca resulta el verde. Este proceso se aplica al pigmento de las pinturas. Cada componente refleja su propio color y absorbe otro. La resultante es el color más reflejado. 
Mientras que en el sistema aditivo aumenta la energía electromagnética de la luz mezclada, en el método sustractivo disminuye el nivel de energía mediante la absorción. Cada pigmento de un objeto refleja su propio color y absorbe los demás, por tanto en una mezcla de colores sustractivos, se absorben los colores de cada color primario componente y se reflejan colores sobrantes ${ }^{7}$.
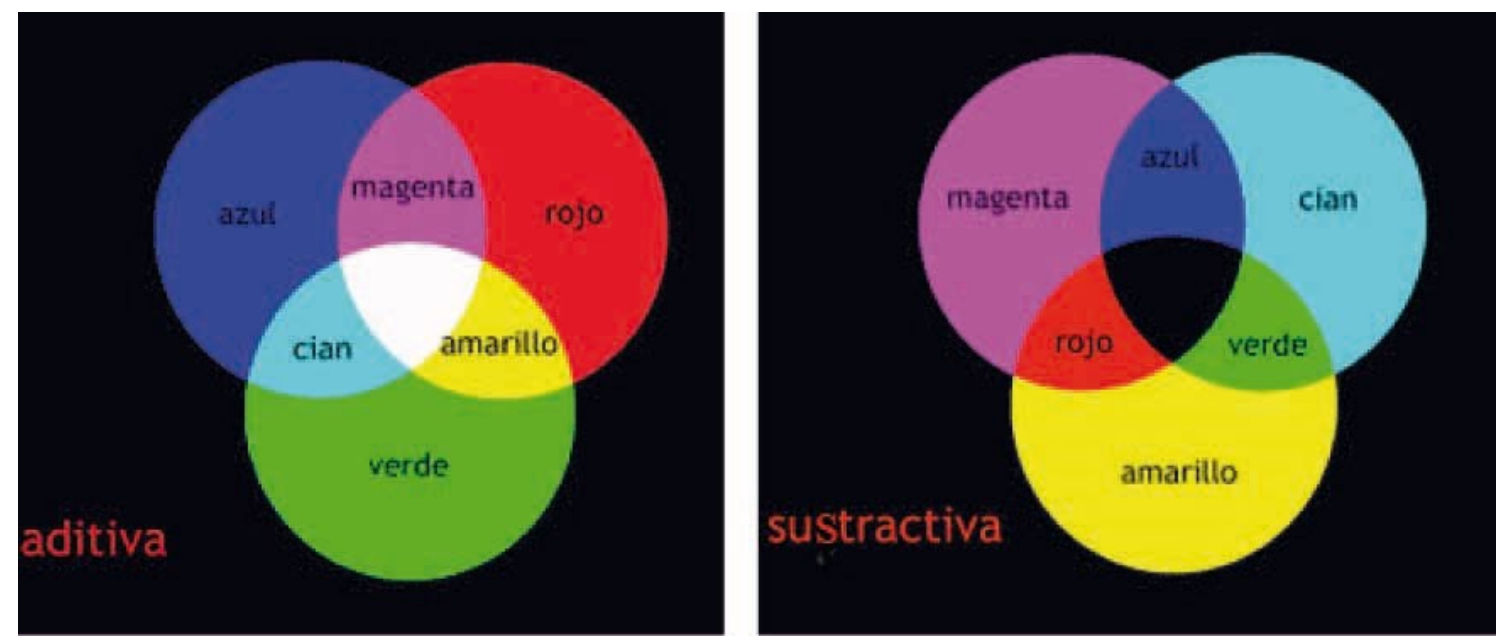

Figura 11: Teoria aditiva y Teoría sustractiva ${ }^{21}$

A lo largo de la historia, diversos investigadores han intentado ordenar el color de varias maneras, ya sea en forma bidimensional o tridimensional, tomando en cuenta las distintas variables. La forma en que los teóricos y artistas plantearon el estudio racional de las armonías de color son los llamados círculos cromáticos, que tienen por objeto interrelacionar los colores del espectro y sus derivaciones. El círculo cromático es el resultante de distribuir alrededor de un círculo, los diferentes colores que conforman el segmento de la luz visible del espectro solar, descubierto por Newton, y manteniendo el orden correlativo: rojo, naranja, amarillo, verde, azul y violeta.

\section{Colores primarios o fundamentales en la Teoría Sustractiva}

- Rojo

- Azul

- Amarillo

\section{Colores intermedios o secundarios}

Se obtienen por la mezcla de dos colores primarios Son el verde, violeta y naranja y se obtienen de la mezcla en una misma proporción de los colores primarios. 


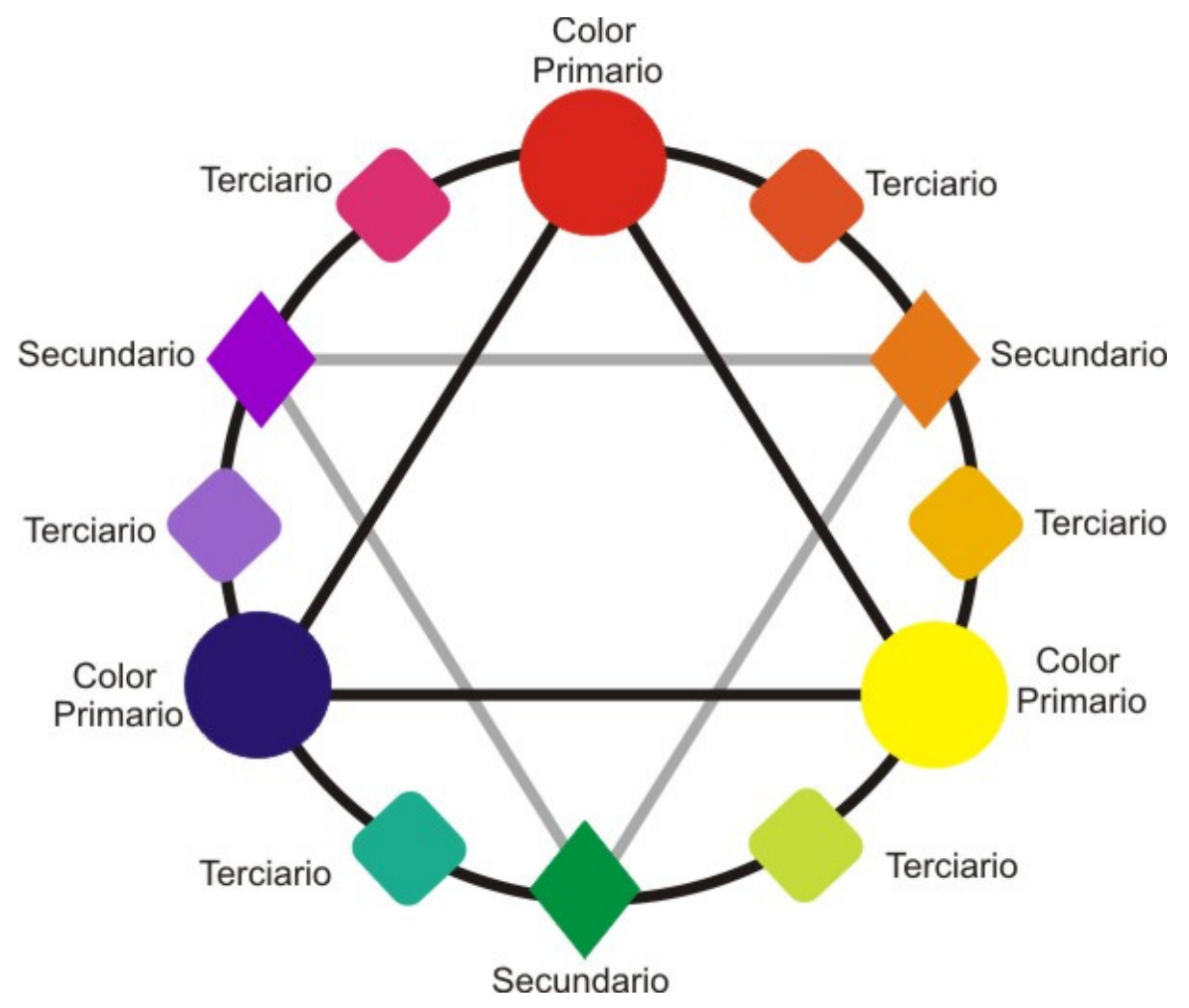

Figura 12: Esquema que relaciona los diferentes tipos de colores ${ }^{22}$

\section{Colores terciarios}

Son el rojo violáceo, rojo anaranjado, amarillo anaranjado, amarillo verdoso, azul verdoso y azul violáceo, que surgen de la combinación en una misma proporción de un color primario y otro secundario.

\section{Colores complementarios}

Son los que al mezclarse con su antagonista primario proporcionan un color gris, cuando dos complementarios se unen entre sí, se destruyen mutuamente y se produce un neutro, que varía entre los tintes grises y marrones.

- El complementario del rojo es el verde

- El complementario del azul es el naranja

- El complementario del amarillo es el violeta.

\subsubsection{2.- Esfera cromática de Munsell}

Es un sistema que clasifica y ordena los colores en una secuencia lógica, que permite que un color pueda describirse con exactitud y que además analiza sus diferencias con otros colores de modo que estas diferencias se puedan comprender y especificar. 
Este sistema establece grados de percepción iguales desde un color a otro en cualquier dimensión de color en que se trabaje.

Muestra una buena distribución cuando se trabaja con pequeñas diferencias de color, pero es notablemente desigual para los cambios grandes.

Se trata de un sistema de coordenadas similar a una esfera, en el que los colores se definen físicamente por su espectro y se describen en un modelo tridimensional: el espacio cromático que se define mediante las tres dimensiones físicas del color: tinte valor e intensidad.

No es una esfera simétrica porque no todos los tintes desarrollan igual pureza y niveles de valor. Albert Munsell (1858 - 1918) establece en su teoría 10 tintes, los tintes se disponen de forma ordenada alrededor del perímetro del cilindro, en tanto que la intensidad del color aumenta a lo largo de un radio que se aleja desde el eje central, estando los colores más puros en la periferia. En este sistema hay un eje acromático sin color que se extiende verticalmente a lo largo del color; por tanto, la coordenada del valor varía a lo largo de la longitud del cilindro, desde el negro en el extremo inferior al que se le da un valor 0 , hasta el blanco, en el extremo superior, al que se le da un valor 10, pasando por el gris neutro en el centro.

En lugar de esfera, Munsell creó un "árbol" en que los colores se distribuían por ramas en orden de saturación o pureza. $Y$ donde las ramas pueden ser de distinta longitud, por ejemplo, la rama del amarillo es muy larga, y la del naranja, mucho más corta.

En el cilindro la progresión de tintes de color comienza en el rojo ( $r$ ), 1r2r3r...10r siguiendo el rojo amarillo ( anaranjado, yr) 1yr2yr...10yr a continuación el amarillo 1y $2 \mathrm{y} . . .10$ y, el amarillo verde(v) 1v2... el verde azul(va),1va,2va..,el azul(a), $1^{\text {a }} 2^{2}$...,el azul violeta(ap)1ap2ap.., el violeta(p) 1p2p..,y por último el violeta rojo(PR)1pr 2pr.

Los dientes humanos poseen una considerable variación del color y los datos espectrofotométricos disponibles son muy limitados considerando su gran variedad. Si se aplican las coordenadas Munsell al color de los dientes humanos se observa que sus tintes varían de 7,5(yr) anaranjado al 4,7 (y) amarillo, el valor de 5.8 a 8,5 (y) la intensidad de 1.5 a 5.6 . 
En este sistema de coordenadas el color de los dientes naturales solo comprende una pequeña parte de este espacio cromático.

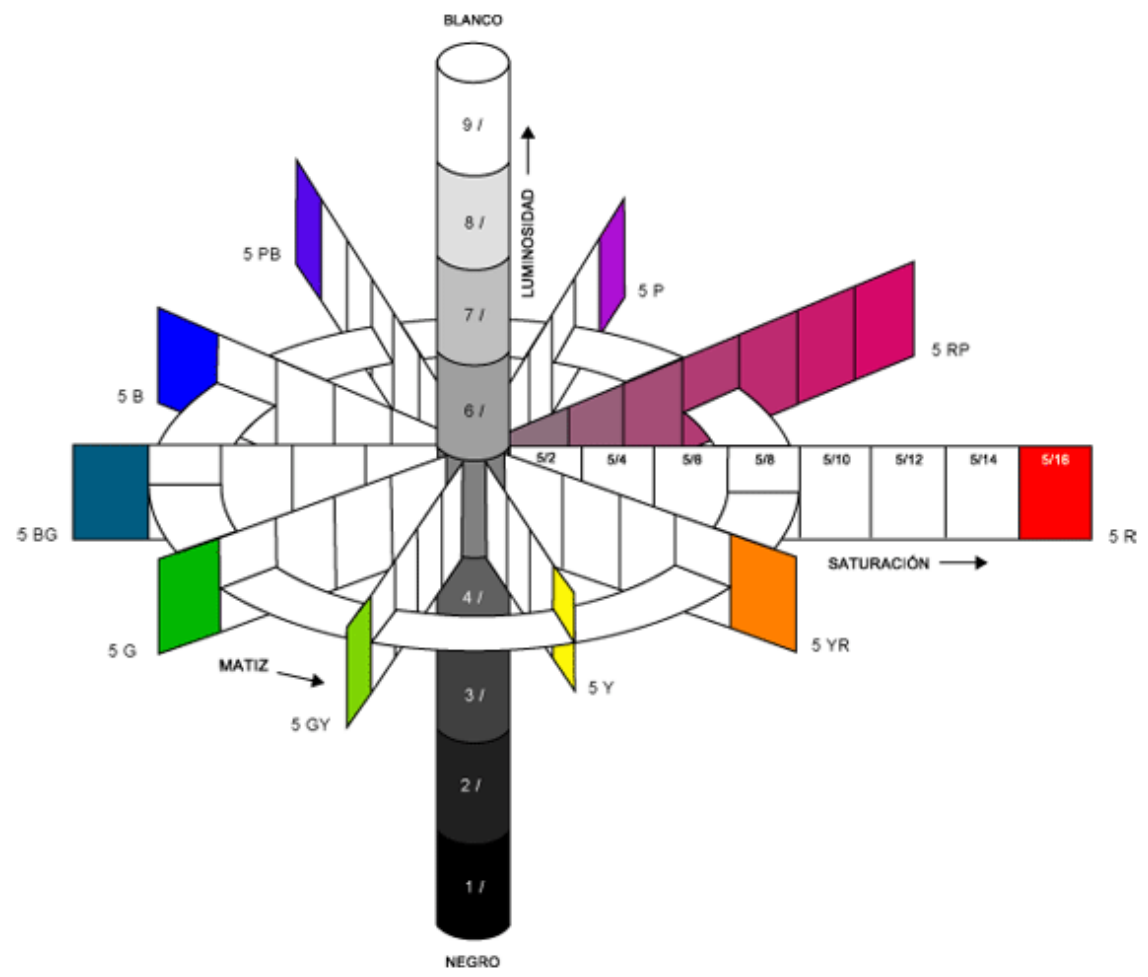

Figura 13: Árbol de Albert Munsell ${ }^{23}$

\subsubsection{3.- CIE $1931(x, y, z)$}

La Comisión Internacional de lluminación CIE (Standard comisión internationale de l'eclairage) es un organismo dedicado a la estandarización de los colores. Definió el color como una valoración objetiva de la fuente de luz, desarrollado por un observador estándar y capaz de calcularlo por coordenadas, representando como el sistema visual humano responde al color ${ }^{24}$.

En 1931, la CIE definió en profundidad el color espacial por CIE, que soporta la ya aceptada teoría de la percepción del color basado en tres colores receptores separados, (rojo, azul y verde) en el ojo y es uno de los sistemas de medición más extendidos. Con él se definieron con precisión los tres colores primarios, a partir de los cuales pueden crearse todos los demás, mediante una representación axial en la que las distintas coordenadas representan a cada uno de los colores primarios "x" (rojo), "y" (verde), "z" (azul). 
Este sistema representativo del color se basa en los estudios de Thomas Young (1801). En su "Teoría Tricromática" redujo los cinco colores básicos de Newton a tres. En esta teoría proponía la existencia de tres tipos de sensores primarios que respondieran específicamente al "rojo, verde y azul". En esencia, Young mantenía que hay tres tipos de receptores en la retina: uno, sensible al rojo, otro, sensible al verde, y otro, sensible al azul. Cada tipo de receptor recibía la información por una senda diferente y la transmitía hacia el cerebro. Young imaginaba que hay sendas neurales separadas para el rojo, el verde, y el azul.

Su hipótesis se basaba en que la mezcla apropiada de los tres colores primarios produciría la sensación de blanco, o bien cualquier otro de los colores que pudieran ser reconocidos por el ser humano. La confirmación la dio James Maxwell poco tiempo después. Esta teoría es la llamada teoría tricromática o de Young-Maxwell- Helmholtz.

Basado en su conocimiento de que virtualmente cualquier color puede ser creado mezclando alguna combinación de rojo, verde, y azul, Young postuló que los tres colores se mezclan en algún lugar del sistema nervioso para crear el verdadero color del objeto.

Este sistema se utiliza sobre todo en la industria y en la experimentación científica, y pretende unificar el color en relación con un marco de referencia.

- El sistema CIE asigna una descripción del color dependiendo de la percepción humana de tres elementos ( estimación del color tridimensional).

- El sistema CIE representa un color espacial uniforme, que es aquel en el cual sus elementos están igualmente distribuidos en el espacio en base a la percepción del color individual.

- El sistema CIE tiene degradaciones menos arbitrarias si las comparamos con el sistema Munsell y todos los colores de la naturaleza se obtienen mezclando en ciertas proporciones tres colores básicos (rojo, azul y verde).

- El sistema CIE también permite especificar la cromaticidad del color, es decir, su tinte y su intensidad; sin embargo, el valor debe intervenir para definir globalmente el color. 


\subsubsection{4.-CIE 1976 (CIELab)}

En 1976, la Standard Comisión Internationale de l'Eclairage ${ }^{25}$, define el espacio del color propuesto en $1931^{26}$, basándose en tres medidas que corresponden a las tres dimensiones del espacio en los tres ejes de coordenadas ordinales representadas (X, $\mathrm{Y}, \mathrm{Z}$, para $\mathrm{L}, \mathrm{a}, \mathrm{b}$, ). Las coordinadas a y $\mathrm{b}$ se aproximan a cero para colores neutros (blanco) y aumentan su magnitud cuanto mayor intensidad del color.

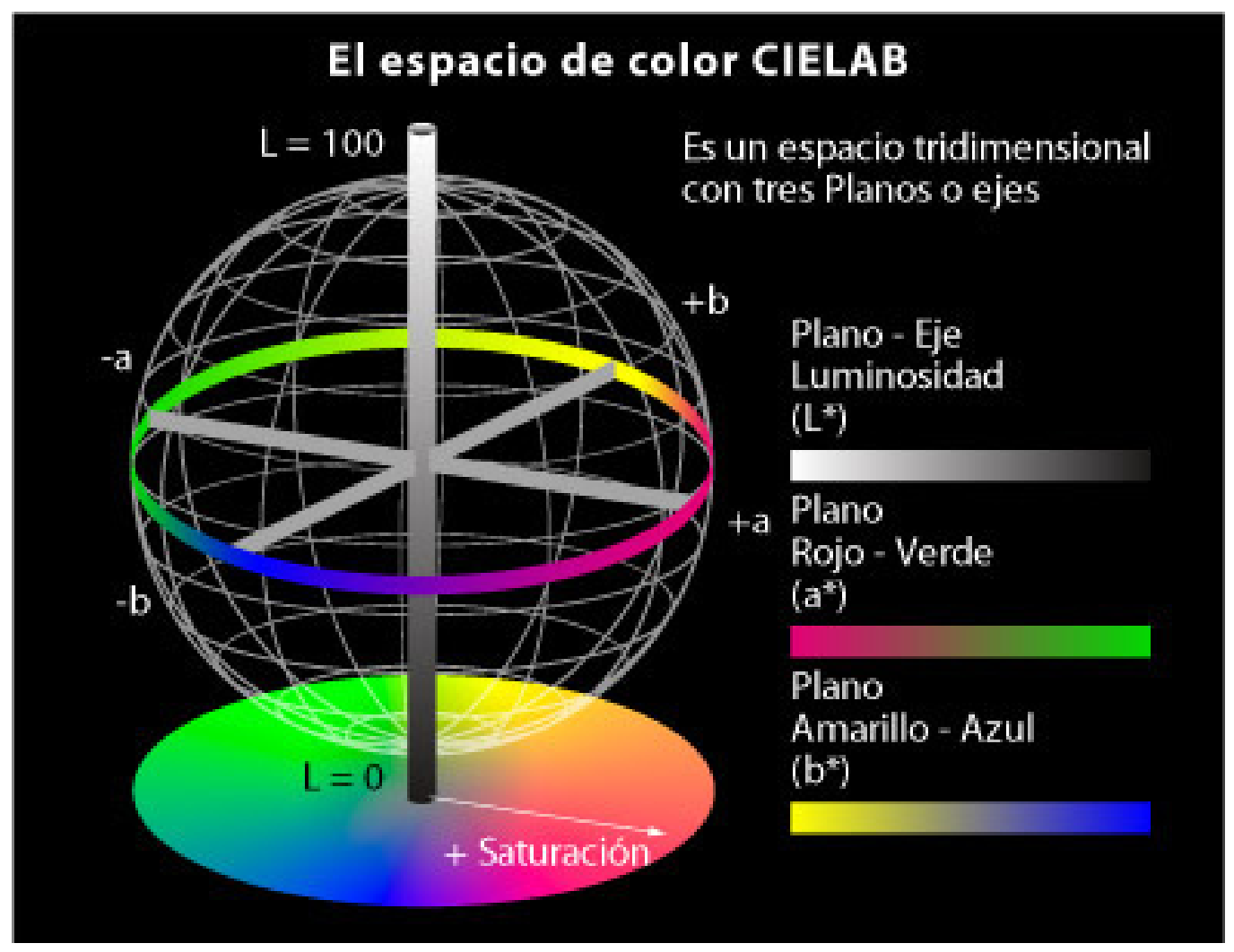

Figura 14: Espacio de color CIELab ${ }^{7}$

L=> medida del valor o luminosidad (eje vertical) y está cuantificado de la siguiente manera:

$$
L=>0 \text { negro } \quad L=>100 \text {-reflexión total de la luz (blanco) }
$$

$\mathbf{a}=>$ Eje de coordenadas que mide la cantidad de rojo y de verde:
a positivo $=>$ tendencia hacia el rojo
a negativo $=>$ tendencia hacia el verde

$\mathbf{b}=>$ Eje de coordenadas que mide la cantidad de amarillo y de azul:

$\mathrm{b}$ positivo $=>$ tendencia hacia el amarillo $\quad \mathrm{b}$ negativo $=>$ tendencia hacia el azul 


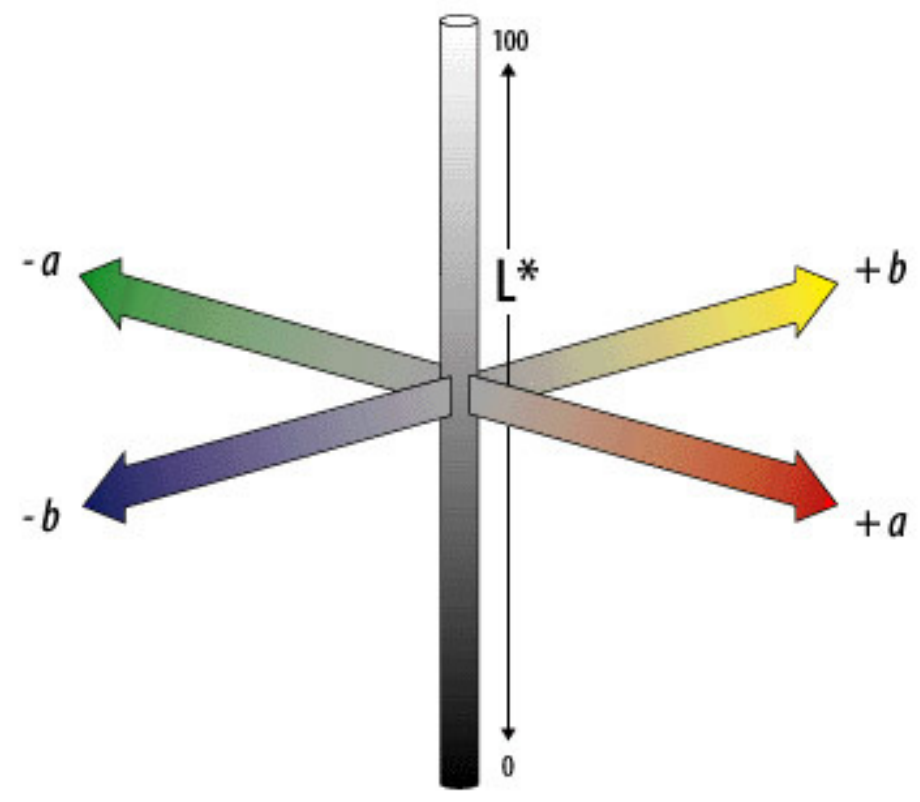

Figura 15: Ejes ordinales de las coordenadas de color $^{27}$

A través de la siguiente ecuación matemática se puede calcular la diferencia entre dos colores de forma cuantitativa. Se utiliza la formula euclidiana de la diferencia entre dos puntos en el espacio.

\section{Diferencia de color entre dos objetos:}

$$
\Delta E^{*}=\left[\left(\Delta L^{*}\right)^{2}+\left(\Delta a^{*}\right)^{2}+\left(\Delta b^{*}\right)^{2}\right]^{1 / 2}
$$

$\Delta \mathbf{E}^{\star}$ Representa la magnitud de la diferencia de color, pero no indica la dirección en los ejes de coordenadas.

Muchos son los autores que se han preocupado de conocer hasta qué punto los humanos somos capaces de percibir si existe diferencia entre dos colores. En Odontología podemos destacar los estudios de umbral de perceptibilidad clínica con datos comprendidos entre $\Delta \mathrm{E}^{*}=1,0$ a 3,7 unidades ${ }^{28,29}$.

Una vez que el hombre ha sido capaz de diferenciar dos colores, nos podemos preguntar hasta que umbral esa diferencia es aceptable clínicamente. Al igual que con la capacidad de percepción existen múltiples estudios donde las cifras varían. Señalamos el umbral de aceptabilidad $=\Delta E^{*}=2.72$ a 6.8 unidades ${ }^{29}, 30$ debido a que sirve de referencia para muchas de las publicaciones consultadas a lo largo de este trabajo de investigación. 
En Odontología el umbral de aceptabilidad para diferencias de color es mayor que el umbral de perceptibilidad ${ }^{29,31}$.

Este sistema de colores es el utilizado actualmente en Odontología por ser el recomendado por la Asociación Dental Americana. En él se basan las guías dentarias y colorímetros electrónicos actuales.

Para la mejor comprensión de los ejes de coordenadas ordinales y las tres dimensiones del color (tinte, valor e intensidad) estas coordenadas $L$, a y b se relacionan con $\mathrm{L}$ (representa también la luminosidad o valor), $\mathrm{C}$ (representa la intensidad) y h (representa el tinte).

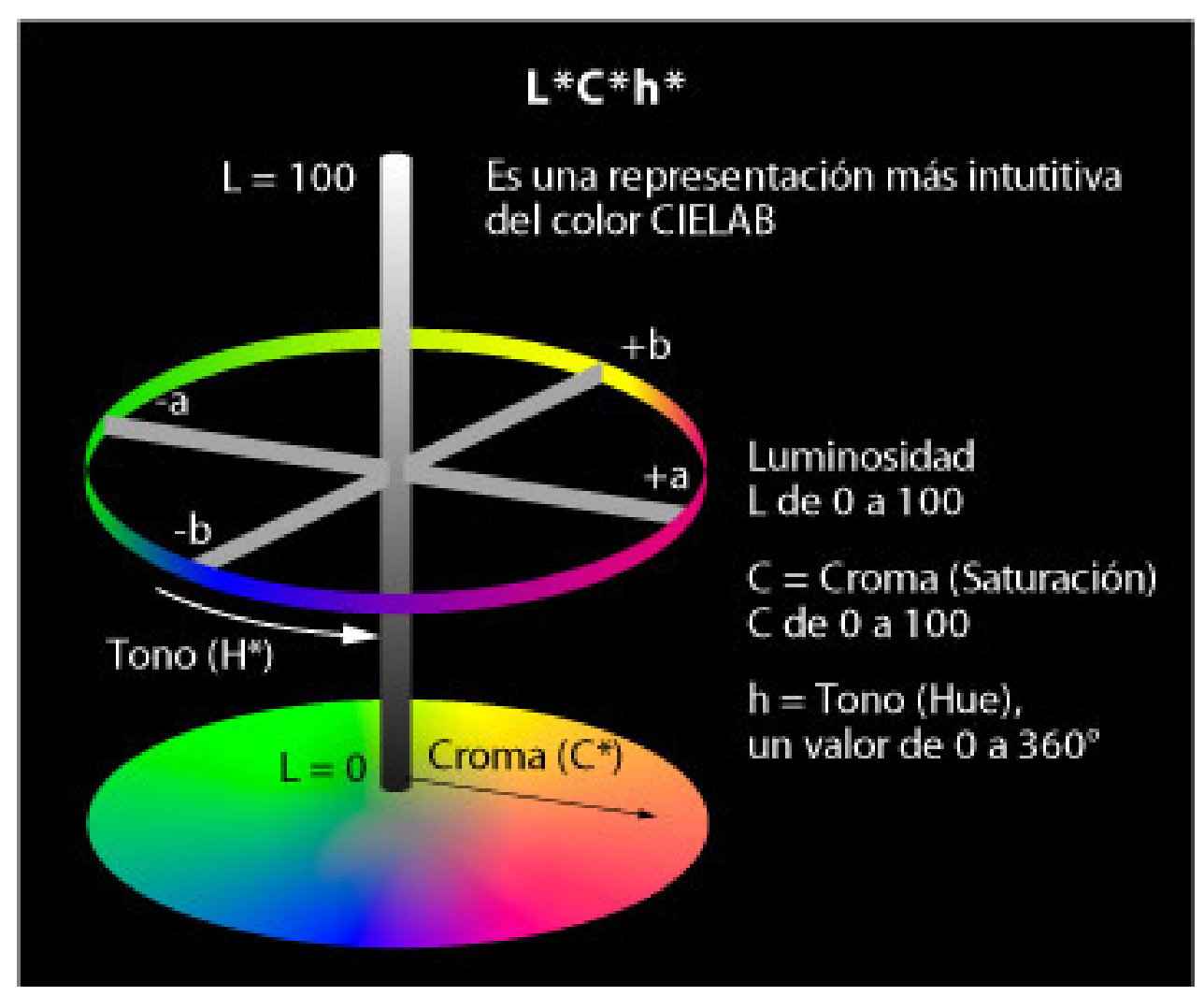

Figura 16: Relación espacial entre ejes ordinales y polares del color ${ }^{7}$

En el CIE 1976 L, a, b, se identifican con los componentes de las coordenadas cilíndricas CIE L, C, h (valor, intensidad y tinte) ${ }^{25}$. El parámetro $\mathrm{L}$, no se ve modificado ya que se corresponde con el eje vertical. 
La transformación de, a y $\mathrm{b}$ en $\mathrm{C}$ y $\mathrm{h}$, se relaciona por las siguientes fórmulas matemáticas:

$$
\begin{aligned}
C_{a b}^{*} & =\sqrt{a^{* 2}+b^{* 2}} \\
h_{a b} & =\arctan \frac{b^{*}}{a^{*}}
\end{aligned}
$$

Figura 17: Fórmulas matemáticas de relación entre coordenadas ordinales y polares

\subsection{4.- Umbrales de discriminación cromática}

Tanto desde puntos de vista científicos como técnicos, a veces ofrece más interés la evaluación de diferencias entre colores, o del color de un estímulo respecto a un color patrón, que la medida en si de un color. Se plantea pues una doble necesidad: cuantificar estas diferencias y hacerlas reproducibles en un sistema de representación, lo que obliga a conocer la métrica del espacio del color o el elemento de línea asociado a ella ${ }^{32}$.

Tradicionalmente se han abordado estos problemas de la medida experimental de diferencias de color, extendiéndolas como "mínimas diferencias perceptibles" o "umbrales diferenciales de color", para una posterior generalización al elemento de línea que satisfaga la predicción de dichos resultados experimentales.

En este sentido a veces ha surgido la polémica aún no resuelta sobre si hay diferencias entre los criterios de perceptibilidad y aceptabilidad de diferencias de color, pero la mayoría de los estudios en los que se basa la Colorimetría de Diferencia, optan por criterios de evaluación de diferencias perceptibles. No obstante, en determinadas aplicaciones industriales si se emplean, a veces, criterios de aceptabilidad en los procesos de control colorimétrico. Podemos decir, que el estudio de diferencias de color es más bien un problema científico, mientras que el establecimiento de tolerancias es una cuestión derivada de tipo técnico ligada a las necesidades industriales ${ }^{32}$.

En el campo de la Colorimetría Diferencial existen numerosos trabajos sobre la estimación de umbrales de discriminación cromática, tanto de aceptabilidad como de perceptibilidad $^{33}$. No obstante, la mayoría de ellos muestran la falta de uniformidad de 
los sistemas de representación del color como podemos observar en la siguiente figura, correspondiente a las clásicas elipses de MacAdam en el espacio CIE $1931^{34}$.

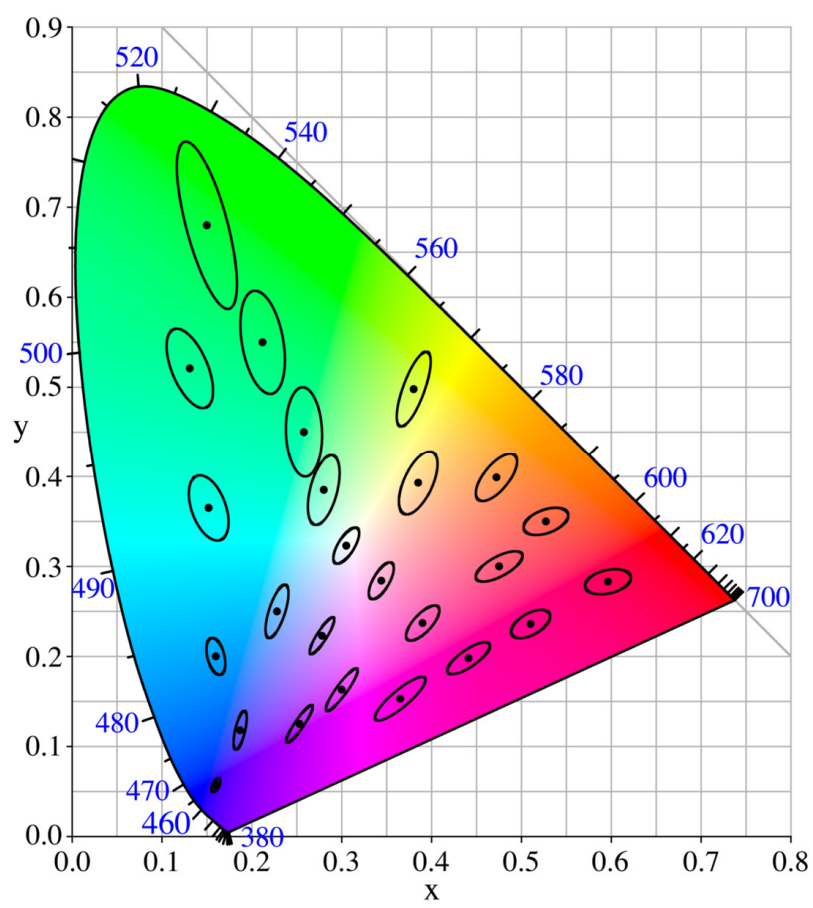

Figura 18: Elipses de Mac Adam ${ }^{35}$

Se observa que dichas elipses son diferentes en tamaño, orientación y forma a lo largo del diagrama cromático, siendo más pequeñas en la zona de los azules, intermedias en la región de los rojos y más grandes en la zona de los verdes.

Si tomamos la distancia desde el centro a cada punto de la elipse como la unidad de diferencias de color, un espacio cromático uniforme sería aquel en el que al representar dichas diferencias los resultados sean circunferenciales de igual radio, es decir, que exista una correlación entre la diferencia de color y la media de la distancia. En la figura anterior comprobamos que esa distancia no es la misma ni a lo largo de cada elipse ni de una elipse con otra. Por lo tanto, se deduce que el espacio CIE 1931 no es un espacio uniforme ${ }^{34}$. Esto ha llevado a la búsqueda de espacios de representación de color uniforme y a pesar de que no se ha conseguido, sí que se ha llegado a otros espacios mucho más homogéneos como sistema CIELAB, desarrollado posteriormente. 


\section{2.- COLOR EN ODONTOLOGÍA}

El estudio del color es una parte fundamental de la Odontología Estética. Sin duda, el color es uno de los parámetros de mayor peso cuando el paciente juzga la calidad de la restauración que le acaba de realizar su Odontólogo sobre todo en la región anterior. El alcanzar un perfecto mimetismo con los tejidos o los dientes circundantes se convierte así en un objetivo de primera importancia para el profesional de la Odontología y para el paciente. Motivo éste por el cual, el odontólogo está obligado a conocer y comprender todo lo relacionado con el cromatismo dentario y con los materiales de restauración, tanto en cerámicas como en resinas compuestas.

Nuestra sociedad se halla inmersa en un creciente proceso de culto a la estética dental y por este motivo la demanda de tratamientos odontológicos pretenden que, además de rehabilitar morfofuncionalmente el diente, le devuelvan su aspecto natural o incluso lo mejoren, se incrementa día a día ${ }^{36}$ Las disciplinas odontológicas estéticas se encargan de intentar satisfacer estos requisitos, y de entre ellas destaca el blanqueamiento dental por tratarse de un tratamiento que permite conseguir resultados satisfactorios para el paciente y el dentista en un tiempo prudencial y con un alto grado de seguridad ${ }^{37,38}$.

El cromatismo dental, a diferencia de lo que sucede con otros factores estéticos esenciales (forma, tamaño y posición del diente), cuya armonización con los demás dientes naturales no suelen plantear ningún problema resulta relativamente difícil de determinar y reproducir ${ }^{39,40}$. Hoy en día la odontología proporciona la oportunidad de restaurar las características de color exclusivas de cada paciente ya que cada diente natural tiene muchas características ópticas que aumentan su complejidad 13

En la actualidad, son muchos los pacientes que se interesan por tratamientos odontológicos estéticos por razones diversas: desde la búsqueda de satisfacción personal hasta necesidades de tipo laboral ${ }^{38,41}$. El referente estético dental en nuestra sociedad viene determinado por varios factores, de entre ellos, uno de los que más insatisfacción produce es un color anómalo del diente o que no satisfaga las expectativas del paciente ${ }^{42,43}$. 
En este capítulo en primer lugar, hablaremos de las propiedades ópticas de los dientes, en general, y de su color en particular, para analizar cómo los tejidos dentales determinan la complejidad cromática del diente. A continuación, comentaremos la información disponible sobre el denominado "espacio cromático dental". Finalmente, se describirán los procedimientos y técnicas para la medición del color en la práctica odontológica, tanto las guías de color dentarias como los modernos dispositivos electrónicos.

\subsection{1.-Características ópticas de los dientes}

El doctor Bruce Clark ${ }^{44}$ fue el primero en someter los dientes naturales a medición y análisis científico del color, comunicando la importancia de las dimensiones del color al manifestar en 1931 que en el estudio del color o la consideración de las tres dimensiones no sólo es un requisito básico sino el más importante. Este autor reconoce la necesidad de una aproximación más exacta del color dental, mediante la observación visual del diente humano basado en el sistema Munsell.

Las propiedades ópticas describen el comportamiento de un material ante la luz.

El color de los dientes está determinado por una combinación de propiedades ópticas. Cuando la luz se encuentra con un diente, cuatro fenómenos asociados con el flujo de luz se han descrito:

- Transmisión especular de la luz a través del diente

- Reflexión especular en la superficie

- Reflexión de la luz difusa en la superficie

- Absorción y difusión de la luz en los objetos adyacentes

El color definitivo es un resultado de la absorción y reflexión de la luz a lo largo del espesor del diente, donde depende directamente del coeficiente de absorción de los tejidos dentales.

El diente está constituido por tres tejidos, el esmalte, la dentina y pulpa y su color natural depende del grosor, composición y estructura de estos tejidos que, en definitiva, son los responsables de su complejidad desde el punto de vista óptico. Los tres parámetros a los que hemos hecho alusión, evolucionan considerablemente a lo largo de la vida, influyendo en el color del diente. Cada 
uno de estos tejidos presenta propiedades ópticas distintas ${ }^{45}$.

Pulpa dental: La pulpa está constituida por un 25\% de materia orgánica y un $75 \%$ de agua. La materia orgánica está compuesta por células, fibras y sustancia fundamental. Se trata, por tanto, de un tejido conectivo laxo, bien irrigado e inervado, que se encuentra encerrado en el interior de la cámara pulpar y de los conductos radiculares, lo que condiciona que su volumen vaya disminuyendo con el paso de los años por la continua formación de dentina ${ }^{46}$. Tiene un color rojizo oscuro. Su tamaño es mayor en dientes jóvenes, lo que tiene influencia en el color, ya que da lugar a un tinte rosado, a menudo más visible en las superficies linguales. El estrechamiento progresivo que se produce con los años, hace que su influencia sobre el valor del diente disminuya con la edad.

Dentina: Es el tejido más importante desde el punto de vista cromático. Es la responsable del tinte y de la intensidad dentaria. Rodea la cavidad pulpar y, en circunstancias normales, está cubierta por el esmalte o cemento. En su composición encontramos minerales (hidroxiapatita en un 70\%), material orgánico $(20 \%)$ y agua (10\%). El bajo contenido mineral, comparado con el del esmalte, y la elevada proporción de materia orgánica, explica la opacidad relativa de la dentina primaria (la formada antes de la erupción del diente). Está atravesada por un gran número de cavidades estrechas y largas, los túbulos dentinales, que producen una difracción selectiva de la luz, según la cual, ciertos rayos serán reflejados y otros absorbidos. Este efecto es el responsable de la opacidad de la dentina primaria ${ }^{46}$.

Las distintas estructuras microanatómicas, la arquitectura tubular, combinada con la anatomía macroscópica de la dentina, resultan en áreas con diferencias en el índice de reflectancia, dando un reflejo y dispersión no homogéneo de la luz. Esto da lugar a áreas de opacidad densa y de saturación de color elevada, confiriendo a la dentina un aspecto policromático. Con la edad la dentina primaria evoluciona y se forman otros tipos de dentina, con estructura y propiedades ópticas diferentes que influyen en la cromacidad dentaria ${ }^{45}$.

Los pigmentos orgánicos presentes en la microestructura de la dentina son responsables de la fluorescencia de este tejido, es decir, de su capacidad de absorber en el rango ultravioleta y emitir luz visible, una luz fluorescente policromática con una longitud de onda aproximada entre 400-410nm. Este 
fenómeno se evidencia en algunas situaciones, como por ejemplo, cuando los dientes naturales son vistos bajo la luz ultravioleta de la iluminación de las discotecas.

Esmalte: Es el tejido más duro y mineralizado del organismo. Está constituido por un $95 \%$ de minerales y un $5 \%$ de agua y materia orgánica. El alto contenido mineral y la naturaleza y disposición de los prismas que lo constituyen, hacen que el esmalte sea duro, brillante, translúcido, prácticamente acromático y radio-denso. La apariencia óptica del esmalte dental depende de su composición, estructura, grosor y textura superficial, parámetros que varían de una zona dentaria a otra y que evolucionan a lo largo de la vida. En un diente joven, el esmalte tiene menos contenido mineral y es muy grueso, creando el efecto óptico de una leve translucidez y alta luminosidad; en el diente anciano, el esmalte es más rico en minerales y más delgado por el desgaste natural, lo que se traduce en una mayor translucidez (incluso transparencia), que permitirá que, a su través, se haga patente el color de la dentina. El esmalte se caracteriza porque su coeficiente de transmisión depende de la longitud de onda incidente, esto significa que, la transmisión de luz por el esmalte aumenta conforme aumenta la longitud de onda; es más translúcido para altas longitudes de onda. Por este motivo, el esmalte es el responsable de la opalescencia dentaria. El esmalte es básicamente translúcido por su composición, pero su translucidez no es uniforme sino que muestra un gradiente de opacidad, de manera que la mitad más externa es más translúcida que la interna al ser los prismas del esmalte más densos en esta región. Este gradiente de opacidad en el esmalte se puede reproducir en las restauraciones considerando el esmalte como dividido en dos zonas de translucidez: una zona translúcida y una semi-translúcida. Estas capas permiten que la luz penetre a través de la estructura dental y se refleje sobre la capa de dentina, que es básicamente opaca y que es la responsable del color del diente.

Por lo anteriormente descrito se puede afirmar que el diente natural es un auténtico mosaico de color, en el rango de los blancos amarillentos, y el resultado de los efectos combinados del esmalte y la dentina, fundamentalmente. Por lo tanto, es esencial comprender la influencia que ejerce cada componente sobre las propiedades básicas del otro. La dentina, responsable del tinte e intensidad dentarios, reduce el valor del esmalte. Si el esmalte es muy delgado y la dentina es muy saturada, como sucede en la zona del cuello del diente (unión entre la corona y la raíz), entonces la intensidad de la dentina domina la percepción cromática del 
diente. Si avanzamos en dirección incisal, a nivel del tercio medio, el esmalte es más grueso por lo que aumenta el valor y disminuye la intensidad. Finalmente en el tercio incisal, sólo hay esmalte, lo que condiciona las cualidades ópticas únicas de esta zona. A este nivel, el diente se vuelve translucido, prácticamente acromático, y presenta opalescencia, es decir refleja las longitudes de onda más cortas (aspecto azulado con luz reflejada) y transmite las largas (aspecto anaranjado con luz transmitida) ${ }^{6}$.

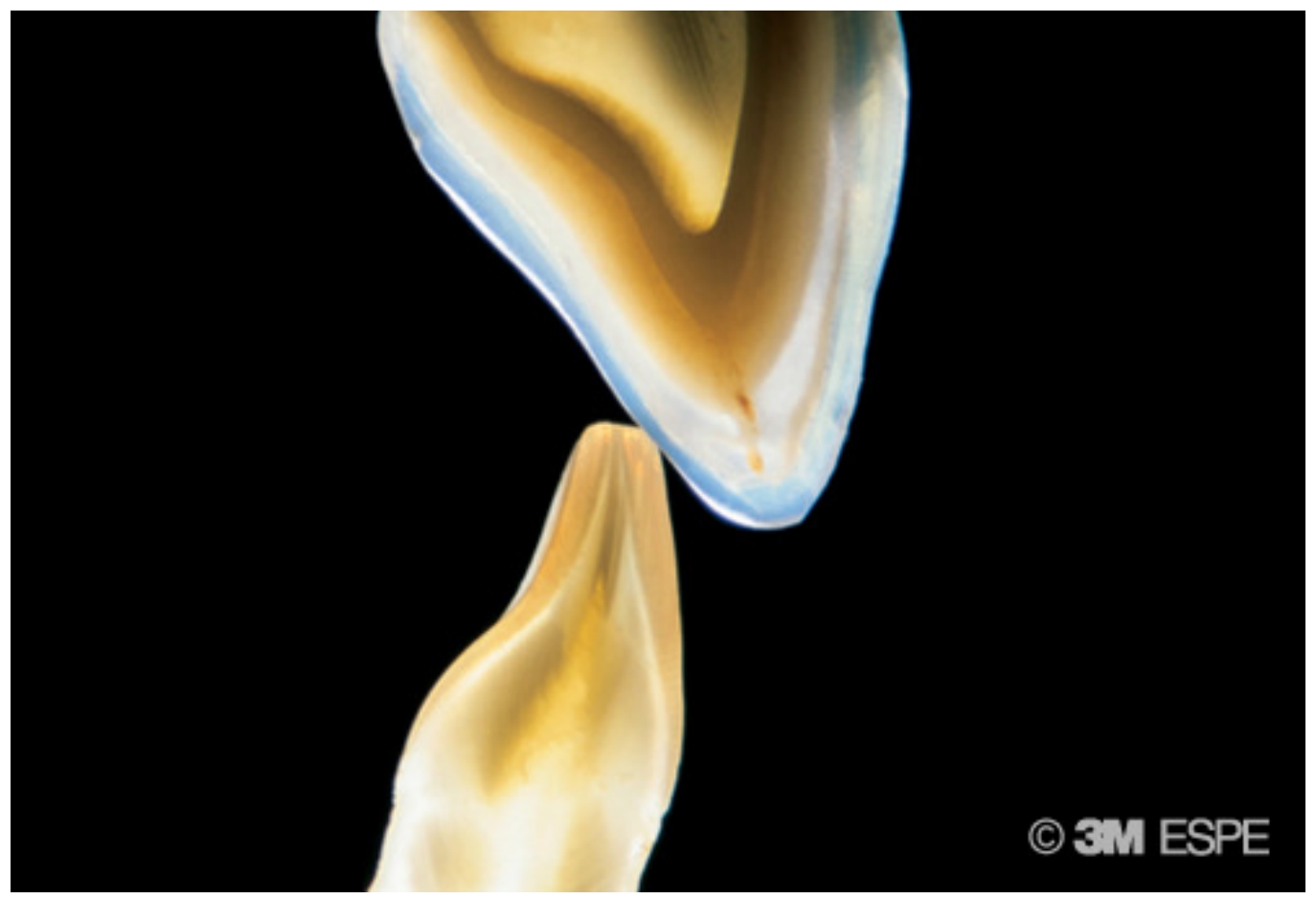

Figura 19: Diferentes tejidos que forman el diente 47

Este estudio confirmó que el color dental está determinado principalmente por el color de la dentina, mientras que el esmalte juega un papel menor en la difusión de la longitud de onda en el rango del azul ${ }^{48}$.

En un diente recién erupcionado, las capas superficiales del esmalte son las más opacas. Estas capas se presentan con frecuencia con un aspecto blanco helado. Este esmalte puede tener un mayor contenido orgánico ${ }^{49}$, es menos mineralizado y tiene espacios más vacíos entre los cristales de esmalte, por lo cual aumenta su opacidad ${ }^{48}$. A medida que se gastan estas capas superiores, es menos opaco el esmalte subyacente. La intensidad de un diente, procede principalmente de la dentina, será menor en un diente joven a causa del efecto máscara del esmalte. El espesor natural del esmalte es mayor por incisal que por la zona cervical, por lo que la intensidad será 
mayor por cervical y disminuirá hacia la zona incisal. A medida que el esmalte se adelgaza con el tiempo, se hace más evidente la dentina y el diente se vuelve menos monocromático. El esmalte joven también es más permeable y se deshidratará más rápidamente. Las capas más profundas del esmalte tienen menos espacios de aire y están más mineralizadas. Este esmalte más profundo es más translúcido ${ }^{50}$.

Además existe aún mayor grado de complejidad al tener que contar con varios fenómenos que se producen al contactar la luz con el diente.

Existen varias propiedades intrínsecas de los dientes que les caracterizan, que hacen aún más compleja la reproducción de un diente natural, a continuación las describimos:

Metamerismo: es el fenómeno por el que dos objetos de naturaleza diferente, por ejemplo un diente natural y un diente artificial, pueden aparecer del mismo color y aspecto bajo un tipo de luz, y de diferente color y aspecto bajo otro tipo de fuente luminosa. Efectos metaméricos se dan entre el consultorio dental y el laboratorio pudiendo provocar una mala igualación del color en la restauración terminada. De no ser así, molestaría al paciente en su vida diaria por lo que la industria se esfuerza en adaptar los espectros de absorción de sus materiales a los modelos naturales; en el caso de las porcelanas se ha conseguido de forma satisfactoria, y en el caso de los composites solo de forma aceptable ${ }^{51}$.

Para intentar minimizar el fenómeno del metamerismo, la toma de color de una restauración debería hacerse bajo diferentes fuentes de luz, y comprobar que en todas ellas se mantiene constante.

En un estudio publicado por Carballo V. ${ }^{52}$ y colaboradores en el año 2008 concluyen que los odontólogos deben tener en cuenta el efecto del metamerismo a la hora de identificar los colores dentales en su práctica diaria, ya que no es lo mismo percibirlos bajo luz natural, que bajo luz fluorescente (del gabinete dental) o bajo luz incandescente (del sillón dental). La luz fluorescente es la que nos produce menos errores a la hora de percibir el color dental, por lo que es la que debemos utilizar para evitar este efecto. De los tres atributos del color, el que se ve más afectado a la hora de percibir el color dental es:

- Bajo luz natural: se percibe peor el tinte 
- Bajo luz fluorescente: se perciben peor tanto el tinte como la intensidad

- Bajo luz incandescente: se percibe peor el tinte

Fluorescencia: es la absorción de la luz por un material y la emisión espontánea de la misma en una longitud de onda ligeramente mayor, y por lo tanto con menor energía ${ }^{24}$. En un diente natural se da principalmente en la dentina debido al mayor contenido de material orgánico presente ${ }^{53,54,55,56}$.

El pico de excitación máxima del esmalte ha sido encontrado alrededor de 285 y 330nm y la emisión máxima a 360 y $410 \mathrm{~nm}{ }^{57}$. Varios investigadores han estudiado la luminiscencia (fluorescencia y fosforescencia) de esmalte y dentina a lo largo de la historia $^{48,58,59}$.

La dentina tiene un pico de excitación de fluorescencia inferior a 300, 325, 380, y 410nm, con una emisión correspondiente máxima de 350, 400, 450 y 520nm ${ }^{60}$.

Los objetos fluorecen con un color distinto del de la fuente lumínica. La mayoría de las porcelanas dentales actuales fluorecen para imitar a los dientes naturales. Así la luz ultravioleta puede repercutir de forma importante sobre el nivel de vitalidad mostrado por las restauraciones. Gracias a la fluorescencia parecen más brillantes y vivas ${ }^{13}$.

Opalescencia: Esta propiedad en los dientes se debe a la diferencia entre los índices de refracción de la estructura prismática del esmalte y la matriz orgánica. La semejanza del ópalo natural con el esmalte dental hace que se considere a este último como un material totalmente opalescente.

Es el fenómeno en el que un material parece tener un color cuando la luz es reflejada por uno mismo, y otro cuando se transmite a través de él ${ }^{61}$.

Los cristales de hidroxiapatita del esmalte también actúan como prismas. Cuando se iluminan los ópalos, el esmalte transmitirá los rojos y dispersará los azules en su seno, por lo que el esmalte aparecerá azulado a pesar de carecer de color ${ }^{53,54,62 .}$

Los efectos opalescentes del esmalte dan brillo al diente y le confieren profundidad óptica y vitalidad $^{63}$. 
La mejora de las propiedades de las porcelanas en cuanto a opalescencia y fluorescencia, dan lugar a restauraciones más estéticas, que parecen naturales, cuando la restauración reacciona con cualquier tipo de luz, ya que lo hace de la misma manera que los dientes naturales ${ }^{64}$.

Zena R. en el año 2001, estudió las puntuaciones de opalescencia en el diente natural, las cuales estaban en el rango de 19,8- 27,6. Estas, están influenciadas por las diferentes orientaciones de los cristales de hidroxiapatita y también por la configuración del espectrofotómetro con el que se ha medido ${ }^{64}$.

Diferentes estudios se han dedicado a medir la diferente influencia de cada uno de los tejidos dentarios sobre el color resultante del diente obteniendo resultados dispares. A continuación expondremos algunos de ellos.

Cuando la luz penetra en el diente puede reflejarse en muchas superficies internas del mismo antes de que salga, lo que cambia sustancialmente su carácter. A mayor dispersión en el esmalte, mayor será el valor ${ }^{56,62}$.

Para el esmalte, se encontró que los cristales de hidroxiapatita contribuyen significativamente a la difusión de la luz, mientras que para la dentina la anisotropía óptica observada soporta la idea de que los túbulos dentinarios causan la difusión ${ }^{60}$.

El poder de difusión óptica de los bloques de esmalte fue medido como una función del descenso del contenido mineral, observando que la desmineralización aumenta el coeficiente de difusión ${ }^{65}$.

Estudios in vitro mostraron que los colores de 28 dientes de diferentes pacientes donde el esmalte fue retirado estaban fuertemente relacionados con los colores del diente completo ${ }^{62}$. Además este estudio confirmó que el color dental está determinado principalmente por el color de la dentina, mientras que el esmalte juega un papel menor en la difusión de la longitud de onda en el rango del azul.

La dentina tiene un pico de excitación de fluorescencia inferior a 300, 325, 380, y 410nm, con una emisión correspondiente máxima de 350, 400, 450 y 520nm ${ }^{60}$.

El pico de excitación máxima del esmalte ha sido encontrado alrededor de 285 y 330nm 
y la emisión máxima a 360 y 410nm ${ }^{57}$. Años después, Ten Bosch y Coops en 1995, midieron el color de dientes bajo dos fuentes de luz distintas y concluyeron que bajo la luz del día, la fluorescencia no contribuye de manera medible a la apreciación del color dental ${ }^{62}$.

\subsection{2.-Espacio cromático dental}

Muchos han sido los autores que han intentado definir el espacio de color de los dientes naturales, unos a través de dientes humanos extraídos con espectrofotometría $66,67,68$. Otros aplicaron la tecnología instrumental "in vivo" 69, 70, 71, 72.

Es reconocido por todos los autores que el diente no es monocromático y que el tercio medio es la zona más representativa del mismo ${ }^{6,10,18}$. Por un lado, el tercio incisal es muy translúcido, por lo que su percepción cromática está afectada por el fondo, mientras que en el color del tercio cervical influye la cercanía del margen gingival.

Por estos motivos, en los trabajos de investigación sobre color en dientes naturales, es el tercio medio la zona donde se suelen realizar las mediciones.

Recientemente, para su mejor comprensión por parte de los clínicos, la zona del espacio cromático correspondiente a los dientes naturales ha sido descrita como un sub- espacio cromático con "forma de plátano", en los sistemas $L a b$ y $L C h$. Este espacio cromático dental está situado entre el rojo claro y el amarillo claro; tiene forma alargada y se extiende paralelamente al eje de luminosidad. Los valores extremos de este sub-espacio cromático, es decir, los del diente más claro existente en la naturaleza y los del diente más oscuro, son, en el sistema $L$ a b los valores de 78/1/12 y 62/6/31. En el sistema L, C, h estos valores son de 78/12/86 y 62/32/78.

El rango de coordenadas cromáticas y su distribución dentro del espacio cromático de los dientes han sido descritos en numerosas investigaciones ${ }^{6}$. No existe consenso absoluto en la bibliografía sobre cuales son los límites de coordenadas donde se encuentran el conjunto de colores de la dentición natural.

Para una mejor visualización de los valores extremos antes citados, la siguiente figura muestra la representación gráfica del sub-espacio cromático dental en $L$ a b (coordenadas ordinales) y en L C h (coordenadas polares). 


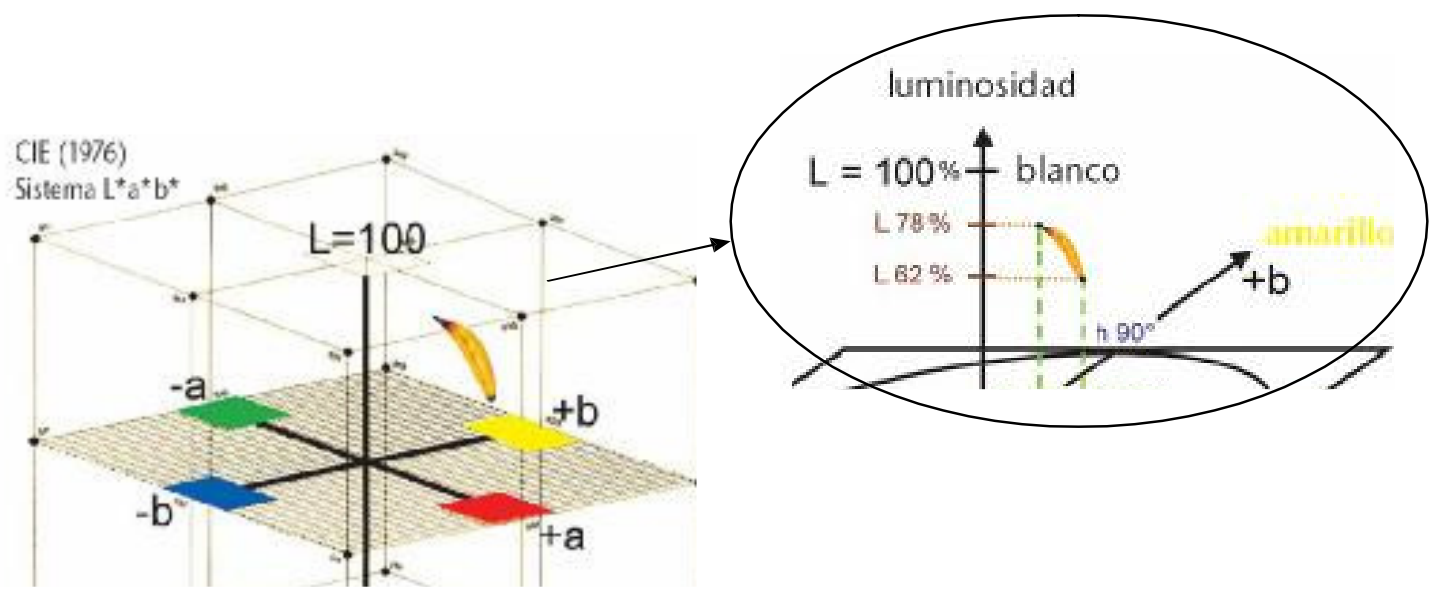

Figura 20: Espacio cromático dental dentro del espacio cromático de L, $a, b^{73}$

De la figura se puede deducir que los dientes que presentan mayor valor tienen un mayor ángulo de tinte (una mayor proporción de amarillo) y menor intensidad. Sin embargo, cuanto más oscuro sea el diente (menor valor) mayor es su intensidad y menor el ángulo de tinte, es decir, mayor proporción de rojo.

\subsection{3.- Medición del color en Odontología}

El registro del color se convierte en un procedimiento complejo debido a su naturaleza subjetiva derivada de la participación del observador en el proceso, lo que ha supuesto que se haya visto abordada desde diferentes puntos de vista a lo largo del tiempo ${ }^{51}$. Se han empleado dos tipos de sistemas de medición del color en la valoración y cuantificación del mismo: por un lado, los modelos psicofísicos o subjetivos, basados en la comparación del color con patrones o guías de referencia; y por otro, los métodos objetivos o matemáticos, que tratan de representar los colores del espectro visible de una forma numérica, y que se basan en la obtención del color buscado mediante la mezcla en diferentes proporciones de los colores principales o primarios 45,74

Según Bergen S.F. 1985, el color es uno de los factores que más influyen en los resultados estéticos en Odontología ${ }^{75}$. Muchos métodos son actualmente utilizados para medir el color dental. Desde la comparación visual subjetiva usando papel a 
guías de color acrílicas o de porcelana, espectrofotómetros, colorímetros y técnicas de análisis por imagen ${ }^{76}$ :

1. Subjetiva: Se basa en la comparación del objeto (diente) con muestras de color que pueden ser de papel, de resina o de porcelana. Este es el método en el que se fundamentan las guías de color que se utilizan en Odontología y que actualmente son las de uso más frecuente en clínica diaria.

2. Objetiva: Mediante el uso de colorímetros, espectrofotómetros, o mediante técnicas digitales de análisis de imagen.

Las guías de color son las herramientas que se utilizan en clínica para la medición del color mientras que, los instrumentos digitales de medida no tienen un uso extendido en el campo odontológico. La falta de preparación sobre el manejo, así como su alto coste hace que estos dispositivos digitales no sean empleados usualmente en clínica.

En el siguiente apartado se describen algunas de las guías más empleadas en Odontología y también algunos de los sistemas de medición instrumentales más extendidos en la profesión y disponibles en el mercado actualmente.

\subsubsection{1.- Métodos Subjetivos}

Las guías dentales suelen constar de tablillas de color que se comparan sucesivamente con el diente, en condiciones de iluminación idénticas, hasta encontrar aquella que presenta una mayor similitud cromática. La utilización de guías para medir el color en Odontología es un procedimiento subjetivo y son muchas las variables que influyen en el resultado: la iluminación, la experiencia profesional, la edad, los colores del entorno, el ángulo de visión del diente y la tablilla, la ropa y maquillaje del paciente y desde luego, la capacidad perceptiva cromática del individuo ${ }^{77,78}$.

En 1984 la American Dental Association llegó a un consenso que dictaba los siguientes puntos:

1.-Las tablillas de colores disponibles no se corresponden con los colores de los dientes naturales. 
2.-Así mismo, tampoco se corresponden con los materiales utilizados para las restauraciones.

3.-Para establecer unos colores estándar es preciso efectuar mediciones espectrofotométricas de los dientes naturales.

4.-Las dos cualidades más importantes a tener en cuenta son la opalescencia y la fluorescencia.

Jack Preston en 1985, resumió los problemas existentes en la determinación de los colores al demostrar que en la captación del color intervienen diversos factores que interactúan entre sí. Además identificó varios problemas asociados a las guías de color, y describió la inevitable influencia del color gingival durante la selección del color, la diferencia de materiales en las guías y de las cerámicas restauradoras ${ }^{79}$.

La determinación del color visual por comparación de los dientes con colores estándar dentarios en guías de color, es el método común más aplicado en Odontología ${ }^{76}$. Es un proceso subjetivo donde el diente y la guía de color son observados simultáneamente bajo las mismas condiciones de luz. Variables generales con las condiciones de luz externas, experiencia, edad, fatiga ocular, fatiga psicológica son variables que podrían conducir a errores inconscientes ${ }^{80}$. Además la evaluación visual de los colores es limitada ${ }^{81}$.

Aún así, el ojo humano es muy eficiente en detectar pequeñas diferencias de color entre dos objetos ${ }^{82}$.

Se han descrito varias guías de color dental para la toma de color ${ }^{83}$. En general, la guía básica de color está representada en solo el tercio medio del diente ${ }^{83}$, porque el rango de los cambios de color desde incisal a cervical y la experiencia del observador deben intentar enfocar sobre esa área ${ }^{84}$.

Las guías de color para prótesis sirven también como color estándar, aunque se han descrito varias desventajas.

- Los colores no están sistemáticamente colocados según su ubicación espacial 85,86

- Hay una falta de acuerdo entre varios dentistas en elegir el color $84,87,88$.

- Los resultados no pueden ser transformados en el sistema CIE Lab ${ }^{89}$. 
- Ninguna guía comercial es idéntica a otra ${ }^{82,90,91 .}$

- El color estándar de las guías de color varía enormemente debido a parámetros difíciles de controlar durante su fabricación, como el recubrimiento, el espesor de capa, el sinterizado,....Por ello ninguna guía de las disponibles en el mercado es idéntica a otra.

A pesar de estas limitaciones, el uso de guías de colores es un metodos rápido y barato para medir el color dental. Se han utilizado con éxito en un alto número de estudios de agentes blanqueantes y se han medido con dichas guías, cambios longitudinales en el color del diente ${ }^{92,93,94}$.

Miller A. en 1993 reconoce que el material de las guías de color debería ser el mismo que el futuro material restaurador y que el espesor de los dientes artificiales no debería ser mayor que una carilla de porcelana ${ }^{12}$.

Las guías de color son indispensables, tanto para la selección del color de los materiales en clínica como para comunicar éste al laboratorio, en el caso de que la restauración se realice con materiales que precisan ser elaborados allí. Sin embargo, lamentablemente, no existe ninguna escala que consiga reproducir todos los colores existentes en los dientes naturales y, por tanto, no existe una guía de color ideal. A pesar de sus limitaciones, las guías más utilizas son la Vitapan Classical, la Vitapan 3D Master, la guía Linearguide pertenecientes a la casa comercial Vita-Zahnfabrik y la guía dental Chromascop (Ivoclar-Vivadent).

Vitapan Classical: La Vita Classical es el referente para las guías de color.

Consta de 16 muestras clasificadas en cuatro grupos o familias. La ordenación de las 16 muestras puede hacerse de dos formas, bien según familias de tintes o bien según el valor.

Las familias se identifican por letras A (rojiza-pardusca), B (rojiza-amarillenta), C (matices grises) y a la D (rojiza-gris).

La familia $A$ esta más próxima a la región anaranjada, que a la designada por el fabricante. La familia B tiende más a la gama del amarillo. La familia C es mal 
denominada gama de grises porque el gris es una especificación acromática y no se considera un matiz, y por último la familia $\mathrm{D}$ tiende más hacia la gama del naranja.

Las 16 tablillas de color están colocadas según su valor en orden decreciente de la siguiente manera: $\mathrm{B} 1>\mathrm{A} 1>\mathrm{B} 2>\mathrm{D} 2>\mathrm{A} 2>\mathrm{C} 1>\mathrm{C} 2>\mathrm{D} 4>\mathrm{A} 3>\mathrm{D} 3>\mathrm{B} 3>\mathrm{A} 3,5>\mathrm{B} 4>\mathrm{C} 3>\mathrm{A} 4>\mathrm{C} 4$ 95

La guía de colores Lumin-Vacum de Vita está constituida por 4 tintes principales expresados por las letras A, B, C y D:

- La A corresponde a las tonalidades amarillo anaranjadas. Son frecuentes en los jóvenes y se encuentran en el $65 \%$ de los pacientes, es propia de los incisivos centrales y laterales.

- La B corresponde a las tonalidades amarillas. Corresponde a pacientes de mediana edad cuyos dientes muestran mezclas del A y del B.

- La C corresponde a tinte marrón-grisáceo. Es propia de pacientes maduros. Se trata de un subgrupo del B aunque con un valor menor.

- La D corresponde a tintes rojos grisáceos.

A pesar de ser la más ampliamente utilizada, por su extrema facilidad de uso, esta escala posee muchos inconvenientes, entre los que podemos destacar:

- En caso de ser usadas para toma de color en las restauraciones cerámicas, éstas poseen un espesor inadecuado, que normalmente varía entre 4 a $5 \mathrm{~mm}$, y que deberá ser reproducido en tan solamente una capa de 1 a $1.5 \mathrm{~mm}$ de cerámica.

- Las tablillas no cubren todo el espacio cromático dental, es decir, en ellas no están representadas todos los posibles colores de los dientes naturales humanos.

- Sus variaciones de color no están sistemáticamente distribuidas en el espacio cromático dental. 


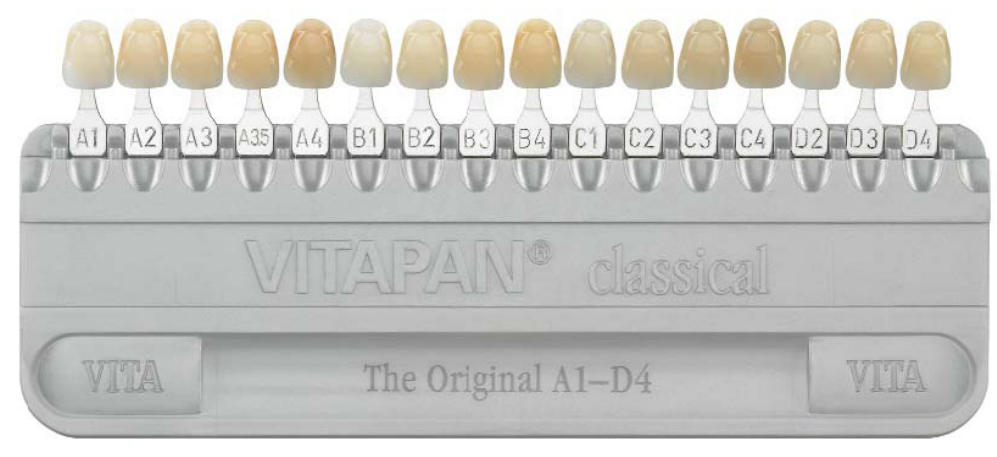

Figura 21: Guía dental Vitapan Classical ${ }^{96}$

Técnica:

- Colocaremos los 4 tintes de máxima intensidad: A4, B4, C4 y D4. en un muestrario, ya que ésta será la mejor forma de distinguir el color .Nos fijaremos en el canino, que es el diente que tiene la intensidad más alta de toda la arcada. Realizaremos un par de pasadas rápidas con los 4 tintes y los compararemos con la parte cervical del mismo que es la más saturada o tiene más intensidad. Todo esto con luz natural o una lámpara de luz corregida.

- Una vez elegido el apropiado supongamos que sea el A, descartamos los otros tintes y colocamos en el muestrario las distintas intensidades del grupo: A2, $A 3,5$, y $A 4$, y las comparamos fijándonos en la parte central del diente, durante 5 segundos. Supongamos que elegimos el color A2. Mirando la carta de colores de Vita vemos que a ese tinte le corresponde la intensidad seleccionada. Si no es así, buscaremos en las lengüetas el color de la dentina que más se le asemeje. Una vez individualizado, habremos conseguido el color que debe tener la dentina.

Vita Toothguide 3D Master: En febrero de 1998 Vita lanzó al mercado ésta nueva escala con el objetivo de minimizar los problemas de la Classical. Esta guía contiene 26 tablillas, que cubren el espacio cromático de los dientes naturales, cubiertos de manera uniforme y completa, según su fabricante ${ }^{96}$.

Se ha introducido una nueva guía de color, la cual ha sido diseñada específicamente para la selección del color basándose en una distribución uniforme ${ }^{97}$. Este sistema 3D Master contiene tablas de color que están uniformemente colocadas por el espacio según el color de los dientes naturales. Esta guía de color se ha diseñado para 
mejorar de forma significativa la reproducción de la medida de color dental comparándolo con la guía de color tradicional ${ }^{98}$.

Desde el lanzamiento del Vita System 3D Master, resulta posible describir con precisión científica todos los colores. El fundamento y elemento esencial del Vita System 3D Master es el descubrimiento del espacio cromático dental, imaginable dentro del universo cromático como una elipse erguida que abarca todos los colores dentales naturales existentes en el mundo. Este espacio cromático dental, como ya he señalado anteriormente, se define en función de tres parámetros: valor, intensidad y tinte. Sólo mediante estas coordenadas resulta posible expresar exactamente en cifras cada color dental. La guía Vita Toothguide 3D Master pone en sus manos todos los colores dentales humanos naturales, según la casa comercial.

Esta guía dental está diseñada por la casa Vita- Zahnfabrik, que la describe de la siguiente manera en su página web ${ }^{96}$.

La guía Vita Bleachedguide 3D Master es un instrumento que permite al odontólogo planificar y controlar los procesos de blanqueamiento dental. Su diseño sigue la lógica del Vita System 3D Master, basada en tres parámetros: valor, intensidad y tinte. Pero los niveles de valor e intensidad incluyen además registros intermedios con más muestras de colores.

Ventajas, según la casa comercial Vita-Zahnfabrik ${ }^{96 .}$

- Permite hablar con el paciente de forma realista sobre el proceso de blanqueamiento.

- Diferencias entre colores uniformes y fáciles de distinguir para el ojo humano.

- Los registros intermedios (valor, intensidad) están disponibles en forma de muestras de colores.

- El odontólogo y el paciente pueden consensuar el resultado deseado con la ayuda de las muestras de colores y comprobar posteriormente el resultado conseguido.

- Permite determinar durante las revisiones si es necesario repetir el blanqueamiento. 
La ordenación de los distintos colores de los dientes en el espacio cromático dental de la guía 3D Master está estructurada en 5 grupos. Cada uno de ellos con el mismo nivel de valor (niveles del 1 al 5). La variación del color de los niveles de valor es constante. El nivel de valor intermedio 3 consta como el segundo y el cuarto de 7 colores dentales. Los tres del medio $\mathrm{M}$ pertenecen al mismo tinte y, de arriba a abajo aumenta únicamente la intensidad del color (1,2 y 3). A la izquierda (L) y a la derecha $(R)$, de éste se encuentran dos colores, con un tinte de color más amarillento $(L) O$ más rojizo $(\mathrm{R})$ que el correspondiente tinte de color central. Dentro de cada tinte más amarillento o más rojizo se aumenta la intensidad del color de arriba abajo (1.5 y 2.5).

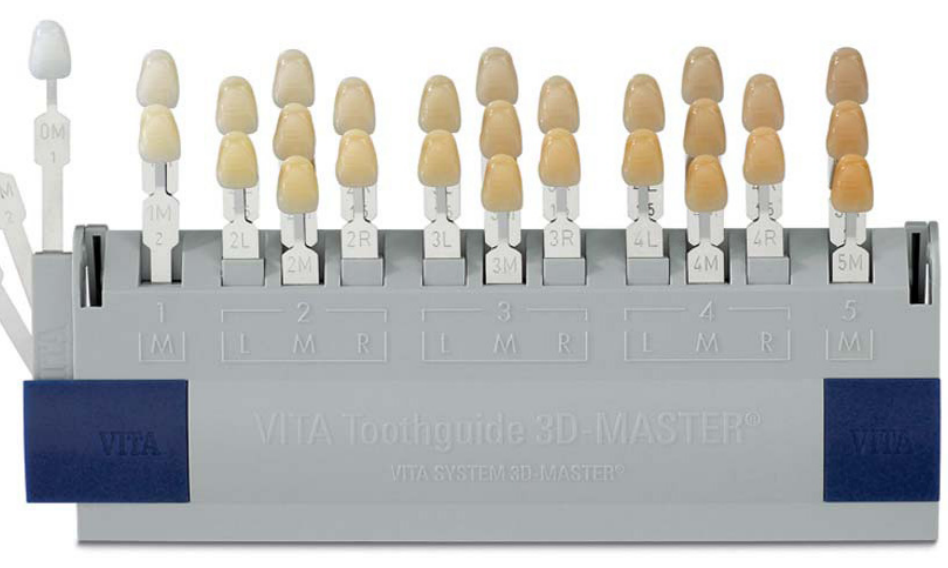

Figura 22: Guía dental Vita Toothguide 3D-Master ${ }^{96}$

- La guía Vitapan 3D Master en comparación con Vita classical muestra una mayor cobertura en el espacio cromático del color del diente. Indican igualmente que Vitapan 3D Master no cubre toda la gama de los dientes naturales y que todavía pueden mejorarse los intervalos de las coordenadas de color. Los errores de cobertura de estas dos guías resultan clínicamente aceptables aunque el error de cobertura de Vitapan Classical con respecto a la guía 3D Master, se sitúa exactamente en el límite de la aceptabilidad clínica.

- Esta guía de colores puede esterilizarse a una temperatura de hasta $140^{\circ} \mathrm{C}$.

- Tipos de prótesis para aplicar con la guía Vitapan 3D Master: metal cerámico, cerámica sin metal y dientes de resina.

Al usar esta guía, primero se selecciona el valor, luego la intensidad y finalmente el tinte. Entre sus ventajas apuntadas por el propio fabricante de la guía están ${ }^{96}$ :

- La mejor distribución de muestras dentro de las variaciones de colores de los dientes naturales existentes. 
- La distribución sistemática de las tablillas en el espacio cromático que ocupan los dientes naturales, con distancias cromáticas uniformes, lo que mejora decisivamente la precisión si se maneja bien.

Guía Vitapan 3D Máster Linearguide: La guía Vita Linearguide 3D Máster permite determinar el color dental correcto de forma rápida y precisa. Gracias al moderno diseño y a la estructura sistemática de Vita Linearguide se localiza con agilidad el color adecuado del sistema 3D Master.

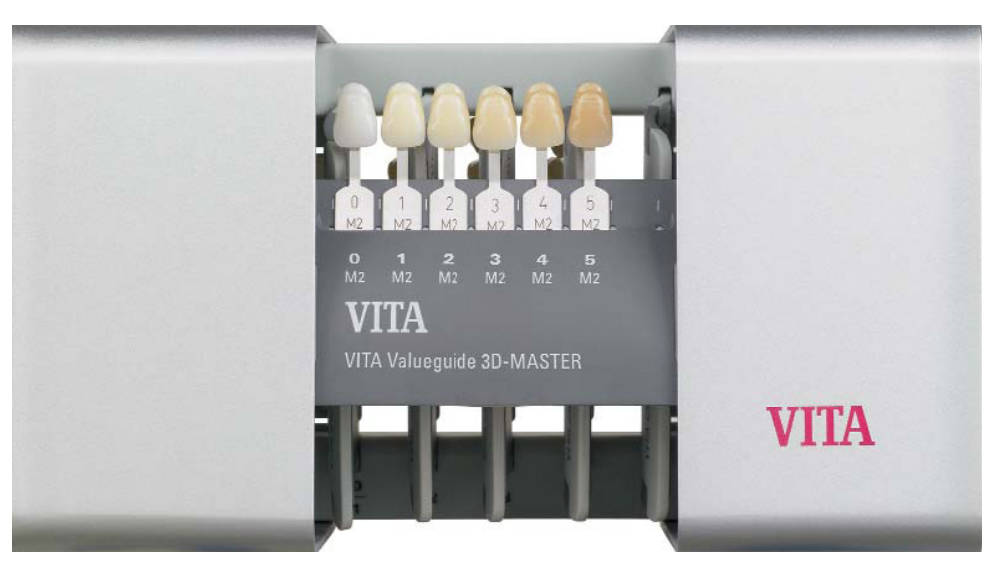

Figura 23: Guía dental Vita Linearguide ${ }^{96}$

Vita Linearguide 3D Master simplifica el cambio de los sistemas de toma del color convencionales a la determinación y la comunicación del color precisas con el Vita System 3D Master.

¿Cuáles son las ventajas que ofrece esta guía respecto a sus predecesoras? Según la propia casa comercial ${ }^{96}$ :

- Manipulación lineal clásica

- Autoexplicativa, fácil de usar

- Clientes satisfechos gracias a una determinación del color segura, rápida y precisa

- Un diseño moderno como la plasmación perfecta de la estética y la facilidad de uso.

La guía dental Vita Linearguide 3D Master contiene muestras de los mismos 29 colores que la guía dental Vita Toothguide 3D Master. 


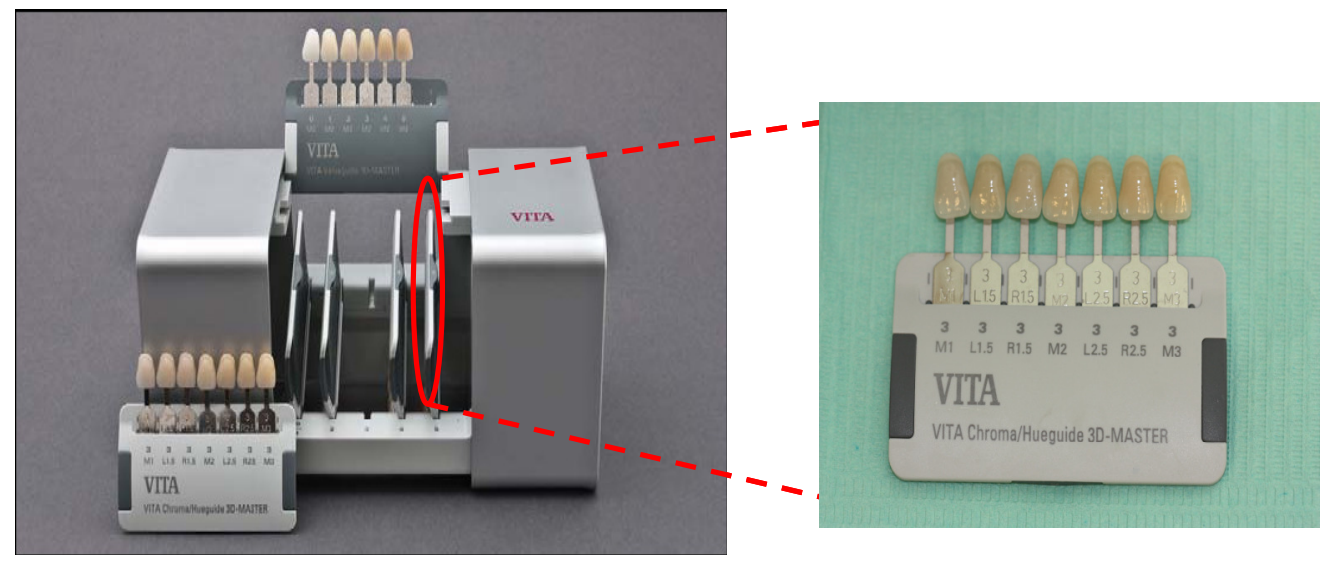

Figura 24: Valor 3 de Vita Linearguide ${ }^{96}$
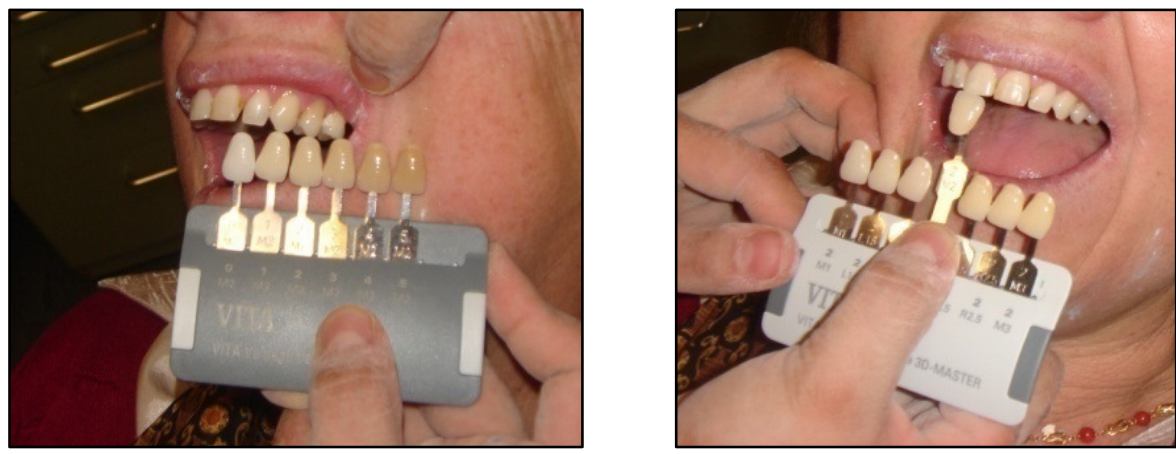

Figura 25: Toma de color en boca con Vita Linearguide

Al igual que en la guía 3D Máster Toothguide, debemos seguir los 3 pasos para la selección del color:

1. Determinar el valor entre los 5 grupos posibles (1-5).

2. Escogeremos las guías correspondientes a dicho valor y seleccionaremos la intensidad de color.

3. Iremos a la selección de izquierda a la derecha para determinar el tinte de la guía seleccionada.

Chromascop: Esta guía es la utilizada por Ivoclar Vivadent en sus sistemas cerámicos. Está ordenada por familias. Consta de 20 colores de diente y agrupa los tintes en 5 familias. Cada una formada a la vez por cuatro intensidades de color, ordenados de izquierda a derecha, de más claros a más oscuros. 


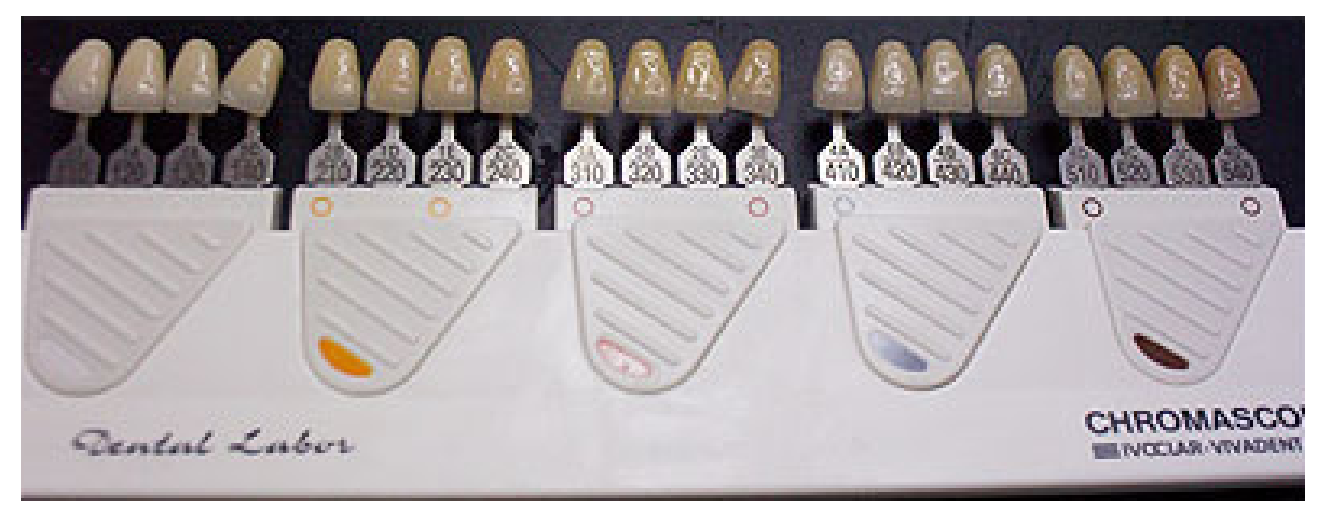

Figura 26: Guía de color Chromascop

Los 5 tintes son el blanco el amarillo el marrón claro, el gris y el marrón oscuro. La nomenclatura que sigue es doble ya que por un lado trae el nombre convencional similar a la guía Vita Clasica y por otro lado se asigna números, 100 a los tintes blancos, 200 a los amarillos, 300 a los marrones claros, 400 a los grises y 500 a los marrones oscuros. Dependiendo de cada tinte numera del 10 al 40 las cuatro intensidades de color de valor decreciente. Es decir, presenta veinte muestras divididas en cinco grupos de tintes, según la siguiente numeración: 100(blanco), 200(amarillo), 300(marrón claro), 400(gris) y 500 (marrón oscuro). Cada grupo posee cuatro muestras ordenadas en intensidad creciente, con el número 10 correspondiendo al más bajo y el 40 al más elevado. Se utiliza de forma similar a la Vita Classical, eligiendo primero el tinte y luego el nivel de intensidad.

Técnica de uso:

- Mantener la boca del paciente a la altura de los ojos del clínico, aprox. $50 \mathrm{~cm}$ de distancia.

- Determinar el color básico amarillo o gris, según tipología Ivoclar.

- Determinar el color básico definitivo del paciente y extraer el grupo cromático.

- Controlar nuevamente la muestra del color seleccionada en el diente natural. 


\subsubsection{2.- Métodos Objetivos}

Los procesos de selección de color mediante sistemas instrumentales, pretenden ayudar a sustituir la sensación subjetiva del ojo humano para suministrar los datos reproductibles de forma exacta para la construcción y la fabricación de prótesis dentales. En los aparatos disponibles actualmente en el mercado se aplican diferentes principios de medición. Básicamente, en todos los aparatos de medición del color se emite luz y se mide su reflexión. Las mediciones duran menos de un segundo y no son perceptibles por el paciente. Hay aparatos que solo miden un punto y otros registran el diente a modo de imagen.

En las mediciones puntuales se requieren varias mediciones para registrar todo un diente.

En la medición de superficies se capta todo el diente en un solo registro. Por tanto la medición de superficies facilita al terapeuta de forma más sencilla los datos reproducibles y comunicables sobre la superficie dental ${ }^{99}$.

En 1975, Lemiere y Burk investigaron la frecuencia y distribución del espacio del diente natural usando un espectrofotómetro y también afirmaron que la variabilidad de color de los dientes naturales era mayor que la de las guías de color, por eso la necesidad actual de poder utilizar estos sistemas digitales de medición de color, facilita el estudio ${ }^{67}$.

En la actualidad existe un importante número de sistemas comerciales diseñados para ayudar a clínicos y a los técnicos de laboratorio en el manejo del color en la práctica clínica. Entre ellos se incluyen colorímetros, espectrofotómetros, analizadores digitales del color e instrumentos híbridos que combinan estas tecnologías. La principal desventaja de los nuevos dispositivos frente a los métodos visuales tradicionales sería el coste económico de los aparatos, especialmente de los espectrofotómetros.

\subsubsection{1.-Colorímetros}

El primer colorímetro específicamente diseñado para medir el color en los dientes fue el Chromascan, a principios de los años 80. Tuvo poco éxito por la dificultad de su uso y la limitada precisión. 
El ShadeEye® NCC (Natural Color Concep), e Identa color II (Identa) supuso la segunda generación de colorímetros dentales. Estos instrumentos, poseen un tipo de sonda de contacto con ventana circular que usa un pulso de flash de xenon para iluminar la superficie vestibular dentaria a medir. La luz se proyecta sobre el diente en forma de donut, de manera que el centro de la sonda (por donde no sale luz) recibe la luz que despide el diente, y a través de una guía de luz este haz reflejado llega al detector, que es el que lleva a cabo la medición. Así se consigue obtener el color dental.

El diseño de la sonda del instrumento y la naturaleza translúcida del diente hacen que la medición pueda verse afectada por el "scattering", es decir, que parte de la luz se pierda para la lectura, que no pase por la ventana del instrumento. Esto hace que, por ejemplo, una cerámica aparentemente igual que un diente natural, dé diferente lectura. Para corregir esta discrepancia, se ha incorporado al ShadeEye un sistema de selección previa del material sobre el que se va a trabajar y que hay que seleccionar antes de la calibración del instrumento. Esta selección del modo seguramente modifica los algoritmos matemáticos que utiliza el dispositivo para la medida del color. Tras la selección del modo (diente, porcelana o blanqueamiento), se calibra y se selecciona el diente a medir. Se hacen de 3 a 5 medidas y la media es la que se suministra finalmente, aportando los siguientes datos: número de diente, color en Vita 3D Master, Chromascop, Vita Classical, NCC and Biodent, y ratios opaquer/cuerpo/esmalte que el técnico puede aplicar. Está diseñada para el Vintage Halo Porcelain System (Shofu Dental) aunque trae referencia también a otros sistemas cerámicos.

Los sistemas de colorímetros electrónicos de triestímulo: estos sistemas analizan tres valores para las porciones roja, verde y azul reflejadas; usando un filtro de color de las mismas características que los receptores del ojo humano. Pueden utilizarse intraoralmente y siguen el sistema CIELab. Estos aparatos solo proporcionan una solución parcial, ya que al trabajar solo con curvas espectrofotométricas, no resuelve el problema del metamerismo. Además leen solo valores RGB (rojo, verde azul). Y no interpretan otros aspectos como la translucidez. La correcta aplicación permite detectar y medir pequeñas diferencias de color entre muestras de colores similares.

Los sistemas RGB (en inglés, rojo, verde y azul) están basados en el principio de una cámara digital que capta la luz incidente a través de un sensor CCD. Los filtros de 
color previos (rojo, azul y verde) le añaden a la imagen la información de los colores. Sin embargo, dado que las valencias primarias del color no coinciden con las del ojo humano, "ven" los colores de forma diferente, y por ello no son ideales para la medición del color. Se puede llevar a cabo una especie de calibrado de estos sistemas a través de un registro de un color gris definido como valor de comparación, pero sólo se utiliza para la igualación interna del sistema, no para la adaptación de la "vista del color" 51 .

Los colorímetros de espectro completo son la solución a los anteriores. Constan de un sensor que se coloca en la superficie de los dientes que se quiere medir. Dicho sensor emite un foco de luz de espectro completo. El ordenador analiza la reflactancia y muestra una lectura que determina el espectro del reflejo exacto del diente al que se va a determinar el color. Ya que a diferencia de los aparatos RGB tienen filtros adaptados a la curva patrón de valores espectrales y, por tanto, a la percepción del color del ojo humano.

Otra definición recogida en el artículo de Nuñez Díaz P. en el año $2007^{100}$, define los colorímetros como cualquier instrumento que identifica el tinte para una medida más objetiva del color. Mide la absorción de la luz por los objetos; se basa en el principio de que dicha absorción es proporcional a la densidad del objeto, por lo que a mayor densidad mayor es la absorción. Los colorímetros incorporan una serie de ventajas:

- Incorporan una fuente de luz para no depender de las condiciones de luz del entorno.

- Tienen la capacidad de poder tomar el color de diferentes zonas de un diente (mediante una punta pequeña).

- Poseen la posibilidad de estandarizar, mediante posicionadores, la zona del diente en la que medimos el color ${ }^{101,102,103 .}$

Pero tienen el inconveniente de que su aplicación en la clínica dental se ve dificultada por la superficie convexa de los dientes, lo que complica la correcta colocación de la punta lectora del colorímetro. Aspecto esencial para poder obtener mediciones fiables. Además puede resultar invasivo para el paciente y puede ser de complicado manejo para el clínico ${ }^{104}$. 
Tratando de sintetizar, vamos a recoger algunas de las desventajas de utilizar colorímetros para medir el color dental:

- Que son instrumentos diseñados para medir superficies lisas, y los dientes no son totalmente lisos y pueden presentar en su superficie irregularidades.

- Que con una pequeña apertura en el colorímetro es propenso a significativos efectos de pérdida del límite en la determinación del color que conllevará errores ${ }^{76,105}$. Necesario el uso de posicionadores o férulas transparentes perforadas, con el mismo diámetro de la punta lectora que entrará en contacto con la superficie del diente, en el tercio medio de la superficie vestibular de diente a medir.

- Que los errores sistemáticos que se produzcan son difíciles de manejar y pueden estar asociados al instrumental afectando el grado de precisión ${ }^{106}$. Es decir, existe una pobre correlación entre varios colorímetros en comparación con la fiabilidad de otros instrumentos intraorales.

- Que consecuentemente, la comparación de datos entre colorímetros es desaconsejada y poco fiable ${ }^{106,107}$.

Hay que destacar la importancia del uso de posicionadores o guías para colocar siempre el colorímetro en el mismo punto y efectuar la medición repetidamente en el mismo, utilizando sistemas estandarizados de colocación. La mayoría de los autores coinciden en la aceptable reproducibilidad de estos sistemas 103, 106, 108 . Dada la convexidad de la cara vestibular de los dientes anteriores, si dividimos dicha superficie en tres partes, Amengual Lorenzo J. y colaboradores toman el color en la zona central ya que es la que muestra una superficie más plana y por lo tanto la que permite colocar la punta del colorímetro mejor ajustada a la superficie del diente y un mejor ángulo de refracción de la luz ${ }^{109}$.

Para la determinación del color dental existe, entre otros, el colorímetro Shade Eye® (casa comercial Shofu). Los datos determinados por este sistema proveen una imagen visual en el monitor del computador y la imprime siendo más fácil para la comprensión que las instrucciones escritas o verbales. Los datos son archivados y pueden ser fácilmente utilizados para futuros casos clínicos.

Amengual-Lorenzo publicó en el año 2005 un estudio comparativo entre diferentes colorímetros en cuanto a la reproductibilidad en la medición del color in vivo e in vitro. 
Se resalta la escasa reproductibilidad de los métodos subjetivos utilizando guías, que oscila entre el $30 \%$ y el $60 \%$, mientras que la de los sistemas electrónicos (colorímetros y espectrofotómetros) se encuentran entre el $80 \%$ y el $100 \%{ }^{109}$.

En un estudio publicado por Wang X. y colaboradores en el 2005 comparando espectrofotómetros y colorímetros en cuanto a la medición del color de la cerámica, concluía que los resultados eran correlativos aunque hubiera diferencias estadísticas entre los datos obtenidos ${ }^{110}$.

Los colorímetros más utilizados actualmente son:

- El Shade Ex-Eye@ de la casa Shofu, compuesto por un terminal con una fuente de luz y un lector con pantalla digital, conectado a una unidad central que incorpora una impresora térmica. Está muy indicado para el análisis y registro del color en dientes naturales y revestimientos ceramometálicos y presenta el análisis del color además de con parámetros numéricos, con las referencias del sistema de colores de la guía Vitapan Classical.

- El Identa Color IIC de la casa Identa, es un colorímetro para la toma del color dental compuesto por un terminal con una fuente de luz y un lector, conectado a una unidad central con pantalla, que a diferencia del anterior permite comparar con las guías de color de la casa Vita (Vitapan Classical y Vitapan 3D Master), Dentsply y Vivadent, así como la toma de color en un punto del diente o en cinco zonas del mismo de forma simultánea y que también dispone de un dispositivo de impresión en papel de los valores registrados.

Para marcar la diferencia entre espectrofotómetro y colorímetro, podemos decir que ambos instrumentos miden la luz, pero lo hacen de forma distinta. Los colorímetros son más simples. Usan filtros de color para separar la luz que les llega en sus componentes rojo, verde y azul (colores primarios). Los espectrofotómetros son bastante más complejos y producen un conjunto de mediciones diferentes. Divide el espectro de la luz visible en franjas separadas y distintas y, mide el número de fotones que cae en cada una de ellas ${ }^{100}$. Otra forma de describir la diferencia es que los colorímetros proporcionan triestímulos, mientras que los espectrofotómetros proporcionan mediciones espectrales ${ }^{111,112}$. 
Los colorímetros llevan siendo utilizados en Odontología con éxito desde hace unos años para medir el color en Odontología como demuestran por ejemplo los estudios publicados por Carrillo y colaboradores en los años 2001 y $2002{ }^{113,114}$.

La espectrofotometría es el método de análisis óptico más utilizado en las ciencias biológicas.

Cho BH. y colaboradores en el año $2007{ }^{26}$ comparan la medida realizada por un colorímetro con la realizada por Shade Vision System (espectrofotómetro)y afirman con las limitaciones del estudio, que, excepto para la tonalidad, los parámetros de color medidos por colorímetros y espectrofotómetro mostraron correlaciones débilmente significativas. Las mediciones realizadas por el Shade Vision System fueron más altas que aquellas medidas determinadas por colorímetro. Cuando el valor y la intensidad de los dientes fueron altos, la diferencia de color entre las medidas realizadas por ambos instrumentos fue pequeña.

Los resultados de investigaciones entre el color percibido por el ojo humano y el colorímetro no han sido concluyentes ${ }^{102}$. Algunos estudios afirman que existe una significativa correlación entre los colores medidos por el colorímetro y el ojo humano 29, 76 , mientras que otros estudios afirman que no existe correlación significativa ${ }^{84,108 .}$

\subsubsection{2.- Espectrofotómetros}

El espectrofotómetro dental es un aparato de medición que emite una luz definida y es capaz de medir la calidad y la cantidad de luz reflejada por un objeto y clasificarla en un grupo de colores. Esta cantidad de luz se clasifica en el espectro visible entre 380 y 720 nanómetros aproximadamente. La aplicación de un espectrofotómetro, para la reproducción cromática asistida por ordenador se ha hecho posible en la presente gracias a la evolución de la técnica de semiconductores. Los programas de software realizan la conversión de curvas espectrales a notación Munsell y CIELab.

Estos aparatos aportan el mayor número de datos de medición. Puede aportar más información que los aparatos RGB o un aparato de medición triestímulo. Es cierto que la mayoría de los aparatos triestímulo (colorímetros) suelen ser más imprecisos que los aparatos espectrales, pero el sentido de utilizar la medición espectral y sus ventajas prácticas dependen de cómo se utilicen. 
Según Nuñez Díaz P. en el año 2007, definió el espectrofotómetro como un instrumento que sirve para medir en función de la longitud de onda, la relación entre valores de una misma magnitud fotométrica relativos a dos haces de radiaciones ${ }^{100}$.

En estos aparatos los colores se miden en el Sistema CIELab. No solo sirven para medir el color dental, sino que además los espectrofotómetros han sido ya utilizados para valorar la influencia óptica de diferentes aleaciones metálicas y porcelanas en las restauraciones ceramometálicas ${ }^{115}$, la efectividad de la protección con cemento de vidrio-ionómero modificado con resina ${ }^{116}$, o la influencia del $\mathrm{pH}$ y el tiempo en la degradación de los composites ${ }^{117}$.

El Vita Easyshade compact es un espectofotómetro portátil e inalámbrico, con una especie de pistola de mano con fibra óptica. El orificio de salida de la pieza de mano se cubre con una lámina muy fina de poliuretano al contactar con la superficie dental.

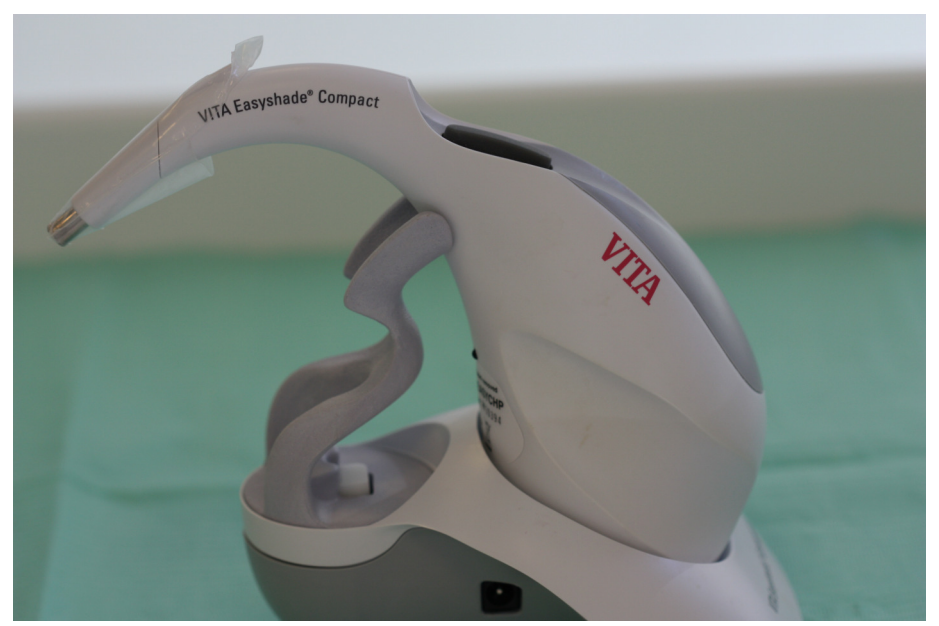

Figura 27: Espectrofotómetro Easyshade Compact (Vita Zahnfabrik)

La pieza de mano presenta fibras ópticas para la iluminación de la superficie (halógenas) y múltiples espectrómetros para el proceso de medida. Uno monitoriza la emisión de la luz mientras que los otros dos miden la luz dispersa por el diente a dos distancias diferentes al punto donde incide para evitar el "scattering" o difusión en lo posible.

El Easyshade compact@ de la casa Vita, es un espectrofotómetro digital integrado igualmente por una unidad inalámbrica con una fuente de luz y un lector, que compara tanto con los colores Vitapan Classical como con los colores del Vita System 3D- 
Master y que, además, incorpora tres colores específicos para los dientes blanqueados.

\subsection{4.- Condiciones óptimas en la selección del color}

Durante el proceso de selección del color se pueden producir numerosos errores e irregularidades, como deficiencias en el estándar del color dental, guías de color, ${ }^{66}$ discrepancias de color entre las diferentes capas de porcelana ${ }^{118}$, variaciones en los lotes del color ${ }^{119}$, deficiencias en la capacidad para valorar los colores por parte del examinador ${ }^{120}$, falta de educación y adiestramiento en la toma del color ${ }^{121,}{ }^{122}$, métodos inadecuados para la toma del color $^{90}$, comunicación incorrecta del $\operatorname{color}^{12}$, y para finalizar, la reproducción inexacta del color ${ }^{123}$.

Para intentar minimizar estos posibles errores a continuación se recoge una secuencia para la determinación del color en clínica:

1. Comparar y determinar el color dental con luz natural, preferiblemente al mediodía. La luz de la tarde presenta longitudes de onda largas con altas concentraciones de amarillo y naranja. Es importante tener en cuenta que la luz incandescente de la lámpara de la unidad dental tiene elevadas concentraciones de amarillo-rojo y poco en azul, por el contrario, la luz fluorescente tiene más cantidad de azul ${ }^{124}$.

Sin embargo la luz diurna varía constantemente, con una fluctuación en el coeficiente de temperatura del color que puede superar la proporción 1:20 ${ }^{125}$.

- Cuando no sea posible contar con la luz natural, ya sea por la hora o porque nos encontramos en una habitación interior, podemos optar por la utilización de lámparas de luz corregida. Esta lámpara nos proporciona una iluminación con una temperatura parecida a la de la luz natural del mediodía entre los $5500^{\circ}$ y $6500^{\circ} \mathrm{K}$. Se han diseñado distintos dispositivos, uno de ellos es Shademat Visual $+(\mathrm{SV}+)$ que es un aparato nuevo diseñado para proporcionar unas condiciones ópticamente "ideales" para la determinación de los colores ${ }^{126}$.

- Como método sencillo y eficaz está la lámpara Trueshade Optilume, que es de momento la única luz LED que evita que se reflejen las luces ambientales en la zona del enfoque, proporcionando al campo de trabajo luz de día natural. De momento es una de las más óptimas para el uso de cualquier técnica para la 
definición del color y de las tonalidades de las piezas dentales, ya que consigue restaurar el color natural de la materia a la luz del día (5.500K), siendo además correcta, constante e inmediata en el momento del encendido y de enfoque en la zona correcta, o en toda la cavidad bucal ${ }^{127}$.

Por ejemplo, a mayor longitud de onda de la luz, mayor translucidez del diente. Así el esmalte es vuelve más translúcido ante una luz rica en amarillo-rojo y mostrará más dentina, dando al diente un aspecto más rojizo, con mayor intensidad y menor valor del que tiene realmente ${ }^{128}$.

La luz ambiental de lugares de trabajo según la Normativa del Alumbrado para interiores del BOE une-en 12464-1:2003 afirma que la luz debe tener una

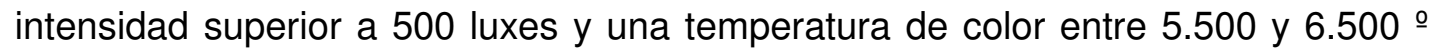
Kelvin.

2. Valorarse a una distancia equivalente a la longitud de un brazo. Sin embargo la visión cercana funciona mejor a una distancia de 25 o $33 \mathrm{~cm}{ }^{89,129}$.

3. Considerar que el gris claro neutro es el color de fondo ideal para la determinación del color ${ }^{10,67 .}$

4. Realizar unas tres o cuatro miradas cortas para evitar la fatiga y la adaptación visual. Es conveniente no mirar durante más de 5 seg seguidos, porque se genera una imagen persistente y negativa durante otros 15 a $20 \mathrm{seg}{ }^{130}$.

5. Observar los cambios multicromáticos (áreas con diferencia de color) y los transicionales (cervical-cuerpo-incisal).

6. Neutralizar los colores fuertes (ropa) y eliminar el pintalabios. No esta demás recordar que la selección del color debe realizarse después de una adecuada limpieza con pasta profiláctica ${ }^{10}$.

7. Registrar por escrito todas las observaciones y esquematizar las áreas del diente con colores específicos para establecer una estrecha relación con el técnico de laboratorio. 
Al seleccionar el color existe una norma general relacionada con los siguientes puntos:

- -Los incisivos centrales laterales y premolares maxilares presentan el mismo tinte.

- $\quad$-Los caninos maxilares presentan una intensidad mayor. Cuando la diferencia cromática entre los caninos y laterales es muy marcada, es aconsejable aumentar ligeramente la intensidad de los laterales para establecer una suave transición de color en esta área y que la diferencia no sea tan notoria.

- Los incisivos mandibulares suelen tener una intensidad más suave que los maxilares.

En el año 2007, Chu SJ. describe siete pasos para acercarse al éxito en la toma de color. Un protocolo clínico que necesita la combinación de instrumentos tecnológicos, técnicas convencionales y referencias fotográficas ${ }^{131}$ :

1.-Evaluación

2.-Imagen capturada y análisis de tinte

3.-Transmitir la información en un formato visual

4.-Interpretar la información del tinte.

5.-Fabricación de la restauración

6.-Verificar la precisión del color

7.-Colocación (inserción y cementación) 

2.- JUSTIFICACIÓN 



\section{2.- JUSTIFICACIÓN}

Desde hace tiempo tenemos la preocupación de si realmente los métodos subjetivos mediante guías de color dental existentes representan en su totalidad los colores de la población española y más concretamente la de Castilla y León. Según Jiménez Rubio y colaboradores en el año 1998, las guías dentales están fabricadas tomando como referencia el color de los dientes más frecuentemente encontrado en la población anglosajona y centroeuropea, lo que hace muchas veces difícil encontrar el color correcto para las restauraciones en nuestra población ${ }^{132}$. Por todo ello justificamos la realización de este trabajo.

En la actualidad estamos contemplando la introducción de nuevas tecnologías en Odontología con el fin de mejorar la toma de color tradicional a través de guías de color. Esto, a la vez que simplifica y objetiviza el proceso para el profesional, mejora los resultados estéticos de las restauraciones protésicas de nuestros pacientes. Nos referimos a los sistemas de color digital como son espectrofotómetros y colorímetros, ambos capaces de obtener información a partir de la medición de las longitudes de onda reflejadas de la superficie del diente a medir. Este tipo de sistema de toma de color, está siendo una innovación muy atractiva para este sector, ya que tradicionalmente la única forma de tomar el color y poder transmitirlo al laboratorio era a través de las guías de color que ponen a nuestra disposición las diferentes casas comerciales. Por eso, es fundamental conocer si la distribución de las tablillas de color de las guías de color dentarias están distribuidas de manera uniforme y si son capaces de representar la variabilidad de color dental existente en la población.

Sin embargo, y aunque el futuro en la toma de color dental parece encaminarse hacia el uso de estos dispositivos electrónicos 51, ${ }^{133}$, para así eliminar la subjetividad inherente en el proceso de toma de color con guías de color, debemos tener presente que no disponemos de información fiable entre los registros del ojo humano ni en los registros provenientes del espectrofotómetro. También es muy importante que el profesional debe de estar entrenado en el uso del dispositivo, y sobre todo, no olvidar que todavía estos sistemas están poco integrados en el mercado debido a su alto coste, por lo que la mayoría de las mediciones del color se siguen realizando con las guías de color convencionales. 
Por todo los anterior, hay que considerar que es prioritario la formación de los profesionales sobre los principios de la toma de color dental. Esta formación es básica para poder mimetizar nuestras restauraciones dentro del entorno orofacial del paciente y conseguir una restauración en armonía.

De este modo, observamos que los dispositivos electrónicos de la toma de color están en constante proceso de renovación y perfección.

A pesar de la aparición en el mercado de espectrofotómetros y colorímetros, pocos son los estudios que evalúan, a través de un método objetivo y un método subjetivo la distribución del color dental en la población según los diferentes grupos de edad.

Por ello nuestro trabajo va dirigido a conocer cual es el color dental de la población y su distribución. 


\section{3.- HIPÓTESIS Y OBJETIVOS}





\section{3.- HIPÓTESIS Y OBJETIVOS}

En el presente estudio in vivo se planteó la siguiente hipótesis:

-No existen diferencias en el color dental de la población de Castilla y León y el color dental de otras poblaciones a través de espectrofotometría.

Para el estudio clínico del color dental en la población de Castilla y León, hemos definido los siguientes objetivos:

1. Conocer el color dental de la población de Castilla y León a través del valor, intensidad y tinte según género y edad.

2. Conocer el grado de acuerdo entre el método objetivo (Especrofotómetro EasyShade compact $\circledast$ ) y subjetivo (Toothguide 3D Master®) en la toma de color.

3. Estudiar la asociación entre el valor, tinte e intensidad con los grupos de edad y el género con los datos proporcionados por el espectrofotómetro, así como la frecuencia de colores en dichos grupos, según la nomenclatura de la guía dental 3D Master.

4. Evaluar la influencia que tienen las diferencias de edad y de género sobre las variables continuas ordinales: valor o luminosidad (L), tinte (h) e intensidad (C) .

5. Analizar el color dental según las tres dimensiones de color (tinte, valor e intensidad) y estudiar su evolución en función del envejecimiento por las diferentes décadas.

6. Conocer la ordenación y la ubicación espacial de las tablillas de color de la guía dental 3D Master. 

4.- MATERIAL Y MÉTODO 



\section{4.- MATERIAL Y MÉTODO}

Se presentan, dentro de este capítulo, tres tipos de subepígrafes para conseguir profundizar en el estudio y análisis de los contenidos.

En el primer subepígrafe se recoge una descripción de las condiciones y las características de la población (pacientes) entre la que se ha llevado a cabo la recogida de datos e información. En el segundo subepígrafe, se describen los materiales odontológicos del trabajo de laboratorio, los dispositivos de medida y las condiciones experimentales del registro del color dental. Y, en el tercer subepígrafe, se narra el método utilizado para la medición, se describen las características cromáticas de los dientes naturales "in vivo" y las fómulas de diferencias de color sistemas CIElab y CIEDE2000.

\section{1.- MUESTRA}

\subsection{1.-Muestra}

Seleccionamos pacientes con nacionalidad española, con edad mínima de 16 años y edad máxima de 89 años, previamente informados del proceso a seguir para la toma de color, sin historial médico que pudiera influir en el proceso.

Se utilizaron 1.361 incisivos centrales superiores para el registro del color según los diferentes grupos. Los pacientes provienen de diferentes áreas geográficas, de la Comunidad Autónoma de Castilla y León.

Se excluyen pacientes fumadores, ya que se sabe que el tabaco en un factor conocido de discoloraciones extrínsecas ${ }^{41,80}$.

El Comité Ético de Investigación Clínica del Hospital de San Carlos evaluó positivamente el protocolo de actuación para este estudio, es decir, es conforme a la guía de buena práctica clínica. Se ofreció a cada uno de los sujetos que participaron en este estudio un consentimiento informado donde se explicaba de manera expresa el procedimiento a realizar para que bien firmaran, o bien consintieran de manera verbal y explícita (Anexo II). 


\subsection{2.- Incisivo Central Superior}

El diente está constituido por tres tejidos, el esmalte, la dentina y pulpa y su color natural depende del grosor, composición y estructura de estos tejidos que, en definitiva, son los responsables de su complejidad desde el punto de vista óptico. Los tres parámetros a los que hemos hecho alusión, evolucionan considerablemente a lo largo de la vida, influyendo en el color del diente. Cada uno de estos tejidos presenta propiedades ópticas distintas ${ }^{45}$.

La selección del incisivo central superior entre todos los dientes de la arcada, se debe a varios motivos:

- Presenta una cara vestibular relativamente plana con lo cual favorece la medición mediante espectrofotómetro.

- Fácil acceso, para comparar con la tablilla de color de la guía dentaria sin interferencias de labio o mejilla.

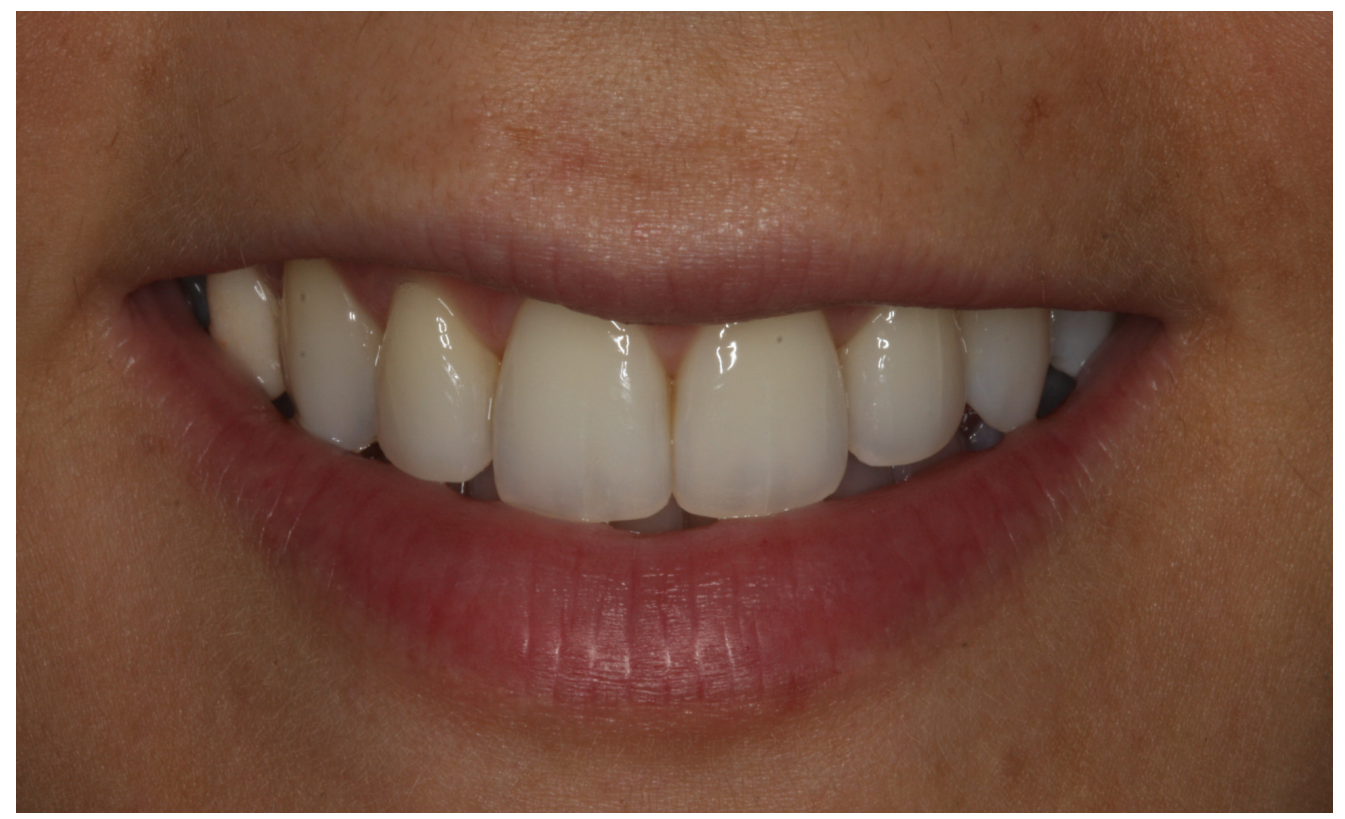

Figura 28: Incisivos Centrales superiores

Todas las mediciones se realizaron sobre incisivos centrales superiores "in vivo" con las siguientes condiciones.

- Sin antecedentes de traumatismo en la región oral

- Sin tinciones intrínsecas 
- Sin tinciones extrínsecas

- Sin hiperpigmentación por tetraciclinas

- Sin haber sido sometidos a tratamientos blanqueadores

- Con integridad en la superficie del esmalte

- Sin presentar restauraciones

Los 1.361 pacientes se distribuyeron de la siguiente manera, según edad y sexo:

- Grupo 1: Edad entre 16-29 años se sexo masculino

- Grupo 2: Edad entre 16-29 años de sexo femenino

- Grupo 3: Edad entre 30 -59 años de sexo masculino

- Grupo 4: Edad entre 30-59 años de sexo femenino

- Grupo 5: Edad entre 60-89 años de sexo masculino

- Grupo 6: Edad entre 60-89 años de sexo femenino

A todos y cada uno de los pacientes se les aportó un consentimiento informado sobre el proceso que se iba a seguir para la medición del color dental, prácticamente la totalidad de la muestra rehusó el proceso formal y optó por un consentimiento de manera verbal.

\subsection{3.- Operador}

Todas las mediciones fueron realizadas por una misma persona. Una mujer adulta de 30 años con siete años de experiencia clínica y con un entrenamiento específico en los programas Trainer Guide y Toothguide Training Box de la casa Vita Dental (VitaZahnfabrik) ${ }^{96}$.

La observadora, superó el test de Ishihara y de esta manera descartamos alteraciones de la visión cromática.Igualmente sin antecedentes de visión alterada.

Para disminuir en lo posible el efecto del entrenamiento visual de la operadora y considerar que cada observación fuera independiente, se retiraron de la muestra a estudiar las 100 primeras mediciones. 


\section{2.- MATERIAL}

A continuación vamos a describir el material que hemos utilizado en este estudio.

\subsection{1.- Micromotor y Contrángulo}

Para pulir la superficie de los incisivos centrales superiores se utilizó un micromotror y el contrángulo dental de la marca.

Kavo Dental $\mathrm{GmbH}$ \& Co. KG, modelo Mango intramatic $20 \mathrm{CH}$ ( $\mathrm{n}^{\circ}$ de material $0.534 .5820)$.

Kavo Dental GmbH \& Co. KG, modelo Cabeza intralux 68 LH. (no de material $0.540 .2040)$.

Con los correspondientes daros técnicos: Velocidad máxima de accionamiento: 40.000rpm. Marcación: azul. Transmisión: 1:1. Velocidad máxima de 40.000 rpm con pinza de sujeción por botón. En ella se emplean fresas de contrángulo, en este caso utilizamos copas de goma de pulir.

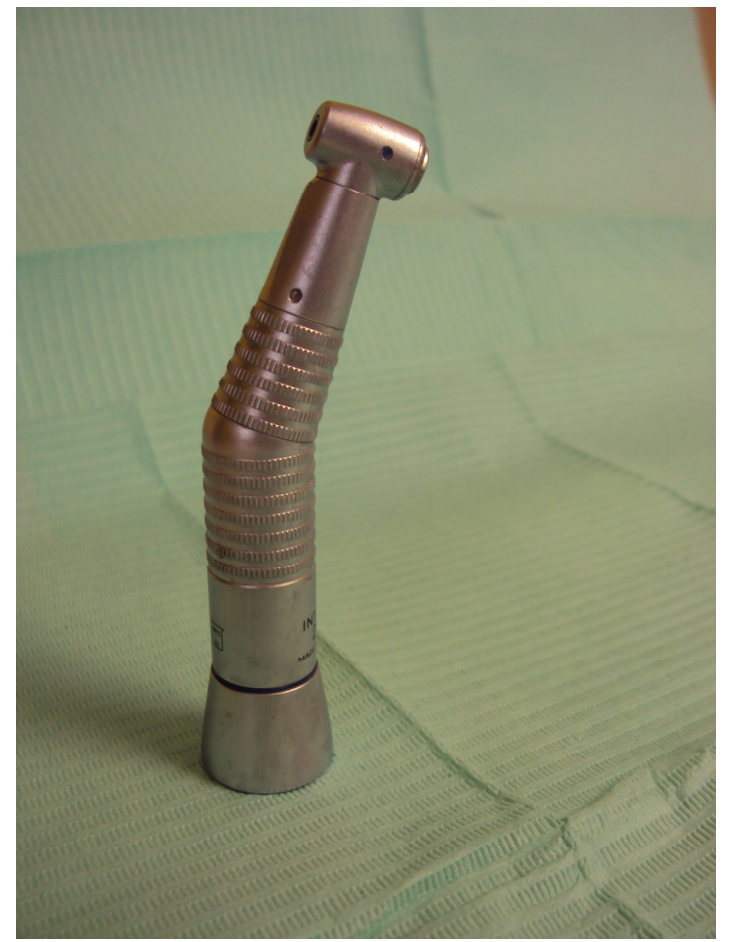

Figura 29: Contraángulo utilizado en el estudio 


\subsection{2.- Copa de Goma de pulir}

Copa de goma de silicona para micromotor utilizada para eliminar restos de placa bacteriana, y residuos superficiales de la cara vestibular del incisivo central superior.

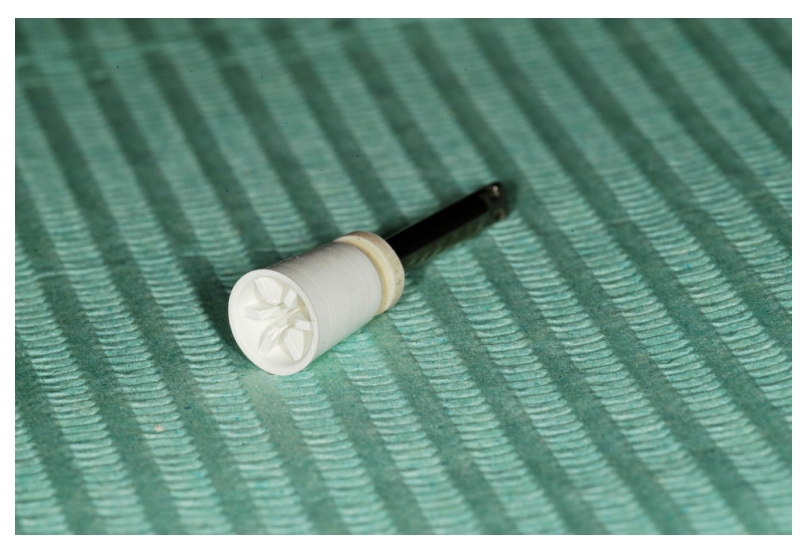

Figura 30: Copa de goma de pulir para contraángulo

\subsection{3.- Pasta Profiláctica}

La pasta profiláctica utilizada pertenece a la marca "Dentaflux", donde su componente principal es Dióxido de Silicio.

Esta pasta profiláctica con ayuda de la copa de goma e impulsados por el micromotor sirvió para eliminar restos de alimentos y depósitos de la superficie del diente antes de medir el color dental.
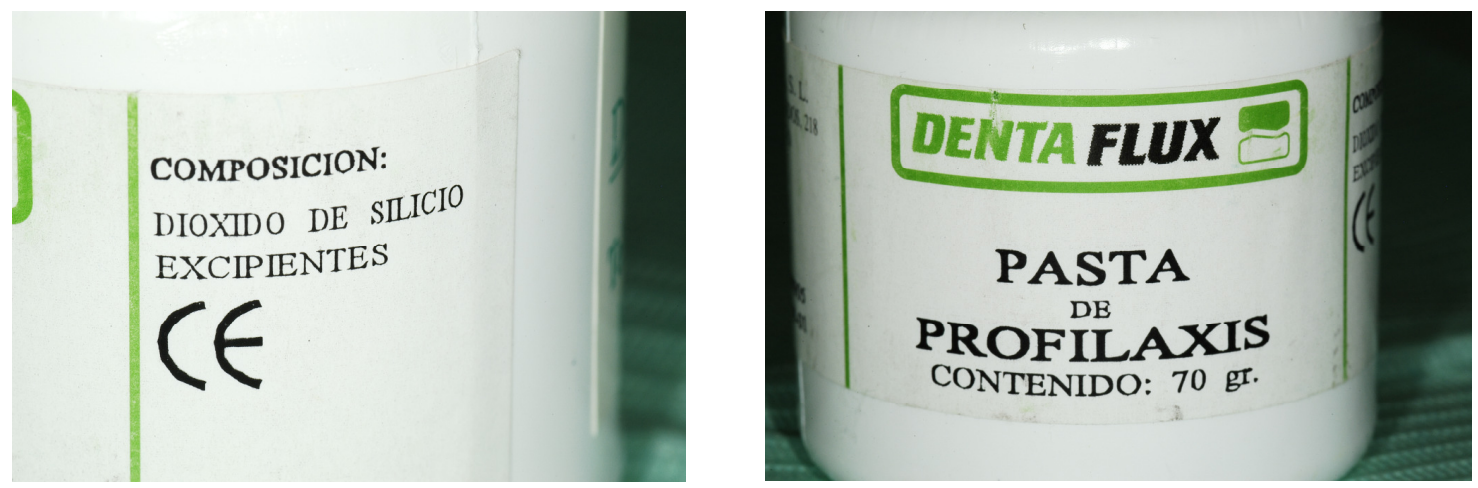

Figura 31: Pasta profiláctica utilizada 


\subsection{4.- Fuente de luz}

La iluminación en cada uno de los gabinetes donde se tomaron los registros cumplía una serie de características:

- Tubos fluorescentes de luz de día TDL 90/65 Delux (6.500K).

- Intensidad de luz de 1.200 a 1500 luxes.

La iluminación del techo del gabinete dental es baja y más azulada que la luz natural, la del equipo dental es de tipo incandescente, muy elevada y más amarillo-rojiza que la natural, ambas están contraindicadas para la toma de color; por ello utilizamos la luz natural o luz del día que son fuentes fluorescentes de luz corregida que ofrecen temperaturas de color de $5.500^{\circ}$ a $6.500^{\circ} \mathrm{K}$ y que se conocen comúnmente como D50 y D65.

Siempre se retiró para el registro del color, la luz que proviene de la lámpara del equipo dental, debido a su influencia negativa en el proceso.

\subsection{5.- Guía de color Toothguide 3D Master (Vita-Zahnfabrik)}

La guía de color 3D Master utilizada en este estudio pertenece al lote B360ASP. Cada una de las tablillas de dicha guía dental fueron comprobadas antes para poder asegurar que cada color de la tablilla realmente coincidía con el color que indicaba, esta comprobación se llevó a cabo con el espectrofotómetro Easyshade Compact ${ }^{\circledR}$ (Vita-Zahnfabrik).

Tomamos la información básica de la página web de la casa comercial Vita-Zahnfabrik sobre su guía dental Toothguide 3D Master. El espacio cromático dental. Nuestra máxima meta siempre ha sido lograr una imitación perfecta de la naturaleza. Desde el lanzamiento de la guía dental 3D Master, esta aspiración se ha convertido en una realidad de éxito, acreditada en millones de casos: todos los colores dentales humanos naturales pueden determinarse sistemáticamente y reproducirse con seguridad. Actualmente, los colores Vita están considerados en todo el mundo como el estándar más elevado para la prótesis dental de aspecto natural. Todos los colores en una mano: El descubrimiento del espacio cromático dental ${ }^{96}$.

Esta guía dental ya ha sido descrita en el apartado de introducción, a continuación 
vamos a desarrollar la técnica de utilización. El mecanismo para determinar el color con la guía Vita 3D Master ha sido el siguiente, siguiendo las recomendaciones del fabricante ${ }^{96}$.

- En un primer lugar seleccionamos el valor. Sostenemos la guía junto a la boca abierta del paciente y elegimos el grupo de color a un brazo de distancia, empezando por el grupo más oscuro.

- Luego seleccionamos la intensidad. Abrimos el abanico de colores y seleccionamos la intensidad de color.

- El último paso es fijar el tinte, donde debemos comparar si el incisivo central superior es más rojizo o más amarillento que la muestra de color seleccionada $^{134}$.

Esta guía tiene cinco grupos de colores, con los correspondientes subgrupos, donde se determina la frecuencia de selección del color. Los estudios estadísticos a escala mundial muestran claramente una acumulación en el centro del espacio cromático, esto es válido tanto para el valor como para la intensidad y el tinte.

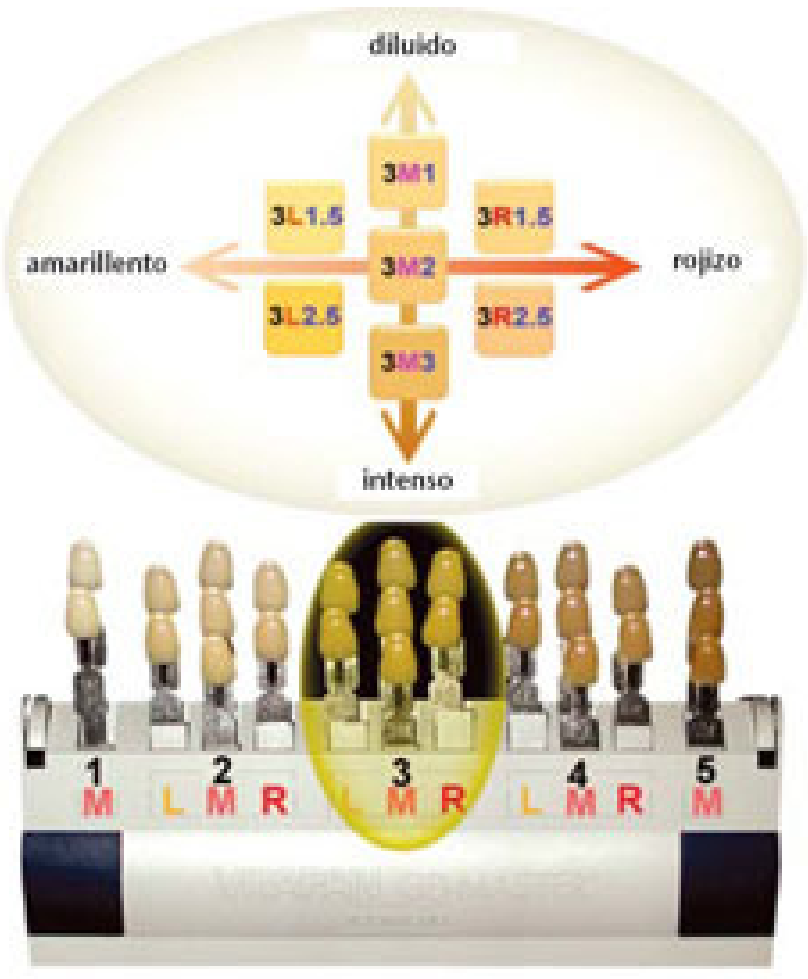

Figura 32: Explicación de la guía 3D Master $^{135}$ 
- El situado más arriba indica el grupo de valor al que pertenece la tablilla, del 1 al 5 , en orden decreciente.

- El número detrás de la letra indica la intensidad $(1,1.5,2,2.5,3)$ en orden creciente.

- La letra indica el tinte, que puede ser M (medio), L (amarillento), R (rojo).

Esta guía incorpora, además, tres colores de blanqueamiento el 0M1, 0M2, 0M3: el 0 indica alto valor, el 1, 2, y 3 el nivel de intensidad y la $\mathrm{M}$ el tinte o, que se sitúa en la parte central..

Describiremos esta distribución y proceso de selección de color en imágenes:

\section{Pasos para la selección del color:}

1.- Definir el nivel de valor. Partiendo o tomando como tablilla coloreada la M.

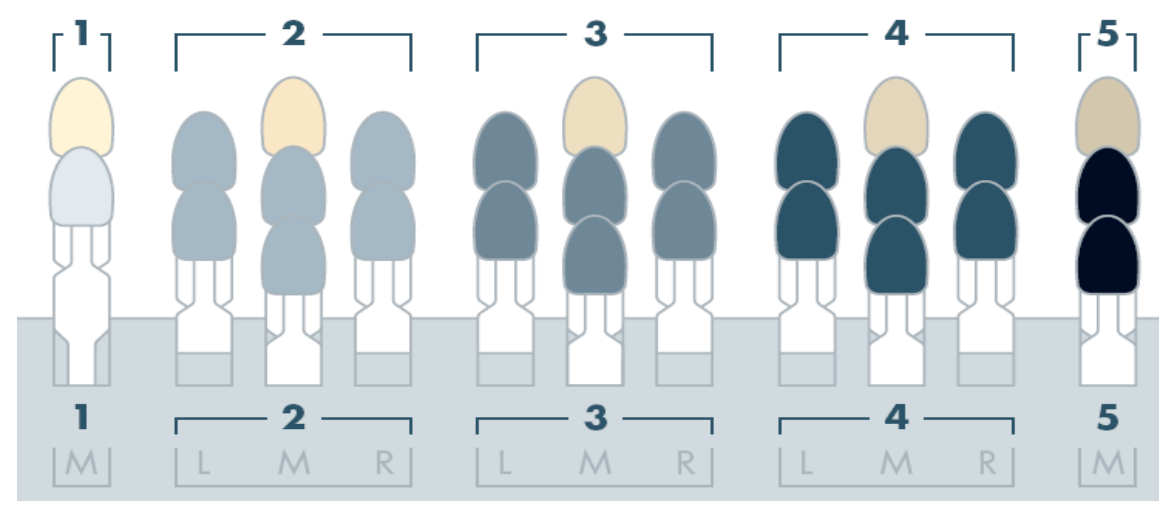

\section{5}

Claro

\section{Oscuro}

2.- Determinar la intensidad del color (cromatismo)

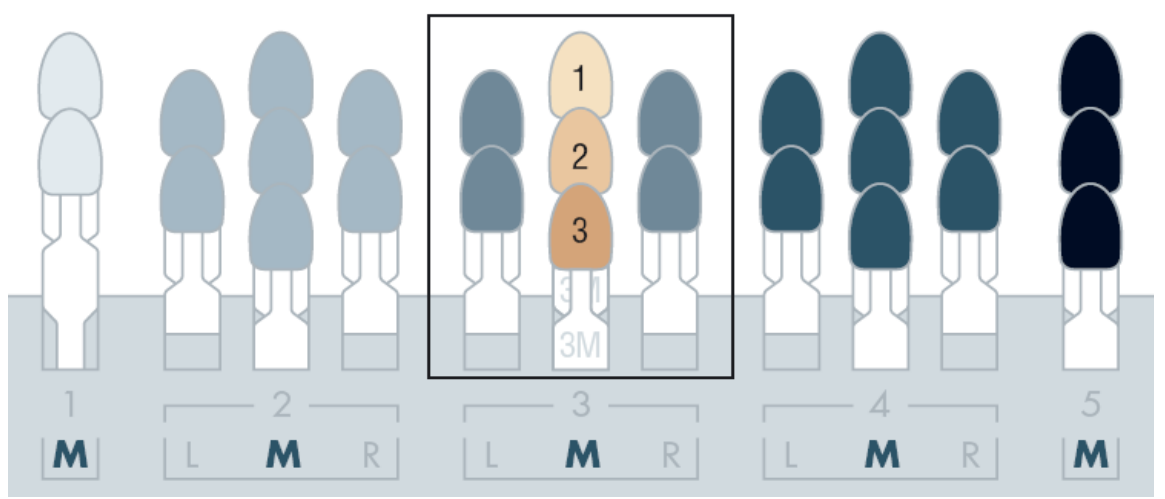

En $M$ 1 -2 -3

Pálido 1...1.5...2...2.5...3 Saturado 
3.- Comprobar el tinte. Comprobar si el diente natural resulta más amarillo o más rojizo que la muestra de color elegida en $\mathrm{M}$.

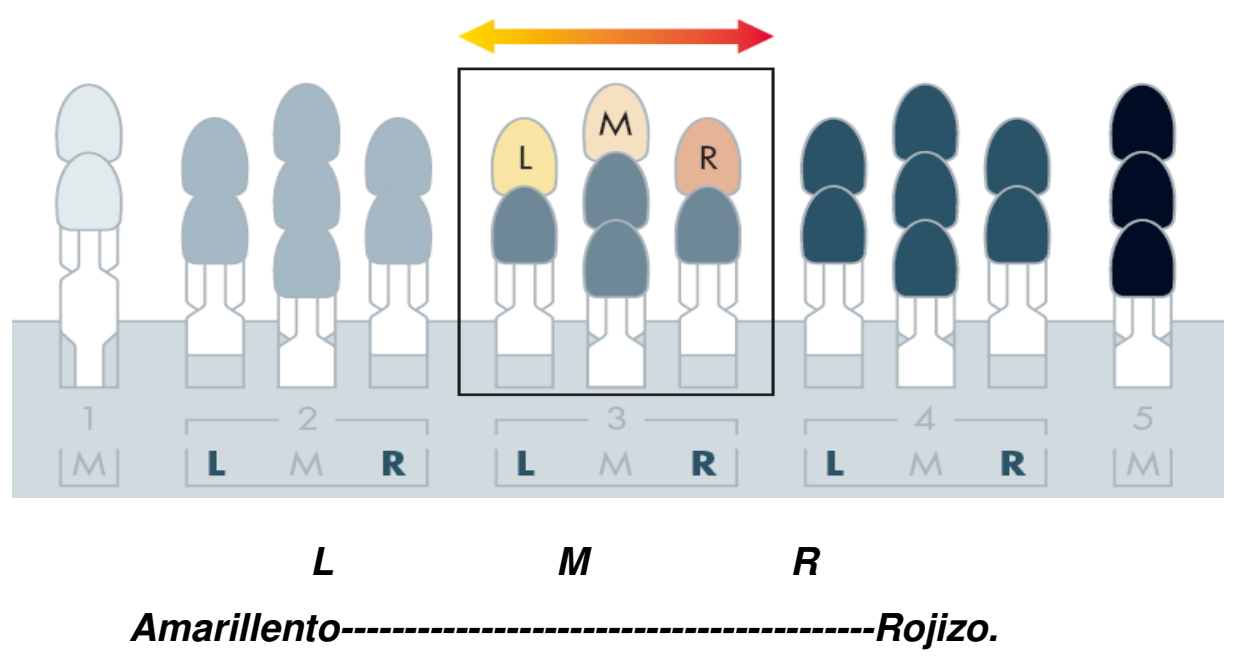

Figura 33: Modo del uso de la guía 3D Master ${ }^{96}$

\subsection{6.- Espectrofotómetro: Easyshade Compact ${ }^{\circledR}$ (Vita-Zahnfabrik)}

El espectrofotómetro Easyshade compact@ de la casa Vita (no de serie: H20394), es un espectrofotómetro digital integrado igualmente por un terminal con una fuente de luz con pantalla inalámbrico que incorpora una punta lectora, que mide el color del diente en el diámetro donde se coloca dicha punta.

Presenta varias alternativas de utilización:

- Medición del color en el tercio medio de un diente natural

- Medición del color representativo de los tres tercios del diente

- Comprobación del color de las restauraciones protésicas

- Comprobación de las tablillas de las guías

Particularmente para este estudio solo se utilizó el modo de medición del color en el tercio medio del diente.

En el año 2008, aparece en el mercado un nuevo espectrofotómetro de la casa comercial Vita-Zahnfabrik: Easyshade Compact, inalámbrico, que proporciona unos resultados de medición claros en tan sólo unos segundos, de manera inapreciable por parte del paciente ${ }^{96}$. 


\begin{tabular}{|c|c|}
\hline \multicolumn{2}{|c|}{ DATOS TÉCNICOS VITA EASYSHADE COMPACT } \\
\hline ALTURA/ANCHURA/PROFUNDIDAD & $15,9 \mathrm{~cm} / 17,2 \mathrm{~cm} / 10,8 \mathrm{~cm}$ \\
\hline PESO & $511 \mathrm{~g}$ \\
\hline BATERÍA & Batería recargable de ión-litio \\
\hline FUENTE DE LUZ & LED blanco de alta potencia \\
\hline CONEXIÓN & $\begin{array}{c}\text { Utilizar exclusivamente con la fuente de alimentación } \\
\text { autorizada VITA, } \\
\text { ref. D46002 }\end{array}$ \\
\hline CLASIFICACIONES & $\begin{array}{c}\text { UL 60601-1 Aparato de clase II } \\
\text { Grado de protección tipo B } \\
\text { IPXO }\end{array}$ \\
& $\begin{array}{c}\text { Este apartado no está indicado para el uso con aplicación de } \\
\text { narcótico inflamable con aire o gas de la risa }\end{array}$ \\
\hline INTERVALO DE TEMPERATURA & De $15^{\circ} \mathrm{C}$ a $40{ }^{\circ} \mathrm{C}$ \\
\hline
\end{tabular}

Figura 34: Datos técnicos Espectrofotómetro Easyshade Compact

Según instrucciones del fabricante, la punta lectora ( $5 \mathrm{~mm}$ de diámetro) debe colocarse a $2 \mathrm{~mm}$ del borde incisal y a $2 \mathrm{~mm}$ desde el margen cervical, en contacto con la superficie del diente y en nuestro caso, siempre en el tercio medio que es la posición más representativa del color global del diente ${ }^{71,136}$.

Ésta punta lectora contiene 19 fibras ópticas de $1 \mathrm{~mm}$ de diámetro, el anillo externo lo forman 12 paquetes de fibras y es utilizado para iluminar los $5 \mathrm{~mm}$ de diámetro (de $0^{\circ}$ a $\left.30^{\circ}\right)$.

Según aparece en el prospecto on line de la casa comercial Vita-Zahnfabrik, el espectrofotómetro Vita Easyshade Compact permite determinar de forma rápida y unívoca el color dental, así como verificarlo en restauraciones. Este ligero aparato, inalámbrico y móvil, es muy fácil de usar y muestra el color dental exacto de forma segura en sólo unos segundos. Su elevada precisión de medición de los colores del Vita System 3D-Master y Vita classical A1-D4 se debe al sistema espectrofotométrico utilizado, que constituye la base para obtener un resultado perfecto.

Según la casa comercial cuenta con las siguientes ventajas ${ }^{96}$ :

- Toma de color rápida y objetiva

- Buena visibilidad del punto de medición en el diente

- Coordinación perfecta con los colores Vita classical A1-D4 y 3D Master

- Independiente de la iluminación y del usuario 
- Ligero aparato compacto, inalámbrico (batería) y móvil

- Control de calidad mediante la verificación de las restauraciones

- Posibilidad de guardar 25 tomas de color

- Software de comunicación del color para PC

- Prolongada vida útil gracias a la moderna tecnología LED

Antes de cada uno de los registros el espectrofotómetro debe ser sometido a dos consideraciones:

- Colocación sobre la punta lectora de un capuchón de acetato.

- Calibración en el dispositivo que se encuentra en la base. Tendremos la certeza de que esto ocurre cuando se escucha varios pitidos agudos.

Debemos de señalar que el espectrofotómetro utilizado para este estudio ha sido sometido previamente a un test de validación. Este test consiste en medir un incisivo central superior extraído donde cinco operadores registran en cinco días distintos sus coordenadas de color en el sistema ClELab, y se comprueba la homogeneidad de resultados del mismo (ver Anexo III).

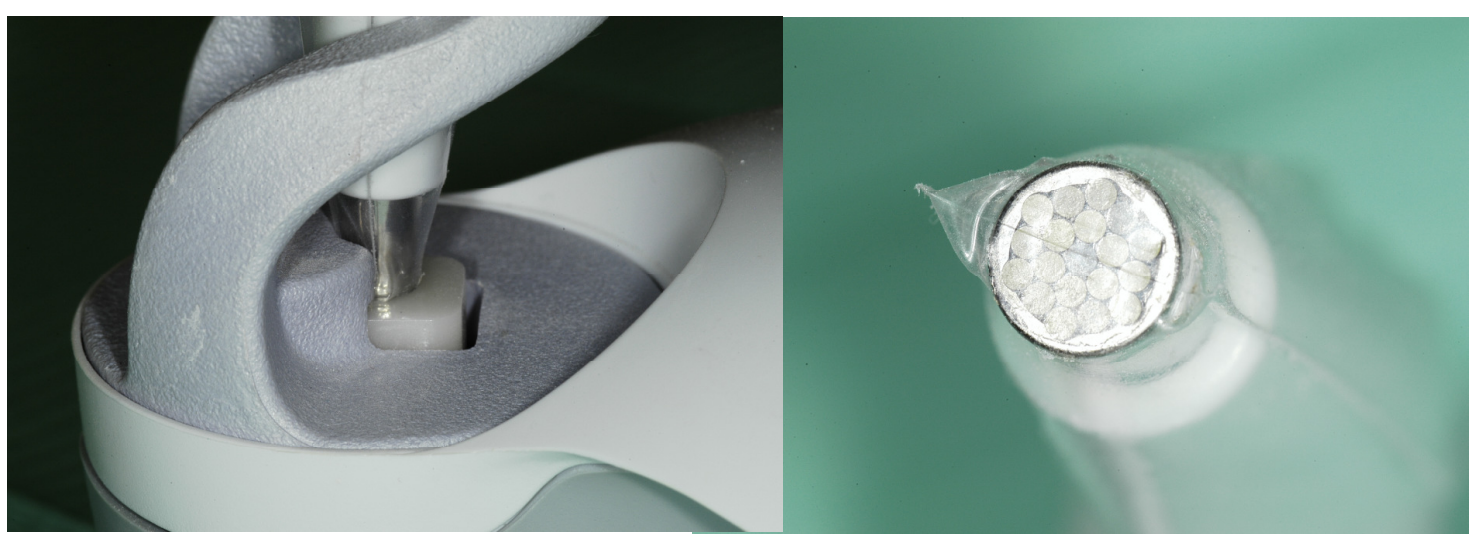

Figura 35: Punta lectora del espectrofotómetro Easyshade compact (Vita-Zahnfabrik) 


\subsection{7.- Cámara Fotográfica}

Se utilizaron dos cámaras fotográficas para ilustrar este trabajo.

\subsubsection{1.- Nikon D100,}

Es una cámara tipo réflex, un modelo de la gama SLR de Nikon. Algunas de sus señas de identidad son su sensor de 6.3 megapíxeles y su monitor LCD de 1.8 pulgadas, tamaño de sensor óptico 15,6×23,7 mm, velocidad máxima de obturador $1 / 4000$ seg.

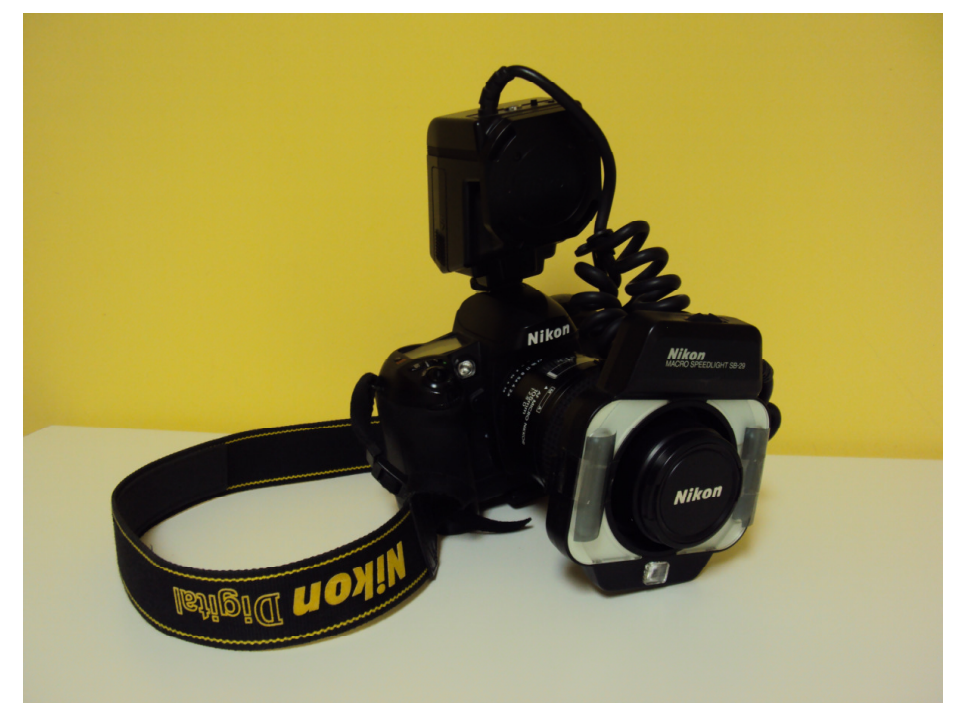

Figura 36: Cámara Fotográfica Nikon

Flash Nikon SB -29: Señalaremos las características más importantes, cobertura de flash de $20 \mathrm{~mm}$ (flash módulos establecidos en horizontal), $24 \mathrm{~mm}$ (flash módulos establecidos verticalmente). Construido en el reductor de luz que ajusta la relación entre el brillo del flash de la derecha del módulo para el de la izquierda (o viceversa) a $1: 4$.

Objetivo AF Micro Nikkor 105mm 1:2.8D de la marca Nikkon, cuenta con una serie de especificaciones, la primera lente con macro del mundo equipada con VR. VR II ofrece la estabilidad equivalente a una velocidad de disparo 4 stops más rápida.

SWM (Silent Wave Motor) permite un enfoque automático silencioso con rapidez y adecuado cambio entre autoenfoque y manual.

Un cristal con elemento ED que minimiza la aberración cromática. 
La capa de Nano Cristal reduce drásticamente los destellos asegurando un detalle nítido e imágenes claras.

IF (Internal Focusing) diseñado para una distancia focal fija y el elemento frontal no giratorio permite el uso de filtros redondos polarizados y accesorios de flash que se montan en el objetivo.

Opciones de enfoque - Automático con prioridad al manual o Manual solamente.

El diafragma redondeado de 9 cortinillas hace que los elementos que están fuera de foco se mezclen fácilmente con los fondos naturales.

Rosca para filtros de 62mm de diámetro (no-giratorio).

\subsubsection{2.- Cámara fotográfica Sony Cyber-shot DSC-W180.}

Es una cámara fotográfica digital compacta con las siguientes características técnicas principales:

- $\quad$ 10.1 Mega píxel

- 3 x Zoom Óptico

- Alta sensibilidad: ISO3200

- 2,7 pulgadas de pantalla LCD 


\section{3.- MÉTODO}

\subsection{1- Descripción de la toma de los registros de color}

El proceso que detallaremos a continuación, ha sido realizado únicamente con los materiales detallados previamente.

Cada uno de los incisivos centrales superiores seleccionados para este trabajo, tenían un historial clínico sin relevancia, y el incisivo central superior completamente íntegro. Todos fueron sometidos a una limpieza superficial mediante pasta profiláctica, micromotor y contraángulo hasta que la superficie del diente aparecía totalmente limpia. Posteriormente se eliminaban los excesos de pasta profiláctica y posibles depósitos dentarios mediante spray de agua. A continuación, se le indicaba al paciente que se enjuagase y de esta manera el diente se hidrata con saliva.

Posteriormente procederemos a neutralizar el color del entorno, colocando un paño gris sobre la ropa del paciente en el caso de que ésta tenga colores demasiado llamativos, eliminando lápiz de labios, etc. Debíamos prestar atención a los dientes antagonistas, los labios y lengua, para evitar interferencias que pueden afectar negativamente al resultado.

Diferentes autores y la casa comercial recomiendan que todo el entorno debería ser lo más discreto posible en cuanto al color. Esto es, el paciente no debe llevar pintalabios, ni cristales de gafas tintados, ni prendas de colores chillones, y si las hubiera, conviene cubrirlas con un paño de color gris ${ }^{10,96}$. Esta recomendación se mantiene tanto en la toma de color subjetiva, como en la toma de color objetiva.

Todo el proceso que estamos detallando se desarrolló con el paciente sentado en el sillón dental, en una posición de sentado, con el respaldo vertical y el maxilar superior del paciente a una altura aproximada del hombro del operador.

Antes, señalar que todos los registros de color se realizaron bajo tubos fluorescentes de luz de día D65 de Phillips (lámpara de luz natural normalizada), y con una intensidad de luz ideal entre 1.200-1.500 luxes (determinada con luxómetro). La iluminación del techo del gabinete con tubos fluorescentes sin las características anteriores es baja y más azulada que la luz natural, la del equipo dental es del tipo 
incandescente, elevada y más amarillo-rojiza que la natural, ambas están contraindicadas para la toma del color ${ }^{14}$.

Ya tenemos el diente preparado para medir. Primero se realiza una medición subjetiva con la guía dental Vita 3D Master (Vita Zahnfabrik). El procedimiento de la toma del color está constituido de forma más sistemática que en otras guías, por la determinación del valor, intensidad y tinte en este orden ${ }^{96}$.

Seleccionamos el color dental con la guía 3D Master siguiendo las instrucciones del fabricante, a una distancia de $33 \mathrm{~cm}$, mediante observaciones cortas, colocando borde incisal de la tablilla con borde incisal del incisivo central superior. Según recomendaciones del fabricante se debe elegir con rapidez, aceptando siempre la primera decisión, ya que los ojos se fatigan al cabo de aprox. $5-7$ segundos ${ }^{10,96}$. Son preferibles unas tres o cuatro miradas cortas para evitar la fatiga y la adaptación visual. Es conveniente no mirar durante más de 5 segundos seguidos ${ }^{130}$, porque se genera una imagen persistente y negativa durante 15 o 20 seg.

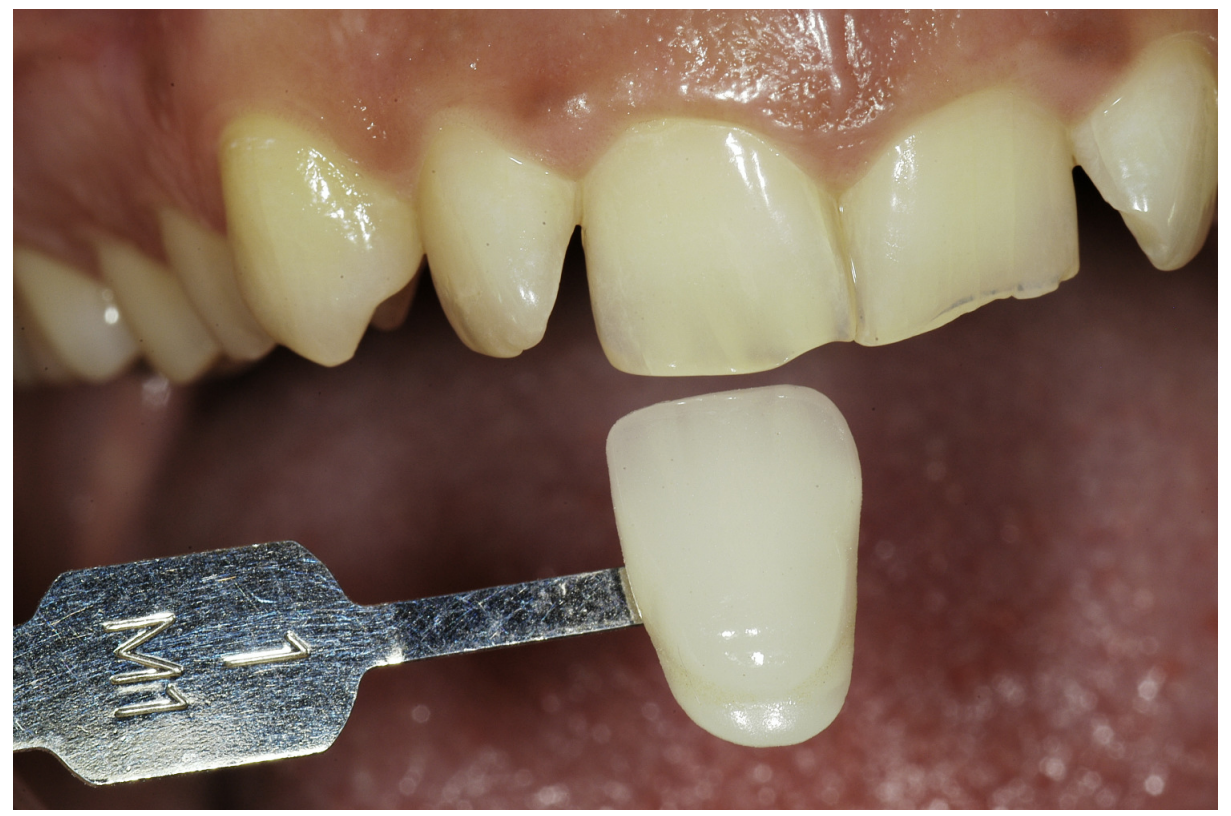

Figura 37: Toma de color subjetiva

Una vez anotado el color seleccionado con la guía Vita 3D Master, se procede a la toma de color objetiva mediante espectrofotómetro Easyshade compact (Vita Zahnfabrik). 


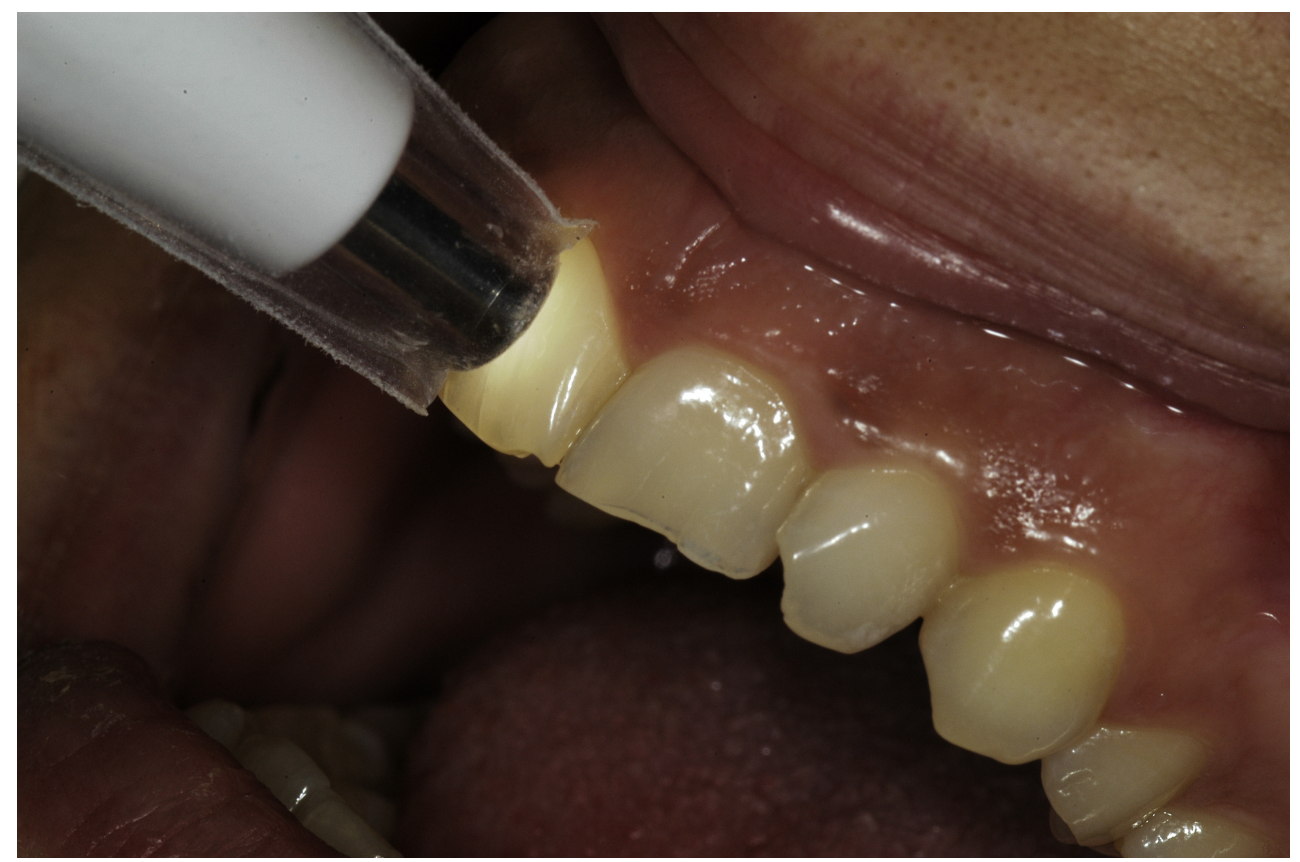

Figura 38: Toma de color objetiva

Antes de proceder a la medición, se coloca el protector higiénico en la punta lectora y se calibra la lámpara, según las indicaciones del fabricante ${ }^{96,137}$.

A continuación le pedimos al paciente que abra la boca ligeramente, retirando los labios y posicionando la punta lectora sobre el diente elegido para determinar el color, en un área de $3 \mathrm{~mm}$ de diámetro sobre la superficie de la zona central del tercio medio del diente ${ }^{82}$. Todo esto para conseguir un correcto ángulo de refracción de la luz, ya que esta zona es la más representativa del color del mismo.

Se anota el primer resultado que coincida dos veces. Se registra de dos formas, la primera el color según la nomenclatura de la guía dental Vita 3D Master y la segunda según el sistema CIELab correspondiente según L, C, h, a y b.

De cada incisivo central superior tenemos dos mediciones del color:

- - Una medición subjetiva, mediante comparación visual con la guía dental 3D Master.

- - Una medición objetiva, mediante el espectrofotómetro Easyshade compact.

Seguidamente con estos datos se confeccionó una tabla de Excell para ser analizados estadísticamente posteriormente. 


\subsection{2.- Fórmulas de diferencia de color: Sistemas CIELab y CIEDE2000.}

Para la evaluación de los variaciones que se producen en el color de los incisivos centrales superiores a lo largo del tiempo y en función del sexo, empleamos, el sistema de especificación de color CIELab y su diferencia de color asociada $\Delta E$ ab. Por ello creemos conveniente realizar algunas consideraciones al respecto de este sistema, empezando por resaltar el hecho de que es en la actualidad, hasta la esperadas nuevas recomendaciones de la CIE es, junto a CIELUV, el sistema de especificación de color recomendado por la Comisión Internacional de lluminación ${ }^{138}$.

En 1976 la CIE ${ }^{25}$ recomendó el uso de dos sistemas de especificación del color CIELab y CIELUV, con sus correspondientes fórmulas de diferencia de color asociadas, principalmente con el deseo de promover una uniformidad en la práctica de la medida del color. A lo largo del tiempo han sido muchos los sistemas de especificación del color y las diferencias de color que se han propuesto ${ }^{139}$ buscando mejorar la correlación entre medidas de color y percepción visual. A pesar de los avances conseguidos en este sentido, es importante destacar que habitualmente resulta imposible pasar la diferencia de color de unos sistemas a otros, con la consiguiente dificultad para el intercambio de información en aplicaciones industriales y en trabajos científicos.

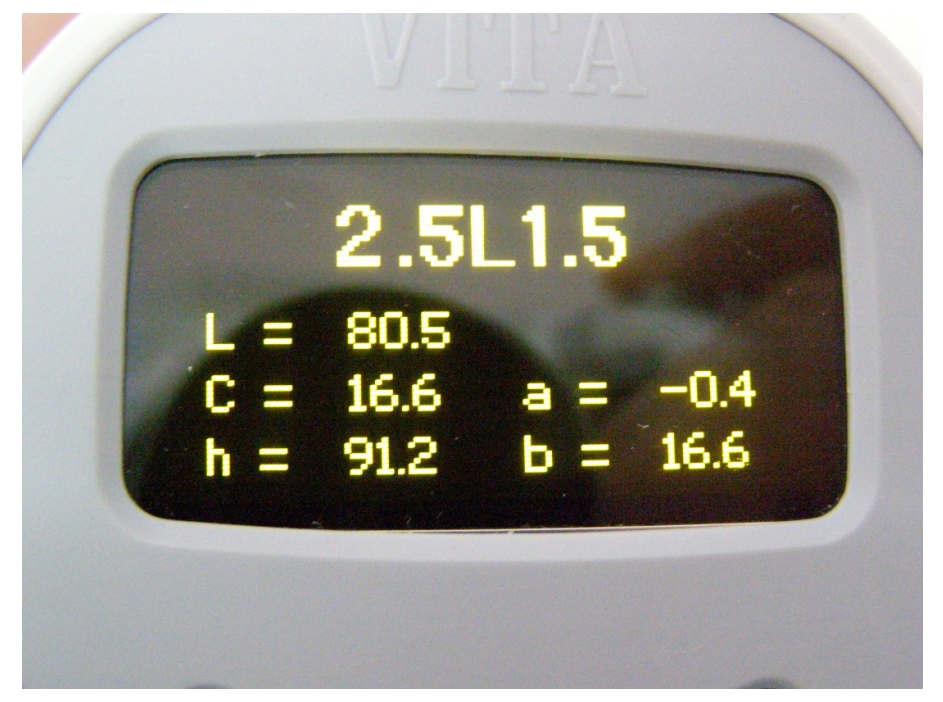

Figura 39: Coordenadas de CIELab para el color 2.5L1.5

Una característica importante de CIELab es la posibilidad que ofrece de realizar una especificación del color en coordenadas cilíndricas o polares, que se correlacionan con 
el valor tinte e intensidad, L, h y $\mathrm{C}$, respectivamente. En la siguiente imagen se tiene una representación de las coordenadas $L, C, h$, a y b. Esta característica fue recogida por la CIE en 1976, siendo las expresiones para la intensidad y el ángulo de tinte las siguientes:

Queremos señalar que en la actualidad el uso de CIELab está ampliamente difundido y su empleo es mayoritario en la práctica industrial. Además en base a CIELab se han desarrollado muchas de las fórmulas de diferencia de color que actualmente se emplean, en particular la fórmula CIE94 ${ }^{4}$ y la fórmula CIEDE2000 ${ }^{138,140}$. En cualquier caso el uso de estas nuevas fórmulas, no reemplaza aún, según la CIE, el empleo de CIELab como sistema de especificación del color. La obtención de un nuevo sistema de especificación que supere estos sistemas, es más compleja que la resolución en la evaluación de diferencias de color.

Para finalizar, queremos indicar que el sistema CIELab es el más empleado en los trabajos realizados, hasta la actualidad en Odontología, lo cual permitirá realizar comparaciones con dichos estudios.

La expresión de la diferencia de color en el espacio CIELab viene dada por las siguientes expresiones

$$
\begin{gathered}
\Delta E_{a b}^{*}=\sqrt{\Delta L^{* 2}+\Delta a^{* 2}+\Delta b^{* 2}} \\
\Delta E_{a b}^{*}=\sqrt{\Delta L^{* 2}+\Delta C^{* 2}+\Delta H^{* 2}}
\end{gathered}
$$

Figura 40: Fórmula euclidiana para expresar la diferencia entre dos colores

Hasta ahora en el campo de la restauración dental, como se ha indicado, para la especificación del color y el cálculo de diferencias de color se ha empleado el sistema CIELab y su diferencia de color asociada $\Delta \mathrm{E}$ ab. Con el objeto de obtener, una mejora de la correlación entre las diferencias color perceptibles y las instrumentales en las aplicaciones industriales, ha sido desarrollada recientemente ${ }^{138,140}$ una nueva diferencia de color, llamada CIEDE2000. Dicha fórmula incorpora correcciones específicas a la no uniformidad del CIELab, llamadas funciones de peso y designadas por SL, SC, and SH y unos parámetros que tienen en cuenta la influencia de las condiciones de iluminación y observación en la evaluación de la diferencia de color. 
Dichos parámetros (KL, KC y $\mathrm{KH}$ ) son llamados factores paramétricos. La $\mathrm{CIE}{ }^{138}$ indica que bajo unas condiciones experimentales de referencia ${ }^{138,141}$, usuales en la práctica industrial, el valor de cada factor es igual a 1.0 .La fórmula de diferencia de color CIEDE2000 4, 134, 135 viene dada por la expresión:

$$
\Delta E_{00}=\left[\left(\frac{\Delta L^{\prime}}{K_{L} S_{L}}\right)^{2}+\left(\frac{\Delta C^{\prime}}{K_{C} S_{C}}\right)^{2}+\left(\frac{\Delta H^{\prime}}{K_{H} S_{H}}\right)^{2}+R_{T}\left(\frac{\Delta C^{\prime}}{K_{C} S_{C}}\right)\left(\frac{\Delta H^{\prime}}{K_{H} S_{H}}\right)^{1 / 2}\right.
$$

Figura 41: Fórmula matemática para expresar la diferencia entre dos colores

Debido a la complejidad en los cálculos y a la mayor difusión de la fórmula clásica de $\Delta \mathrm{E}$, se ha optado por esta última, en los resultados de este trabajo.

\subsection{3.- Material y método sobre el análisis estadístico}

El análisis estadístico se ha elaborado por personal perteneciente al Servicio de apoyo a la investigación del la Universidad Complutense de Madrid.Se ha elaborado introduciendo la hoja de cálculo con los datos registrados en los siguientes programas para su adecuado tratamiento:

- SAS 9.1.3, para el estudio estadístico descriptivo

- SPSS, para la realización de gráficos de cajas y bigotes

- R 2.7.2, para confeccionar los gráficos en tres y dos dimensiones

- SPAD, para realizar el Análisis de Conglomerados

Se aplicó una técnica de análisis de multivariante de componentes principales a las medianas de cada tablilla de color de la guía dental 3D Master para las variables L, C, h. Este análisis proyecta las tablillas en un espacio de dimensión 2, permitiendo interrelacionarlas con las variables $L, C, h$ de manera visual. Se realizó un análisis de conglomerados jerárquico utilizando el método Ward para encontrar grupos de tablillas con valores similares de L, C, h (Anexo I). 



\section{5.- RESULTADOS}





\section{5.- RESULTADOS}

En el presente capítulo vamos a presentar los resultados más significativos de nuestro trabajo de acuerdo a los objetivos planteados. Los cinco primeros objetivos van dirigidos a conocer la distribución del color dental de la población de Castilla y León y el último a estudiar la ordenación la guía de color dental 3D Master.

En primer lugar vamos a exponer la descriptiva de las variables empleadas en este estudio con objeto de conocer cuál es la distribución de las variables por género y edad, tanto en el método objetivo como con el método subjetivo.

En segundo lugar estudiaremos las coincidencias que se han producido entre el espectrofotómetro (método objetivo) y el ojo humano (método subjetivo), para el tinte, el valor, y la intensidad.

El tercer objetivo consiste en valorar el grado de asociación entre los grupos de edad y sexo con las tres dimensiones del color aportadas por el espectrofotómetro según la guía de color $3 \mathrm{D}$ Master. Además se enumeran los colores más frecuentes en la muestra de población seleccionada por los grupos establecidos.

El siguiente objetivo, evalúa como la edad y el género influencian las varibles ordinales continuas: valor o luminosidad (L), tinte (h) e intensidad (C).

Posteriormente, en el quinto apartado, observamos el cambio que ejerce el paso del tiempo sobre el color del diente, y su correspondiente modificación en las tres dimensiones del color.

Como sexto apartado hemos estudiado la distribución de la guía 3D Master (VitaZahnfabrik), dentro del espacio del color. Finalmente, presentamos los resultados obtenidos de forma gráfica para observar su ordenación espacial. 


\section{1.- ESTUDIO ESTADÍSTICO DESCRIPTIVO APLICADO A LAS TRES DIMENSIONES DEL COLOR}

La muestra recogida, tiene un $n=1361$ sujetos, $y$ ha sido obtenida de las provincias de Castilla y León. Dichos datos se han analizado estadísticamente de la forma que desarrollaremos a continuación.

\subsection{1.- Descriptiva de la muestra}

Exponemos en la tabla resumen número 1, la totalidad de la muestra y su correspondiente distribución por sexo y edad. En esta tabla queda reflejado una totalidad de 1361 pacientes a los que se le ha registrado el color, dividido en 671 hombres (49.3\%) y en 690 mujeres (50.7\%). Estos porcentajes se vuelven a desglosar en los tres grupos de edad determinados para este estudio. En los hombres estas 3 categorías se distribuyen de forma similar con porcentajes que van desde el 30,7\% hasta el 35,3\%. En las mujeres, de forma similar, la distribución de edad es aproximadamente homogénea, tasas entre un $31,4 \%$ y un $36,1 \%$.

\begin{tabular}{|c|c|c|c|c|c|}
\hline \multicolumn{6}{|c|}{ TABLA RESUMEN DE DISTRIBUCIÓN DE LA MUESTRA TOTAL } \\
\hline & & $<\mathbf{3 0}$ AÑOS & $\mathbf{3 0 - 5 9}$ AÑOS & $\geq 60$ AÑOS & TOTAL \\
\hline \multirow{3}{*}{ HOMBRES } & Recuento & $\mathbf{2 0 6}$ & $\mathbf{2 3 7}$ & $\mathbf{2 2 8}$ & $\mathbf{6 7 1}$ \\
\cline { 2 - 6 } & Porcentaje de sexo & $30.7 \%$ & $35.3 \%$ & $34.0 \%$ & $100 \%$ \\
\cline { 2 - 6 } & Porcentaje de edad & $48.7 \%$ & $48.8 \%$ & $50.4 \%$ & $49.3 \%$ \\
\hline \multirow{3}{*}{ MUJERES } & Recuento & $\mathbf{2 1 7}$ & $\mathbf{2 4 9}$ & $\mathbf{2 2 4}$ & $\mathbf{6 9 0}$ \\
\cline { 2 - 6 } & Porcentaje de sexo & $31.4 \%$ & $36.1 \%$ & $32.5 \%$ & $100 \%$ \\
\cline { 2 - 6 } & Porcentaje de edad & $51.3 \%$ & $51.2 \%$ & $49.6 \%$ & $50.7 \%$ \\
\hline \multirow{3}{*}{ TOTAL } & Recuento & $\mathbf{4 2 3}$ & $\mathbf{4 8 6}$ & $\mathbf{4 5 2}$ & $\mathbf{1 3 6 1}$ \\
\cline { 2 - 6 } & Porcentaje de sexo & $31.1 \%$ & $35.7 \%$ & $33.2 \%$ & $100 \%$ \\
\cline { 2 - 6 } & Porcentaje de edad & $100 \%$ & $100 \%$ & $100 \%$ & $100 \%$ \\
\hline
\end{tabular}

Tabla 1

La prueba $\mathrm{Chi}^{2}$ de homogeneidad, con una $p>, 05$ demuestra que no hay diferencias entre los grupos, en ninguna de las 2 variables; es decir demuestra que hay homogeneidad tanto por edad como sexo en todos los sub-grupos que hemos formado en función de estas 2 variables (Chi2=0,353; $2 \mathrm{gl} ; \mathrm{n}=1361 ; \mathrm{p}=, 838$ ) según la tabla 2. 


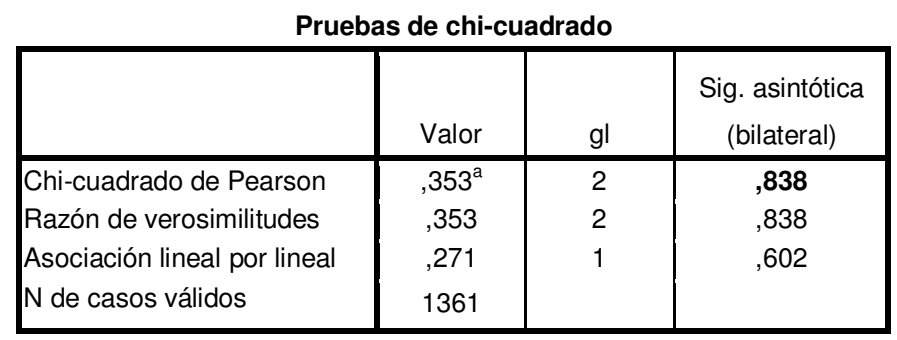

a. 0 casillas $(, 0 \%)$ tienen una frecuencia esperada inferior a 5 . La

frecuencia mínima esperada es 208,55.

\section{Tabla 2}

\subsection{2.- Descriptiva de variables cualitativas}

Dentro de este apartado vamos a representar a través de tablas, los valores numéricos obtenidos en las tres dimensiones del color, tanto para la luminosidad o valor, para la intensidad o croma y finalmente para el tinte, asociados a los grupos de edad establecidos.

Para una correcta interpretación de la tabla vamos a desarrollar la siguiente leyenda:

F, Representa la frecuencia.

$P$, Representa el porcentaje.

F.A, Representa la frecuencia acumulada.

P. A, Representa el porcentaje acumulado.

Comenzaremos por el método subjetivo:

\section{$\underline{\text { 5.1.2.1.- Subjetivas }}$}

\subsubsection{1.- Grupo de edad de Menores de treinta años:}

En la tabla número 3 se representa, como datos más significativos, que ni hombres ni mujeres sobrepasan del valor 3. Encontramos los porcentajes más elevados en el valor número 2 tanto en hombres (64.56\%) como en mujeres (59.91\%). La intensidad más elevada, intensidad número 3 , solo se registró cuatro veces en hombres y dos veces en mujeres. 


\begin{tabular}{|c|c|c|c|c|c|c|c|c|c|}
\hline & & \multicolumn{8}{|c|}{ SUBJETIVA } \\
\hline & & \multicolumn{4}{|c|}{ HOMBRES <30 AÑOS } & \multicolumn{4}{|c|}{ MUJERES <30 AÑOS } \\
\hline & & $\mathbf{F}$ & $\mathbf{P}$ & FA & PA & $\mathbf{F}$ & $\mathbf{P}$ & FA & PA \\
\hline \multirow{3}{*}{ VALOR } & 1 & 58 & 28.16 & 58 & 28.16 & 79 & 36.41 & 79 & 36.41 \\
\hline & 2 & 133 & 64.56 & 191 & 92.72 & 130 & 59.91 & 209 & 96.31 \\
\hline & 3 & 15 & 7.28 & 206 & 100 & 8 & 3.69 & 217 & 100 \\
\hline \multirow{3}{*}{ TINTE } & $\mathbf{L}$ & 44 & 21.36 & 44 & 21.36 & 44 & 20.28 & 44 & 20.28 \\
\hline & $\mathbf{M}$ & 151 & 73.30 & 195 & 94.66 & 165 & 76.04 & 209 & 96.31 \\
\hline & $\mathbf{R}$ & 11 & 5.34 & 206 & 100 & 8 & 3.69 & 217 & 100 \\
\hline \multirow{5}{*}{ INTENSIDAD } & 1 & 78 & 37.86 & 78 & 37.86 & 104 & 47.93 & 104 & 47.93 \\
\hline & 1,5 & 37 & 17.96 & 115 & 55.83 & 41 & 18.89 & 145 & 66.82 \\
\hline & 2 & 69 & 33.50 & 184 & 89.32 & 59 & 27.19 & 204 & 94.01 \\
\hline & 2,5 & 18 & 8.74 & 202 & 98.06 & 11 & 5.07 & 215 & 99.08 \\
\hline & 3 & 4 & 1.94 & 206 & 100 & 2 & 0.92 & 217 & 100 \\
\hline
\end{tabular}

Tabla 3

\subsubsection{2. - Grupo de edad de treinta a cincuenta y nueve años:}

Comparando con la tabla 3 que representa la grupo de población de menor edad, en la tabla de edad intermedia (Tabla 4) vemos la diferencia en que el grado de luminosidad o valor se va ampliando, llegando al nivel máximo, nivel 5, en los hombres, aunque ninguna mujer alcanzó ese valor. El valor o luminosidad más frecuente para hombres registrado de manera visual fue el 3 , con 111 sujetos (46.84\%) mientras que para mujeres fue el valor 2 , con 126 sujetos $(50.60 \%)$.

\begin{tabular}{|c|c|c|c|c|c|c|c|c|c|}
\hline & \multicolumn{8}{|c|}{ SUBJETIVA } \\
\hline & & \multicolumn{4}{|c|}{ HOMBRES 30-59 AÑOS } & \multicolumn{4}{|c|}{ MUJERES 30-59 AÑOS } \\
\hline & & $\mathbf{F}$ & $\mathbf{P}$ & FA & PA & $\mathbf{F}$ & $\mathbf{P}$ & FA & PA \\
\hline \multirow{5}{*}{ VALOR } & 1 & 6 & 2.53 & 6 & 2.53 & 11 & 4.42 & 11 & 4.42 \\
\hline & 2 & 67 & 28.27 & 73 & 30.80 & 126 & 50.60 & 137 & 55.02 \\
\hline & 3 & 111 & 46.84 & 184 & 77.64 & 89 & 35.74 & 226 & 90.76 \\
\hline & 4 & 48 & 20.25 & 232 & 97.89 & 23 & 9.24 & 249 & 100 \\
\hline & 5 & 5 & 2.11 & 237 & 100 & & & & \\
\hline \multirow{3}{*}{ TINTE } & $\mathbf{L}$ & 53 & 22.36 & 53 & 22.36 & 58 & 23.29 & 58 & 23.29 \\
\hline & $\mathbf{M}$ & 151 & 63.71 & 204 & 86.08 & 163 & 65.46 & 221 & 88.76 \\
\hline & $\mathbf{R}$ & 33 & 13.92 & 237 & 100 & 28 & 11.24 & 249 & 100 \\
\hline \multirow{5}{*}{ INTENSIDAD } & 1 & 80 & 33.76 & 80 & 33.76 & 113 & 45.38 & 113 & 45.38 \\
\hline & 1,5 & 54 & 22.78 & 134 & 56.54 & 65 & 26.10 & 178 & 71.49 \\
\hline & 2 & 54 & 22.78 & 188 & 79.32 & 47 & 18.88 & 225 & 90.36 \\
\hline & 2,5 & 32 & 13.50 & 220 & 92.83 & 21 & 8.43 & 246 & 98.80 \\
\hline & 3 & 17 & 7.17 & 237 & 100 & 3 & 1.20 & 249 & 100 \\
\hline
\end{tabular}

Tabla 4 


\subsubsection{3.- Grupo de edad de mayores de sesenta años:}

La tabla 5, representa el grupo de población de edad superior, destacamos que en hombres no hay ningún sujeto con valor número1, también que el número de sujetos con un valor de 5 aparece 31 veces (13.60\%). En el grupo femenino, la intensidad máxima de los dientes tiene un porcentaje de $4.02 \%$, mientras que los hombres pasan a un porcentaje de $10.09 \%$.El valor o luminosidad más frecuente en mujeres con edad igual o superior a 60 años es el 3, con 112 sujetos (50\%), en hombres el valor o luminosidad más frecuente es el 4 , donde curiosamente también representa el $50 \%$ de los sujetos estudiados.

Recordamos que en este apartado solo se describen las variables subjetivas.

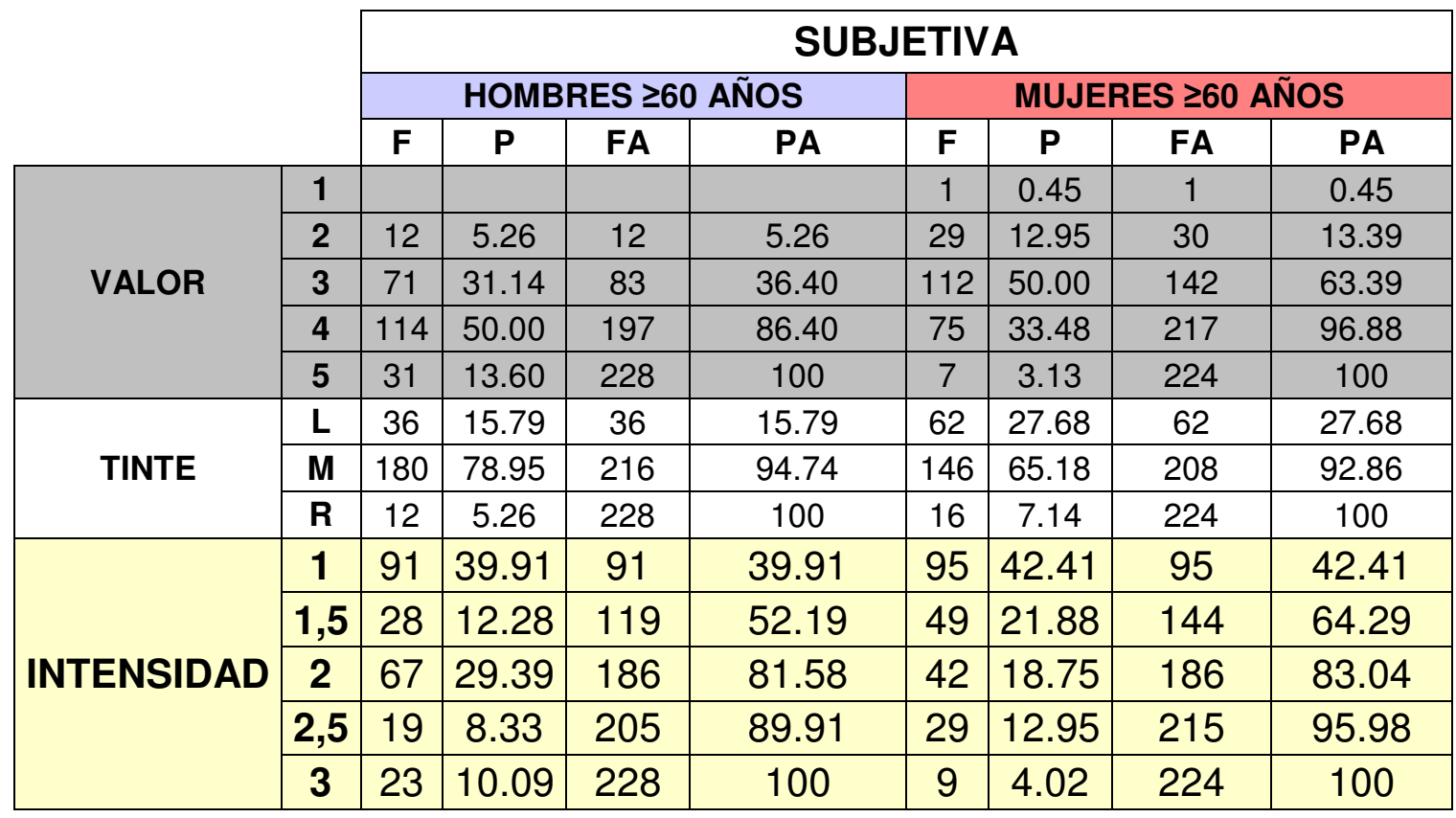

Tabla 5

A continuación vamos a representar en las tres tablas siguientes los resultados aportados por el espectrofotómetro, método objetivo.

\subsubsection{2.- Objetivas}

Una vez revisadas las tres tablas resumen del método objetivo podemos afirmar que las tres dimensiones del color se encuentran distribuidas según nuestros resultados de la siguiente manera: 


\subsubsection{1.- Grupo de edad de Menores de treinta años:}

El valor es más frecuente es 1 para hombres (33.01\%) y para mujeres también representando un $44.70 \%$ de todos los resultados.

En ambos sexos el tinte más frecuente en hombres y en mujeres también fue coincidente, el tinte $\mathrm{M}$, llegando a porcentajes del $73.30 \%$ en hombres y $75.58 \%$ en mujeres.

La intensidad 1,5 fue la más registrada, en hombres representada con un $37.38 \%$ y en mujeres en un $46.08 \%$.

En la tabla 6, vemos como el espectrofotómetro aportó valores de 0 tanto para la mustra masculina como para la muestra femenina y un único valor de 0,5 se localizó en mujeres con edad inferior a treinta años. Este dato desaparece según aumentamos el grupo de edad.

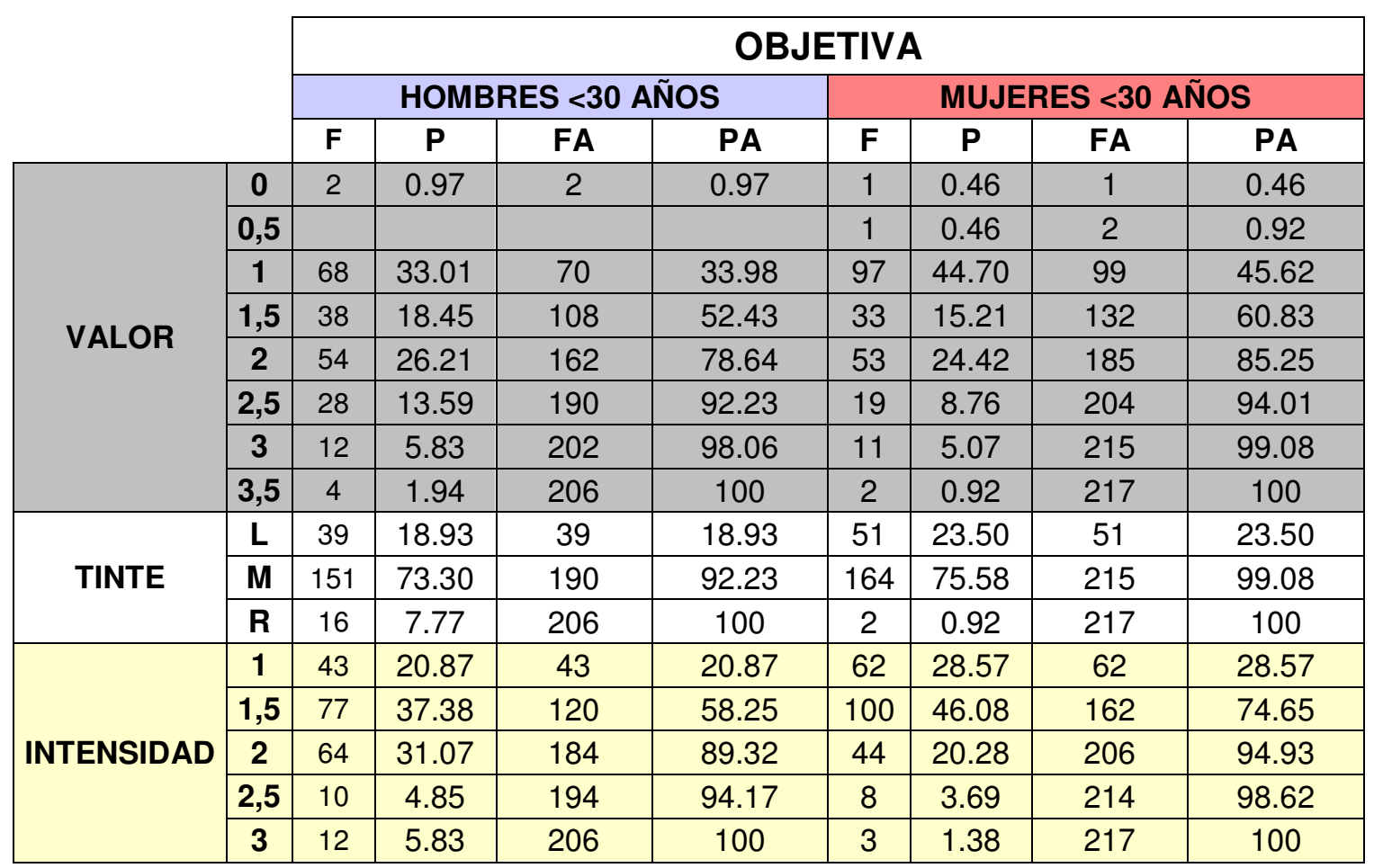

Tabla 6 


\subsubsection{2. - Grupo de edad de treinta a cincuenta y nueve años:}

En la tabla 7 el valor se encuentra más repartido, y no coincide en hombres y en mujeres. En hombres el valor con mayor presencia es 3,5 (21.52\%), en mujeres es 2,5 $(20.08 \%)$.

El tinte con mayor peso dentro de la muestra es el tinte $\mathrm{M}$, siendo sus porcentajes de un $55.70 \%$ en hombres y un $60.24 \%$ en mujeres. Los porcentajes de los tres tipos de tinte son bastante homogéneos.

La intensidad más frecuente en hombres es de 1,5 (35.86\%) y en cambio, en mujeres es de $1(38.96 \%)$.

\begin{tabular}{|c|c|c|c|c|c|c|c|c|c|}
\hline & \multicolumn{8}{|c|}{ OBJETIVA } \\
\hline & & \multicolumn{4}{|c|}{ HOMBRES 30-59 AÑOS } & \multicolumn{4}{|c|}{ MUJERES 30-59 AÑOS } \\
\hline & & $\mathbf{F}$ & $\mathbf{P}$ & FA & PA & $\mathbf{F}$ & $\mathbf{P}$ & FA & PA \\
\hline \multirow{9}{*}{ VALOR } & 1 & 5 & 2.11 & 5 & 2.11 & 19 & 7.63 & 19 & 7.63 \\
\hline & 1,5 & 6 & 2.53 & 11 & 4.64 & 19 & 7.63 & 38 & 15.26 \\
\hline & 2 & 33 & 13.92 & 44 & 18.57 & 71 & 28.51 & 109 & 43.78 \\
\hline & 2,5 & 45 & 18.99 & 89 & 37.55 & 50 & 20.08 & 159 & 63.86 \\
\hline & 3 & 46 & 19.41 & 135 & 56.96 & 41 & 16.47 & 200 & 80.32 \\
\hline & 3,5 & 51 & 21.52 & 186 & 78.48 & 34 & 13.65 & 234 & 93.98 \\
\hline & 4 & 28 & 11.81 & 214 & 90.30 & 9 & 3.61 & 243 & 97.59 \\
\hline & 4,5 & 20 & 8.44 & 234 & 98.73 & 6 & 2.41 & 249 & 100 \\
\hline & 5 & 3 & 1.27 & 237 & 100 & & & & \\
\hline \multirow{3}{*}{ TINTE } & $\mathbf{L}$ & 73 & 30.80 & 73 & 30.80 & 74 & 29.72 & 74 & 29.72 \\
\hline & $\mathbf{M}$ & 132 & 55.70 & 205 & 86.50 & 150 & 60.24 & 224 & 89.96 \\
\hline & $\mathbf{R}$ & 32 & 13.50 & 237 & 100 & 25 & 10.04 & 249 & 100 \\
\hline \multirow{5}{*}{ INTENSIDAD } & 1 & 64 & 27.00 & 64 & 27.00 & 97 & 38.96 & 97 & 38.96 \\
\hline & 1,5 & 85 & 35.86 & 149 & 62.87 & 91 & 36.55 & 188 & 75.50 \\
\hline & 2 & 49 & 20.68 & 198 & 83.54 & 38 & 15.26 & 226 & 90.76 \\
\hline & 2,5 & 28 & 11.81 & 226 & 95.36 & 18 & 7.23 & 244 & 97.99 \\
\hline & 3 & 11 & 4.64 & 237 & 100 & 5 & 2.01 & 249 & 100 \\
\hline
\end{tabular}

Tabla 7

\subsubsection{3.- Grupo de edad de mayores de sesenta años:}

Si analizamos la tabla 8, el valor en hombres vuelve a ser menor que en mujeres. En hombres aparece como más frecuente el valor $4,5(23.68 \%)$, mientras que en mujeres el valor más frecuente es el 3,5 (22.32\%). 
El tinte $\mathrm{M}$ aparece destacado por encima del resto, como en el resto de grupos con unos porcentajes de $70.61 \%$ en hombres y del $58.04 \%$ en mujeres.

La intensidad 1,5 y 2,5 aparece con la misma frecuencia en el grupo de los hombres (24.56\%) y en el grupo de las mujeres destaca 1,5 que representa el $32.59 \%$ de los resultados.

\begin{tabular}{|c|c|c|c|c|c|c|c|c|c|}
\hline & \multicolumn{8}{|c|}{ OBJETIVA } \\
\hline & & \multicolumn{4}{|c|}{ HOMBRES $\geq 60$ AÑOS } & \multicolumn{4}{|c|}{ MUJERES $\geq 60$ AÑOS } \\
\hline & & $\mathbf{F}$ & $\mathbf{P}$ & FA & PA & $\mathbf{F}$ & $\mathbf{P}$ & FA & PA \\
\hline \multirow{9}{*}{ VALOR } & 1 & 5 & 2.19 & 5 & 2.19 & 4 & 1.79 & 4 & 1.79 \\
\hline & 1,5 & 1 & 0.44 & 6 & 2.63 & 3 & 1.34 & 7 & 3.13 \\
\hline & 2 & 8 & 3.51 & 14 & 6.14 & 25 & 11.16 & 32 & 14.29 \\
\hline & 2,5 & 20 & 8.77 & 34 & 14.91 & 39 & 17.41 & 71 & 31.70 \\
\hline & 3 & 32 & 14.04 & 66 & 28.95 & 49 & 21.88 & 120 & 53.57 \\
\hline & 3,5 & 51 & 22.37 & 117 & 51.32 & 50 & 22.32 & 170 & 75.89 \\
\hline & 4 & 32 & 14.04 & 149 & 65.35 & 18 & 8.04 & 188 & 83.93 \\
\hline & 4,5 & 54 & 23.68 & 203 & 89.04 & 28 & 12.50 & 216 & 96.43 \\
\hline & 5 & 25 & 10.96 & 228 & 100 & 8 & 3.57 & 224 & 100 \\
\hline \multirow{3}{*}{ TINTE } & $\mathbf{L}$ & 51 & 22.37 & 51 & 22.37 & 71 & 31.70 & 71 & 31.70 \\
\hline & $\mathbf{M}$ & 161 & 70.61 & 212 & 92.98 & 130 & 58.04 & 201 & 89.73 \\
\hline & $\mathbf{R}$ & 16 & 7.02 & 228 & 100 & 23 & 10.27 & 224 & 100 \\
\hline \multirow{5}{*}{ INTENSIDAD } & 1 & 38 & 16.67 & 38 & 16.67 & 60 & 26.79 & 60 & 26.79 \\
\hline & 1,5 & 56 & 24.56 & 94 & 41.23 & 73 & 32.59 & 133 & 59.38 \\
\hline & 2 & 40 & 17.54 & 134 & 58.77 & 41 & 18.30 & 174 & 77.68 \\
\hline & 2,5 & 56 & 24.56 & 190 & 83.33 & 36 & 16.07 & 210 & 93.75 \\
\hline & 3 & 38 & 16.67 & 228 & 100 & 14 & 6.25 & 224 & 100 \\
\hline
\end{tabular}

Tabla 8

\subsection{3.- Comparativa de las tres dimensiones del color en ambos métodos}

\subsubsection{1.- Descriptivas de variables ordinales}

Otra representación visual que nos ha parecido de interés indica los valores numéricos medios objetivos y subjetivos con la correspondiente desviación estándar en sexos y en cada grupo de edad.

En la siguiente tabla, tabla 9, aparece la comparativa de los valores numéricos medios con la desviación estándar para hombres en valor e intensidad. 


\begin{tabular}{|c|c|c|c|}
\cline { 2 - 4 } \multicolumn{1}{c|}{} & \multicolumn{3}{c|}{ DESCRIPTIVA VARIABLES ORDINALES HOMBRES } \\
\cline { 2 - 4 } \multicolumn{1}{c|}{} & $\mathbf{3 0}$ AÑOS & $\mathbf{3 0 - 5 9}$ AÑOS & $\geq 60$ AÑOS \\
\cline { 2 - 4 } \multicolumn{1}{c|}{ MEDIA \pm SD } & MEDIA $\pm S D$ & MEDIA $\pm S D$ \\
\hline VALOR SUBJETIVO & $1.791 \pm 0.559$ & $2.911 \pm 0.816$ & $3.719 \pm 0.763$ \\
\hline INTENSIDAD SUBJETIVA & $1.595 \pm 0.550$ & $1.688 \pm 0.636$ & $1.682 \pm 0.673$ \\
\hline VALOR OBJETIVO & $1.714 \pm 0.686$ & $3.063 \pm 0.860$ & $3.697 \pm 0.916$ \\
\hline INTENSIDAD OBJETIVA & $1.687 \pm 0.525$ & $1.656 \pm 0.565$ & $2.000 \pm 0.677$ \\
\hline
\end{tabular}

\section{Tabla 9}

En estas tablas 9 y 10 , observamos como la intensidad media en los diferentes grupos de edad es un dato que cambia poco, por el contrario el valor media sí que aumenta sus cifras con el aumento de la edad, tanto en hombres como en mujeres.

\begin{tabular}{|c|c|c|c|}
\cline { 2 - 4 } \multicolumn{1}{c|}{} & \multicolumn{3}{c|}{ DESCRIPTIVA VARIABLES ORDINALES MUJERES } \\
\cline { 2 - 4 } \multicolumn{1}{c|}{} & $<\mathbf{3 0}$ AÑOS & $\mathbf{3 0 - 5 9}$ AÑ OS & $\geq \mathbf{6 0}$ AÑOS \\
\cline { 2 - 4 } & MEDIA \pm SD & MEDIA $\pm S D$ & MEDIA $\pm S D$ \\
\hline VALOR SUBJETIVO & $1.673 \pm 0.543$ & $2.498 \pm 0.725$ & $3.259 \pm 0.737$ \\
\hline INTENSIDAD SUBJETIVA & $1.461 \pm 0.509$ & $1.470 \pm 0.522$ & $1.571 \pm 0.608$ \\
\hline VALOR OBJETIVO & $1.569 \pm 0.651$ & $2.488 \pm 0.823$ & $3.196 \pm 0.884$ \\
\hline INTENSIDAD OBJETIVA & $1.516 \pm 0.437$ & $1.484 \pm 0.504$ & $1.712 \pm 0.609$ \\
\hline
\end{tabular}

Tabla 10

El diagrama de barras resulta más útil en estos casos ya que entre $L, R, y M$, no existe correlación numérica, simplemente indica la familia de colores a la que pertenece cada diente medido.

Se puede cuantificar el número de representantes por grupo de edad y sexo para cada uno de los tres tintes estudiados.

Estos gráficos informan sobre la homogeneidad presente entre los sexos y entre los grupos de edad.

El gráfico 1 con los datos recogidos a través del espectrofotómetro, se asemeja mucho al gráfico 2 donde aparecen los datos subjetivos. Vemos que el tinte $M$, es el más frecuente, seguido por el tinte $\mathrm{L}$, y por último el tinte $\mathrm{R}$, con independencia del grupo de edad, y sexo

Para representar el tinte, hemos optado por un diagrama de barras. 
RESULTADOS

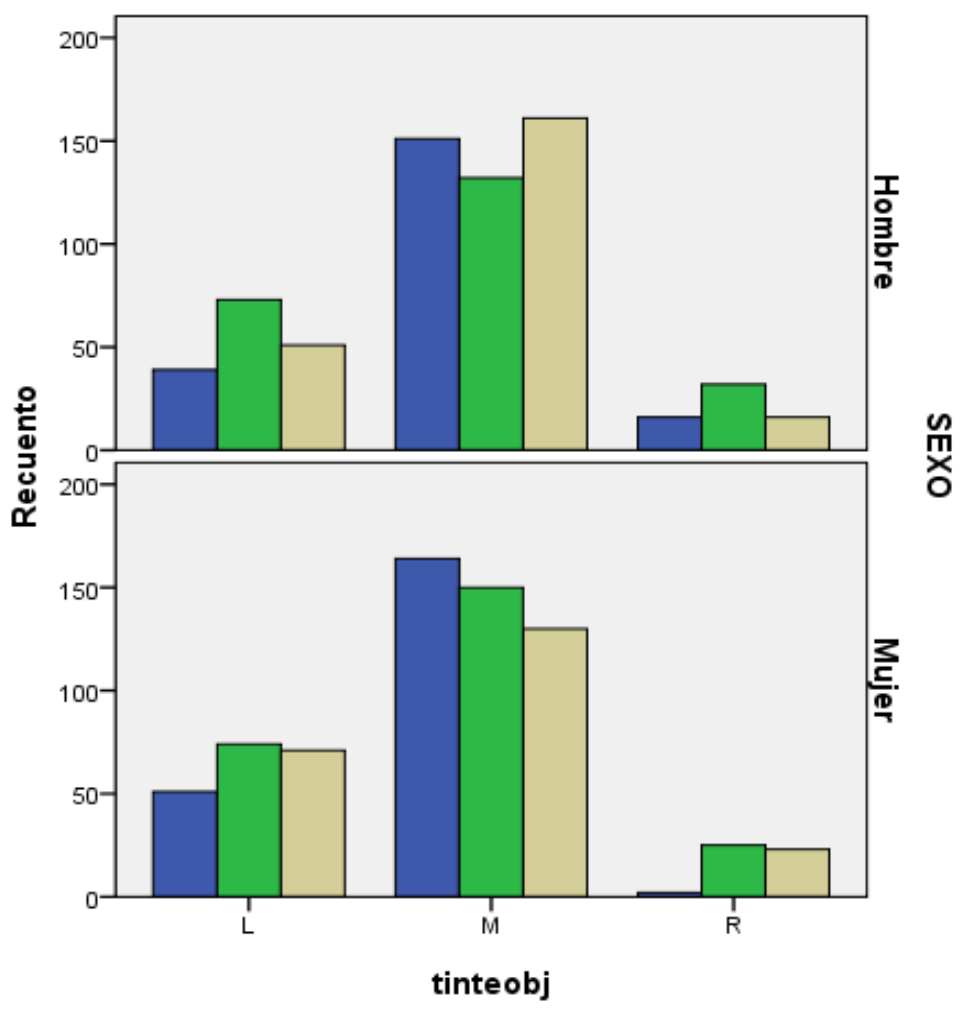

Edad (grupos)

$\square<30$ años

$\square$ de 30 a 59 años

$\square>=60$ años

m

Gráfico 1

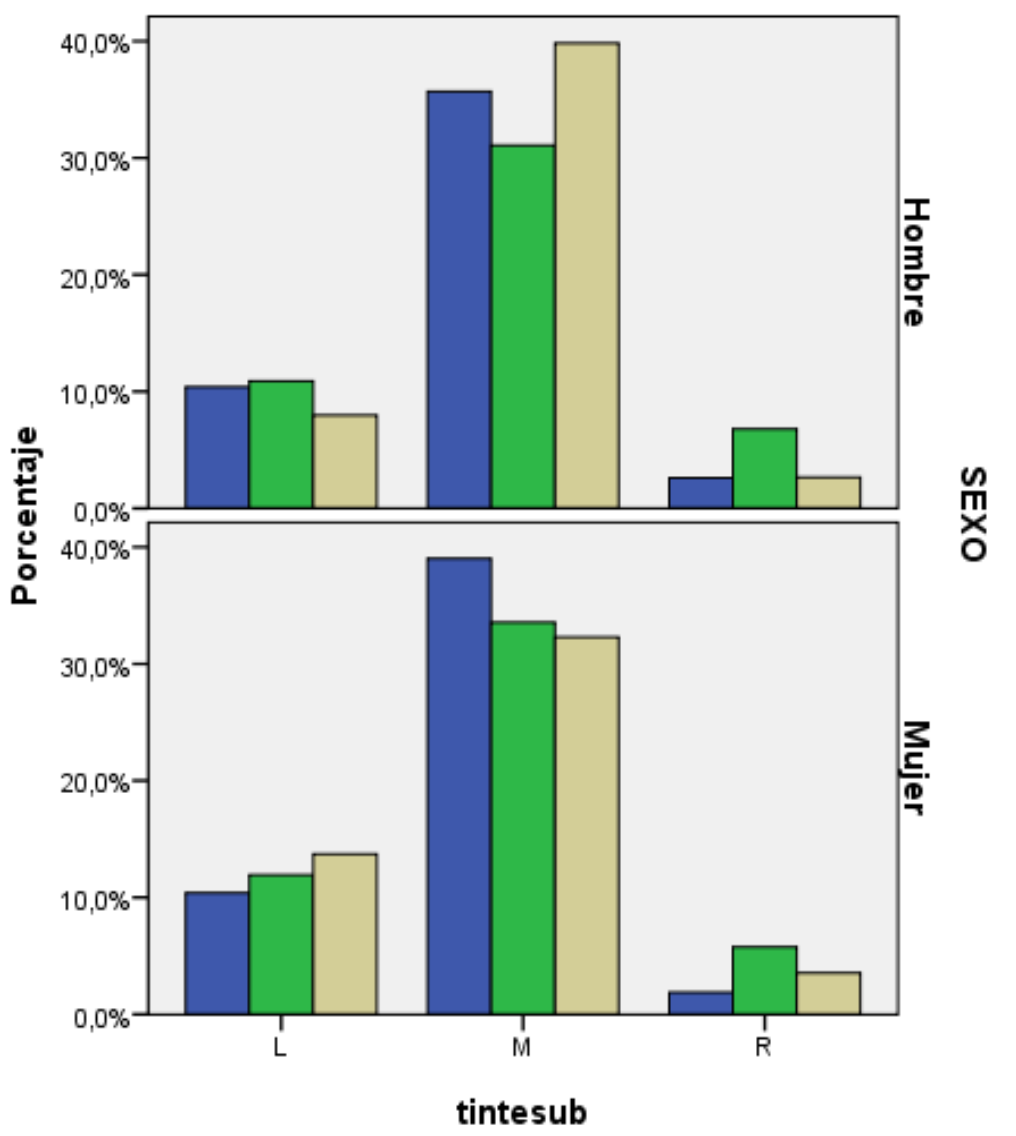

Gráfico 2 


\section{2.- GRADO DE ACUERDO ENTRE EL MÉTOdO OBJETIVO Y EL MÉTODO SUBJETIVO}

En este apartado vamos a representar el número de coincidencias absolutas del ojo humano con el espectrofotómetro, en las tres dimensiones del color. Posteriormente para el valor, registraremos las diferencias en medio punto, que con la guía de color empleada en este estudio, guía de color 3D Master (Vita-Zahnfabrik), no se pueden registrar.

Para desvelar el grado de acuerdo del ojo humano con el espectrofotómetro hemos recurrido al análisis estadístico de kappa, que es capaz de medir variables discretas y ordinales.

- Kappa simple: mide variables cualitativas.

- Kappa ponderado: mide variables ordinales, además es capaz de cuantificar las diferencias (en una escala -1, 0, 1).

\subsection{1.- Relativo a Coincidencias Absolutas}

\subsubsection{1.- Tinte}

La siguiente tabla de contingencia, tabla 11, representa las coincidencias absolutas entre el ojo humano y el espectrofotómetro. Marcamos en negrita los porcentajes de coincidencia absolutas para el tinte, L, M, y R. Debajo la significación por Chi2, y posteriormente el valor del coeficiente de concordancia Kappa.

Como se puede comprobar, ha habido un $14,1 \%$ de coincidencias en tinte L, un $56,7 \%$ en tinte $\mathrm{M}$ y un $2,1 \%$ en tinte $\mathrm{R}$. Con lo cual la tasa de coincidencia total alcanza casi el $73 \%$. A pesar de algunos errores siempre menores al 10\%, se encontró la existencia de una correlación altamente significativa, con $p<0,05$, entre ambos métodos (Chi2=401,518; $4 \mathrm{gl} ; n=1361 ; p=, 000$ ). El grado de concordancia, como aparece en la tabla 12, estimado según el método Kappa es de 0,43 (IC al 95\%: 0,39-0,48). 


\begin{tabular}{|c|c|c|c|c|c|c|}
\hline \multicolumn{7}{|c|}{ TABLA DE CONTINGENCIA TINTEOBJ/TINTESUB } \\
\hline & & & \multicolumn{3}{|c|}{ tintesub } & \multirow[b]{2}{*}{ Total } \\
\hline & & & $\mathrm{L}$ & M & $\mathrm{R}$ & \\
\hline \multirow[t]{9}{*}{ tinteobj } & $\mathrm{L}$ & Recuento & 192 & 129 & 38 & 359 \\
\hline & & $\%$ del total & $14,1 \%$ & $9,5 \%$ & $2,8 \%$ & $26,4 \%$ \\
\hline & & Residuos corregidos & 16,9 & $-16,6$ & 2,2 & \\
\hline & $\mathrm{M}$ & Recuento & 75 & 772 & 41 & 888 \\
\hline & & $\%$ del total & $5,5 \%$ & $56,7 \%$ & $3,0 \%$ & $65,2 \%$ \\
\hline & & Residuos corregidos & $-16,4$ & 18,5 & $-6,2$ & \\
\hline & $\mathrm{R}$ & Recuento & 30 & 55 & 29 & 114 \\
\hline & & $\%$ del total & $2,2 \%$ & $4,0 \%$ & $2,1 \%$ & $8,4 \%$ \\
\hline & & Residuos corregidos & 1,2 & $-5,4$ & 7,2 & \\
\hline \multirow[t]{2}{*}{ Total } & & Recuento & 297 & 956 & 108 & 1361 \\
\hline & & $\%$ del total & $21,8 \%$ & $70,2 \%$ & $7,9 \%$ & $100,0 \%$ \\
\hline
\end{tabular}

\begin{tabular}{|l|c|c|c|}
\hline \multicolumn{4}{|c|}{ PRUEBA CHI-CUADRADO } \\
\hline & Valor & gl & $\begin{array}{c}\text { Sig. asintótica } \\
\text { (bilateral) }\end{array}$ \\
\hline Chi-cuadrado de Pearson & $401,518^{\mathrm{a}}$ & 4 &, 000 \\
Razón de verosimilitudes & 373,097 & 4 &, 000 \\
N de casos válidos & 1361 & & \\
\hline
\end{tabular}

a. 0 casillas $(, 0 \%)$ tienen una frecuencia esperada inferior a 5 . La frecuencia mínima esperada es 9,05 .

Tabla 11

\begin{tabular}{|l|c|c|c|}
\cline { 2 - 4 } \multicolumn{1}{c|}{} & \multicolumn{3}{c|}{ ÍNDICE DE KAPPA (TINTE) } \\
\cline { 2 - 4 } \multicolumn{1}{c|}{} & VALOR & ASE & L. INF 95\% - L. SUP. 95\% \\
\hline KAPPA SIMPLE & $\mathbf{0 . 4 3 3 7}$ & 0.0226 & $0.3895-0.4779$ \\
\hline KAPPA PONDERADO & 0.3800 & 0.0249 & $0.3312-0.488$ \\
\hline
\end{tabular}

Tabla 12

\subsubsection{2.-Intensidad}

La tabla 13, representa las coincidencias en intensidad entre el ojo humano y el espectrofotómetro. De nuevo se marca en negrita los porcentajes de coincidencia. Debajo aparece la significación por Chi2, y el valor del índice de Kappa en la tabla 14.

Como se puede comprobar, el grado de coincidencia es mejor en valores numéricos más pequeños: $20,4 \%$ en el valor 1 y $11,2 \%$ en el valor 1,5 . A partir de ahí, a medida que aumenta el cifra de la intensidad disminuyen las coincidencias (desde una 6,5\% hasta un 1,5\%). A pesar de algunos errores (los marcados en rojo) sólo en un caso 
mayor al 10\%, se encontró la existencia de una correlación altamente significativa, con $\mathrm{p}<0,05$, entre ambos métodos (Chi2=477,769; $16 \mathrm{gl} ; \mathrm{n}=1361 ; \mathrm{p}=, 000$ ). El grado de concordancia estimado según el método Kappa es de 0,36 (IC al 95\%: 0,32 - 0,39).

Tabla de contingencia intenobj * intensub

\begin{tabular}{|c|c|c|c|c|c|c|c|c|}
\hline \multicolumn{8}{|c|}{ intensub } & \multirow[b]{2}{*}{ Total } \\
\hline & & & 1,00 & 1,50 & 2,00 & 2,50 & 3,00 & \\
\hline \multirow[t]{15}{*}{ intenobj } & \multirow[t]{3}{*}{1,00} & Recuento & 278 & 26 & 47 & 8 & 5 & 364 \\
\hline & & $\%$ del total & $20,4 \%$ & $1,9 \%$ & $3,5 \%$ & ,6\% & ,4\% & $26,7 \%$ \\
\hline & & Residuos corregidos & 15,9 & $-7,2$ & $-6,2$ & $-5,6$ & $-3,2$ & \\
\hline & \multirow[t]{3}{*}{1,50} & Recuento & 181 & 152 & 118 & 26 & 5 & 482 \\
\hline & & $\%$ del total & $13,3 \%$ & $11,2 \%$ & $8,7 \%$ & $1,9 \%$ & ,4\% & $35,4 \%$ \\
\hline & & Residuos corregidos & $-2,0$ & 7,8 &,- 2 & $-3,9$ & $-4,4$ & \\
\hline & \multirow[t]{3}{*}{2,00} & Recuento & 66 & 63 & 88 & 48 & 11 & 276 \\
\hline & & $\%$ del total & $4,8 \%$ & $4,6 \%$ & $6,5 \%$ & $3,5 \%$ & ,8\% & $20,3 \%$ \\
\hline & & Residuos corregidos & $-6,5$ & 1,2 & 3,0 & 5,0 &,- 3 & \\
\hline & \multirow[t]{3}{*}{2,50} & Recuento & 27 & 25 & 51 & 37 & 16 & 156 \\
\hline & & $\%$ del total & $2,0 \%$ & $1,8 \%$ & $3,7 \%$ & $2,7 \%$ & $1,2 \%$ & $11,5 \%$ \\
\hline & & Residuos corregidos & $-6,4$ & $-1,4$ & 2,4 & 6,4 & 3,9 & \\
\hline & \multirow[t]{3}{*}{3,00} & Recuento & 9 & 8 & 34 & 11 & 21 & 83 \\
\hline & & $\%$ del total &, $7 \%$ &, $6 \%$ & $2,5 \%$ & ,8\% & $1,5 \%$ & $6,1 \%$ \\
\hline & & Residuos corregidos & $-5,8$ & $-2,5$ & 3,5 & 1,2 & 9,8 & \\
\hline \multirow{2}{*}{\multicolumn{2}{|c|}{ Total }} & Recuento & 561 & 274 & 338 & 130 & 58 & 1361 \\
\hline & & $\%$ del total & $41,2 \%$ & $20,1 \%$ & $24,8 \%$ & $9,6 \%$ & $4,3 \%$ & $100,0 \%$ \\
\hline
\end{tabular}

Pruebas de chi-cuadrado

\begin{tabular}{|l|c|c|c|}
\hline & Valor & gl & $\begin{array}{c}\text { Sig. asintótica } \\
\text { (bilateral) }\end{array}$ \\
\hline Chi-cuadrado de Pearson & $477,769^{\mathrm{a}}$ & 16 &, 000 \\
Razón de verosimilitudes & 437,557 & 16 &, 000 \\
Asociación lineal por lineal & 312,381 & 1 &, 000 \\
N de casos válidos & 1361 & & \\
\hline
\end{tabular}

a. 1 casillas $(4,0 \%)$ tienen una frecuencia esperada inferior a 5 . La frecuencia mínima esperada es 3,54 .

Tabla 13

\begin{tabular}{|c|c|c|c|}
\cline { 2 - 4 } \multicolumn{1}{c|}{} & \multicolumn{3}{c|}{ ÍNDICE DE KAPPA (INTENSIDAD) } \\
\cline { 2 - 4 } \multicolumn{1}{c|}{} & VALOR & ASE & L. INF 95\% - L. SUP. 95\% \\
\hline KAPPA SIMPLE & 0.2356 & 0.0166 & $0.2032-0.2680$ \\
\hline KAPPA PONDERADO & $\mathbf{0 . 3 5 7 8}$ & 0.0181 & $0.3223-0.3934$ \\
\hline
\end{tabular}

Tabla 14

Dado el carácter numérico de la intensidad, esta variable admite la posibilidad de ser contrastada cuantitativamente. Desde esa perspectiva podemos corroborar y completar el resultado de la prueba anterior con la utilización de otra técnica 
estadística. Debido al elevado número de casos de la muestra, nos podemos permitir sin riesgos el empleo de una prueba de tipo paramétrico; en concreto, nos planteamos realizar una prueba $\mathrm{T}$ de Student para datos pareados, con objeto de comprobar que no existen diferencias significativas entre las medias de los datos arrojados por ambas formas de medida.

Los resultados, ver tabla 15, nos indican que la media de las observaciones objetivas es de 1,67 (d.t. 0,58) mientras que la media de las subjetivas es de 1,58 (d.t. 0,59). Esta diferencia, de 0,09 unidades ha resultado estadísticamente significativa con una $\mathrm{p}<, 001$ (valor $\mathrm{t}=5,92 ; 1360 \mathrm{gl} ; \mathrm{p}=, 0000$ ). Sin embargo, es una diferencia apenas perceptible.

\begin{tabular}{|c|c|c|c|c|c|}
\hline & & Media & $\mathrm{N}$ & Desviación típ. & $\begin{array}{c}\text { Error típ. de la } \\
\text { media }\end{array}$ \\
\hline Par 1 & $\begin{array}{l}\text { intensub } \\
\text { intenobj }\end{array}$ & $\begin{array}{l}1,5775 \\
1,6738\end{array}$ & $\begin{array}{l}1361 \\
1361\end{array}$ & $\begin{array}{l}, 59227 \\
, 58262\end{array}$ & $\begin{array}{l}, 01605 \\
, 01579\end{array}$ \\
\hline
\end{tabular}

Prueba T de Student para muestras de datos pareados

\begin{tabular}{|c|c|c|c|c|c|c|c|c|}
\hline & \multicolumn{5}{|c|}{ Diferencias relacionadas } & \multirow[b]{3}{*}{$\mathrm{t}$} & \multirow[b]{3}{*}{$g l$} & \multirow{3}{*}{$\begin{array}{c}\text { Sig. } \\
\text { (bilateral) }\end{array}$} \\
\hline & \multirow[b]{2}{*}{ Media } & \multirow{2}{*}{$\begin{array}{c}\text { Desviación } \\
\text { típ. }\end{array}$} & \multirow{2}{*}{$\begin{array}{c}\text { Error típ. } \\
\text { de la } \\
\text { media }\end{array}$} & \multicolumn{2}{|c|}{$\begin{array}{c}95 \% \text { Intervalo de } \\
\text { confianza para la } \\
\text { diferencia }\end{array}$} & & & \\
\hline & & & & Inferior & Superior & & & \\
\hline $\begin{array}{ll}\text { Par intensub - } \\
1 & \text { intenobj }\end{array}$ &,- 09625 &, 59957 & ,01625 &,- 12813 &,- 06437 & $-5,923$ & 1360 & ,0000 \\
\hline
\end{tabular}

\section{Tabla 15}

\subsubsection{3.-Valor (Luminosidad)}

De forma semejante a lo que ocurría en intensidad y que se acaba de comentar, el grado de coincidencia es mejor en cifras más pequeñas: $8,5 \%$ en el valor $1,14,1 \%$ en el valor 2 y 9,4\% en el valor 3. A partir de ahí, a medida que aumenta el valor disminuyen las coincidencias, según muestra la tabla 16. A pesar de algunos errores, se encontró la existencia de una correlación altamente significativa para el valor entre ambos métodos, con $p<0,05$, entre ambos métodos (Chi2=2226,604; $40 \mathrm{gl} ; \mathrm{n}=1361$; $\mathrm{p}=, 000$ ). El grado de concordancia estimado según el método Kappa es de 0,66 (IC al $95 \%$ : 0,64 - 0,68). Que es como se aprecia en la tabla 17 , el dato más elevado de coincidencia de los tres analizados. 
Tabla de contingencia valorobj * valorsub

\begin{tabular}{|c|c|c|c|c|c|c|c|c|}
\hline & & & \multicolumn{5}{|c|}{ valorsub } & \multirow[b]{2}{*}{ Total } \\
\hline & & & 1 & 2 & 3 & 4 & 5 & \\
\hline \multirow[t]{33}{*}{ valorobj } & \multirow[t]{3}{*}{, 00} & Recuento & 3 & 0 & 0 & 0 & 0 & 3 \\
\hline & & $\%$ del total & ,2\% &, $0 \%$ &, $0 \%$ &, $0 \%$ &, $0 \%$ & ,2\% \\
\hline & & Residuos corregidos & 4,8 & $-1,3$ & $-1,1$ &,- 8 &,- 3 & \\
\hline & \multirow[t]{3}{*}{, 50} & Recuento & 0 & 1 & 0 & 0 & 0 & 1 \\
\hline & & $\%$ del total &, $0 \%$ &, $1 \%$ &, $0 \%$ &, $0 \%$ &, $0 \%$ &, $1 \%$ \\
\hline & & Residuos corregidos &,- 4 & 1,3 &,- 7 &,- 5 &,- 2 & \\
\hline & \multirow[t]{3}{*}{1,00} & Recuento & 116 & 81 & 1 & 0 & 0 & 198 \\
\hline & & $\%$ del total & $8,5 \%$ & $6,0 \%$ &, $1 \%$ &, $0 \%$ &, $0 \%$ & $14,5 \%$ \\
\hline & & Residuos corregidos & 22,6 & 1,4 & $-9,8$ & $-7,4$ & $-2,7$ & \\
\hline & \multirow[t]{3}{*}{1,50} & Recuento & 25 & 71 & 4 & 0 & 0 & 100 \\
\hline & & $\%$ del total & $1,8 \%$ & $5,2 \%$ & ,3\% &, $0 \%$ &, $0 \%$ & $7,3 \%$ \\
\hline & & Residuos corregidos & 4,5 & 7,4 & $-5,9$ & $-5,0$ & $-1,9$ & \\
\hline & \multirow[t]{3}{*}{2,00} & Recuento & 10 & 192 & 40 & 2 & 0 & 244 \\
\hline & & $\%$ del total & ,7\% & $14,1 \%$ & $2,9 \%$ &, $1 \%$ &, $0 \%$ & $17,9 \%$ \\
\hline & & Residuos corregidos & $-4,0$ & 15,1 & $-5,1$ & $-8,0$ & $-3,1$ & \\
\hline & \multirow[t]{3}{*}{2,50} & Recuento & 0 & 104 & 95 & 2 & 0 & 201 \\
\hline & & $\%$ del total &, $0 \%$ & $7,6 \%$ & $7,0 \%$ &, $1 \%$ &, $0 \%$ & $14,8 \%$ \\
\hline & & Residuos corregidos & $-5,5$ & 4,9 & 5,9 & $-7,1$ & $-2,8$ & \\
\hline & \multirow[t]{3}{*}{3,00} & Recuento & 1 & 35 & 128 & 27 & 0 & 191 \\
\hline & & $\%$ del total &, $1 \%$ & $2,6 \%$ & $9,4 \%$ & $2,0 \%$ &, $0 \%$ & $14,0 \%$ \\
\hline & & Residuos corregidos & $-5,1$ & $-5,6$ & 12,1 & $-1,9$ & $-2,7$ & \\
\hline & \multirow[t]{3}{*}{3,50} & Recuento & 0 & 12 & 118 & 62 & 0 & 192 \\
\hline & & $\%$ del total &, $0 \%$ &, $9 \%$ & $8,7 \%$ & $4,6 \%$ &, $0 \%$ & $14,1 \%$ \\
\hline & & Residuos corregidos & $-5,4$ & $-9,4$ & 10,3 & 5,0 & $-2,7$ & \\
\hline & \multirow[t]{3}{*}{4,00} & Recuento & 0 & 1 & 18 & 65 & 3 & 87 \\
\hline & & $\%$ del total &, $0 \%$ &, $1 \%$ & $1,3 \%$ & $4,8 \%$ &, $2 \%$ & $6,4 \%$ \\
\hline & & Residuos corregidos & $-3,5$ & $-7,1$ & $-1,9$ & 13,6 & ,2 & \\
\hline & \multirow[t]{3}{*}{4,50} & Recuento & 0 & 0 & 2 & 90 & 16 & 108 \\
\hline & & $\%$ del total &, $0 \%$ &, $0 \%$ &, $1 \%$ & $6,6 \%$ & $1,2 \%$ & $7,9 \%$ \\
\hline & & Residuos corregidos & $-3,9$ & $-8,2$ & $-6,6$ & 17,7 & 7,2 & \\
\hline & \multirow[t]{3}{*}{5,00} & Recuento & 0 & 0 & 0 & 12 & 24 & 36 \\
\hline & & $\%$ del total &, $0 \%$ &, $0 \%$ &, $0 \%$ &, $9 \%$ & $1,8 \%$ & $2,6 \%$ \\
\hline & & Residuos corregidos & $-2,2$ & $-4,6$ & $-4,0$ & 2,2 & 22,1 & \\
\hline \multirow{2}{*}{\multicolumn{2}{|c|}{ Total }} & Recuento & 155 & 497 & 406 & 260 & 43 & 1361 \\
\hline & & $\%$ del total & $11,4 \%$ & $36,5 \%$ & $29,8 \%$ & $19,1 \%$ & $3,2 \%$ & $100,0 \%$ \\
\hline
\end{tabular}

Pruebas de chi-cuadrado

\begin{tabular}{|l|c|c|c|}
\hline & Valor & gl & $\begin{array}{c}\text { Sig. asintótica } \\
\text { (bilateral) }\end{array}$ \\
\hline Chi-cuadrado de Pearson & $2226,604^{\mathrm{a}}$ & 40 &, 000 \\
Razón de verosimilitudes & 1835,642 & 40 &, 000 \\
Asociación lineal por lineal & 1008,655 & 1 &, 000 \\
N de casos válidos & 1361 & & \\
\hline
\end{tabular}

a. 15 casillas $(27,3 \%)$ tienen una frecuencia esperada inferior a 5 . La frecuencia mínima esperada es, 03 .

Tabla 16 


\begin{tabular}{|c|c|c|c|}
\cline { 2 - 4 } \multicolumn{1}{c|}{} & \multicolumn{3}{c|}{ ÍNDICE DE KAPPA (VALOR) } \\
\cline { 2 - 4 } \multicolumn{1}{c|}{} & VALOR & ASE & L. INF 95\% - L. SUP. 95\% \\
\hline KAPPA SIMPLE & 0.2883 & 0.0134 & $0.2619-0.3146$ \\
\hline KAPPA PONDERADO & $\mathbf{0 . 6 5 8 7}$ & 0.0103 & $0.6389-0.6789$ \\
\hline
\end{tabular}

Tabla 17

De la misma forma que con la intensidad, el carácter numérico del valor también nos permite realizar el mismo doble análisis anterior. Es decir que nos planteamos otra prueba $\mathrm{T}$ de Student de diferencia entre medias para comprobar si existe o no una diferencia que sea estadísticamente significativa.

Los resultados, ver tabla 18, nos indican que la media de los valores objetivos es de 2,643 (d.t. 1,12) mientras que la media de los subjetivos es de 2,660 (d.t. 1,01). Esta diferencia, de apenas 0,017 unidades no ha resultado ser estadísticamente significativa con una $p>, 05$ (valor $t=1,14 ; 1360 \mathrm{gl} ; \mathrm{p}=, 2535$ ). En consecuencia no existen diferencias entre ambas mediciones.

\begin{tabular}{|c|c|c|c|c|c|}
\hline & & Media & $\mathrm{N}$ & Desviación típ. & $\begin{array}{l}\text { Error típ. de la } \\
\text { media }\end{array}$ \\
\hline Par 1 & $\begin{array}{l}\text { valorsub } \\
\text { valorobj }\end{array}$ & $\begin{array}{l}2,6600 \\
2,6436\end{array}$ & $\begin{array}{l}1361 \\
1361\end{array}$ & $\begin{array}{l}1,01200 \\
1,11595\end{array}$ & $\begin{array}{r}, 027 \\
, 03025\end{array}$ \\
\hline
\end{tabular}

Prueba T de Student para muestras de datos pareados

\begin{tabular}{|c|c|c|c|c|c|c|c|c|}
\hline & \multicolumn{5}{|c|}{ Diferencias relacionadas } & \multirow[b]{3}{*}{$t$} & \multirow[b]{3}{*}{$\mathrm{gl}$} & \multirow{3}{*}{$\begin{array}{c}\text { Sig. } \\
\text { (bilateral) }\end{array}$} \\
\hline & \multirow[b]{2}{*}{ Media } & \multirow{2}{*}{$\begin{array}{l}\text { Desviación } \\
\text { típ. }\end{array}$} & \multirow{2}{*}{$\begin{array}{l}\text { Error típ. } \\
\text { de la } \\
\text { media }\end{array}$} & \multicolumn{2}{|c|}{$\begin{array}{c}95 \% \text { Intervalo de } \\
\text { confianza para la } \\
\text { diferencia }\end{array}$} & & & \\
\hline & & & & Inferior & Superior & & & \\
\hline $\begin{array}{ll}\text { Par } & \text { valorsub - } \\
1 & \text { valorobj }\end{array}$ & ,01763 & ,56949 & ,01544 &,- 01265 & ,04792 & 1,142 & 1360 & ,2535 \\
\hline
\end{tabular}

Tabla 18

\subsection{2.- Relativo a Coincidencias en Medios}

La próxima tabla, tabla 19, representa a los menores de treinta años separados por sexos.

Vamos a comparar las coincidencias absolutas del color, con las diferentes en medio puntos y haciendo referencias en las tablas a las coincidencias totales para la intensidad y el valor. Es decir, en aquellos colores que no representan las 26 guía 3D Master, pero que si que aporta el espectrofotómetro, con lo cual es imposible coincidir. 
Las coincidencias absolutas de color, es decir, coincidencia en valor, tinte e intensidad, aparecieron en un $21.35 \%$ en hombres y un $24.42 \%$ en mujeres en el grupo de edad de menores de treinta años.

Las no coincidencias en medio punto, para el valor en hombres se registraron un $33.00 \%$ y en mujeres un $21.28 \%$. Porcentajes ligeramente más altos se reflejan en intensidad, siendo para hombres un $42.23 \%$ y para mujeres un $38.95 \%$.

\begin{tabular}{|c|c|c|c|c|c|}
\hline \multicolumn{6}{|c|}{ COINCIDENCIAS } \\
\hline \multicolumn{3}{|c|}{ Hombres $<30$ años } & \multicolumn{3}{|c|}{ Mujeres $<30$ años } \\
\hline & Frecuencia & Porcentaje & & Frecuencia & Porcentaje \\
\hline C. Absolutas & 44 & 21.35 & C. Absolutas & 53 & 24.42 \\
\hline C Valor & 97 & 47.08 & C Valor & 117 & 53.91 \\
\hline C. Intensidad & 78 & 37.86 & C. Intensidad & 90 & 41.47 \\
\hline C. Tinte & 154 & 74.75 & C. Tinte & 175 & 80.64 \\
\hline C. Valor $1 / 2$ & 68 & 33.00 & C. Valor $1 / 2$ & 53 & 21.28 \\
\hline C. Intensidad $1 / 2$ & 87 & 42.23 & C. Intensidad $1 / 2$ & 97 & 38.95 \\
\hline
\end{tabular}

Tabla 19

En el grupo de edad intermedia, las coincidencias absolutas de color, es decir, coincidencia en valor, tinte e intensidad, fueron 42 representando un $17.72 \%$ en hombres y 54 representando un $21.68 \%$ en mujeres. Las coincidencias en medio punto del valor fueron 119 (50.21\%), y en tinte fueron 84 (35.44\%) para hombres. Es decir el $50.21 \%$ de la discrepancia del método subjetivo con el método objetivo del valor en hombres de edad intermedia se debió a cambios en medio punto.

\begin{tabular}{|c|c|c|c|c|c|}
\hline \multicolumn{6}{|c|}{ COINCIDENCIAS } \\
\hline \multicolumn{3}{|c|}{ Hombres 30-59 años } & \multicolumn{3}{|c|}{ Mujeres $30-59$ años } \\
\hline & Frecuencia & Porcentaje & & Frecuencia & Porcentaje \\
\hline C. Absolutas & 42 & 17.72 & C. Absolutas & 54 & 21.68 \\
\hline C Valor & 85 & 35.86 & C Valor & 87 & 34.93 \\
\hline C. Intensidad & 105 & 44.30 & C. Intensidad & 129 & 51.80 \\
\hline C. Tinte & 163 & 68.77 & C. Tinte & 180 & 72.28 \\
\hline C. Valor $1 / 2$ & 119 & 50.21 & C. Valor $1 / 2$ & 102 & 40.96 \\
\hline C. Intensidad $1 / 2$ & 84 & 35.44 & C. Intensidad $1 / 2$ & 78 & 31.32 \\
\hline
\end{tabular}

\section{Tabla 20}

Y por último queda expuesto el grupo de edad más avanzada, tabla 21, similar a grupo anterior, el $54.38 \%$ de las diferencias de registro entre el método objetivo y el método subjetivo se debió a diferencias de medio punto para el valor, esta vez en hombres mayores de sesenta años. 
En mujeres las coincidencias absolutas obtuvieron un resultado de 33 (14.73\%). Las no coincidencias en intensidad en medio punto alcanzaron porcentajes similares tanto en hombres (39.47\%) como en mujeres (35.71\%).

\begin{tabular}{|c|c|c|c|c|c|}
\hline \multicolumn{6}{|c|}{ COINCIDENCIAS } \\
\hline \multicolumn{3}{|c|}{ Hombres $\geq 60$ años } & \multicolumn{3}{|c|}{ Mujeres $\geq 60$ años } \\
\hline & Frecuencia & Porcentaje & & Frecuencia & Porcentaje \\
\hline C. Absolutas & 24 & 10.52 & C. Absolutas & 33 & 14.73 \\
\hline C Valor & 70 & 30.70 & C Valor & 69 & 30.80 \\
\hline C. Intensidad & 76 & 33.33 & C. Intensidad & 98 & 43.75 \\
\hline C. Tinte & 169 & 74.12 & C. Tinte & 152 & 67.85 \\
\hline C. Valor $1 / 2$ & 124 & 54.38 & C. Valor $1 / 2$ & 105 & 46.87 \\
\hline C. Intensidad $1 / 2$ & 90 & 39.47 & C. Intensidad $1 / 2$ & 80 & 35.71 \\
\hline
\end{tabular}

Tabla 21

Las coincidencias de color totales en la población de hombres, coincidencias en tinte, valor e intensidad, alcanzaron un número de 110, es decir un porcentaje sobre el total de la población masculina de $16.40 \%$. En la población total de mujeres, se coincidió plenamente en el color en un $20.29 \%$. El porcentaje de coincidencias absolutas entre ambos métodos en el color de la población total es de $18.37 \%$, coincidencias absolutas en valor, intensidad y tinte.

A continuación analizamos las coincidencias exactas en el valor, para hombres y para mujeres. Las coincidencias absolutas en el valor fueron 252 para los hombres y 273 para las mujeres, una suma de 525 sujetos. A esta cifra se le asocia un porcentaje con respecto a la población total de $38.58 \%$. Con respecto a la intensidad el número de coincidencias absolutas fue para los hombres de 259 y para las mujeres de 317 , suman 576 , y hacen un porcentaje con respecto a la población total de $42.32 \%$.

Vamos a analizar las coincidencias en medio punto del valor y de la intensidad. Las coincidencias en medio punto del valor fueron de 315 hombres y 260 mujeres, sumadas a las coincidencias absolutas hacen un total de 1100 , con un porcentaje con respecto a la población total de $80.82 \%$. De forma análoga estudiamos la intensidad, las coincidencias en medio punto son para los hombres de 261 y para las mujeres de 255 , sumadas a las coincidencias absolutas hacen un total de 1092, y representan un porcentaje de $80.24 \%$. 
5.3.- ASOCIACIÓN ENTRE VALOR, EL TINTE LA INTENSIDAD OBJETIVAS CON LOS GRUPOS DE EDAD Y GÉNERO

Para poder conseguir este objetivo, empleamos nuevamente el test estadístico no paramétrico $\mathrm{Chi}^{2}$. A continuación vamos a reflejar en las siguientes tablas los valores de la muestra total según, luminosidad o valor, tinte e intensidad: Primero lo analizamos en función de la edad, posteriormente repetiremos el análisis en función del sexo.

\subsubsection{Valor (Luminosidad)}

\subsubsection{1.- Valor-Grupos de edad}

Como se observa en la tabla siguiente (tabla 22), existe correlación altamente significativa con $\mathrm{p}<, 05$ entre los grupos de edad establecidos y el valor objetivo (valor de Chi2=702,277; $20 \mathrm{gl} ; \mathrm{n}=1361, \mathrm{p}=, 000$ ). Debajo, en la tabla de contingencia, vemos cómo se asocian. Así, al grupo de edad de menores de 30 años, se les asocian los valores entre el 0 y el 1,5 (y en algún caso hasta el 2). El 2 es un valor dudoso en el sentido de que está asociado a 2 categorías de edad, a los anteriores y a los del grupo entre 30 y 59 años, por lo que es un como un punto de corte, pero que se asocia a ambas edades. Al grupo de 30 a 59 años se le asocian los valores desde 2 a 3,5 sin embargo solo el valor 2,5 es característico de esta edad. Igual que comparte el valor con los menores de 30, y comparte los valores 3 y 3,5 con los mayores de 59 años. Para este último grupo, quedan en exclusiva los valores del 4 al 5 . En conclusión, cuanto mayor es la edad de las personas, mayor es esta dimensión del color: hasta 1,5 en jóvenes, del 2 al 3,5 en personas de mediana edad y desde el 4 para personas mayores.

\begin{tabular}{|l|c|c|c|}
\hline \multicolumn{1}{|c|}{ Pruebas de chi-cuadrado } \\
\hline Chi-cuadrado de Pearson & Valor & gl & $\begin{array}{c}\text { Sig. asintótica } \\
\text { (bilateral) }\end{array}$ \\
Razón de verosimilitudes & $\mathbf{7 0 2 , 2 7 7 ^ { \mathbf { a } }}$ & $\mathbf{2 0}$ &, $\mathbf{0 0 0}$ \\
Asociación lineal por lineal & 774,224 & 20 &, 000 \\
N de casos válidos & 571,454 & 1 &, 000 \\
\hline
\end{tabular}

a. 6 casillas $(18,2 \%)$ tienen una frecuencia esperada inferior a 5 . La frecuencia mínima esperada es, 31 . 
RESULTADOS

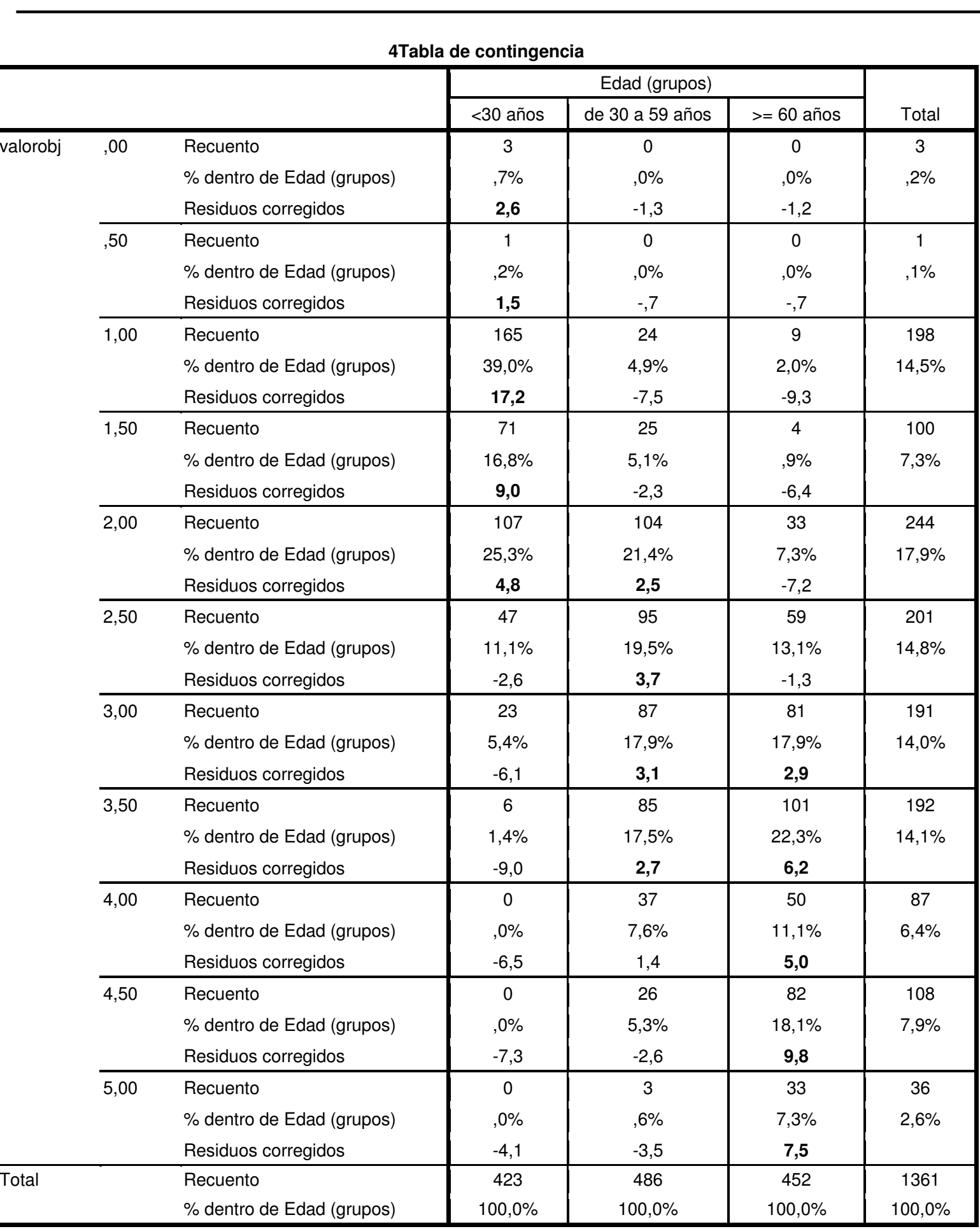

Tabla 22

\subsubsection{2.-Valor - Sexo}

Repetimos el análisis anterior, pero ahora separando a los personas por género. Se mantiene la significación de la correlación anteriormente comentada, con $p<0,05$ en cada uno de los sexos; con un peso muy similar en ambos (se aprecia porque el valor del Chi2 es parecido; en hombres: 406,036; $18 \mathrm{gl} n=671 ; \mathrm{p}=, 000$ y en mujeres: 334,$831 ; 20 \mathrm{gl} ; n=690 ; p=, 000$ ). 
Estudiando la tabla de contingencia 23, observamos que en hombres, menores de 30 años aparecen fundamentalmente valores hasta el 2 incluido (pequeña diferencia con la muestra total); entre 30 y 59 años con valores entre 2,5 y 3; los valores 3,5 y 4 están entre grupo de edad y los mayores; y en mayores de 59 años valores del 4 al 5.

En mujeres varía ligeramente. Las mujeres menores de 30 años con valores hasta 1,5 incluido; las de 30 a 59 años con valores sólo desde el 2 hasta el 2,5; y para las mayores de 59 años valores desde 3 al 5.

\begin{tabular}{|c|c|c|c|c|}
\hline \multicolumn{5}{|c|}{ Pruebas de chi-cuadrado } \\
\hline \multicolumn{2}{|l|}{ SEXO } & Valor & $\mathrm{gl}$ & $\begin{array}{l}\text { Sig. asintótica } \\
\text { (bilateral) }\end{array}$ \\
\hline \multirow[t]{4}{*}{ Hombre } & Chi-cuadrado de Pearson & $406,036^{a}$ & 18 & ,000 \\
\hline & Razón de verosimilitudes & 449,284 & 18 &, 000 \\
\hline & Asociación lineal por lineal & 312,498 & 1 & ,000 \\
\hline & $\mathrm{N}$ de casos válidos & 671 & & \\
\hline \multirow[t]{4}{*}{ Mujer } & Chi-cuadrado de Pearson & $334,831^{b}$ & 20 & ,000 \\
\hline & Razón de verosimilitudes & 364,966 & 20 & ,000 \\
\hline & Asociación lineal por lineal & 276,233 & 1 &, 000 \\
\hline & $\mathrm{N}$ de casos válidos & 690 & & \\
\hline
\end{tabular}

Tabla de contingencia

\begin{tabular}{|c|c|c|c|c|c|c|}
\hline \multirow[b]{2}{*}{ SEXO } & & & \multicolumn{3}{|c|}{ Edad (grupos) } & \multirow[b]{2}{*}{ Total } \\
\hline & & & $<30$ años & de 30 a 59 años & $>=60$ años & \\
\hline \multirow[t]{21}{*}{ Hombre valorobj } & 00 & Recuento & 2 & 0 & 0 & 2 \\
\hline & & $\%$ dentro de Edad (grupos) & $1,0 \%$ &, $0 \%$ &, $0 \%$ &, $3 \%$ \\
\hline & & Residuos corregidos & 2,1 & $-1,0$ & $-1,0$ & \\
\hline & 1,00 & Recuento & 68 & 5 & 5 & 78 \\
\hline & & $\%$ dentro de Edad (grupos) & $33,0 \%$ & $2,1 \%$ & $2,2 \%$ & $11,6 \%$ \\
\hline & & Residuos corregidos & 11,5 & $-5,7$ & $-5,5$ & \\
\hline & 1,50 & Recuento & 38 & 6 & 1 & 45 \\
\hline & & $\%$ dentro de Edad (grupos) & $18,4 \%$ & $2,5 \%$ &, $4 \%$ & $6,7 \%$ \\
\hline & & Residuos corregidos & 8,1 & $-3,2$ & $-4,7$ & \\
\hline & 2,00 & Recuento & 54 & 33 & 8 & 95 \\
\hline & & $\%$ dentro de Edad (grupos) & $26,2 \%$ & $13,9 \%$ & $3,5 \%$ & $14,2 \%$ \\
\hline & & Residuos corregidos & 6,0 &,- 1 & $-5,7$ & \\
\hline & 2,50 & Recuento & 28 & 45 & 20 & 93 \\
\hline & & $\%$ dentro de Edad (grupos) & $13,6 \%$ & $19,0 \%$ & $8,8 \%$ & $13,9 \%$ \\
\hline & & Residuos corregidos &,- 1 & 2,8 & $-2,7$ & \\
\hline & 3,00 & Recuento & 12 & 46 & 32 & 90 \\
\hline & & $\%$ dentro de Edad (grupos) & $5,8 \%$ & $19,4 \%$ & $14,0 \%$ & $13,4 \%$ \\
\hline & & Residuos corregidos & $-3,8$ & 3,4 & ,3 & \\
\hline & 3,50 & Recuento & 4 & 51 & 51 & 106 \\
\hline & & $\%$ dentro de Edad (grupos) & $1,9 \%$ & $21,5 \%$ & $22,4 \%$ & $15,8 \%$ \\
\hline & & Residuos corregidos & $-6,5$ & 3,0 & 3,3 & \\
\hline
\end{tabular}


RESULTADOS

\begin{tabular}{|c|c|c|c|c|c|c|c|}
\hline & & 4,00 & $\begin{array}{l}\text { Recuento } \\
\% \text { dentro de Edad (grupos) } \\
\text { Residuos corregidos }\end{array}$ & $\begin{array}{c}0 \\
, 0 \% \\
-5,4\end{array}$ & $\begin{array}{c}28 \\
11,8 \% \\
\mathbf{1 , 9}\end{array}$ & $\begin{array}{c}32 \\
14,0 \% \\
\mathbf{3 , 3}\end{array}$ & $\begin{array}{c}60 \\
8,9 \%\end{array}$ \\
\hline & & 4,50 & $\begin{array}{l}\text { Recuento } \\
\text { \% dentro de Edad (grupos) } \\
\text { Residuos corregidos }\end{array}$ & $\begin{array}{c}0 \\
, 0 \% \\
-6,1\end{array}$ & $\begin{array}{c}20 \\
8,4 \% \\
-1,6\end{array}$ & $\begin{array}{c}54 \\
23,7 \% \\
7,5\end{array}$ & $\begin{array}{c}74 \\
11,0 \%\end{array}$ \\
\hline & & 5,00 & $\begin{array}{l}\text { Recuento } \\
\text { \% dentro de Edad (grupos) } \\
\text { Residuos corregidos }\end{array}$ & $\begin{array}{c}0 \\
, 0 \% \\
-3,6\end{array}$ & $\begin{array}{c}3 \\
1,3 \% \\
-2,8\end{array}$ & $\begin{array}{c}25 \\
11,0 \% \\
6,3\end{array}$ & $\begin{array}{c}28 \\
4,2 \%\end{array}$ \\
\hline & Total & & $\begin{array}{l}\text { Recuento } \\
\% \text { dentro de Edad (grupos) }\end{array}$ & $\begin{array}{c}206 \\
100,0 \%\end{array}$ & $\begin{array}{c}237 \\
100,0 \%\end{array}$ & $\begin{array}{c}228 \\
100,0 \%\end{array}$ & $\begin{array}{c}671 \\
100,0 \%\end{array}$ \\
\hline \multirow[t]{12}{*}{ Mujer } & valorobj &, 00 & $\begin{array}{l}\text { Recuento } \\
\% \text { dentro de Edad (grupos) } \\
\text { Residuos corregidos }\end{array}$ & $\begin{array}{c}1 \\
, 5 \% \\
1,5\end{array}$ & $\begin{array}{c}0 \\
, 0 \% \\
-, 8\end{array}$ & $\begin{array}{c}0 \\
, 0 \% \\
-, 7\end{array}$ & $\begin{array}{c}1 \\
, 1 \%\end{array}$ \\
\hline & &, 50 & $\begin{array}{l}\text { Recuento } \\
\text { \% dentro de Edad (grupos) } \\
\text { Residuos corregidos }\end{array}$ & $\begin{array}{c}1 \\
, 5 \% \\
1,5 \\
\end{array}$ & $\begin{array}{c}0 \\
, 0 \% \\
-, 8\end{array}$ & $\begin{array}{c}0 \\
, 0 \% \\
-, 7 \\
\end{array}$ & $\begin{array}{c}1 \\
, 1 \%\end{array}$ \\
\hline & & 1,00 & $\begin{array}{l}\text { Recuento } \\
\text { \% dentro de Edad (grupos) } \\
\text { Residuos corregidos }\end{array}$ & $\begin{array}{c}97 \\
44,7 \% \\
12,8\end{array}$ & $\begin{array}{c}19 \\
7,6 \% \\
-5,1\end{array}$ & $\begin{array}{c}4 \\
1,8 \% \\
-7,5\end{array}$ & $\begin{array}{c}120 \\
17,4 \%\end{array}$ \\
\hline & & 1,50 & $\begin{array}{l}\text { Recuento } \\
\text { \% dentro de Edad (grupos) } \\
\text { Residuos corregidos }\end{array}$ & $\begin{array}{c}33 \\
15,2 \% \\
\mathbf{4 , 8}\end{array}$ & $\begin{array}{c}19 \\
7,6 \% \\
-, 2\end{array}$ & $\begin{array}{c}3 \\
1,3 \% \\
-4,5\end{array}$ & $\begin{array}{c}55 \\
8,0 \%\end{array}$ \\
\hline & & 2,00 & $\begin{array}{l}\text { Recuento } \\
\text { \% dentro de Edad (grupos) } \\
\text { Residuos corregidos }\end{array}$ & $\begin{array}{c}53 \\
24,4 \% \\
1,2\end{array}$ & $\begin{array}{c}71 \\
28,5 \% \\
3,3\end{array}$ & $\begin{array}{c}25 \\
11,2 \% \\
-4,6\end{array}$ & $\begin{array}{c}149 \\
21,6 \%\end{array}$ \\
\hline & & 2,50 & $\begin{array}{l}\text { Recuento } \\
\% \text { dentro de Edad (grupos) } \\
\text { Residuos corregidos }\end{array}$ & $\begin{array}{c}19 \\
8,8 \% \\
-3,4\end{array}$ & $\begin{array}{c}50 \\
20,1 \% \\
\mathbf{2 , 4}\end{array}$ & $\begin{array}{c}39 \\
17,4 \% \\
, 9\end{array}$ & $\begin{array}{c}108 \\
15,7 \%\end{array}$ \\
\hline & & 3,00 & $\begin{array}{l}\text { Recuento } \\
\text { \% dentro de Edad (grupos) } \\
\text { Residuos corregidos }\end{array}$ & $\begin{array}{c}11 \\
5,1 \% \\
-4,8 \\
\end{array}$ & $\begin{array}{c}41 \\
16,5 \% \\
1,0 \\
\end{array}$ & $\begin{array}{c}49 \\
21,9 \% \\
3,7 \\
\end{array}$ & $\begin{array}{c}101 \\
14,6 \%\end{array}$ \\
\hline & & 3,50 & $\begin{array}{l}\text { Recuento } \\
\text { \% dentro de Edad (grupos) } \\
\text { Residuos corregidos }\end{array}$ & $\begin{array}{c}2 \\
, 9 \% \\
-6,2 \\
\end{array}$ & $\begin{array}{c}34 \\
13,7 \% \\
, 7 \\
\end{array}$ & $\begin{array}{c}50 \\
22,3 \% \\
\mathbf{5 , 4} \\
\end{array}$ & $\begin{array}{c}86 \\
12,5 \%\end{array}$ \\
\hline & & 4,00 & $\begin{array}{l}\text { Recuento } \\
\text { \% dentro de Edad (grupos) } \\
\text { Residuos corregidos }\end{array}$ & $\begin{array}{c}0 \\
, 0 \% \\
-3,6 \\
\end{array}$ & $\begin{array}{c}9 \\
3,6 \% \\
-, 3 \\
\end{array}$ & $\begin{array}{c}18 \\
8,0 \% \\
3,9 \\
\end{array}$ & $\begin{array}{c}27 \\
3,9 \%\end{array}$ \\
\hline & & 4,50 & $\begin{array}{l}\text { Recuento } \\
\text { \% dentro de Edad (grupos) } \\
\text { Residuos corregidos }\end{array}$ & $\begin{array}{c}0 \\
, 0 \% \\
-4,1\end{array}$ & $\begin{array}{c}6 \\
2,4 \% \\
-2,3 \\
\end{array}$ & $\begin{array}{c}28 \\
12,5 \% \\
6,4\end{array}$ & $\begin{array}{c}34 \\
4,9 \%\end{array}$ \\
\hline & & 5,00 & $\begin{array}{l}\text { Recuento } \\
\text { \% dentro de Edad (grupos) } \\
\text { Residuos corregidos }\end{array}$ & $\begin{array}{c}0 \\
, 0 \% \\
-1,9\end{array}$ & $\begin{array}{c}0 \\
, 0 \% \\
-2,1\end{array}$ & $\begin{array}{c}8 \\
3,6 \% \\
\mathbf{4 , 1}\end{array}$ & $\begin{array}{c}8 \\
1,2 \%\end{array}$ \\
\hline & Total & & $\begin{array}{l}\text { Recuento } \\
\% \text { dentro de Edad (grupos) }\end{array}$ & $\begin{array}{c}217 \\
100,0 \%\end{array}$ & $\begin{array}{c}249 \\
100,0 \%\end{array}$ & $\begin{array}{c}224 \\
100,0 \%\end{array}$ & $\begin{array}{c}690 \\
100,0 \%\end{array}$ \\
\hline
\end{tabular}

Tabla 23 


\subsection{2.- Tinte}

\subsubsection{1.- Tinte- Grupos edad}

Como se observa en la tabla 24 , existe correlación altamente significativa con $p<, 05$ entre los grupos de edad establecidos y el tinte objetivo (valor de Chi2=31,576; $4 \mathrm{gl}$; $n=1361, p=, 000)$. En la tabla de contingencia inferior observamos cómo se asocian.

En la tabla de contingencia vemos cómo se asocian. El tinte $\mathrm{M}$ se asocia más con los jóvenes (<30 años); mientras que el tinte $L$ ó $R$ que son bastante menos comunes, se asocian a los de media edad. Y cualquiera de los 3 se puede presentar en los de mayor edad. Señalar que como hemos visto anteriormente en el gráfico 1 de barras sobre el tinte objetivo, el tinte $\mathrm{M}$ es el más numeroso de la muestra.

\begin{tabular}{|c|c|c|c|}
\hline \multicolumn{1}{|c|}{ Pruebas de chi-cuadrado } \\
\hline Chi-cuadrado de Pearson & Valor & gl & Sig. asintótica (bilateral) \\
Razón de verosimilitudes & $\mathbf{3 1 , 5 7 6 ^ { \mathrm { a } }}$ & $\mathbf{4}$ &, $\mathbf{0 0 0}$ \\
$\mathrm{N}$ de casos válidos & 32,835 & 4 &, 000 \\
\hline
\end{tabular}

a. 0 casillas (,0\%) tienen una frecuencia esperada inferior a 5 . La frecuencia mínima esperada es 35,43.

\begin{tabular}{|c|c|c|c|c|c|c|}
\hline & & & \multicolumn{3}{|c|}{ Edad (grupos) } & \multirow[b]{2}{*}{ Total } \\
\hline & & & $<30$ años & de 30 a 59 años & $>=60$ años & \\
\hline \multirow[t]{9}{*}{ tinteobj } & $\mathrm{L}$ & Recuento & 90 & 147 & 122 & 359 \\
\hline & & $\%$ dentro de Edad (grupos) & $21,3 \%$ & $30,2 \%$ & $27,0 \%$ & $26,4 \%$ \\
\hline & & Residuos corregidos & $-2,9$ & 2,4 & ,4 & \\
\hline & M & Recuento & 315 & 282 & 291 & 888 \\
\hline & & $\%$ dentro de Edad (grupos) & $74,5 \%$ & $58,0 \%$ & $64,4 \%$ & $65,2 \%$ \\
\hline & & Residuos corregidos & 4,8 & $-4,2$ &,- 5 & \\
\hline & $\mathrm{R}$ & Recuento & 18 & 57 & 39 & 114 \\
\hline & & $\%$ dentro de Edad (grupos) & $4,3 \%$ & $11,7 \%$ & $8,6 \%$ & $8,4 \%$ \\
\hline & & Residuos corregidos & $-3,7$ & 3,3 & ,2 & \\
\hline \multirow[t]{2}{*}{ Total } & & Recuento & 423 & 486 & 452 & 1361 \\
\hline & & $\%$ dentro de Edad (grupos) & $100,0 \%$ & $100,0 \%$ & $100,0 \%$ & $100,0 \%$ \\
\hline
\end{tabular}

Tabla 24

\subsubsection{2.- Tinte-Sexo}

Si ahora revisamos éste análisis por sexos, se comprueba que sigue existiendo una correlación altamente significativa con $p<0,05$. $p<, 05$ entre los grupos de edad establecidos y el tinte objetivo (Hombres, valor de Chi2=19,211; $4 \mathrm{gl}$; $=671, p=, 001$ y Mujeres valor de Chi2=26,616; $4 \mathrm{gl} ; n=690 ; p=, 000$ ). 
Analizando la tabla de contingencia 25, presentada para valorar la influencia de los sexos sobre el tinte, podemos destacar lo siguiente: en hombres, el tinte con el que existe mayor relación en menores de treinta años, al igual que en la muestra total es el tinte $\mathrm{M}$. Con respecto al grupo de mediana edad, el tinte con el que la relación es más evidente, es el tinte L, es decir, más amarillentos. En mujeres, de nuevo cambia. El tinte $\mathrm{M}$ sigue siendo característico de los menores de 30 años. Mientras que el tinte $\mathrm{R}$ está más relacionado en edades intermedias, y en mayores de sesenta años. El tinte L no se asocia con ningún grupo de edad.

\section{Pruebas de chi-cuadrado}

\begin{tabular}{|ll|c|c|c|}
\hline SEXO & & Valor & gl & $\begin{array}{c}\text { Sig. asintótica } \\
\text { (bilateral) }\end{array}$ \\
\hline Hombre & Chi-cuadrado de Pearson & $\mathbf{1 9 , 2 1 1 ^ { \mathbf { a } }}$ & $\mathbf{4}$ &, $\mathbf{0 0 1}$ \\
& Razón de verosimilitudes & 19,004 & 4 &, 001 \\
& N de casos válidos & 671 & & \\
\hline Mujer & Chi-cuadrado de Pearson & $\mathbf{2 6 , 6 1 6 ^ { \mathbf { b } }}$ & $\mathbf{4}$ &, $\mathbf{0 0 0}$ \\
& Razón de verosimilitudes & 33,138 & 4 &, 000 \\
& N de casos válidos & 690 & & \\
\hline
\end{tabular}

a. 0 casillas $(, 0 \%)$ tienen una frecuencia esperada inferior a 5. La frecuencia mínima esperada es 19,65 .

b. 0 casillas $(, 0 \%)$ tienen una frecuencia esperada inferior a 5 . La frecuencia mínima esperada es 15,72 .

Tabla de contingencia

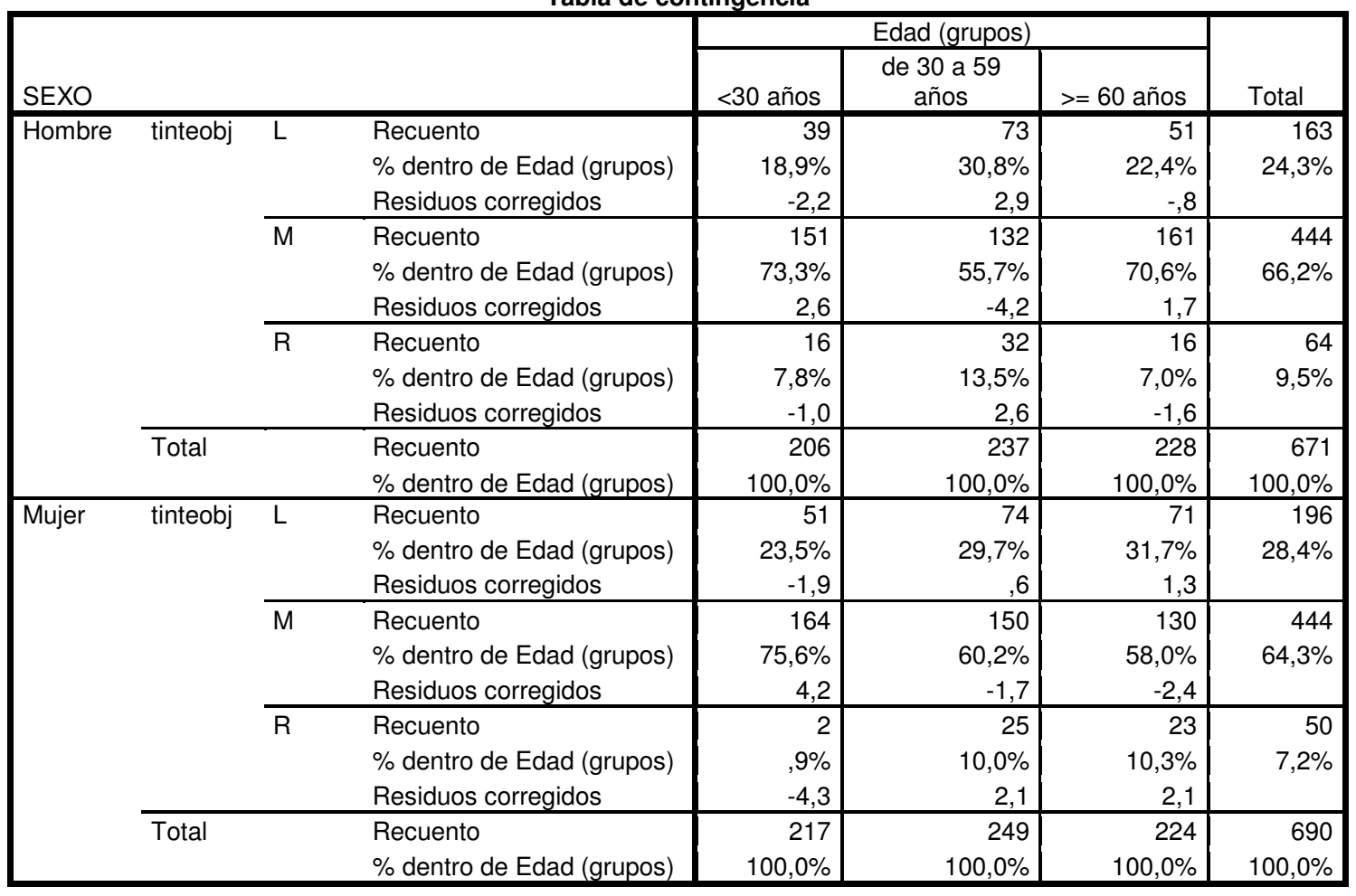

Tabla 25 


\subsection{3.- Intensidad}

\subsubsection{1.- Intensidad-Grupos de edad}

Existe correlación altamente significativa con $\mathrm{p}<, 05$ entre los grupos de edad establecidos y la intensidad objetiva (valor de Chi2=116,220; $8 \mathrm{gl} ; \mathrm{n}=1361, \mathrm{p}=, 000$ ).

En el grupo de edad de menores de 30 años, se les asocian los valores de intensidad entre 1,5 y 2. La intensidad 1, se relaciona de una forma más evidente con el grupo de edad intermedia. Las intensidades superiores, 2,5 y 3 se encuentran relacionadas con el grupo de edad superior (ver tabla 26).

\begin{tabular}{|c|c|c|c|}
\hline & Valor & gl & $\begin{array}{l}\text { Sig. asintótica } \\
\text { (bilateral) }\end{array}$ \\
\hline Chi-cuadrado de Pearson & $116,220^{\mathrm{a}}$ & 8 & ,000 \\
\hline Razón de verosimilitudes & 113,730 & 8 & ,000 \\
\hline Asociación lineal por lineal & 44,140 & 1 & ,000 \\
\hline $\mathrm{N}$ de casos válidos & 1361 & & \\
\hline
\end{tabular}

a. 0 casillas $(, 0 \%)$ tienen una frecuencia esperada inferior a 5 . La frecuencia mínima esperada es 25,80 .

Tabla de contingencia

\begin{tabular}{|c|c|c|c|c|c|c|}
\hline & & & & Edad (grupos) & & \\
\hline & & & $<30$ años & de 30 a 59 años & $>=60$ años & Total \\
\hline intenobj & 1,00 & Recuento & 105 & 161 & 98 & 364 \\
\hline & & $\%$ dentro de Edad (grupos) & $24,8 \%$ & $33,1 \%$ & $21,7 \%$ & $26,7 \%$ \\
\hline & & Residuos corregidos & $-1,1$ & 4,0 & $-3,0$ & \\
\hline & 1,50 & Recuento & 177 & 176 & 129 & 482 \\
\hline & & $\%$ dentro de Edad (grupos) & $41,8 \%$ & $36,2 \%$ & $28,5 \%$ & $35,4 \%$ \\
\hline & & Residuos corregidos & 3,3 & ,5 & $-3,7$ & \\
\hline & 2,00 & Recuento & 108 & 87 & 81 & 276 \\
\hline & & $\%$ dentro de Edad (grupos) & $25,5 \%$ & $17,9 \%$ & $17,9 \%$ & $20,3 \%$ \\
\hline & & Residuos corregidos & 3,2 & $-1,6$ & $-1,5$ & \\
\hline & 2,50 & Recuento & 18 & 46 & 92 & 156 \\
\hline & & $\%$ dentro de Edad (grupos) & $4,3 \%$ & $9,5 \%$ & $20,4 \%$ & $11,5 \%$ \\
\hline & & Residuos corregidos & $-5,6$ & $-1,7$ & 7,3 & \\
\hline & 3,00 & Recuento & 15 & 16 & 52 & 83 \\
\hline & & $\%$ dentro de Edad (grupos) & $3,5 \%$ & $3,3 \%$ & $11,5 \%$ & $6,1 \%$ \\
\hline & & Residuos corregidos & $-2,6$ & $-3,2$ & 5,9 & \\
\hline Total & & Recuento & 423 & 486 & 452 & 1361 \\
\hline & & $\%$ dentro de Edad (grupos) & $100,0 \%$ & $100,0 \%$ & $100,0 \%$ & $100,0 \%$ \\
\hline
\end{tabular}

Tabla 26 


\subsubsection{2.- Intensidad-Sexo}

Según el sexo, también se mantiene la significación de la correlación anteriormente comentada, con $p<0,05$ en cada uno de los sexos; con un peso muy similar en ambos (se aprecia porque el valor del Chi2 es parecido; en hombres: 75,220; 8gl; $\mathrm{n}=671$; $p=, 000$ y en mujeres: 43,$773 ; 8 \mathrm{gl} n=690 ; p=, 000)$. Es decir, se mantiene la significación de la correlación, con $p=, 000$ en cada uno de los sexos.

Vamos a desarrollar la tabla de contingencia 27, tanto en hombres como en mujeres, los resultados son similares, menores de 30 años existe asociación en la intensidad 1,5 y 2; entre 30 y 59 años existe una ligera relación en la intensidad 1; los valores de intensidad 2.5 y 3 están más asociados al grupo mayores de 59 años.

Pruebas de chi-cuadrado

\begin{tabular}{|ll|c|c|c|}
\hline SEXO & & Valor & gl & $\begin{array}{c}\text { Sig. asintótica } \\
\text { (bilateral) }\end{array}$ \\
\hline Hombre & Chi-cuadrado de Pearson & $\mathbf{7 5 , 2 2 0 ^ { \mathbf { a } }}$ & $\mathbf{8}$ &, $\mathbf{0 0 0}$ \\
& Razón de verosimilitudes & 74,650 & 8 &, 000 \\
& Asociación lineal por lineal & 29,431 & 1 &, 000 \\
& N de casos válidos & 671 & &, 000 \\
\hline Mujer & Chi-cuadrado de Pearson & $\mathbf{4 3 , 7 7 3 ^ { \mathbf { b } }}$ & $\mathbf{8}$ &, 000 \\
& Razón de verosimilitudes & 42,461 & 8 &, 000 \\
& Asociación lineal por lineal & 15,274 & 1 & \\
& N de casos válidos & 690 & & \\
\hline
\end{tabular}

a. 0 casillas $(, 0 \%)$ tienen una frecuencia esperada inferior a 5. La frecuencia mínima esperada es 18,73 .

b. 0 casillas $(, 0 \%)$ tienen una frecuencia esperada inferior a 5 . La frecuencia mínima esperada es 6,92 .

Tabla de contingencia

\begin{tabular}{|c|c|c|c|c|c|c|}
\hline \multirow[b]{2}{*}{ SEXO } & & & \multicolumn{3}{|c|}{ Edad (grupos) } & \multirow[b]{2}{*}{ Total } \\
\hline & & & $<30$ años & de 30 a 59 años & $>=60$ años & \\
\hline \multirow[t]{15}{*}{ Hombre intenobj } & 1,00 & Recuento & 43 & 64 & 38 & 145 \\
\hline & & $\%$ dentro de Edad (grupos) & $20,9 \%$ & $27,0 \%$ & $16,7 \%$ & $21,6 \%$ \\
\hline & & Residuos corregidos &,- 3 & 2,5 & $-2,2$ & \\
\hline & 1,50 & Recuento & 77 & 85 & 56 & 218 \\
\hline & & $\%$ dentro de Edad (grupos) & $37,4 \%$ & $35,9 \%$ & $24,6 \%$ & $32,5 \%$ \\
\hline & & Residuos corregidos & 1,8 & 1,4 & $-3,1$ & \\
\hline & 2,00 & Recuento & 64 & 49 & 40 & 153 \\
\hline & & $\%$ dentro de Edad (grupos) & $31,1 \%$ & $20,7 \%$ & $17,5 \%$ & $22,8 \%$ \\
\hline & & Residuos corregidos & 3,4 & $-1,0$ & $-2,3$ & \\
\hline & 2,50 & Recuento & 10 & 28 & 56 & 94 \\
\hline & & $\%$ dentro de Edad (grupos) & $4,9 \%$ & $11,8 \%$ & $24,6 \%$ & $14,0 \%$ \\
\hline & & Residuos corregidos & $-4,5$ & $-1,2$ & 5,7 & \\
\hline & 3,00 & Recuento & 12 & 11 & 38 & 61 \\
\hline & & $\%$ dentro de Edad (grupos) & $5,8 \%$ & $4,6 \%$ & $16,7 \%$ & $9,1 \%$ \\
\hline & & Residuos corregidos & $-2,0$ & $-3,0$ & 4,9 & \\
\hline
\end{tabular}


RESULTADOS

\begin{tabular}{|c|c|c|c|c|c|c|c|}
\hline & \multicolumn{2}{|l|}{ Total } & \multirow{2}{*}{$\begin{array}{l}\text { Recuento } \\
\% \text { dentro de Edad (grupos) }\end{array}$} & \multirow{2}{*}{$\begin{array}{c}206 \\
100,0 \%\end{array}$} & \multirow{2}{*}{$\begin{array}{c}237 \\
100,0 \%\end{array}$} & \multirow{2}{*}{$\begin{array}{c}228 \\
100,0 \%\end{array}$} & \multirow{2}{*}{$\begin{array}{c}671 \\
100,0 \% \\
\end{array}$} \\
\hline & \multirow{16}{*}{ intenobj } & & & & & & \\
\hline \multirow[t]{17}{*}{ Mujer } & & \multirow[t]{3}{*}{1,00} & Recuento & 62 & 97 & 60 & 219 \\
\hline & & & $\%$ dentro de Edad (grupos) & $28,6 \%$ & $39,0 \%$ & $26,8 \%$ & $31,7 \%$ \\
\hline & & & Residuos corregidos & $-1,2$ & 3,1 & $-1,9$ & \\
\hline & & \multirow[t]{3}{*}{1,50} & Recuento & 100 & 91 & 73 & 264 \\
\hline & & & $\%$ dentro de Edad (grupos) & $46,1 \%$ & $36,5 \%$ & $32,6 \%$ & $38,3 \%$ \\
\hline & & & Residuos corregidos & 2,9 &,- 7 & $-2,1$ & \\
\hline & & \multirow[t]{3}{*}{2,00} & Recuento & 44 & 38 & 41 & 123 \\
\hline & & & $\%$ dentro de Edad (grupos) & $20,3 \%$ & $15,3 \%$ & $18,3 \%$ & $17,8 \%$ \\
\hline & & & Residuos corregidos & 1,1 & $-1,3$ & ,2 & \\
\hline & & \multirow[t]{3}{*}{2,50} & Recuento & 8 & 18 & 36 & 62 \\
\hline & & & $\%$ dentro de Edad (grupos) & $3,7 \%$ & $7,2 \%$ & $16,1 \%$ & $9,0 \%$ \\
\hline & & & Residuos corregidos & $-3,3$ & $-1,2$ & 4,5 & \\
\hline & & \multirow[t]{3}{*}{3,00} & Recuento & 3 & 5 & 14 & 22 \\
\hline & & & $\%$ dentro de Edad (grupos) & $1,4 \%$ & $2,0 \%$ & $6,3 \%$ & $3,2 \%$ \\
\hline & & & Residuos corregidos & $-1,8$ & $-1,3$ & 3,2 & \\
\hline & \multirow{2}{*}{\multicolumn{2}{|c|}{ Total }} & Recuento & 217 & 249 & 224 & 690 \\
\hline & & & $\%$ dentro de Edad (grupos) & $100,0 \%$ & $100,0 \%$ & $100,0 \%$ & $100,0 \%$ \\
\hline
\end{tabular}

Tabla 27

\subsubsection{Frecuencia de color de los dientes}

En este apartado vamos a describir según grupo de edad y sexo, la frecuencia de los colores según el método objetivo y haremos las inferencias correspondientes a la población muestral estudiada.

Primero a través del texto señalamos los datos de mayor importancia de cada grupo y posteriormente se presentarán las tablas para facilitar su visualización, tanto en hombres como en mujeres.

\subsubsection{1.- Muestra Total}

En la tabla 28 observamos la frecuencia registrada por el espectrofotómetro de la muestra total, con respecto a la guía 3D Master. Vamos a resumir sus datos más significativos, se refleja el número de veces que se registró dicho color (frecuencia) y el porcentaje correspondiente, junto con la frecuencia y el porcentaje acumulado.

Aparece el color 3M1de la guía dental 3D Master con 96 casos de 1361, como el color más frecuente $(7.05 \%)$, seguido por el color $1 \mathrm{M} 1,5$ con 94 casos $(6.91 \%)$, posteriormente $2 \mathrm{~L} 1,5$ representando a 82 sujetos (6.02\%). Por el contrario, aquellos colores que se encuentran con único representante en nuestra muestra son el 0,5M2, 
0M1,5 (correspondientes según el fabricante con dientes blanqueados), 2M1,5, 2M2,5 y 4L2,5.

Sobre estos datos podemos afirmar que el $57.29 \%$ de los pacientes de la muestra total poseen un color más valor que el 3M1. Si de todos los colores registrados observamos el porcentaje que corresponde exclusivamente a colores de tablillas de la guía 3D Master, observamos que el 40.16\%, es decir, 545 sujetos tienen un color representado en esta guía de color (sin contar los colores con valor 0, que consideramos como excepciones).

Anotamos la frecuencia del tinte, un $26.38 \%$ (359 sujetos) corresponde al tinte L, un $65.24 \%$ (884 sujetos) corresponde al tinte $\mathrm{M}$, y tan solo un $8.38 \%$ (114sujetos) al tinte $\mathrm{R}$.

\begin{tabular}{|c|c|c|c|c|c|c|c|c|c|}
\hline \multicolumn{10}{|c|}{ Población Total } \\
\hline \multicolumn{1}{|c|}{ Folor } & F & P & F. A. & P. A. & Color & F & P & F. A. & P. A. \\
\hline OM1,5 & 1 & 0.07 & 1 & 0.07 & $3 \mathrm{M} 2,5$ & 10 & 0.73 & 909 & 65.87 \\
\hline 0M3 & 2 & 0.15 & 3 & 0.22 & $3 \mathrm{M} 3$ & 16 & 1.18 & 925 & 67.05 \\
\hline $0,5 \mathrm{M} 2$ & 1 & 0.07 & 4 & 0.29 & $3 \mathrm{R} 1,5$ & 3 & 0.22 & 928 & 67.27 \\
\hline $1 \mathrm{M} 1$ & 45 & 3.31 & 49 & 3.6 & $3 \mathrm{R} 2$ & 7 & 0.51 & 935 & 67.78 \\
\hline $1 \mathrm{M} 1,5$ & 94 & 6.91 & 143 & 10.51 & $3 \mathrm{R} 2,5$ & 2 & 0.15 & 937 & 67.93 \\
\hline $1 \mathrm{M} 2$ & 59 & 4.34 & 202 & 14.85 & $3,5 \mathrm{~L} 1,5$ & 37 & 2.72 & 974 & 70.65 \\
\hline $1,5 \mathrm{M} 1$ & 14 & 1.03 & 216 & 15.88 & $3,5 \mathrm{~L} 2$ & 18 & 1.32 & 992 & 71.97 \\
\hline $1,5 \mathrm{M} 1,5$ & 52 & 3.82 & 268 & 19.7 & $3,5 \mathrm{~L} 2,5$ & 5 & 0.37 & 997 & 72.34 \\
\hline $1,5 \mathrm{M} 2$ & 21 & 1.54 & 289 & 21.24 & $3,5 \mathrm{M} 1$ & 50 & 3.67 & 1047 & 76.01 \\
\hline $1,5 \mathrm{M} 2,5$ & 13 & 0.96 & 302 & 22.2 & $3,5 \mathrm{M} 1,5$ & 11 & 0.81 & 1058 & 76.82 \\
\hline $2 \mathrm{~L} 1,5$ & 82 & 6.02 & 384 & 28.22 & $3,5 \mathrm{M} 2$ & 4 & 0.29 & 1062 & 77.11 \\
\hline $2 \mathrm{~L} 2$ & 22 & 1.62 & 406 & 29.84 & $3,5 \mathrm{M} 2,5$ & 20 & 1.47 & 1082 & 78.58 \\
\hline $2 \mathrm{~L} 2,5$ & 14 & 0.13 & 420 & 29.97 & $3,5 \mathrm{M} 3$ & 9 & 0.66 & 1091 & 79.24 \\
\hline $2 \mathrm{M} 1$ & 65 & 4.78 & 485 & 34.75 & $3,5 \mathrm{R} 1,5$ & 8 & 0.59 & 1099 & 79.83 \\
\hline $2 \mathrm{M} 1,5$ & 1 & 0.07 & 486 & 34.82 & $3,5 \mathrm{R} 2$ & 15 & 1.10 & 1114 & 80.93 \\
\hline $2 \mathrm{M} 2$ & 6 & 0.44 & 492 & 35.26 & $3,5 \mathrm{R} 2,5$ & 16 & 1.18 & 1130 & 82.11 \\
\hline $2 \mathrm{M} 2,5$ & 1 & 0.07 & 493 & 35.33 & $4 \mathrm{~L} 1,5$ & 15 & 1.10 & 1145 & 83.21 \\
\hline $2 \mathrm{M} 3$ & 21 & 1.54 & 514 & 36.87 & $4 \mathrm{~L} 2$ & 6 & 0.44 & 1151 & 83.65 \\
\hline $2 \mathrm{R} 1,5$ & 6 & 0.44 & 520 & 37.31 & $4 \mathrm{~L} 2,5$ & 1 & 0.07 & 1152 & 83.72 \\
\hline $2 \mathrm{R} 2$ & 20 & 1.47 & 540 & 38.78 & $4 \mathrm{M} 1$ & 22 & 1.62 & 1174 & 85.34 \\
\hline $2 \mathrm{R} 2,5$ & 6 & 0.44 & 546 & 39.22 & $4 \mathrm{M} 1,5$ & 8 & 0.59 & 1182 & 85.93 \\
\hline $2,5 \mathrm{~L} 1,5$ & 71 & 5.22 & 617 & 44.44 & $4 \mathrm{M} 2$ & 3 & 0.22 & 1185 & 86.15 \\
\hline $2,5 \mathrm{~L} 2$ & 38 & 2.79 & 655 & 47.23 & $4 \mathrm{M} 2,5$ & 4 & 0.29 & 1189 & 86.44 \\
\hline $2,5 \mathrm{~L} 2,5$ & 5 & 0.37 & 660 & 47.6 & $4 \mathrm{M} 3$ & 16 & 1.18 & 1205 & 87.62 \\
\hline $2,5 \mathrm{M} 1$ & 35 & 2.57 & 695 & 50.17 & $4 \mathrm{R} 1,5$ & 2 & 0.15 & 1207 & 87.77 \\
\hline $2,5 \mathrm{M} 1,5$ & 14 & 1.03 & 709 & 51.2 & $4 \mathrm{R} 2$ & 4 & 0.29 & 1211 & 88.06 \\
\hline $2,5 \mathrm{M} 2$ & 6 & 0.44 & 715 & 51.64 & $4 \mathrm{R} 2,5$ & 6 & 0.44 & 1217 & 88.5 \\
\hline $2,5 \mathrm{M} 2,5$ & 8 & 0.59 & 723 & 52.23 & $4,5 \mathrm{M} 1$ & 20 & 1.47 & 1237 & 89.97 \\
\hline $2,5 \mathrm{M} 3$ & 5 & 0.37 & 728 & 52.6 & $4,5 \mathrm{M} 1,5$ & 43 & 3.16 & 1280 & 93.13 \\
\hline & & & & & & & & & \\
\hline
\end{tabular}




\begin{tabular}{|c|c|c|c|c|c|c|c|c|c|}
\hline \multicolumn{10}{|c|}{ Población Total } \\
\hline \multicolumn{1}{|c|}{ Color } & F & P & F. A. & P. A. & Color & F & P & F. A. & P. A. \\
\hline $2,5 R 1,5$ & 5 & 0.37 & 733 & 52.97 & $4,5 \mathrm{M} 2$ & 13 & 0.96 & 1293 & 94.09 \\
\hline $2,5 \mathrm{R} 2$ & 7 & 0.51 & 740 & 53.48 & $4,5 \mathrm{M} 2,5$ & 24 & 1.76 & 1317 & 95.85 \\
\hline $2,5 \mathrm{R} 2,5$ & 7 & 0.51 & 747 & 53.99 & $4,5 \mathrm{M} 3$ & 8 & 0.59 & 1325 & 96.44 \\
\hline 3L1,5 & 24 & 1.76 & 771 & 55.75 & $5 \mathrm{M} 1$ & 9 & 0.66 & 1334 & 97.1 \\
\hline 3L2 & 11 & 0.81 & 782 & 56.56 & $5 \mathrm{M} 1,5$ & 9 & 0.66 & 1343 & 97.76 \\
\hline 3L2,5 & 10 & 0.73 & 792 & 57.29 & $5 \mathrm{M} 2$ & 3 & 0.22 & 1346 & 97.98 \\
\hline 3M1 & 96 & 7.05 & 888 & 64.34 & $5 \mathrm{M} 2,5$ & 9 & 0.66 & 1355 & 98.64 \\
\hline 3M1,5 & 4 & 0.29 & 892 & 64.63 & $5 \mathrm{M} 3$ & 6 & 0.44 & 1361 & 99.08 \\
\hline 3M2 & 7 & 0.51 & 899 & 65.14 & & & & & \\
\hline
\end{tabular}

Tabla 28

\subsubsection{2.-Hombres}

\subsubsection{1.-Muestra total de hombres:}

Con respecto a la muestra total del género masculino, observamos que no todos los colores se encuentran presentes, encontramos ausencia de 2M1,5, 2M2,5, y 4L2,5, omitiendo los colores pertenecientes al grupo de "dientes blanqueados" (ver tabla 29).

Coincide con el resultado de la muestra total, siendo también en este grupo el color más frecuente el $3 \mathrm{M} 1$, con 42 sujetos (6.26\%). A continuación y con resultados muy similares encontramos tres colores, el $1 \mathrm{M} 1,5,1 \mathrm{M} 2,2,5 \mathrm{~L} 1,5$ con 33,34 y 32 sujetos en cada color respectivamente.

Como ecuador de la tabla, el color 3L2,5 que deja el 50\% de la misma con un color con más luminoso, y al otro $50 \%$ de la tabla con un color con mayor cantidad de gris.

Representados en la guía 3D Master, es decir, englobados en un 26 tablillas de color se encuentran el $36.48 \%$ de la población de hombres (247sujetos). Al igual que en la estadística anterior y así lo haremos también en las sucesivas no tendremos en cuanta los colores con un valor 0 .

De toda la población de hombres, el tinte $\mathrm{M}$, está presente en el $66.06 \%$ de todos los hombres (442 sujetos), el tinte $L$ es el segundo más frecuente con un 24.36\% (163 sujetos), y por último, el menos frecuente, con un porcentaje de 9.58\% (64 sujetos) el tinte $\mathrm{R}$. 


\begin{tabular}{|c|c|c|c|c|c|c|c|c|c|}
\hline \multicolumn{10}{|c|}{ METODO OBJETIVO } \\
\hline \multicolumn{10}{|c|}{ FRECUENCIA DE COLORES } \\
\hline \multicolumn{10}{|c|}{ Hombres } \\
\hline Color & $\mathbf{F}$ & $\mathbf{P}$ & F. A. & P. A. & Color & $\mathbf{F}$ & $\mathbf{P}$ & F. A. & P. A. \\
\hline OM3 & 2 & 0.3 & 2 & 0.3 & $3 \mathrm{M} 3$ & 10 & 1.49 & 398 & 59.37 \\
\hline $1 \mathrm{M} 1$ & 11 & 1.64 & 13 & 1.94 & $3 R 1,5$ & 1 & 0.15 & 399 & 59.52 \\
\hline $1 \mathrm{M} 1,5$ & 33 & 4.92 & 46 & 6.86 & 3R2 & 2 & 0.30 & 401 & 59.82 \\
\hline $1 \mathrm{M} 2$ & 34 & 5.07 & 80 & 11.93 & $3 R 2,5$ & 2 & 0.30 & 403 & 60.12 \\
\hline $1,5 \mathrm{M} 1$ & 5 & 0.75 & 85 & 12.68 & $3,5 \mathrm{~L} 1,5$ & 23 & 3.43 & 426 & 63.55 \\
\hline $1,5 \mathrm{M} 1,5$ & 22 & 3.28 & 107 & 15.96 & $3,5 \mathrm{~L} 2$ & 9 & 1.34 & 435 & 64.89 \\
\hline $1,5 \mathrm{M} 2$ & 12 & 1.79 & 119 & 17.75 & $3,5 \mathrm{~L} 2,5$ & 2 & 0.30 & 437 & 65.19 \\
\hline $1,5 \mathrm{M} 2,5$ & 6 & 0.89 & 125 & 18.64 & $3,5 \mathrm{M} 1$ & 19 & 2.83 & 456 & 68.02 \\
\hline $2 \mathrm{~L} 1,5$ & 23 & 3.43 & 148 & 22.07 & $3,5 \mathrm{M} 1,5$ & 6 & 0.89 & 462 & 68.91 \\
\hline $2 \mathrm{~L} 2$ & 12 & 1.79 & 160 & 23.86 & $3,5 \mathrm{M} 2$ & 3 & 0.45 & 465 & 69.36 \\
\hline $2 \mathrm{~L} 2,5$ & 5 & 0.75 & 165 & 24.61 & $3,5 \mathrm{M} 2,5$ & 14 & 2.09 & 479 & 71.45 \\
\hline $2 \mathrm{M} 1$ & 20 & 2.98 & 185 & 27.59 & $3,5 \mathrm{M} 3$ & 9 & 1.34 & 488 & 72.79 \\
\hline $2 \mathrm{M} 2$ & 3 & 0.45 & 188 & 28.04 & $3,5 \mathrm{R} 1,5$ & 3 & 0.45 & 491 & 73.24 \\
\hline $2 \mathrm{M} 3$ & 14 & 2.09 & 202 & 30.13 & 3,5R2 & 9 & 1.34 & 500 & 74.58 \\
\hline $2 \mathrm{R} 1,5$ & 2 & 0.30 & 204 & 30.43 & $3,5 \mathrm{R} 2,5$ & 9 & 1.34 & 509 & 75.92 \\
\hline 2R2 & 12 & 1.79 & 216 & 32.22 & $4 \mathrm{~L} 1,5$ & 9 & 1.34 & 518 & 77.26 \\
\hline $2 \mathrm{R} 2,5$ & 4 & 0.60 & 220 & 32.82 & 4L2 & 6 & 0.89 & 524 & 78.15 \\
\hline $2,5 \mathrm{~L} 1,5$ & 32 & 4.77 & 252 & 37.59 & $4 \mathrm{M} 1$ & 11 & 1.64 & 535 & 79.79 \\
\hline $2,5 \mathrm{~L} 2$ & 18 & 2.68 & 270 & 40.27 & $4 \mathrm{M} 1,5$ & 5 & 0.75 & 541 & 80.54 \\
\hline $2,5 \mathrm{~L} 2,5$ & 2 & 0.30 & 272 & 40.57 & $4 \mathrm{M} 2$ & 3 & 0.45 & 544 & 80.99 \\
\hline $2,5 \mathrm{M} 1$ & 13 & 1.94 & 285 & 42.51 & $4 \mathrm{M} 2,5$ & 3 & 0.45 & 547 & 81.44 \\
\hline $2,5 \mathrm{M} 1,5$ & 10 & 1.49 & 295 & 44 & $4 \mathrm{M} 3$ & 13 & 1.94 & 560 & 83.38 \\
\hline $2,5 \mathrm{M} 2$ & 2 & 0.30 & 297 & 44.3 & $4 \mathrm{R} 1,5$ & 2 & 0.30 & 562 & 83.68 \\
\hline $2,5 \mathrm{M} 2,5$ & 5 & 0.75 & 302 & 45.05 & 4R2 & 3 & 0.45 & 565 & 84.13 \\
\hline $2,5 \mathrm{M} 3$ & 1 & 0.15 & 303 & 45.2 & $4 \mathrm{R} 2,5$ & 5 & 0.75 & 570 & 84.88 \\
\hline $2,5 \mathrm{R} 1,5$ & 3 & 0.45 & 306 & 45.65 & $4,5 \mathrm{M} 1$ & 14 & 2.09 & 584 & 86.97 \\
\hline $2,5 \mathrm{R} 2$ & 1 & 0.15 & 307 & 45.8 & $4,5 \mathrm{M} 1,5$ & 27 & 4.02 & 611 & 90.99 \\
\hline $2,5 \mathrm{R} 2,5$ & 6 & 0.89 & 313 & 46.69 & $4,5 \mathrm{M} 2$ & 6 & 0.89 & 617 & 91.88 \\
\hline $3 \mathrm{~L} 1,5$ & 13 & 1.94 & 326 & 48.63 & $4,5 \mathrm{M} 2,5$ & 20 & 2.98 & 637 & 94.86 \\
\hline 3L2 & 7 & 1.04 & 333 & 49.67 & $4,5 \mathrm{M} 3$ & 7 & 1.04 & 644 & 95.9 \\
\hline $3\llcorner 2,5$ & 2 & 0.30 & 335 & 49.97 & $5 \mathrm{M} 1$ & 6 & 0.89 & 650 & 96.79 \\
\hline $3 \mathrm{M} 1$ & 42 & 6.26 & 377 & 56.23 & $5 \mathrm{M} 1,5$ & 6 & 0.89 & 656 & 97.68 \\
\hline $3 \mathrm{M} 1,5$ & 2 & 0.30 & 379 & 56.53 & $5 \mathrm{M} 2$ & 3 & 0.45 & 659 & 98.13 \\
\hline $3 \mathrm{M} 2$ & 4 & 0.60 & 383 & 57.13 & $5 \mathrm{M} 2,5$ & 8 & 1.19 & 667 & 99.32 \\
\hline $3 \mathrm{M} 2,5$ & 5 & 0.75 & 388 & 57.88 & $5 \mathrm{M} 3$ & 5 & 0.75 & 672 & 100.00 \\
\hline
\end{tabular}

Tabla 29

\subsubsection{2.-Hombres menores de 30 años:}

En la tabla siguiente, se observan que los hombres menores de 30 años el color que aparece con más frecuencia es el 1M1,5 (14.56\%),seguido por el 1M2 (13.59\%) y en tercer lugar el 1,5M1,5 con un $9.71 \%$ de los sujetos (ver tabla 30 ). 
Hay nueve colores que solo se ven representados por un sujeto, es decir, con un porcentaje del $0.49 \%$. Los colores implicados en este grupo son: 2,5M1,5, 2,5M2,5, 2,5R2, 2R1,5, 3,5L1,5, 3,5M1, 3R1,5, 3,5R2,5, 3,5R2.

Es importante señalar que ninguno de los individuos vinculados a este estudio alcanzó el valor número 4, en cambio el color perteneciente al grupo de los blanqueados, el OM3 se obtuvo dos veces como resultado.

En este apartado, hay tablillas de color que no tienen ningún representante, como por ejemplo, el 2M1,5, 2M2,5, 2,5L2,5, ...

El $50 \%$ de los sujetos se encuentran con un valor o luminosidad igual o inferior al $1,5 \mathrm{M} 2$, este resultado es muy similar al encontrado en el grupo femenino, donde el ecuador se encuentra entre el color 1,5M1 y 1,5M1,5.

Dentro de las 26 tablillas de color de la guía 3D Master se encuentran 87 sujetos, que equivalen a un $42.64 \%$ de la población de hombres menores de treinta años.

\begin{tabular}{|c|c|c|c|c|}
\hline \multicolumn{5}{|c|}{ METODO OBJETIVO } \\
\hline \multicolumn{5}{|c|}{ Hombres $<30$ años } \\
\hline Color & Frecuencia & Porcentaje & F. Acumulada & P. Acumulado \\
\hline $0 \mathrm{M} 3$ & 2 & 0.97 & 2 & 0.97 \\
\hline $1 \mathrm{M} 1$ & 10 & 4.85 & 12 & 5.82 \\
\hline $1 \mathrm{M} 1,5$ & 30 & 14.56 & 42 & 20.38 \\
\hline $1 \mathrm{M} 2$ & 28 & 13.59 & 70 & 33.97 \\
\hline $1,5 \mathrm{M} 1$ & 4 & 1.94 & 74 & 35.91 \\
\hline $1,5 \mathrm{M} 1,5$ & 20 & 9.71 & 94 & 45.62 \\
\hline $1,5 \mathrm{M} 2$ & 9 & 4.37 & 103 & 49.99 \\
\hline $1,5 \mathrm{M} 2,5$ & 5 & 2.43 & 108 & 52.42 \\
\hline $2 \mathrm{~L} 1,5$ & 11 & 5.34 & 119 & 57.76 \\
\hline $2 \mathrm{~L} 2$ & 7 & 3.40 & 126 & 61.16 \\
\hline $2 \mathrm{~L} 2,5$ & 1 & 0.49 & 127 & 61.65 \\
\hline $2 \mathrm{M} 1$ & 13 & 6.31 & 140 & 67.96 \\
\hline $2 \mathrm{M} 2$ & 2 & 0.97 & 142 & 68.93 \\
\hline $2 \mathrm{M} 3$ & 8 & 3.88 & 150 & 72.81 \\
\hline $2 \mathrm{R} 1,5$ & 1 & 0.49 & 151 & 73.3 \\
\hline $2 \mathrm{R} 2$ & 9 & 4.37 & 160 & 77.67 \\
\hline $2 \mathrm{R} 2,5$ & 2 & 0.97 & 162 & 78.64 \\
\hline $2,5 \mathrm{~L} 1,5$ & 10 & 4.85 & 172 & 83.49 \\
\hline $2,5 \mathrm{~L} 2$ & 7 & 3.40 & 179 & 86.89 \\
\hline $2,5 \mathrm{M} 1$ & 8 & 3.88 & 187 & 90.77 \\
\hline $2,5 \mathrm{M} 1,5$ & 1 & 0.49 & 188 & 91.26 \\
\hline $2,5 \mathrm{M} 2,5$ & 1 & 0.49 & 189 & 91.75 \\
\hline $2,5 \mathrm{R} 2$ & 1 & 0.49 & 190 & 93.21 \\
\hline $3 \mathrm{~L} 1,5$ & 2 & 0.97 & 192 & \\
\hline & & & & \\
\hline
\end{tabular}




\begin{tabular}{|c|c|c|c|c|}
\hline \multicolumn{5}{|c|}{ METODO OBJETIVO } \\
\hline \multicolumn{5}{|c|}{ FRECUENCIA DE COLORES } \\
\hline \multicolumn{5}{|c|}{ Hombres $<30$ años } \\
\hline Color & Frecuencia & Porcentaje & F. Acumulada & P. Acumulado \\
\hline 3M1 & 7 & 3.40 & 199 & 96.61 \\
\hline 3M3 & 2 & 0.97 & 201 & 97.58 \\
\hline $3,5 \mathrm{~L} 1,5$ & 1 & 0.49 & 202 & 98.07 \\
\hline $3,5 \mathrm{M} 1$ & 1 & 0.49 & 203 & 98.56 \\
\hline $3,5 \mathrm{R} 1,5$ & 1 & 0.49 & 204 & 99.05 \\
\hline 3,5R2 & 1 & 0.49 & 205 & 99.54 \\
\hline $3,5 \mathrm{R} 2,5$ & 1 & 0.49 & 206 & 100.00 \\
\hline
\end{tabular}

\section{Tabla 30}

\subsubsection{3.-Hombres entre 30-59 años:}

Observamos que no existe ningún sujeto con los valores de 0 , como ocurría en el grupo anterior, aparecen tres sujetos englobados en el valor 5 . Dos de estos sujetos con un color de $5 \mathrm{M} 2,5(0.84 \%)$, y el otro sujeto con el color $5 \mathrm{M} 1,5(0.42 \%)$.

Los tres colores con más presencia en este grupo de edad en hombres son por este orden: 3M1 con un peso de 24 individuos (10.13\%), seguido con 14 sujetos el 2,5L1,5 (5.91\%) y en tercer lugar el color $3,5 \mathrm{~L} 1,5$, con una frecuencia de 12 y un porcentaje de $5.06 \%$.

Un $1.27 \%$ de hombres en edad intermedia cumplía con el valor más oscuro, es decir, el valor número 5, por el contrario en el grupo de mujeres de esa mismo rango de edad, no obtuvo resultados.

Representados dentro de la guía 3D Master encontramos a 86 sujetos, que corresponden a un $39.26 \%$ del total de este grupo (ver tabla 31 ).

\begin{tabular}{|c|c|c|c|c|c|c|c|c|c|}
\hline \multicolumn{1}{|c|}{ METODO OBJETIVO } \\
\hline \multicolumn{10}{|c|}{ Hombres 30-59 años } \\
\hline Color & F & P & F. A. & P. A. & Color & F & P & F. A. & P. A. \\
\hline $1 \mathrm{M} 1$ & 1 & 0.42 & 1 & 0.42 & $3 \mathrm{M} 3$ & 3 & 1.27 & 132 & 55.67 \\
\hline $1 \mathrm{M} 1,5$ & 2 & 0.84 & 3 & 1.26 & $3 \mathrm{R} 2$ & 2 & 0.84 & 134 & 56.51 \\
\hline $1 \mathrm{M} 2$ & 2 & 0.84 & 5 & 2.1 & $3 \mathrm{R} 2,5$ & 1 & 0.42 & 135 & 56.93 \\
\hline $1,5 \mathrm{M} 1$ & 1 & 0.42 & 6 & 2.52 & $3,5 \mathrm{~L} 1,5$ & 12 & 5.06 & 147 & 61.99 \\
\hline $1,5 \mathrm{M} 1,5$ & 2 & 0.84 & 8 & 3.36 & $3,5 \mathrm{~L} 2$ & 5 & 2.11 & 152 & 64.10 \\
\hline $1,5 \mathrm{M} 2$ & 3 & 1.27 & 11 & 4.63 & $3,5 \mathrm{~L} 2,5$ & 1 & 0.42 & 153 & 64.55 \\
\hline $2 \mathrm{~L} 1,5$ & 11 & 4.64 & 22 & 9.27 & $3,5 \mathrm{M} 1$ & 9 & 3.80 & 162 & 68.35 \\
\hline $2 \mathrm{~L} 2$ & 5 & 2.11 & 27 & 11.38 & $3,5 \mathrm{M} 1,5$ & 6 & 2.53 & 168 & 70.88 \\
\hline $2 \mathrm{~L} 2,5$ & 1 & 0.42 & 28 & 11.8 & $3,5 \mathrm{M} 2$ & 2 & 0.84 & 170 & 71.72 \\
\hline $2 \mathrm{M} 1$ & 5 & 2.11 & 33 & 13.91 & $3,5 \mathrm{M} 2,5$ & 4 & 1.69 & 174 & 73.41 \\
\hline
\end{tabular}




\begin{tabular}{|c|c|c|c|c|c|c|c|c|c|}
\hline \multicolumn{10}{|c|}{ METODO OBJETIVO } \\
\hline \multicolumn{10}{|c|}{ FRECUENCIA DE COLORES } \\
\hline Color & F & P & F. A. & P. A. & Color & F & P & F. A. & P. A. \\
\hline $2 \mathrm{M} 2$ & 1 & 0.42 & 34 & 14.33 & $3,5 \mathrm{M} 3$ & 1 & 0.42 & 175 & 73.83 \\
\hline $2 \mathrm{M} 3$ & 5 & 2.11 & 39 & 16.44 & $3,5 \mathrm{R} 1,5$ & 2 & 0.84 & 177 & 74.67 \\
\hline $2 \mathrm{R} 1,5$ & 1 & 0.42 & 40 & 16.86 & $3,5 \mathrm{R} 2$ & 5 & 2.11 & 182 & 76.78 \\
\hline 2R2 & 2 & 0.84 & 42 & 17.7 & $3,5 \mathrm{R} 2,5$ & 4 & 1.69 & 186 & 78.47 \\
\hline $2 \mathrm{R} 2,5$ & 2 & 0.84 & 44 & 18.54 & $4 \mathrm{~L} 1,5$ & 4 & 1.69 & 190 & 80.16 \\
\hline $2,5 \mathrm{~L} 1,5$ & 14 & 5.91 & 58 & 24.45 & $4 \mathrm{~L} 2$ & 2 & 0.84 & 192 & 81.00 \\
\hline $2,5 \mathrm{~L} 2$ & 7 & 2.95 & 65 & 27.4 & $4 \mathrm{M} 1$ & 8 & 3.38 & 200 & 84.38 \\
\hline $2,5 \mathrm{~L} 2,5$ & 1 & 0.42 & 66 & 27.82 & $4 \mathrm{M} 1,5$ & 4 & 1.69 & 204 & 86.07 \\
\hline $2,5 \mathrm{M} 1$ & 3 & 1.27 & 69 & 29.09 & $4 \mathrm{M} 2$ & 2 & 0.84 & 206 & 86.91 \\
\hline $2,5 \mathrm{M} 1,5$ & 9 & 3.80 & 78 & 32.89 & $4 \mathrm{M} 2,5$ & 1 & 0.42 & 207 & 87.33 \\
\hline $2,5 \mathrm{M} 2$ & 1 & 0.42 & 79 & 33.31 & $4 \mathrm{M} 3$ & 2 & 0.84 & 209 & 88.17 \\
\hline $2,5 \mathrm{M} 2,5$ & 2 & 0.84 & 81 & 34.15 & $4 \mathrm{R} 1,5$ & 1 & 0.42 & 210 & 88.59 \\
\hline $2,5 \mathrm{R} 1,5$ & 3 & 1.27 & 84 & 35.42 & $4 \mathrm{R} 2$ & 2 & 0.84 & 212 & 89.43 \\
\hline $2,5 \mathrm{R} 2,5$ & 5 & 2.11 & 89 & 37.53 & $4 \mathrm{R} 2,5$ & 2 & 0.84 & 214 & 90.27 \\
\hline 3L1,5 & 8 & 3.38 & 97 & 40.91 & $4,5 \mathrm{M} 1$ & 9 & 3.80 & 223 & 94.07 \\
\hline 3L2 & 2 & 0.84 & 99 & 41.75 & $4,5 \mathrm{M} 1,5$ & 7 & 2.95 & 230 & 97.02 \\
\hline $3 \mathrm{M} 1$ & 24 & 10.13 & 123 & 51.88 & $4,5 \mathrm{M} 2$ & 2 & 0.84 & 232 & 97.86 \\
\hline 3M1,5 & 2 & 0.84 & 125 & 52.72 & $4,5 \mathrm{M} 2,5$ & 2 & 0.84 & 234 & 98.70 \\
\hline $3 \mathrm{M} 2$ & 2 & 0.84 & 127 & 53.56 & $5 \mathrm{M} 1,5$ & 1 & 0.42 & 235 & 99.12 \\
\hline 3M2,5 & 2 & 0.84 & 129 & 54.4 & $5 \mathrm{M} 2,5$ & 2 & 0.84 & 237 & 100.00 \\
\hline
\end{tabular}

\section{Tabla 31}

\subsubsection{4.- Hombres superiores a 60 años:}

El color 4,5M1,5 es el color que aparece con más frecuencia (8.77\%), seguido por el color 4,5M2,5 (7.89\%) y el tercer lugar lo comparten dos colores. Los colores con un representación de 11 sujetos, que son el 4M3, y el 3M1 (4.82\%).

El color con menos valor de este grupo es el $1 \mathrm{M} 1,5(0.44 \%)$ y en solo seis sujetos varones con más de 60 años encontramos luminosidades del 1.

Para el tinte $\mathrm{R}$, un total de 11 sujetos lo reflejaban siendo así solo un $4.82 \%$ del grupo.

En este grupo de edad masculino un $32.42 \%$ está dentro de las 26 tablillas de la guía de color 3D Master, que equivale a 74 sujetos. Todos estos datos vienen resumidos en la tabla siguiente, tabla 32 . 


\begin{tabular}{|c|c|c|c|c|c|c|c|c|c|}
\hline \multicolumn{10}{|c|}{ METODO OBJETIVO } \\
\hline \multicolumn{10}{|c|}{ FRECUENCIA DE COLORES } \\
\hline \multicolumn{10}{|c|}{ Hombres $\geq 60$ años } \\
\hline Color & $\mathbf{F}$ & $\mathbf{P}$ & F. A. & P. A. & Color & $\mathbf{F}$ & $\mathbf{P}$ & F. A. & P. A. \\
\hline $1 \mathrm{M} 1,5$ & 1 & 0.44 & 1 & 0.44 & $3,5 \mathrm{M} 1$ & 9 & 3.95 & 90 & 39.5 \\
\hline $1 \mathrm{M} 2$ & 4 & 1.75 & 5 & 2.19 & $3,5 \mathrm{M} 2$ & 1 & 0.44 & 91 & 39.94 \\
\hline $1,5 \mathrm{M} 2,5$ & 1 & 0.44 & 6 & 2.63 & $3,5 \mathrm{M} 2,5$ & 10 & 4.39 & 101 & 44.33 \\
\hline $2 \mathrm{~L} 1,5$ & 1 & 0.44 & 7 & 3.07 & $3,5 \mathrm{M} 3$ & 8 & 3.51 & 109 & 47.84 \\
\hline $2 \mathrm{~L} 2,5$ & 3 & 1.32 & 10 & 4.39 & $3,5 \mathrm{R} 1,5$ & 1 & 0.44 & 110 & 48.28 \\
\hline $2 \mathrm{M} 1$ & 2 & 0.88 & 12 & 5.27 & $3,5 \mathrm{R} 2$ & 3 & 1.32 & 113 & 49.6 \\
\hline $2 \mathrm{M} 3$ & 1 & 0.44 & 13 & 5.71 & $3,5 \mathrm{R} 2,5$ & 4 & 1.75 & 117 & 51.35 \\
\hline $2 \mathrm{R} 1,5$ & & & 13 & 5.71 & $4 \mathrm{~L} 1,5$ & 5 & 2.19 & 122 & 53.54 \\
\hline 2R2 & 1 & 0.44 & 14 & 6.15 & 4L2 & 4 & 1.75 & 126 & 55.29 \\
\hline $2,5 \mathrm{~L} 1,5$ & 8 & 3.51 & 22 & 9.66 & $4 \mathrm{M} 1$ & 3 & 1.32 & 129 & 56.61 \\
\hline $2,5 \mathrm{~L} 2$ & 4 & 1.75 & 26 & 11.41 & $4 \mathrm{M} 1,5$ & 1 & 0.44 & 130 & 57.05 \\
\hline $2,5 \mathrm{~L} 2,5$ & 1 & 0.44 & 27 & 11.85 & $4 \mathrm{M} 2$ & 1 & 0.44 & 131 & 57.49 \\
\hline $2,5 \mathrm{M} 1$ & 2 & 0.88 & 29 & 12.73 & $4 \mathrm{M} 2,5$ & 2 & 0.88 & 133 & 58.37 \\
\hline $2,5 \mathrm{M} 2$ & 1 & 0.44 & 30 & 13.17 & $4 \mathrm{M} 3$ & 11 & 4.82 & 144 & 63.19 \\
\hline $2,5 \mathrm{M} 2,5$ & 2 & 0.88 & 32 & 14.05 & $4 \mathrm{R} 1,5$ & 1 & 0.44 & 145 & 63.63 \\
\hline $2,5 \mathrm{M} 3$ & 1 & 0.44 & 33 & 14.49 & 4R2 & 1 & 0.44 & 146 & 64.07 \\
\hline $2,5 \mathrm{R} 2,5$ & 1 & 0.44 & 34 & 14.93 & 4R2,5 & 3 & 1.32 & 149 & 65.39 \\
\hline $3 \mathrm{~L} 1,5$ & 3 & 1.32 & 37 & 16.25 & $4,5 \mathrm{M} 1$ & 5 & 2.19 & 154 & 67.58 \\
\hline 3L2 & 5 & 2.19 & 42 & 18.44 & $4,5 \mathrm{M} 1,5$ & 20 & 8.77 & 174 & 76.35 \\
\hline $3 \mathrm{~L} 2,5$ & 2 & 0.88 & 44 & 19.32 & $4,5 \mathrm{M} 2$ & 4 & 1.75 & 178 & 78.1 \\
\hline $3 \mathrm{M} 1$ & 11 & 4.82 & 55 & 24.14 & $4,5 \mathrm{M} 2,5$ & 18 & 7.89 & 196 & 85.99 \\
\hline $3 \mathrm{M} 2$ & 2 & 0.88 & 57 & 25.02 & $4,5 \mathrm{M} 3$ & 7 & 3.07 & 203 & 89.06 \\
\hline $3 \mathrm{M} 2,5$ & 3 & 1.32 & 60 & 26.34 & $5 \mathrm{M} 1$ & 6 & 2.63 & 209 & 91.69 \\
\hline $3 \mathrm{M} 3$ & 5 & 2.19 & 65 & 28.53 & $5 \mathrm{M} 1,5$ & 5 & 2.19 & 214 & 93.88 \\
\hline $3 \mathrm{R} 2,5$ & 1 & 0.44 & 66 & 28.97 & $5 \mathrm{M} 2$ & 3 & 1.32 & 217 & 95.2 \\
\hline $3,5 \mathrm{~L} 1,5$ & 10 & 4.39 & 76 & 33.36 & $5 \mathrm{M} 2,5$ & 6 & 2.63 & 223 & 97.83 \\
\hline $3,5 \mathrm{~L} 2$ & 4 & 1.75 & 80 & 35.11 & $5 \mathrm{M} 3$ & 5 & 2.19 & 228 & 100.00 \\
\hline $3,5 \mathrm{~L} 2,5$ & 1 & 0.44 & 81 & 35.55 & & & & & \\
\hline
\end{tabular}

\section{Tabla 32}

\subsubsection{3.- Mujeres}

\subsubsection{1.- Muestra total de mujeres:}

Con respecto a la muestra total del género femenino, se observa que existen bastantes más colores que no están presentes respecto a los valores de los hombres. Concretamente, están ausentes los colores 0M3, 3R2,5; 3,5M3, 4L2, 4M2, 4R1,5 y $5 \mathrm{M} 2$.

Otra observación importante, que aparece en la tabla 33, es la coincidencia con la mayoría de las cifras encontradas en la tabla de los hombres, respecto a los colores más frecuentes. 
Los colores más frecuentes y por este orden en este grupo son: el 1M1,5, el 2L1,5, el $3 \mathrm{M} 1$ y el 2M1, representando el total de estos colores un porcentaje del $30,43 \%$, respecto al total de los valores registrados en la tabla .

Resumiendo, el $74 \%$ de la muestra total de las mujeres se encuentra en unos valores de color más luminosos que oscuros (26\%). Un porcentaje tan solo superior al de los hombres en un $9,66 \%$.

La frecuencia más numerosa 298 registros presentan colores entre el 1M1,5 y el 2M1, junto con el color 3M1 que presenta 54 registros.

El $43.31 \%$ de las mujeres tienen un color que está representado dentro de la guía 3D Master, es decir, un total de 298 mujeres.

El $64.24 \%$ (442 sujetos) de las mujeres estudiadas tienen un tinte objetivo $\mathrm{M}$, seguido por un $28.48 \%$ (196 sujetos) perteneciente a un tinte $\mathrm{L}$, y por último, al igual que sucede con los hombres el tinte $\mathrm{R}$, que tiene una representación de $7.28 \%$ (50sujetos). Recordamos que para efectuar estos cálculos hemos omitido los resultados con valor 0,2 sujetos.

\begin{tabular}{|c|c|c|c|c|c|c|c|c|c|}
\hline \multicolumn{10}{|c|}{ METODO OBJETIVO } \\
\hline \multicolumn{10}{|c|}{ FRECUENCIA DE COLORES } \\
\hline \multicolumn{10}{|c|}{ Mujeres } \\
\hline Color & $\mathbf{F}$ & $\mathbf{P}$ & F. A. & P. A. & Color & $\mathbf{F}$ & $\mathbf{P}$ & F. A. & P. A. \\
\hline $0 M 1,5$ & 1 & 0.14 & 1 & 0.14 & $3 \mathrm{M} 1$ & 54 & 7.83 & 511 & 74 \\
\hline $0,5 \mathrm{M} 2$ & 1 & 0.14 & 2 & 0.28 & $3 \mathrm{M} 1,5$ & 2 & 0.29 & 513 & 74.29 \\
\hline $1 \mathrm{M} 1$ & 34 & 4.93 & 36 & 5.21 & $3 \mathrm{M} 2$ & 3 & 0.43 & 516 & 74.72 \\
\hline $1 \mathrm{M} 1,5$ & 61 & 8.84 & 97 & 14.05 & $3 \mathrm{M} 2,5$ & 5 & 0.72 & 521 & 75.44 \\
\hline $1 \mathrm{M} 2$ & 25 & 3.62 & 122 & 17.67 & $3 \mathrm{M} 3$ & 6 & 0.87 & 527 & 76.31 \\
\hline $1,5 \mathrm{M} 1$ & 9 & 1.30 & 131 & 18.97 & $3 \mathrm{R} 1,5$ & 2 & 0.29 & 529 & 76.6 \\
\hline $1,5 \mathrm{M} 1,5$ & 30 & 4.35 & 161 & 23.32 & 3R2 & 5 & 0.72 & 534 & 77.32 \\
\hline $1,5 \mathrm{M} 2$ & 9 & 1.30 & 170 & 24.62 & $3,5 \mathrm{~L} 1,5$ & 14 & 2.03 & 548 & 79.35 \\
\hline $1,5 \mathrm{M} 2,5$ & 7 & 1.01 & 177 & 25.63 & 3,5L2 & 9 & 1.30 & 557 & 80.65 \\
\hline $2 \mathrm{~L} 1,5$ & 59 & 8.55 & 236 & 34.18 & $3,5 \mathrm{~L} 2,5$ & 3 & 0.43 & 560 & 81.08 \\
\hline 2L2 & 10 & 1.45 & 246 & 35.63 & $3,5 \mathrm{M} 1$ & 31 & 4.49 & 591 & 85.57 \\
\hline $2 \mathrm{~L} 2,5$ & 9 & 1.30 & 255 & 36.93 & $3,5 \mathrm{M} 1,5$ & 5 & 0.72 & 596 & 86.29 \\
\hline $2 \mathrm{M} 1$ & 45 & 6.52 & 300 & 43.45 & $3,5 \mathrm{M} 2$ & 1 & 0.14 & 597 & 86.43 \\
\hline $2 \mathrm{M} 1,5$ & 1 & 0.14 & 301 & 43.59 & $3,5 \mathrm{M} 2,5$ & 6 & 0.87 & 603 & 87.3 \\
\hline $2 \mathrm{M} 2$ & 3 & 0.43 & 304 & 44.02 & $3,5 \mathrm{R} 1,5$ & 5 & 0.72 & 608 & 88.02 \\
\hline $2 \mathrm{M} 2,5$ & 1 & 0.14 & 305 & 44.16 & 3,5R2 & 6 & 0.87 & 614 & 88.89 \\
\hline $2 \mathrm{M} 3$ & 7 & 1.01 & 312 & 45.17 & $3,5 \mathrm{R} 2,5$ & 7 & 1.01 & 621 & 89.9 \\
\hline $2 \mathrm{R} 1,5$ & 4 & 0.58 & 316 & 45.75 & 4L1,5 & 6 & 0.87 & 621 & 90.77 \\
\hline
\end{tabular}




\begin{tabular}{|c|c|c|c|c|c|c|c|c|c|}
\hline \multicolumn{10}{|c|}{ Mujeres } \\
\hline \multicolumn{10}{|c|}{ FRECUENCIA DE COLORES } \\
\hline Color & F & P & F. A. & P. A. & Color & F & P & F. A. & P. A. \\
\hline 2R2 & 8 & 1.16 & 324 & 46.91 & $4 \mathrm{~L} 2,5$ & 1 & 0.14 & 622 & 90.91 \\
\hline $2 \mathrm{R} 2,5$ & 2 & 0.29 & 326 & 47.2 & $4 \mathrm{M} 1$ & 11 & 1.59 & 633 & 92.50 \\
\hline $2,5 \mathrm{~L} 1,5$ & 39 & 5.65 & 365 & 52.85 & $4 \mathrm{M} 1,5$ & 3 & 0.43 & 636 & 92.93 \\
\hline $2,5 \mathrm{~L} 2$ & 20 & 2.90 & 385 & 55.75 & $4 \mathrm{M} 2,5$ & 1 & 0.14 & 637 & 93.07 \\
\hline $2,5 \mathrm{~L} 2,5$ & 3 & 0.43 & 388 & 56.18 & $4 \mathrm{M} 3$ & 3 & 0.43 & 640 & 93.50 \\
\hline $2,5 \mathrm{M} 1$ & 22 & 3.19 & 410 & 59.37 & $4 \mathrm{R} 2$ & 1 & 0.14 & 641 & 93.64 \\
\hline $2,5 \mathrm{M} 1,5$ & 4 & 0.58 & 414 & 59.95 & $4 \mathrm{R} 2,5$ & 1 & 0.14 & 642 & 93.78 \\
\hline $2,5 \mathrm{M} 2$ & 4 & 0.58 & 418 & 60.53 & $4,5 \mathrm{M} 1$ & 6 & 0.87 & 648 & 94.65 \\
\hline $2,5 \mathrm{M} 2,5$ & 3 & 0.43 & 421 & 60.96 & $4,5 \mathrm{M} 1,5$ & 16 & 2.32 & 664 & 96.97 \\
\hline $2,5 \mathrm{M} 3$ & 4 & 0.58 & 425 & 61.54 & $4,5 \mathrm{M} 2$ & 7 & 1.01 & 671 & 97.98 \\
\hline $2,5 \mathrm{R} 1,5$ & 2 & 0.29 & 427 & 61.83 & $4,5 \mathrm{M} 2,5$ & 4 & 0.58 & 675 & 98.53 \\
\hline $2,5 \mathrm{R} 2$ & 6 & 0.87 & 433 & 62.7 & $4,5 \mathrm{M} 3$ & 1 & 0.14 & 676 & 98.69 \\
\hline $2,5 \mathrm{R} 2,5$ & 1 & 0.14 & 434 & 62.84 & $5 \mathrm{M} 1$ & 3 & 0.43 & 679 & 99.12 \\
\hline 3L1,5 & 11 & 1.59 & 445 & 64.43 & $5 \mathrm{M} 1,5$ & 3 & 0.43 & 682 & 99.55 \\
\hline 3L2 & 4 & 0.58 & 449 & 65.01 & $5 \mathrm{M} 2,5$ & 1 & 0.14 & 683 & 99.79 \\
\hline 3L2,5 & 8 & 1.16 & 457 & 66.17 & $5 \mathrm{M} 3$ & 1 & 0.14 & 684 & 100.00 \\
\hline
\end{tabular}

Tabla 33

\subsubsection{2.- Mujeres menores de 30 años:}

En las mujeres menores de 30 años el color que aparece con más frecuencia es el 1M1,5 (21,66\%), casualmente igual que en los hombres es el color más frecuente, aunque con una pequeña diferencia de porcentaje a favor de las mujeres de $7,10 \%$. Siguen como colores más frecuentes y por este orden: el $1 \mathrm{M} 1(13,82 \%)$, el 2L1,5 $(10,14 \%)$ y $1 \mathrm{M} 2(9,22 \%)$

Hay veinticuatro tablillas de colores que no tienen ninguna representación. Todos ellos se encuentran entre el color 2M1,5 y el 3,5M3; es decir, en los colores o escala de los menos luminosos o más grises. También, se observa que existen 6 colores con un solo representante en el tramo de colores anteriormente citado.

Es importante, según señala la tabla 34, que ninguna de las mujeres vinculadas a este estudio y dentro de este grupo alcanzó el valor número 4, al igual que en el grupo de los hombres menores de treinta años.

El 47,92 \% de las mujeres menores de 30 años se encuentran con un valor o luminosidad igual o inferior al 1,5M1. Recuerdo que en los hombres menores de 30 
años el resultado es muy similar. El ecuador se encuentra entre el color 1,5M,5 y $1,5 \mathrm{M} 2$.

El $48.37 \%$ de la mujeres menores de treinta años (104 sujetos) está representada dentro de la guía de color 3D Master. Señalamos que dentro de estos 104 representantes no existe ninguna mujer con el tinte $\mathrm{R}$.

\begin{tabular}{|c|c|c|c|c|}
\hline \multicolumn{5}{|c|}{ METODO OBJETIVO } \\
\hline \multicolumn{5}{|c|}{ FRECUENCIA DE COLORES } \\
\hline \multicolumn{5}{|c|}{ Mujeres <30 años } \\
\hline Color & Frecuencia & Porcentaje & F. Acumulada & P. Acumulado \\
\hline $0 \mathrm{M} 1,5$ & 1 & 0.46 & 1 & 0.46 \\
\hline $0,5 \mathrm{M} 2$ & 1 & 0.46 & 2 & 0.92 \\
\hline $1 \mathrm{M} 1$ & 30 & 13.82 & 32 & 14.74 \\
\hline $1 \mathrm{M} 1,5$ & 47 & 21.66 & 79 & 36.4 \\
\hline $1 \mathrm{M} 2$ & 20 & 9.22 & 99 & 45.62 \\
\hline $1,5 \mathrm{M} 1$ & 5 & 2.30 & 104 & 47.92 \\
\hline $1,5 \mathrm{M} 1,5$ & 18 & 8.29 & 122 & 56.21 \\
\hline $1,5 \mathrm{M} 2$ & 7 & 3.23 & 129 & 59.44 \\
\hline $1,5 \mathrm{M} 2,5$ & 3 & 1.38 & 132 & 60.82 \\
\hline $2 \mathrm{~L} 1,5$ & 22 & 10.14 & 154 & 70.96 \\
\hline 2L2 & 8 & 3.69 & 162 & 74.65 \\
\hline $2 \mathrm{~L} 2,5$ & 3 & 1.38 & 165 & 76.03 \\
\hline $2 \mathrm{M} 1$ & 14 & 6.45 & 179 & 82.48 \\
\hline $2 \mathrm{M} 2$ & 2 & 0.92 & 181 & 83.4 \\
\hline $2 \mathrm{M3}$ & 3 & 1.38 & 184 & 84.78 \\
\hline $2 \mathrm{R} 2$ & 1 & 0.46 & 185 & 85.24 \\
\hline $2,5 \mathrm{~L} 1,5$ & 11 & 5.07 & 196 & 90.31 \\
\hline $2,5 \mathrm{~L} 2$ & 3 & 1.38 & 199 & 91.69 \\
\hline $2,5 \mathrm{M} 1$ & 4 & 1.84 & 203 & 93.53 \\
\hline $2,5 \mathrm{R} 2$ & 1 & 0.46 & 204 & 93.99 \\
\hline $3 \mathrm{~L} 1,5$ & 2 & 0.92 & 206 & 94.91 \\
\hline 3L2 & 1 & 0.46 & 207 & 95.37 \\
\hline $3 \mathrm{~L} 2,5$ & 1 & 0.46 & 208 & 95.83 \\
\hline $3 \mathrm{M} 1$ & 7 & 3.23 & 215 & 99.06 \\
\hline $3,5 \mathrm{M} 1$ & 1 & 0.46 & 216 & 99.52 \\
\hline $3,5 \mathrm{M} 2,5$ & 1 & 0.46 & 217 & 100.00 \\
\hline
\end{tabular}

Tabla 34

\subsubsection{3. - Mujeres entre 30-59 años:}

Al igual que en el grupo de los hombres, se observa que no existe ninguna mujer con el valor de 0 . Además, en este grupo, tampoco hay nadie con el valor de 5 y tan sólo $15(6,01 \%)$, aparecen dentro de la gama del valor 4 . 
Se puede comprobar, en la tabla 35, que la ausencia de sujetos en este grupo de mujeres al igual que en el grupo de los hombres en los colores 2M2,5, 3M2,5, 4L2,5, $4,5 \mathrm{M} 3,5 \mathrm{M} 1,5 \mathrm{M} 2$ y $5 \mathrm{M} 3$.

Los tres colores con más presencia en este grupo de mujeres son por este orden: el $2 \mathrm{M} 1$ con un peso de 27 individuos (10.84\%), seguido con 25 representantes en el color 2L1,5 (10.04\%) y también con 25 representantes el color 3M1. Significando estos tres colores el $30,92 \%$ del total de la muestra.

En este grupo se observa, de forma global, que el 49,78 \% de las mujeres presentan unas tonalidades de color entre el $1 \mathrm{M} 1$ y el 2,5L1,5, mientras que en los hombres de este grupo la gama del $50 \%$ llega al color $3 \mathrm{M} 1$. Por lo cual, se puede estimar que existe una mayor frecuencia de colores más claros en las mujeres que en los hombres comprendidos en este tramo de edad.

Un 46.98\% de este grupo está representado por las 26 tablillas de la guía 3D Master, con un numero de sujetos de 117.

\begin{tabular}{|c|c|c|c|c|c|c|c|c|c|}
\hline \multicolumn{10}{|c|}{ FRECUENCIA DE COLORES } \\
\hline \multicolumn{10}{|c|}{ Mujeres 30-59 años } \\
\hline Color & $\mathbf{F}$ & $\mathbf{P}$ & F. A. & P. A. & Color & $\mathbf{F}$ & $\mathbf{P}$ & F. A. & P. A. \\
\hline $1 \mathrm{M} 1$ & 4 & 1.61 & 4 & 1.61 & 2,5R2 & 4 & 1.61 & 158 & 63.43 \\
\hline $1 \mathrm{M} 1,5$ & 10 & 4.02 & 14 & 5.63 & $2,5 \mathrm{R} 2,5$ & 1 & 0.40 & 159 & 63.83 \\
\hline $1 \mathrm{M} 2$ & 5 & 2.01 & 19 & 7.64 & $3\llcorner 1,5$ & 5 & 2.01 & 164 & 65.84 \\
\hline $1,5 \mathrm{M} 1$ & 4 & 1.61 & 23 & 9.25 & $3 \mathrm{~L} 2$ & 2 & 0.80 & 166 & 66.64 \\
\hline $1,5 \mathrm{M} 1,5$ & 12 & 4.82 & 35 & 14.07 & $3 \mathrm{~L} 2,5$ & 2 & 0.80 & 168 & 67.44 \\
\hline $1,5 \mathrm{M} 2$ & 2 & 0.80 & 37 & 14.87 & $3 \mathrm{M} 1$ & 25 & 10.04 & 193 & 77.48 \\
\hline $1,5 \mathrm{M} 2,5$ & 1 & 0.40 & 38 & 15.27 & $3 \mathrm{M} 2$ & 2 & 0.80 & 195 & 78.28 \\
\hline $2 \mathrm{~L} 1,5$ & 25 & 10.04 & 63 & 25.31 & $3 \mathrm{M3}$ & 1 & 0.40 & 196 & 78.68 \\
\hline 2L2 & 2 & 0.80 & 65 & 26.11 & 3R2 & 4 & 1.61 & 200 & 80.29 \\
\hline $2 \mathrm{~L} 2,5$ & 4 & 1.61 & 69 & 27.72 & $3,5 \mathrm{~L} 1,5$ & 4 & 1.61 & 204 & 81.9 \\
\hline $2 \mathrm{M} 1$ & 27 & 10.84 & 96 & 38.56 & $3,5 \mathrm{~L} 2$ & 2 & 0.80 & 206 & 82.7 \\
\hline $2 \mathrm{M} 1,5$ & 1 & 0.40 & 97 & 38.96 & $3,5 \mathrm{M} 1$ & 18 & 7.23 & 224 & 89.93 \\
\hline $2 \mathrm{M} 2$ & 1 & 0.40 & 98 & 39.36 & $3,5 \mathrm{M} 1,5$ & 3 & 1.20 & 227 & 91.13 \\
\hline $2 \mathrm{M} 3$ & 3 & 1.20 & 101 & 40.56 & $3,5 \mathrm{M} 2$ & 1 & 0.40 & 228 & 91.53 \\
\hline $2 \mathrm{R} 1,5$ & 3 & 1.20 & 104 & 41.76 & $3,5 \mathrm{M} 2,5$ & 1 & 0.40 & 229 & 91.93 \\
\hline 2R2 & 3 & 1.20 & 107 & 42.96 & $3,5 \mathrm{R} 1,5$ & 3 & 1.20 & 232 & 93.13 \\
\hline $2 \mathrm{R} 2,5$ & 2 & 0.80 & 109 & 43.76 & 3,5R2 & 1 & 0.40 & 233 & 93.53 \\
\hline $2,5 \mathrm{~L} 1,5$ & 15 & 6.02 & 124 & 49.78 & $3,5 \mathrm{R} 2,5$ & 1 & 0.40 & 234 & 93.93 \\
\hline $2,5 \mathrm{~L} 2$ & 7 & 2.81 & 131 & 52.59 & 4L1,5 & 3 & 1.20 & 237 & 95.13 \\
\hline $2,5 \mathrm{~L} 2,5$ & 3 & 1.20 & 134 & 53.79 & $4 \mathrm{M} 1$ & 4 & 1.61 & 241 & 96.74 \\
\hline $2,5 \mathrm{M} 1$ & 12 & 4.82 & 146 & 58.61 & 4R2 & 1 & 0.40 & 242 & 97.14 \\
\hline $2,5 \mathrm{M} 1,5$ & 4 & 1.61 & 150 & 60.22 & $4 \mathrm{R} 2,5$ & 1 & 0.40 & 243 & 97.54 \\
\hline $2,5 \mathrm{M} 2,5$ & 2 & 0.80 & 152 & 61.02 & $4,5 \mathrm{M} 1$ & 2 & 0.80 & 245 & 98.34 \\
\hline
\end{tabular}




\begin{tabular}{|c|c|c|c|c|c|c|c|c|c|}
\hline \multicolumn{10}{|c|}{ FRECUENCIA DE COLORES } \\
\hline \multicolumn{10}{|c|}{ Mujeres 30-59 años } \\
\hline Color & F & P & F. A. & P. A. & Color & F & P & F. A. & P. A. \\
\hline $2,5 \mathrm{M} 3$ & 1 & .40 & 153 & 61.42 & $4,5 \mathrm{M} 1,5$ & 3 & 1.20 & 248 & 99.60 \\
\hline $2,5 \mathrm{R} 1,5$ & 1 & 0.40 & 154 & 61.82 & $4,5 \mathrm{M} 2$ & 1 & 0.40 & 249 & 100.00 \\
\hline
\end{tabular}

\section{Tabla 35}

\subsubsection{4.- Mujeres mayores de 60 años:}

El color $3 \mathrm{M} 1$ es el que aparece con más frecuencia $(9.82 \%)$, seguido por el color $2,5 \mathrm{~L} 1,5(5.80 \%)$ y el tercer lugar lo comparten dos colores con un representación de 12 sujetos cada uno: el 2L1,5 y el 3,5M1 (5.36\%).

Otros aspectos a destacar en este grupo, según la tabla 36, son:

No existen sujetos para el valor 0 , al igual que ocurre en el grupo de hombres de esta edad.

En los colores siguientes: 1,5M1, 1,5M1,5, 1,5M2, 2M1,5, 2M2, 2,5M,1,5 y 2,5R2,5, no hay ninguna mujer como en el grupo de los hombres.

Es relevante observar como en el grupo con el valor 4, hay 43 casos; mientras que en este mismo grupo de color en los hombres hay 86 representantes, el doble que en las mujeres.

En el grupo con valor 5, se constatan 8 casos en mujeres y en el grupo de los hombres 25; es decir el triple de hombres que de mujeres con esta gama de color.

Existe el color con menos valor de este grupo es el $1 \mathrm{M} 1,5(0.44 \%)$ y en solo seis sujetos varones con más de 60 años encontramos valor 1.

Para el tinte $\mathrm{R}$, un total de 11 sujetos lo reflejaban siendo así solo un $4.82 \%$ del grupo.

El color que representa las 26 tablillas de las guía 3D Master contiene a 88 mujeres con edad superior a 60 años (39.28\%). 


\begin{tabular}{|c|c|c|c|c|c|c|c|c|c|}
\hline \multicolumn{10}{|c|}{ METODO OBJETIVO } \\
\hline \multicolumn{10}{|c|}{ FRECUENCIA DE COLORES } \\
\hline \multicolumn{10}{|c|}{ Mujeres $\geq 60$ años } \\
\hline Color & $\mathbf{F}$ & $\mathbf{P}$ & F. A. & P. A. & Color & $\mathbf{F}$ & $\mathbf{P}$ & F. A. & P. A. \\
\hline $1 \mathrm{M} 1,5$ & 4 & 1.79 & 4 & 1.79 & $3 R 2$ & 1 & 0.45 & 119 & 53.15 \\
\hline $1,5 \mathrm{M} 2,5$ & 3 & 1.34 & 7 & 3.13 & $3,5 \mathrm{~L} 1,5$ & 10 & 4.46 & 129 & 57.61 \\
\hline $2 \mathrm{~L} 1,5$ & 12 & 5.36 & 19 & 8.49 & $3,5 \mathrm{~L} 2$ & 7 & 3.13 & 136 & 60.74 \\
\hline $2 \mathrm{~L} 2,5$ & 2 & 0.89 & 21 & 9.38 & $3,5 \mathrm{~L} 2,5$ & 3 & 1.34 & 139 & 62.08 \\
\hline $2 \mathrm{M} 1$ & 4 & 1.79 & 25 & 11.17 & $3,5 \mathrm{M} 1$ & 12 & 5.36 & 151 & 67.44 \\
\hline $2 \mathrm{M} 2,5$ & 1 & 0.45 & 26 & 11.62 & $3,5 \mathrm{M} 1,5$ & 2 & 0.89 & 153 & 68.33 \\
\hline $2 \mathrm{M} 3$ & 1 & 0.45 & 27 & 12.07 & $3,5 \mathrm{M} 2,5$ & 4 & 1.79 & 157 & 70.12 \\
\hline $2 \mathrm{R} 1,5$ & 1 & 0.45 & 28 & 12.52 & $3,5 \mathrm{R} 1,5$ & 2 & 0.89 & 159 & 71.01 \\
\hline 2R2 & 4 & 1.79 & 32 & 14.31 & 3,5R2 & 5 & 2.23 & 164 & 73.24 \\
\hline $2,5 \mathrm{~L} 1,5$ & 13 & 5.80 & 45 & 20.11 & $3,5 \mathrm{R} 2,5$ & 6 & 2.68 & 170 & 75.92 \\
\hline $2,5 \mathrm{~L} 2$ & 10 & 4.46 & 55 & 24.57 & $4 \mathrm{~L} 1,5$ & 3 & 1.34 & 173 & 77.26 \\
\hline $2,5 \mathrm{M} 1$ & 6 & 2.68 & 61 & 27.25 & 4L2,5 & 1 & 0.45 & 174 & 77.71 \\
\hline $2,5 \mathrm{M} 2$ & 4 & 1.79 & 65 & 29.03 & $4 \mathrm{M} 1$ & 7 & 3.13 & 181 & 80.84 \\
\hline $2,5 \mathrm{M} 2,5$ & 1 & 0.45 & 66 & 29.48 & $4 \mathrm{M} 1,5$ & 3 & 1.34 & 184 & 82.18 \\
\hline $2,5 \mathrm{M} 3$ & 3 & 1.34 & 69 & 30.82 & $4 \mathrm{M} 2,5$ & 1 & 0.45 & 185 & 82.63 \\
\hline $2,5 \mathrm{R} 1,5$ & 1 & 0.45 & 70 & 31.27 & $4 \mathrm{M} 3$ & 3 & 1.34 & 188 & 83.97 \\
\hline $2,5 \mathrm{R} 2$ & 1 & 0.45 & 71 & 31.72 & $4,5 \mathrm{M} 1$ & 4 & 1.79 & 192 & 85.76 \\
\hline $3 \mathrm{~L} 1,5$ & 4 & 1.79 & 75 & 33.51 & $4,5 \mathrm{M} 1,5$ & 13 & 5.80 & 205 & 91.56 \\
\hline $3 \mathrm{~L} 2$ & 1 & 0.45 & 76 & 33.96 & $4,5 \mathrm{M} 2$ & 6 & 2.68 & 211 & 94.24 \\
\hline 3L2,5 & 5 & 2.23 & 81 & 36.19 & $4,5 \mathrm{M} 2,5$ & 4 & 1.79 & 215 & 96.03 \\
\hline $3 \mathrm{M} 1$ & 22 & 9.82 & 103 & 46.01 & $4,5 \mathrm{M} 3$ & 1 & 0.45 & 216 & 96.48 \\
\hline $3 \mathrm{M} 1,5$ & 2 & 0.89 & 105 & 46.90 & $5 \mathrm{M} 1,5$ & 3 & 1.34 & 219 & 97.37 \\
\hline $3 \mathrm{M} 2$ & 1 & 0.45 & 106 & 47.35 & $5 \mathrm{M} 2$ & 3 & 1.34 & 222 & 98.71 \\
\hline $3 \mathrm{M} 2,5$ & 5 & 2.23 & 111 & 49.58 & $5 \mathrm{M} 2,5$ & 1 & 0.45 & 223 & 99.55 \\
\hline $3 \mathrm{M} 3$ & 5 & 2.23 & 116 & 51.81 & $5 \mathrm{M} 3$ & 1 & 0.45 & 224 & 100.00 \\
\hline $3 R 1,5$ & 2 & 0.89 & 118 & 52.70 & & & & & \\
\hline
\end{tabular}

Tabla 36 


\section{4.- ANÁLISIS DE VARIABLES CONTINUAS ORDINALES, L, C, h ASOCIADAS A GRUPO DE EDAD Y GÉNERO}

\subsubsection{Estudio estadístico descriptivo de variables continuas}

En este apartado describimos las variables ordinales continuas, media y desviación estándar, mínimo, máximo e intervalos de confianza al 95\% correspondientes a L (Valor o Luminosidad), C (Intensidad o Croma) y h (Tinte o Tono) para cada sexo y por grupos de edad.

En la tabla resumen que exponemos a continuación, tabla 37, estudiamos el grupo d edad inferior. La variable $\mathrm{L}$, que representa el valor medio, es superior al resto de los grupos de edad tanto en hombres como en mujeres. El L máximo para mujeres es de 100 unidades y para hombres de 93.40. Sus medias correspondientes son de 83.22 para mujeres y de 82.21 para hombres.

La intensidad media (C) y el tinte promedio (h) son bastante similares en menores de treinta años en ambos sexos.

La intensidad media, estudiada en la variable ordinal $C$, es más semejante entre el grupo de menores de treinta años y el grupo de edad intermedia.

\begin{tabular}{|c|c|c|c|c|c|c|c|c|}
\cline { 2 - 9 } \multicolumn{1}{c|}{} & \multicolumn{3}{c|}{ DESCRIPTIVA VARIABLES CONTINUAS E INTERVALOS DE CONFIANZA } \\
\cline { 2 - 9 } \multicolumn{1}{c|}{ HOMBRES $<\mathbf{3 0}$ AÑOS } & \multicolumn{4}{c|}{ MUJERES <30 AÑOS } \\
\cline { 2 - 9 } & MIN & MAX & MEDIA $\pm S D$ & INF95\%-SUP95\% & MIN & MAX & MEDIA $\pm S D$ & INF95\%-SUP95\% \\
\hline $\mathbf{L}$ & 68.10 & 93.40 & $82.21 \pm 4.251$ & $81.62-82.79$ & 71.60 & 100.00 & $83.22 \pm 3.855$ & $82.70-83.74$ \\
\hline $\mathbf{C}$ & 6.700 & 34.20 & $17.98 \pm 4.176$ & $17.40-18.55$ & 7.700 & 27.80 & $16.71 \pm 3.717$ & $16.21-17.20$ \\
\hline $\mathbf{h}$ & 83.60 & 106.3 & $93.45 \pm 3.783$ & $92.93-93.97$ & 84.60 & 112.2 & $94.51 \pm 3.223$ & $94.08-94.94$ \\
\hline $\mathbf{a}$ & -3.00 & 3.700 & $-0.809 \pm 1.003$ & $-0.947 /-0.671$ & -2.90 & 2.50 & $-1.19 \pm 0.759$ & $-1.29 /-1.09$ \\
\hline $\mathbf{b}$ & 6.000 & 34.20 & $17.93 \pm 4.218$ & $17.35-18.51$ & 7.10 & 27.80 & $16.64 \pm 3.759$ & $16.13-17.14$ \\
\hline
\end{tabular}

Tabla 37

Con respecto la variable tinte, estudiada en los datos que nos aporta la variable $\mathrm{h}$ en la tabla 38, vemos que en el grupo de edad intermedia, comparado con el grupo de edad inferior, no existe prácticamente diferencias en sus cifras promedio. En el grupo de edad intermedia, el valor media $(\mathrm{L})$ y el tinte promedio $(\mathrm{h})$, son ligeramente 
superiores en mujeres que en hombres, no así la intensidad media (C) donde en hombres es superior que en mujeres.

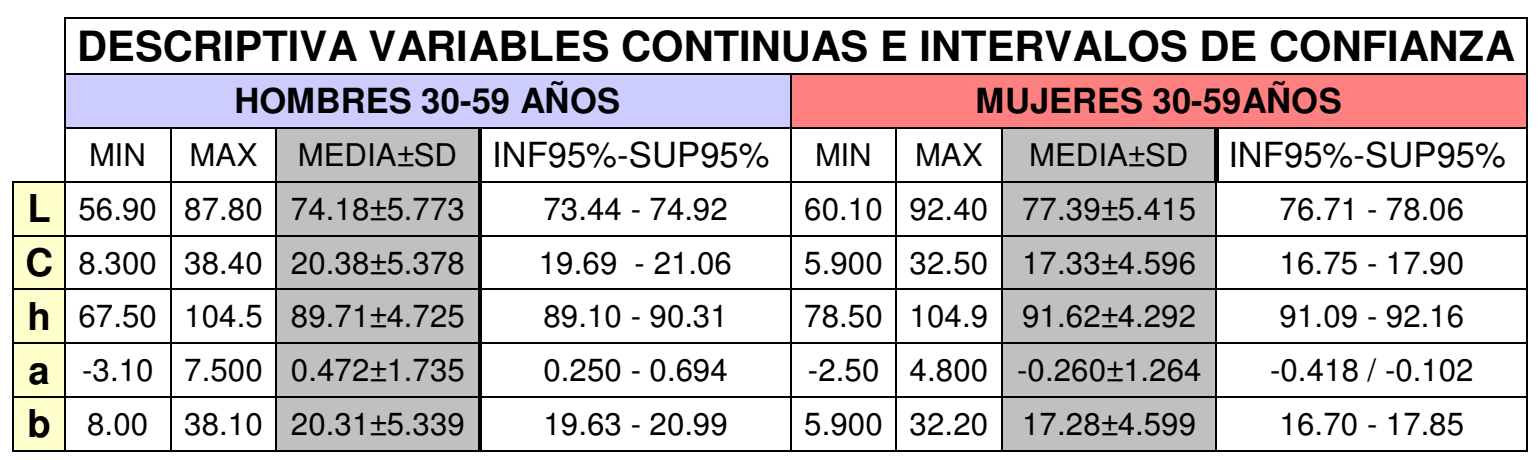

Tabla 38

En la tabla 39, donde aparece la descriptiva y los intervalos de confianza del grupo de edad de mayores de sesenta años comprobamos que al igual que sucede en los grupos de edad previos, el valor medio $(L)$ es ligeramente superior en mujeres que en hombres. Las cifras mínimas de valor (L) descienden según aumenta el grupo de edad de la población. Los datos promedios de la intensidad (C), aumentan con la edad tanto en hombres como en mujeres.

\begin{tabular}{|c|c|c|c|c|c|c|c|c|}
\cline { 2 - 9 } \multicolumn{1}{c|}{} & \multicolumn{3}{c|}{ DESCRIPTIVA VARIABLES CONTINUAS E INTERVALOS DE CONFIANZA } \\
\cline { 2 - 9 } \multicolumn{1}{c|}{ HOMBRES >60 AÑOS } & \multicolumn{4}{c|}{ MUJERES >60 AÑOS } \\
\hline & MIN & MAX & MEDIA $\pm S D$ & INF95\%-SUP95\% & MIN & MAX & MEDIA $\pm S D$ & INF95\%-SUP95\% \\
\hline L & 47.00 & 89.90 & $69.31 \pm 7.184$ & $68.37-70.25$ & 54.80 & 94.30 & $72.30 \pm 6.041$ & $71.33-72.93$ \\
\hline $\mathbf{C}$ & 7.700 & 49.80 & $25.94 \pm 7.951$ & $24.91-26.98$ & 8.600 & 39.40 & $21.16 \pm 5.989$ & $20.37-21.95$ \\
\hline $\mathbf{h}$ & 69.80 & 107.4 & $86.92 \pm 5.179$ & $86.25-87.60$ & 78.90 & 99.40 & $89.60 \pm 3.955$ & $89.08-90.12$ \\
\hline $\mathbf{a}$ & -2.30 & 16.10 & $1.981 \pm 3.006$ & $1.588-2.373$ & -2.30 & 6.400 & $0.432 \pm 1.575$ & $0.224-0.640$ \\
\hline $\mathbf{b}$ & 7.30 & 47.30 & $25.75 \pm 7.727$ & $24.74-26.76$ & 8.600 & 38.90 & $21.09 \pm 5.963$ & $20.31-21.88$ \\
\hline
\end{tabular}

Tabla 39 


\subsubsection{Estudio mediante el test de bondad de ajuste de Kolmogorov-Smirnov}

A continuación someteremos a la muestra al análisis estadístico mediante el test de bondad de ajuste de Kolmogorov-Smirnov, para comprobar si los parámetros L, C y h, se ajustan a criterios de normalidad (ver tabla 40).

\begin{tabular}{|c|c|c|c|c|c|c|}
\hline \multicolumn{7}{|c|}{ Prueba de Kolmogorov-Smirnov para una muestra } \\
\hline & & L & C & $\mathrm{h}$ & $\mathrm{a}$ & $\mathrm{b}$ \\
\hline $\mathrm{N}$ & & 1361 & 1361 & 1361 & 1361 & 1361 \\
\hline \multirow[t]{2}{*}{ Parámetros normales ${ }^{\mathrm{a}, \mathrm{b}}$} & Media & 76,2691 & 19,9317 & 90,9052 &, 1253 & 19,8499 \\
\hline & Desviación típica & 7,46921 & 6,32058 & 4,94106 & 2,00349 & 6,25137 \\
\hline Z de Kolmogorov-Smirnov & & 1,635 & 3,179 & 1,402 & 5,102 & 3,076 \\
\hline Sig. asintót. (bilateral) & & ,010 &, 000 & ,039 &, 000 &, 000 \\
\hline
\end{tabular}

a. La distribución de contraste es la Normal.

b. Se han calculado a partir de los datos.

Tabla 40

La conclusión extraída es que ninguna de estas variables se distribuye normalmente con $p<0,05$. La desviación de la normalidad podría considerarse como leve en los casos de las variables $L$ y $h$ (con valores $p$ menores al 0,05 pero mayores al 0,01 ). No es así en $C$, donde realmente hay un fuerte incumplimiento del ajuste al modelo normal de Gauss $(p<0,01)$.

En los siguientes gráficos se puede apreciar dónde están los datos recogidos que se alejan del modelo. Para entender el gráfico: una variable que se distribuyese normalmente en todos sus puntos, se dispondría totalmente encima de la diagonal del gráfico. Por tanto, todo lo que se aleje de dicha diagonal son valores que se escapan del modelo. Cuanto más alejados de la recta, más se alejan también de la normalidad.

Los puntos rojos que aparecen en el gráfico son la representación de cada uno de los datos para el valor (L), la intensidad (C) y el tinte (h) de los 1361 sujetos estudiados. Estas imágenes sucesivas nombradas como, grafico 3 , gráfico 4 , y gráfico 5 , son una idea muy real de la dispersión exacta de la recta de normalidad de cada uno de los sujetos medidos.

Vamos a insistir en la idea de localizar donde se encuentran los datos que se escapan de la norma. 
En el gráfico 3, evaluamos la variable intensidad (C). En el caso de la intensidad, los datos entre 12 aprox. y 30, si que siguen el modelo normal. La pérdida viene por fuera de ese rango, en ambos extremos. Claramente se alejan más de la norma los datos con una $C$ más elevada, mientras que los datos comprendidos aproximadamente entre los 12 y los 32 puntos, estarían dentro del modelo de Gauss.

\section{Gráfico Q-Q normal de C}

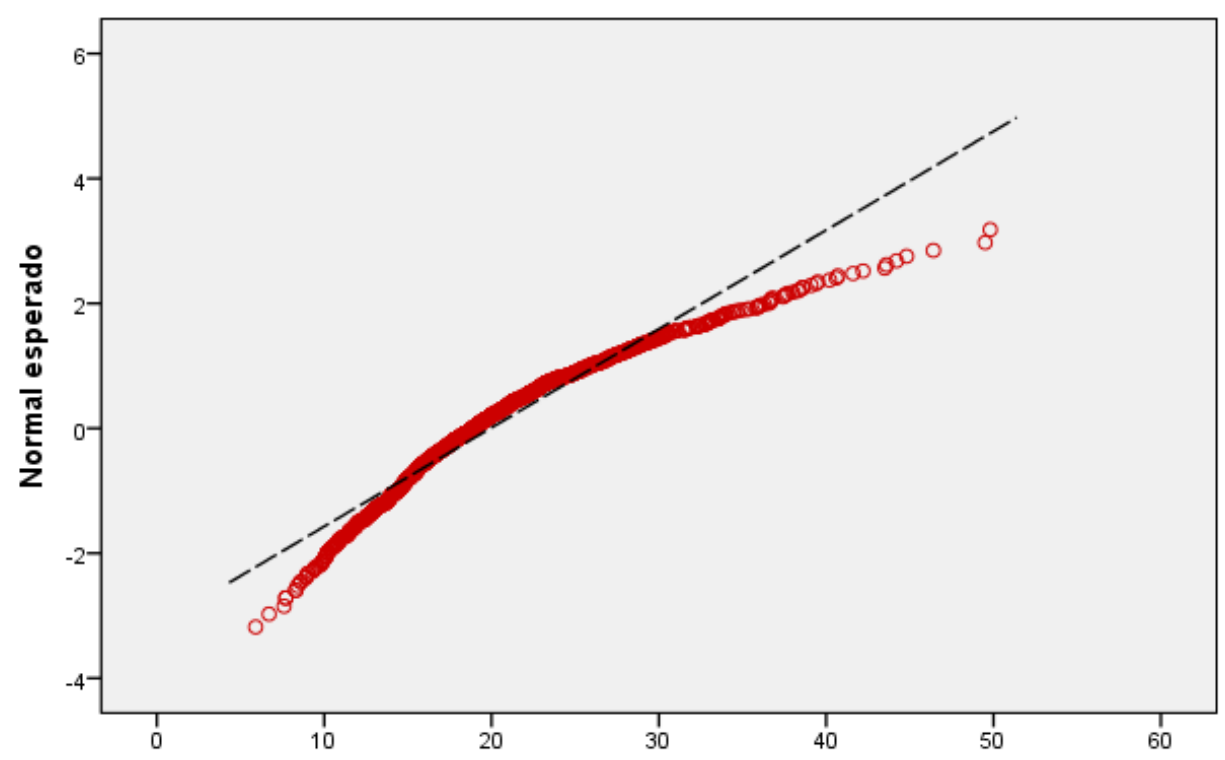

Gráfico 3

En el siguiente gráfico, gráfico 4, evaluamos la variable valor o luminosidad (L). Al visualizar la distribución de la luminosidad, observamos que los datos que se encuentran aproximadamente entre 60 y 90, si que siguen el modelo normal. La pérdida viene por fuera de ese rango, en ambos extremos. Los valores comprendidos aproximadamente entre los 60 y los 90 puntos, estarían dentro del modelo de la campana de Gauss. Comparada con la representación gráfica de la intensidad, el valor esperado abarca una longitud más amplia. 


\section{Gráfico Q-Q normal de L}

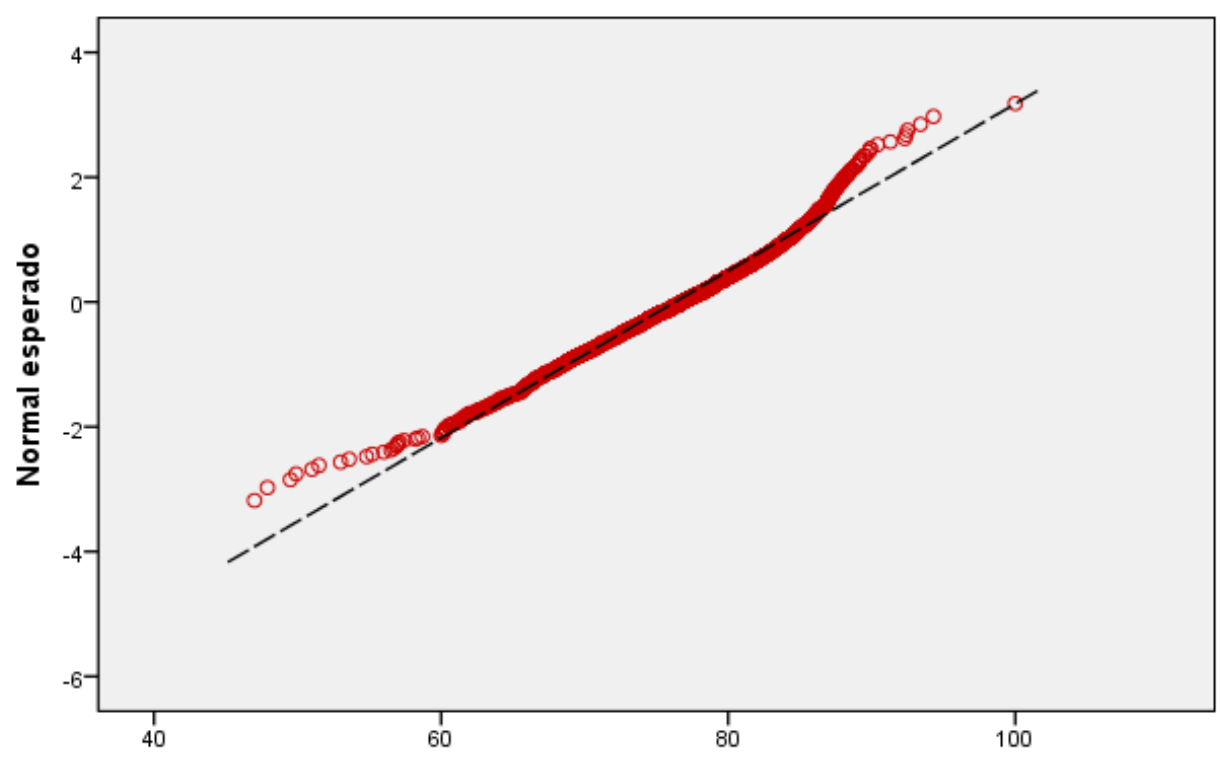

Gráfico 4

En el Gráfico 5 evaluamos la variable tinte $(\mathrm{h})$. En la variable $h$, casi todos los valores siguen el modelo normal. La pérdida se encuentra muy localizada en los extremos de la muestra. Desde la puntuación 80 hasta la puntuación105 los valores recogidos se ajustan perfectamente a la recta de normalidad esperada.

\section{Gráfico Q-Q normal de $\mathrm{h}$}

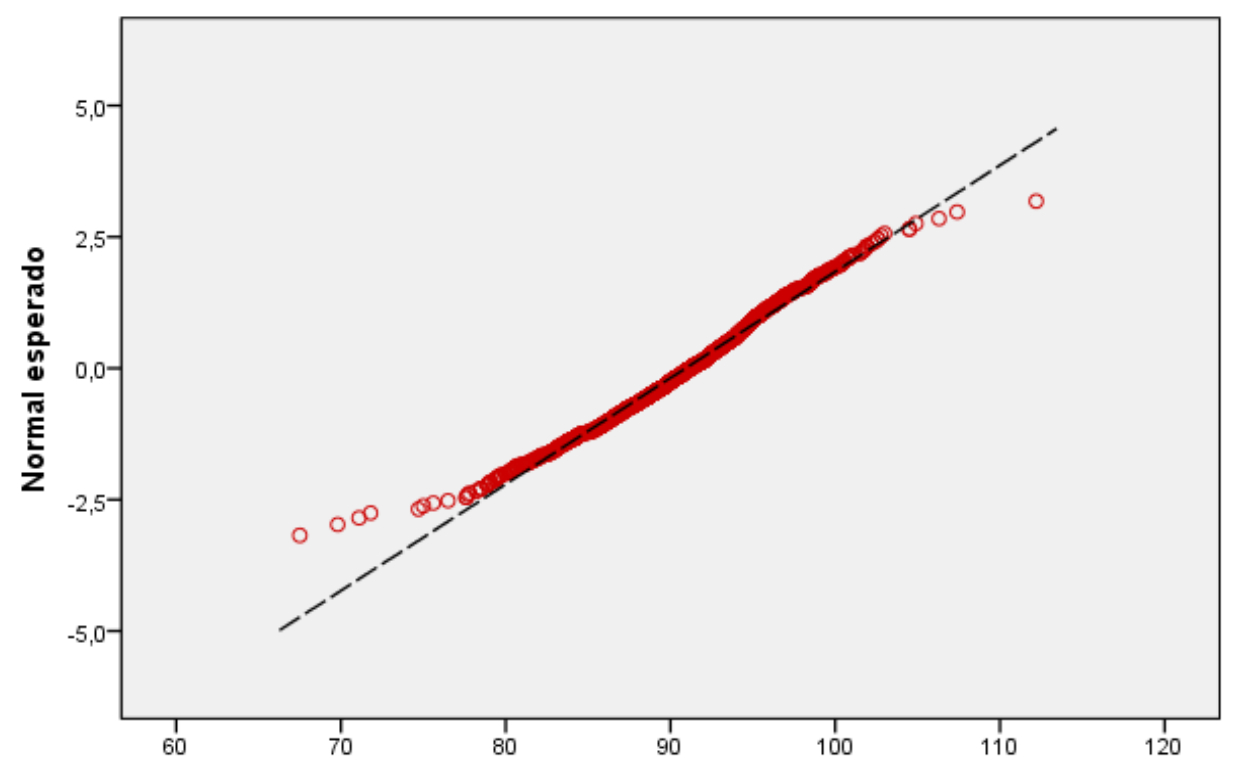

Gráfico 5 
Como consecuencia, aunque realizaremos las pruebas de la significación de la diferencia de medias con el Anova, sí que conviene corroborar con la alternativa noparamétrica que la falta de normalidad no tiene efectos significativos.

A pesar de esta falta de ajuste al modelo normal de la campana de Gauss de la que venimos hablando, de las variables $\mathrm{L} C \mathrm{y} h($ con $\mathrm{p}<, 05)$, el elevado tamaño de la muestra con la que está trabajando nos hace pensar que seguramente no vaya a tener consecuencia en su análisis a través de la prueba Anova (que tiene mayor potencia que una alternativa no-paramétrica). Sin embargo, para asegurarnos de ello, se ha procedido a realizar el estudio de las mismas tanto con Anova seguido de sus pruebas post-hoc, como con el test no-paramétrico de Kruskal-Wallis.

La ventaja de usar el Anova es que podemos analizar el efecto de la edad y del sexo, pero también el efecto conjunto de ambos factores y calcular la potencia del análisis.

\begin{tabular}{|cc|c|c|}
\hline \multicolumn{3}{|c|}{ Factores inter-sujetos a contrastar } \\
\begin{tabular}{|cc|c|c|}
\hline \multirow{2}{*}{ SEXO } & Etiqueta del valor & N \\
& H & Hombre & 671 \\
Edad (grupos) & 1 & Mujer & 690 \\
& 2 & $<30$ años & 423 \\
& 3 & de 30 a 59 años & 486 \\
& M 60 años & 452 \\
\hline
\end{tabular}
\end{tabular}

Tabla 41

\subsubsection{Valor o Luminosidad (L)}

\subsubsection{1.- Valor (L) - Grupos de edad}

La tabla 42 analiza el posible efecto de la edad sobre $L$, se determinó con una $p<0,05$ y elevada potencia que dichos valores disminuyen significativamente entre las categorías de edad establecidas, de forma tal que podemos afirmar que un $43 \%$ de las variaciones en las cifras de $L$ estarían justificadas por la edad ( $F=510,59 ; 2$ y $1355 \mathrm{gl}$; $p=0,000$; Potencia $>0,999$; tamaño del efecto 0,43 ).

Los contrastes múltiples a posteriori, realizados tanto con el método DMS como con el de Bonferroni, determinaron que la media de $L$ en el grupo de menores de 30 años de edad $(82,71$; IC al $95 \%: 82,18-83,24)$ es significativamente mayor $(p=, 000)$ que la media de grupo de entre 30 y 59 años $(75,78$; IC al 95\%: 75,29-76,28). La disminución de $L$ estimada con un $95 \%$ de confianza estaría comprendida entre: 6,20 y 7,66. 
Por su parte entre este segundo grupo de 30 y 59 años y los mayores de 60 años (media: 70,72; IC al 95\%: 70,21-71,23) también hay una disminución significativa $(p=, 000)$ de $L$; dicha disminución se puede estimar al 95\% de confianza, entre: 4,35 y 5,78 unidades.

Pruebas de los efectos inter-sujetos

Variable dependiente:L

\begin{tabular}{|l|c|c|c|c|c|c|c|}
\hline Origen & $\begin{array}{c}\text { Suma de } \\
\text { cuadrados }\end{array}$ & gl & $\begin{array}{c}\text { Media } \\
\text { cuadrática }\end{array}$ & F & Sig. & $\begin{array}{c}\text { Eta al cuadrado } \\
\text { parcial }\end{array}$ & $\begin{array}{c}\text { Potencia } \\
\text { observada }^{b}\end{array}$ \\
\hline Intersección & 7916036,722 & 1 & 7916036,722 & 255962,003 &, 000 &, 995 &, 999 \\
SEXO & 1867,091 & 1 & 1867,091 & 60,372 & $\mathbf{, 0 0 0}$ & $\mathbf{, 0 4 3}$ & $\mathbf{9 9 9}$ \\
edadc & 31581,912 & 2 & 15790,956 & 510,594 & $\mathbf{, 0 0 0}$ & $\mathbf{, 4 3 0}$ &, $\mathbf{9 9 9}$ \\
SEXO * edadc & 301,878 & 2 & 150,939 & 4,881 & $\mathbf{, 0 0 8}$ & $\mathbf{0 0 7}$ & $\mathbf{, 0 5}$ \\
Error & 41905,555 & 1355 & 30,927 & & & & \\
Total & 7992785,270 & 1361 & & & & & \\
\hline
\end{tabular}

b. Calculado con alfa $=, 05$

\section{Tabla 42}

A continuación, el gráfico 6, describe las medias de valor o luminosidad (L) por grupos de edad, se aprecia que según aumenta el grupo de edad la cantidad presente de gris en el color del incisivo central superior aumenta, con lo que la luminosidad o valor disminuye.

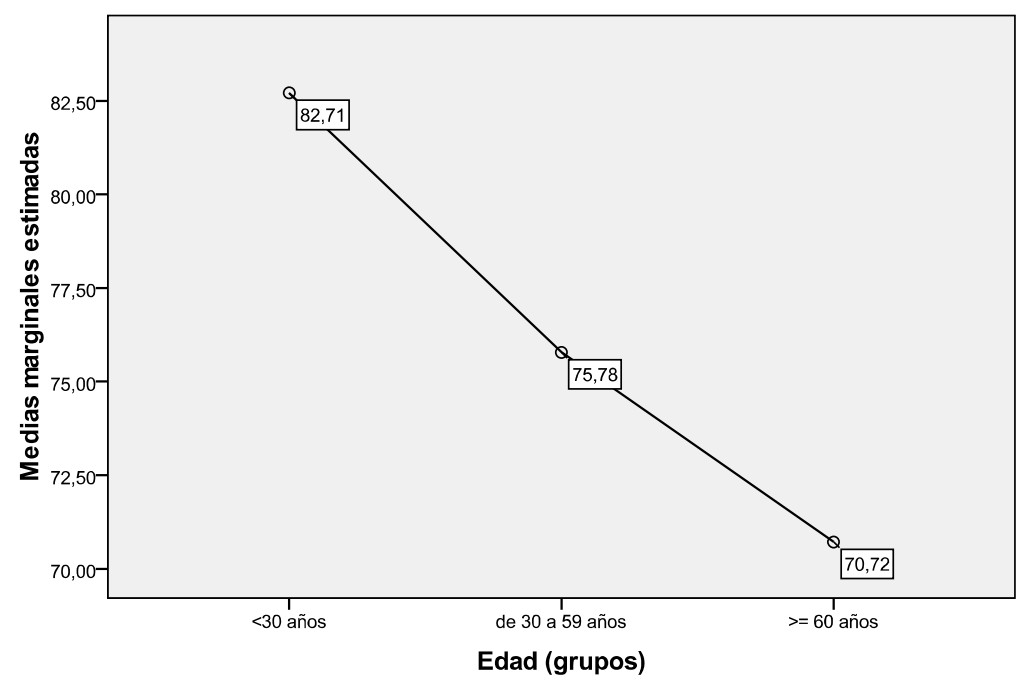

Gráfico 6

Seguidamente, como aparece la tabla 43, con los valores medio de la variable $L$, y con los intervalos de confianza al $95 \%$ de cada uno de los grupos de edad. 
Variable dependiente:L

\begin{tabular}{|l|c|c|c|c|}
\hline \multirow{2}{*}{ Edad (grupos) } & & \multirow{2}{*}{ Intervalo de confianza 95\% } \\
\cline { 4 - 5 } & Media & Error típ. & Límite inferior & Límite superior \\
\hline$<30$ años & 82,712 &, 270 & 82,182 & 83,243 \\
de 30 a 59 años & 75,783 &, 252 & 75,288 & 76,278 \\
> 60 años & 70,720 &, 262 & 70,207 & 71,233 \\
\hline
\end{tabular}

Tabla 43

En la tabla 44, comparamos si existen diferencias estadísticamente significativas entre las medias del valor entre los tres grupos de edad, y en todas las comparaciones de pares encontramos diferencias estadísticamente significativas con $p$ - valor $<0.0001$.

\begin{tabular}{|c|c|c|c|c|c|c|}
\hline \multicolumn{7}{|c|}{ Comparaciones por pares } \\
\hline riable depend & & & & & & \\
\hline \multirow[b]{2}{*}{ (I)Edad (grupos) } & \multirow[b]{2}{*}{ (J)Edad (grupos) } & \multirow{2}{*}{$\begin{array}{l}\text { Diferencia de } \\
\text { medias (I-J) }\end{array}$} & \multirow[b]{2}{*}{ Error típ. } & \multirow[b]{2}{*}{ Sig } & \multicolumn{2}{|c|}{$\begin{array}{c}\text { Intervalo de confianza al } 95 \% \\
\text { para la diferencia }\end{array}$} \\
\hline & & & & & Límite inferior & Límite superior \\
\hline \multirow[t]{2}{*}{$<30$ años } & de 30 a 59 años & 6,930 & ,370 &, 000 & 6,204 & 7,655 \\
\hline & $>=60$ años & 11,993 & ,376 &, 000 & 11,254 & 12,731 \\
\hline \multirow[t]{2}{*}{ de 30 a 59 años } & $<30$ años & $-6,930$ & ,370 & 000 & $-7,655$ & $-6,204$ \\
\hline & $>=60$ años & 5,063 & ,363 &, 000 & 4,350 & 5,776 \\
\hline \multirow[t]{2}{*}{$>=60$ años } & $<30$ años & $-11,993$ & ,376 & ,000 & $-12,731$ & $-11,254$ \\
\hline & de 30 a 59 años & $-5,063$ & ,363 &, 000 & $-5,776$ & $-4,350$ \\
\hline
\end{tabular}

Tabla 44

\subsubsection{2.-Valor (L)- Sexo}

Los resultados de $L$, también difiere significativamente entre sexos con una $p<0,05$ y una elevada potencia para esta conclusión >0,99. ( $F=1867,09 ; 1$ y $1355 \mathrm{gl} ; \mathrm{p}=0,000$; Potencia>0,999; tamaño del efecto 0,043).

Como se puede ver, las mujeres tienen unas cifras de $L$ (media: 77,58 ; IC al $95 \%$ : 77,16-77,99) significativamente mayor con $\mathrm{p}=, 000$ que el de los hombres (media: 75,23; IC al 95\%: 74,81-75,65). La diferencia se puede estimar al 95\% de confianza entre: 1,75-2,94 unidades. Queremos señalar que la diferencia es pequeña entre ambos valores, pero estadísticamente significativas.

El siguiente gráfico, denominado gráfico 7 , es descriptivo de las medias de valor en ambos sexos. 


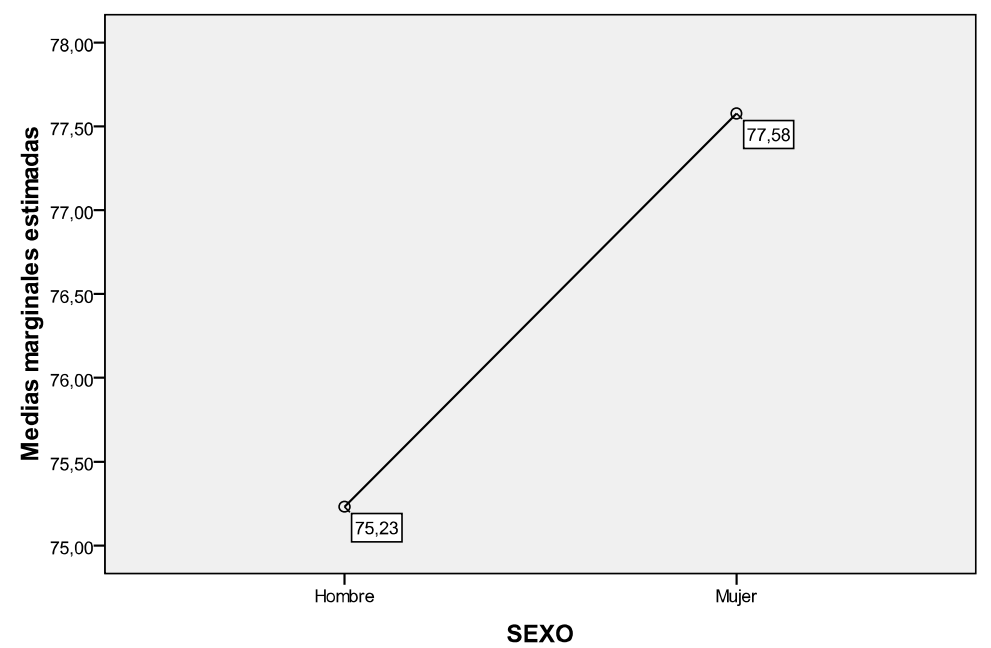

Gráfico 7

Seguidamente, aparece la tabla 45 , con los puntos medios de la variable $L$, y con los intervalos de confianza al 95\% para cada uno de los dos sexos, junto con la diferencia de las medias.

Comparaciones por pares

Variable dependiente:L
\begin{tabular}{|ll|c|c|c|c|c|}
\hline & & & & \multicolumn{2}{|c|}{$\begin{array}{c}\text { Intervalo de confianza al 95 } \\
\% \text { para la diferencia }\end{array}$} \\
\cline { 5 - 8 } \\
(I)SEXO & (J)SEXO & $\begin{array}{c}\text { Diferencia de } \\
\text { medias (I-J) }\end{array}$ & Error típ. & Sig. & Límite inferior & $\begin{array}{c}\text { Límite } \\
\text { superior }\end{array}$ \\
\hline Hombre & Mujer & $-2,347$ &, 302 &, 000 & $-2,939$ & $-1,754$ \\
\hline Mujer & Hombre & 2,347 &, 302 &, 000 & 1,754 & 2,939 \\
\hline
\end{tabular}

Variable dependiente:L
\begin{tabular}{|l|c|c|c|c|}
\hline \multirow{2}{*}{ SEXO } & & & \multicolumn{2}{|c|}{ Intervalo de confianza 95\% } \\
\cline { 4 - 5 } & Media & Error típ. & Límite inferior & Límite superior \\
\hline Hombre & 75,232 &, 215 & 74,810 & 75,653 \\
Mujer & 77,578 &, 212 & 77,162 & 77,994 \\
\hline
\end{tabular}

Tabla 45

\subsubsection{3.- Valor - Interacción de edad y sexo}

Por último se analiza la interacción de ambos factores, es decir si hay diferencias entre los grupos combinados por edad y sexo. Según la tabla de Anova 46, que estamos analizando, también hay diferencias significativas con $p<0,05(p=0,008)$, potencia del $80,5 \%$ y un Eta2 del $0,7 \%$ es decir, prácticamente despreciable. 
Estadísticos descriptivos

Variable dependiente:L

\begin{tabular}{|l|c|c|c|c|c|c|c|c|c|}
\hline \multirow{4}{*}{} & \multicolumn{4}{c|}{ Media } & \multicolumn{3}{c|}{ Desviación típica } & \multicolumn{3}{c|}{ N } \\
\cline { 2 - 10 } Edad (grupos) & \multicolumn{3}{|c|}{ SEXO } & \multicolumn{3}{c|}{ SEXO } & \multicolumn{3}{c|}{ SEXO } \\
\cline { 2 - 11 }$y$ & Hombre & Mujer & Total & Hombre & Mujer & Total & Hombre & Mujer & Total \\
\hline$<30$ años & $\mathbf{8 2 , 2 0 5 3}$ & $\mathbf{8 3 , 2 1 9 4}$ & $\mathbf{8 2 , 7 2 5 5}$ & 4,25058 & 3,85501 & 4,07933 & 206 & 217 & 423 \\
de 30 a 59 años & $\mathbf{7 4 , 1 7 9 7}$ & $\mathbf{7 7 , 3 8 5 9}$ & $\mathbf{7 5 , 8 2 2 4}$ & 5,77341 & 5,41507 & 5,81266 & 237 & 249 & 486 \\
>=60 años & $\mathbf{6 9 , 3 0 9 6}$ & $\mathbf{7 2 , 1 2 9 9}$ & $\mathbf{7 0 , 7 0 7 3}$ & 7,18379 & 6,04114 & 6,78330 & 228 & 224 & 452 \\
\hline Total & $\mathbf{7 4 , 9 8 8 8}$ & $\mathbf{7 7 , 5 1 4 2}$ & $\mathbf{7 6 , 2 6 9 1}$ & $\mathbf{7 , 8 7 2 2 9}$ & 6,83431 & 7,46921 & 671 & 690 & 1361 \\
\hline
\end{tabular}

Tabla 46

En el gráfico 8, compuesto por dos imágenes, observamos como varían los datos medios del valor en función de los grupos de edad y del sexo de manera muy similar.

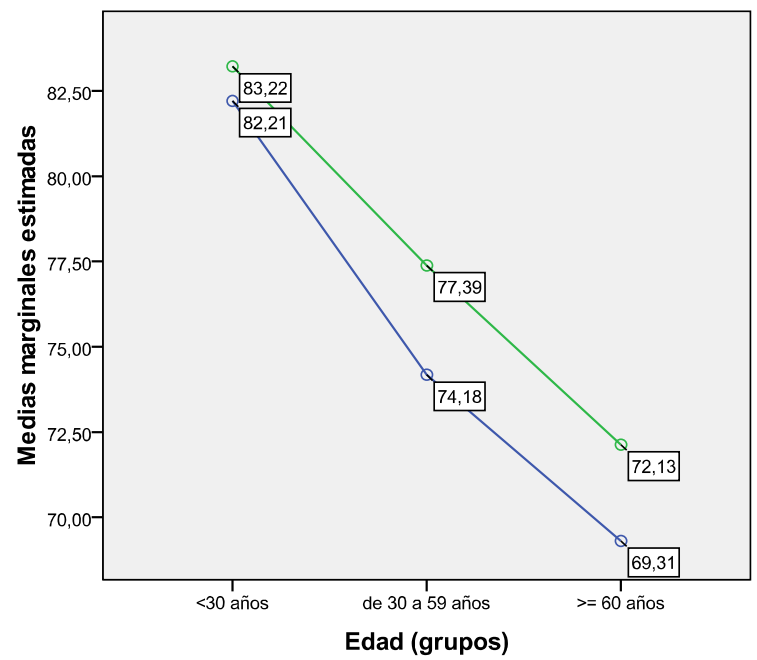

$$
\begin{aligned}
& \text { SEXO } \\
- & \text { Hombre } \\
\hline & \text { Mujer }
\end{aligned}
$$

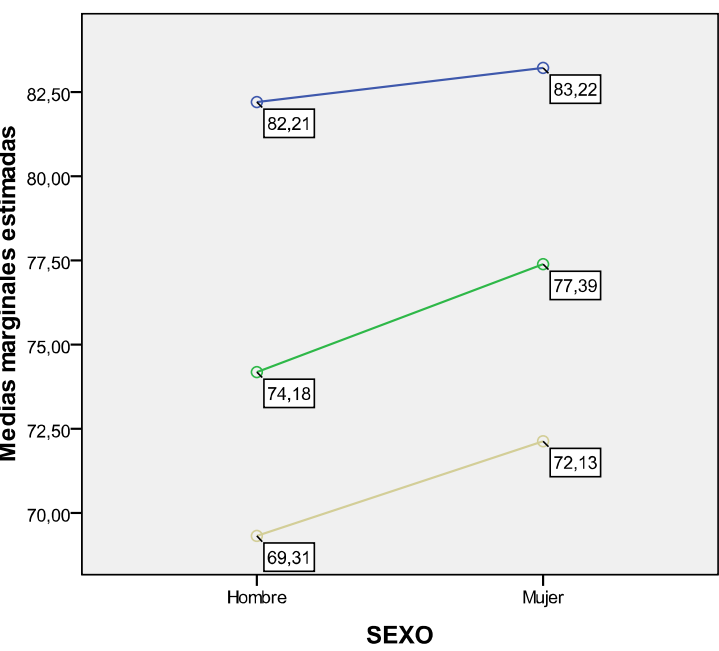

Edad (grupos)

- $<30$ años

- de 30 a 59 años

$\rightarrow=60$ años

\section{Gráfico 8}

A continuación comprobaremos con la alternativa no-paramétrica de Kruskal-Wallis si la falta de normalidad ha tenido alguna consecuencia en las conclusiones anteriores. 
Como se observa, en las 3 tablas se ha contrastado lo mismo que en la de Anova: solo el efecto de la edad, solo el del sexo, y la combinación de edad y sexo. $Y$ en los 3 casos aparecen diferencias significativas con $p=, 000<0,05$. Luego el resultado es el mismo que con Anova y no podemos deducir que la ausencia de normalidad en la variable $L$ tenga influencia en los resultados, debido al gran tamaño de muestra utilizado.

En las tablas siguientes, agrupadas bajo el nombre de tabla 47, corresponde a un estudio no paramétrico de Kruskal-Wallis: solo edad, solo sexo, y la combinación de edad y sexo. En todas las situaciones aparecen diferencias significativas con $p=, 000<$ 0,05 . Luego el resultado es el mismo que con Anova y no podemos deducir que la ausencia de normalidad en la variable $L$ tenga influencia en los resultados, debido al gran tamaño de muestra utilizado.

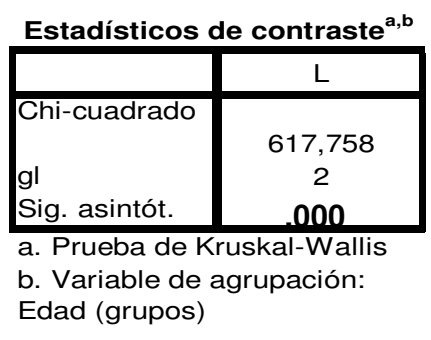

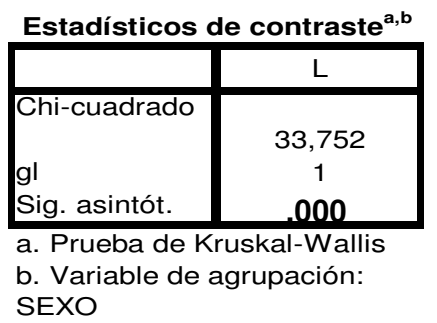

Tabla 47

Un análisis interesante que se deduce de la tabla de Anova 46, es que según el modelo explicativos de efectos, la intersección que es una constante poblacional, aparte de ser también significativa $(p=, 000<0,05)$ y con alta potencia $(>, 999)$ explica un $99,5 \%$ de las variaciones de L. Si de ese total, descontamos el $43 \%$ que viene explicado por la edad, el 4,3\% por el sexo y el 0,7\% de la interacción (es decir descontamos un $48 \%$ en total) nos queda un $52 \%$ de variabilidad sin explicar. Es decir que hay otros factores (variables independientes) que inciden en las variaciones de $L$.

En este gráfico 9, se representa un diagrama de cajas del valor $(\mathrm{L})$, asociado a los tres grupos de edad y en cada uno de los sexos. Las cajas muestran el grado de dispersión del $50 \%$ de los valores centrales (valores entre el percentil 25 y 75 ) y los asteriscos y los círculos muestran los casos extremos (valores alejados más de 3 longitudes de caja del percentil 75 y 25) y los casos atípicos (valores alejados más de 
1.5 longitudes de la caja del percentil 75 y 25), respectivamente. En este caso debemos de apuntar la ausencia total de asteriscos dentro de nuestra muestra.

Como se observa en el diagrama, el valor va disminuyendo con el tiempo.

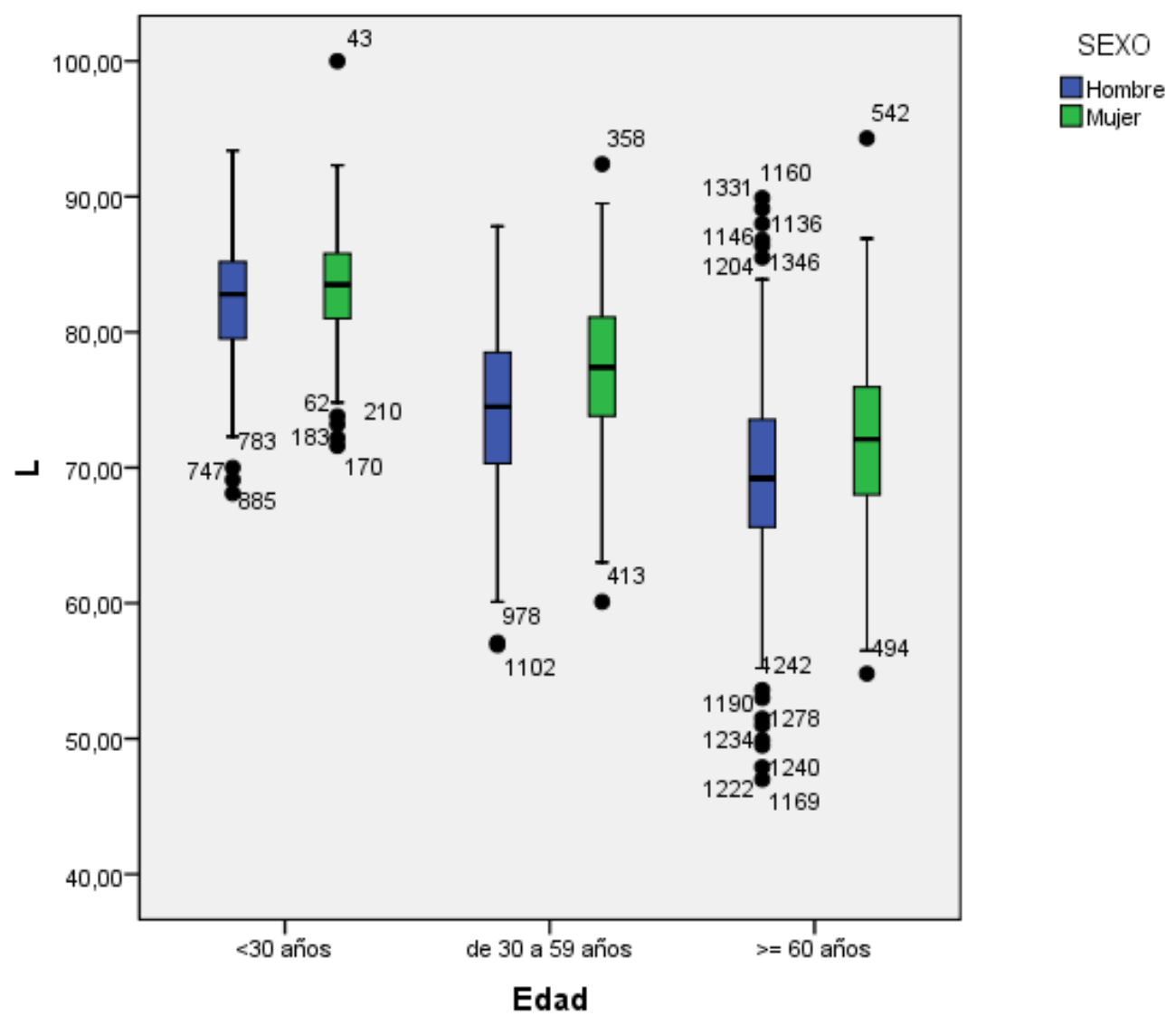

Gráfico 9

\subsection{4.- Intensidad (C)}

\subsubsection{1.-Intensidad - Grupos de edad}

Analizando el posible efecto de la edad sobre $\mathrm{C}$, se determinó con una $p<0,05$ y elevada potencia que dichos valores cambian significativamente entre las categorías de edad establecidas, de forma tal que podemos afirmar que un $18.5 \%$ de las variaciones de C (intensidad) estarían justificadas por la edad ( $F=154,20 ; 2$ y $1355 \mathrm{gl}$; $p=0,000$; Potencia $>0,999$; tamaño del efecto 0,185 ). Útil consultar la tabla resumen número 48.

Los contrastes múltiples a posteriori, realizados tanto con el método DMS como con el de Bonferroni, determinaron que la media de $\mathrm{C}$ en el grupo de menores de 30 años de 
edad (17,34; IC al 95\%: 16,81-17,86) es significativamente mayor $(\mathrm{p}=, 000)$ que la media de grupo de entre 30 y 59 años (18,85; IC al 95\%: 18,36-19,34).

Por su parte entre este segundo grupo de 30 y 59 años y los mayores de 60 años (media: 23,55; IC al 95\%: 23,04-24,05) también hay un aumento significativo $(p=, 000)$ de las cifras de C; dicho aumento se puede estimar al 95\% de confianza, entre 3.99 y 5.40 unidades.

La media de $C$ también difiere significativamente entre grupos de edad con una $p=, 000$ $<0,05$. La potencia calculada para un nivel de confianza del $5 \%$ para esta conclusión es $>0,999$, es decir mayor al $99,99 \%$ y por tanto muy elevada. Se estima que sólo un 18,5\% de la variación de C están explicados por la diferencia entre los tres grupos de edad analizados.

Pruebas de los efectos inter-sujetos

Variable dependiente:C

\begin{tabular}{|c|c|c|c|c|c|c|c|}
\hline Origen & $\begin{array}{l}\text { Suma de } \\
\text { cuadrados }\end{array}$ & gl & $\begin{array}{c}\text { Media } \\
\text { cuadrática }\end{array}$ & $\mathrm{F}$ & Sig. & $\begin{array}{c}\text { Eta al } \\
\text { cuadrado } \\
\text { parcial }\end{array}$ & $\begin{array}{l}\text { Potencia } \\
\text { observada }^{b}\end{array}$ \\
\hline Intersección & 537802,044 & 1 & 537802,044 & 17784,945 &, 000 & ,929 & ,999 \\
\hline edadc & 9325,959 & 2 & 4662,980 & 154,203 &, 000 & ,185 & ,999 \\
\hline sexo & 3120,487 & 1 & 3120,487 & 103,194 & ,000 & ,071 & ,999 \\
\hline edadc * sexo & 672,747 & 2 & 336,373 & 11,124 &, 000 & ,016 & ,992 \\
\hline Error & 40974,081 & 1355 & 30,239 & & & & \\
\hline Total & 595017,940 & 1361 & & & & & \\
\hline
\end{tabular}

b. Calculado con alfa $=, 05$

\section{Tabla 48}

La media de $C$ aumenta significativamente con la edad con una $p=, 000<0,05$. La potencia calculada para un nivel de confianza del $5 \%$ para esta conclusión es $>0,999$, es decir mayor al 99,99\% y por tanto muy elevada. Analizando el valor numérico de Eta cuadrado parcial, que es el porcentaje de los cambios de la variable dependiente estimamos que un 18,5\% del aumento de C están explicados por la diferencia de edad entre los tres grupos.

Hay diferencias significativas en $\mathrm{C}$ entre las tres categorías de edad, entre sexos, y debidas a la interacción de ambas factores. La situación es totalmente análoga a la que se da en la variable anterior, aunque ahora la variable $\mathrm{C}$, aumenta con la edad, en lugar de disminuir como ocurría con el valor. 
El gráfico 10, es representativo de la evolución de la intensidad según los tres grupos de edad, y se nota un claro ascenso según aumenta la misma.

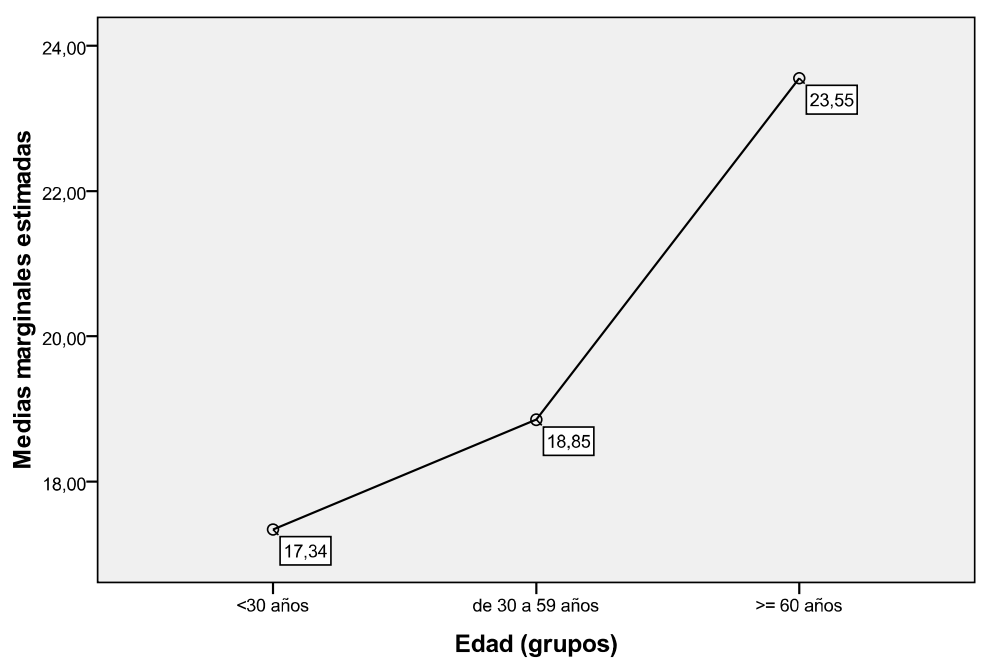

Gráfico 10

En la tabla 49, comparamos si existen diferencias estadísticamente significativas entre las medias de la intensidad entre los tres grupos de edad, y en todas las comparaciones de pares encontramos diferencias estadísticamente significativas con p- valor $<0.0001$.

\begin{tabular}{|c|c|c|c|c|c|c|}
\hline & & Somparacione & $r$ pares & & & \\
\hline Variable dependie & & & & & & \\
\hline & & & & & $\begin{array}{r}\text { Intervalo de cc } \\
\% \text { para la }\end{array}$ & $\begin{array}{l}\text { ianza al } 95 \\
\text { erencia }\end{array}$ \\
\hline (I)Edad (grupos) & (J)Edad (grupos) & $\begin{array}{c}\text { Diferencia de } \\
\text { medias (I-J) }\end{array}$ & Error típ. & Sig & Límite inferior & $\begin{array}{l}\text { Límite } \\
\text { superior }\end{array}$ \\
\hline$<30$ años & de 30 a 59 años & $-1,510^{*}$ & ,366 &, 000 & $-2,228$ &,- 793 \\
\hline & $>=60$ años & $-6,210^{*}$ & ,372 &, 000 & $-6,940$ & $-5,481$ \\
\hline de 30 a 59 años & $<30$ años & $1,510^{x}$ & ,366 & ,000 & ,793 & 2,228 \\
\hline & $>=60$ años & $-4,700^{*}$ & ,359 & ,000 & $-5,405$ & $-3,995$ \\
\hline$>=60$ años & $<30$ años & $6,210^{*}$ & ,372 & ,000 & 5,481 & 6,940 \\
\hline & de 30 a 59 años & $4,700^{*}$ & 359 & ,000 & 3,995 & 5,405 \\
\hline
\end{tabular}

\section{Tabla 49}

Seguidamente, aparece la tabla 50, con los datos medios de la variable C, y con los intervalos de confianza al 95\% para cada uno de los dos sexos, junto con la diferencia de las medias. 


Variable dependiente:C
\begin{tabular}{|l|c|c|c|c|}
\hline & & & \multicolumn{2}{|c|}{ Intervalo de confianza $95 \%$} \\
\cline { 4 - 5 } Edad (grupos) & Media & Error típ. & Límite inferior & Límite superior \\
\hline$<30$ años & 17,341 &, 267 & 16,817 & 17,866 \\
de 30 a 59 años & 18,852 &, 250 & 18,362 & 19,341 \\
>= 60 años & 23,552 &, 259 & 23,044 & 24,059 \\
\hline
\end{tabular}

Tabla 50

Al cuantificar el efecto de la edad sobre la intensidad, representada por el parámetro $C$, se determinó con una $p<0.05$ y una alta potencia que dichos valores aumentan de forma estadísticamente significativa entre los tres grupos de edad, de forma que el $18,5 \%$ de las variaciones de la intensidad estarías justificadas por la edad ( $F=154.20$, potencia >0.999; $p=0,000$; tamaño de efecto 0.185 ).

Los contrastes post-hoc, realizados tanto con el método DMS como con el de Bonferroni, determinaron que la media de $C$ en el grupo de menores de 30 años de edad (17.34; IC al 95\%: 16.81-17.86) es significativamente menor $(p=, 000)$ que la media de grupo de entre 30 y 59 años (18.85; IC al 95\%: 18.36-19.34). El rango de C estimada con un $95 \%$ de confianza estaría comprendida entre: 16.81 y 17.86 para los menores de 30 años. Por su parte entre este segundo grupo de 30 y 59 años y los mayores de 60 años (media: 23.55; IC al 95\%: 23.04-24.05) también hay un aumento significativo $(p=, 000)$ de las cifras de $C$; dicho aumento se puede estimar al $95 \%$ de confianza, entre: 5.40 y 3.99 unidades.

\subsubsection{2.- Intensidad - Sexo}

El valor numérico medio de $\mathrm{C}$ también difiere significativamente entre sexos con una $\mathrm{p}=, 000<0,05$. La potencia calculada para un nivel de confianza del $5 \%$ para esta conclusión es >0,999, es decir mayor al 99,99\% y por tanto muy elevada. Se estima que sólo un $7,1 \%$ de la variación de los valores de C están explicados por la diferencia entre sexos.

El gráfico 11, es descriptivo de las medias de intensidad en ambos sexos. 


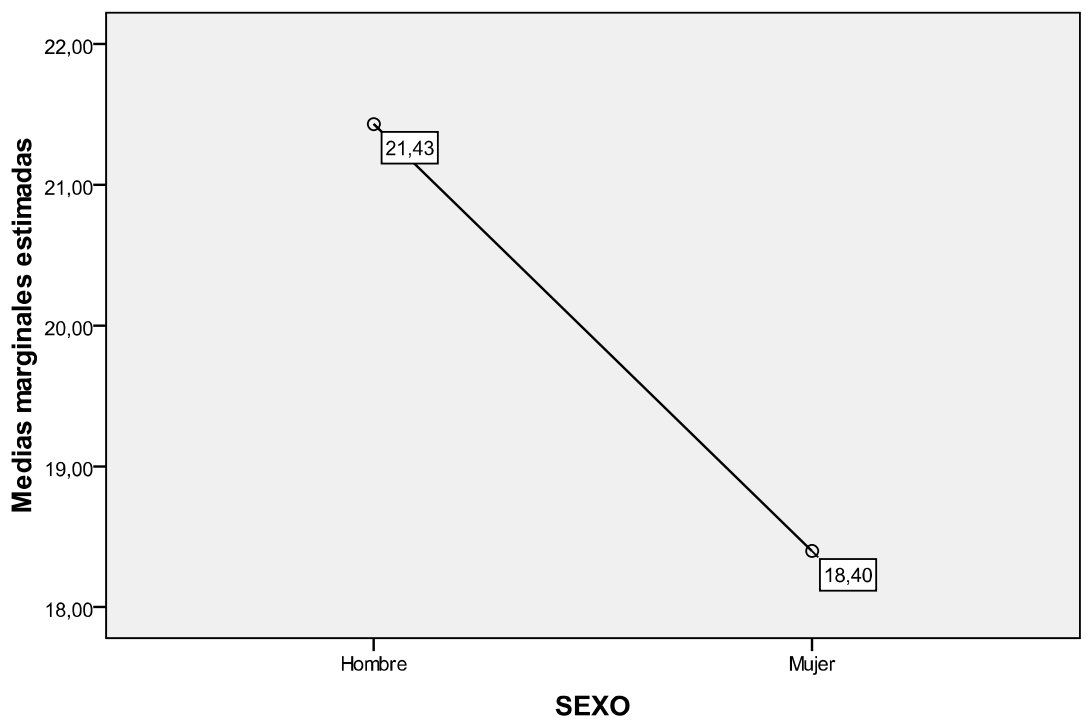

Gráfico 11

Según esta tabla doble, tabla 51, las mujeres tienen un grado de C (media: 18.39; IC al 95\%: 17.98-18.80) significativamente menor con $\mathrm{p}<, 0001$ que el de los hombres (media: 21.43; IC al 95\%: 21.05-21.84). La diferencia se puede estimar al 95\% de confianza entre: $3.62-2.44$ unidades.

Variable dependiente:C
\begin{tabular}{|l|c|c|c|c|}
\hline & & & \multicolumn{2}{|c|}{ Intervalo de confianza 95\% } \\
\cline { 4 - 5 } SEXO & Media & Error típ. & Límite inferior & Límite superior \\
\hline Hombre & 21,432 &, 213 & 21,015 & 21,849 \\
Mujer & 18,398 &, 210 & 17,987 & 18,809 \\
\hline
\end{tabular}

\begin{tabular}{|c|c|c|c|c|c|c|}
\hline \multicolumn{7}{|c|}{ Comparaciones por } \\
\hline Variable & endiente: $\mathrm{C}$ & & & & & \\
\hline \multirow[b]{2}{*}{ (I)SEXO } & \multirow[b]{2}{*}{ (J)SEXO } & \multirow{2}{*}{$\begin{array}{c}\text { Diferencia de } \\
\text { medias (I-J) }\end{array}$} & \multirow[b]{2}{*}{ Error típ. } & \multirow[b]{2}{*}{ Sig. $^{a}$} & \multicolumn{2}{|c|}{$\begin{array}{c}\text { Intervalo de confianza al } 95 \% \\
\text { para la diferencia }^{a}\end{array}$} \\
\hline & & & & & Límite inferior & Límite superior \\
\hline Hombre & Mujer & $3,034^{*}$ & ,299 &, 000 & 2,448 & 3,620 \\
\hline Mujer & Hombre & $-3,034^{\star}$ & ,299 & 000 & $-3,620$ & $-2,448$ \\
\hline
\end{tabular}

Tabla 51

\subsubsection{3.- Intensidad - Interacción de edad y sexo}

En tercer lugar, se analiza la interacción de ambos factores, es decir si hay diferencias entre los grupos combinados por edad y sexo. Según la tabla de Anova, que 
corresponde al número 52, que estamos analizando, también hay diferencias significativas con $p<0,05$ ( $p=0,000)$, potencia del 99,2\% y un valor pequeño de Eta2 igual al 1,6\%. Es decir, podemos afirmar que la intensidad se ve afectada por la interacción ente sexo y edad en un porcentaje de 1,6\%.

Estadísticos descriptivos

Variable dependiente:C

\begin{tabular}{|l|c|c|c|c|c|c|c|c|c|}
\hline \multirow{2}{*}{} & \multicolumn{3}{|c|}{$\begin{array}{c}\text { Media } \\
\text { SEXO }\end{array}$} & \multicolumn{3}{c|}{$\begin{array}{c}\text { Desviación típica } \\
\text { SEXO }\end{array}$} & \multicolumn{3}{c|}{ SEXO } \\
\cline { 2 - 11 } Edad (grupos) & Hombre & Mujer & Total & Hombre & Mujer & Total & Hombre & Mujer & Total \\
\hline$<30$ años & $\mathbf{1 7 , 9 7 7 7}$ & $\mathbf{1 6 , 7 0 5 1}$ & $\mathbf{1 7 , 3 2 4 8}$ & 4,17582 & 3,71672 & 3,99337 & 206 & 217 & 423 \\
de 30 a 59 años & $\mathbf{2 0 , 3 7 5 1}$ & $\mathbf{1 7 , 3 2 8 1}$ & $\mathbf{1 8 , 8 1 4 0}$ & 5,37800 & 4,59618 & 5,21538 & 237 & 249 & 486 \\
>=60 años & $\mathbf{2 5 , 9 4 3 0}$ & $\mathbf{2 1 , 1 6 0 7}$ & $\mathbf{2 3 , 5 7 3 0}$ & 7,95126 & 5,98926 & 7,43560 & 228 & 224 & 452 \\
\hline Total & $\mathbf{2 1 , 5 3 1 0}$ & $\mathbf{1 8 , 3 7 6 4}$ & 19,9317 & 6,92258 & 5,22893 & 6,32058 & 671 & 690 & 1361 \\
\hline
\end{tabular}

Tabla 52

El gráfico 12, representa las variaciones de la intensidad media y su evolución en los diferentes grupos de edad.

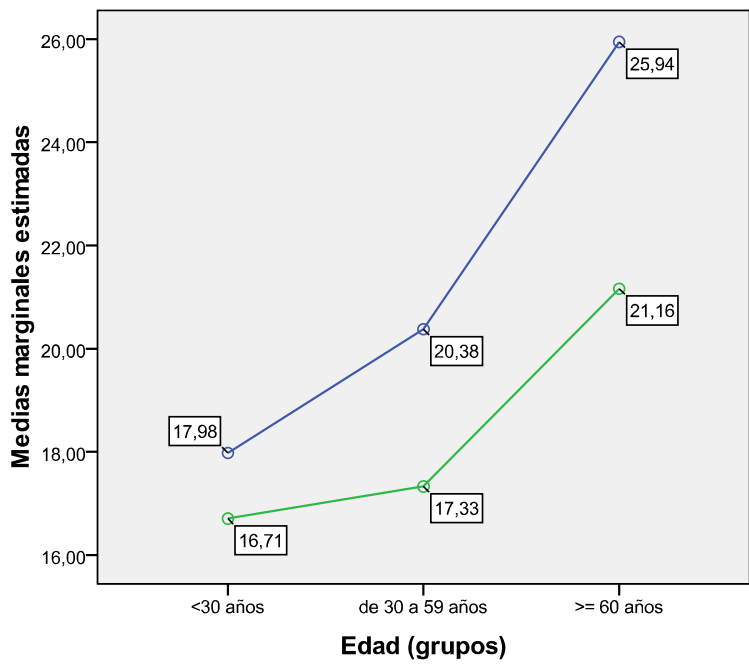

SEXO — Hombre

Gráfico 12

La intensidad superior se encuentra en el grupo de mayores de sesenta años y es superior en hombres que en mujeres. Por el contrario la intensidad inferior está presente en el grupo de menores de treinta años, según representa el gráfico 13. 


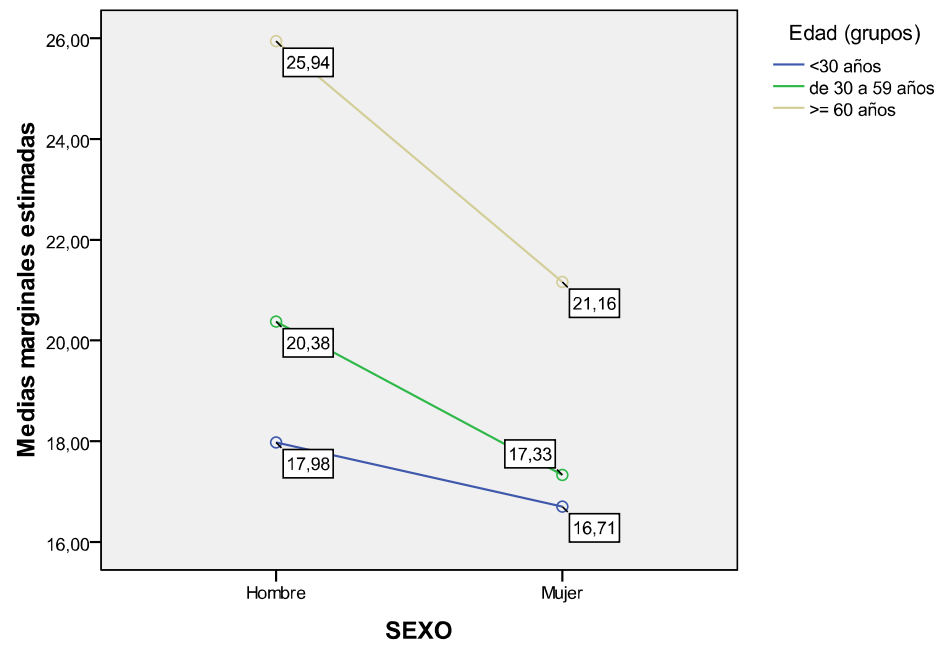

Gráfico 13

A continuación, realizamos la comprobación con Kruskal-Wallis, para conocer si existe alguna variación con respecto al test Anova aplicado anteriormente.

Las próximas tablas se agrupan en una, tabla 53, representa los resultados al aplicar el test de no paramétrico de Kruskal-Wallis sobre la variable C.

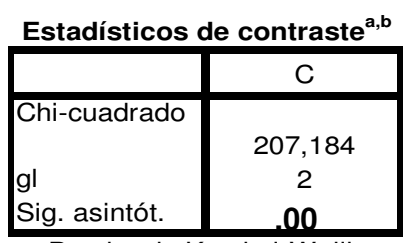

a. Prueba de Kruskal-Wallis b. Variable de agrupación: Edad (grupos)

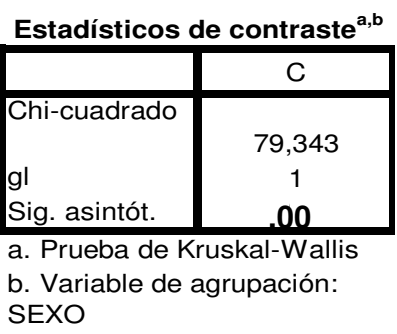

Tabla 53

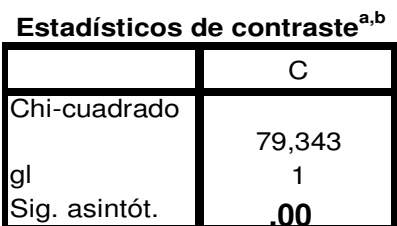

a. Prueba de Kruskal-Wallis

b. Variable de agrupación:

SEXO

Como se observa, en las 3 tablas se ha contrastado lo mismo que en la de Anova: solo edad, solo sexo, y la combinación de edad y sexo. $Y$ en los 3 casos aparecen diferencias significativas con $p=, 000<0,05$. Luego el resultado es el mismo que con Anova y no podemos deducir que la ausencia de normalidad en la variable $C$ tenga influencia en los resultados, debido al gran tamaño de muestra utilizado.

En el siguiente diagrama de cajas, se representa un gráfico de cajas de la intensidad (C), asociada a los tres grupos de edad y en cada uno de los sexos. Las cajas muestran el grado de dispersión del $50 \%$ de los datos centrales (valores entre el 
percentil 25 y 75) y los asteriscos y los círculos muestran los casos extremos (datos alejados más de 3 longitudes de caja del percentil 75 y 25) y los casos atípicos (datos alejados más de 1.5 longitudes de la caja del percentil 75 y 25), respectivamente. En este caso debemos de apuntar la ausencia total de asteriscos dentro de nuestra muestra.

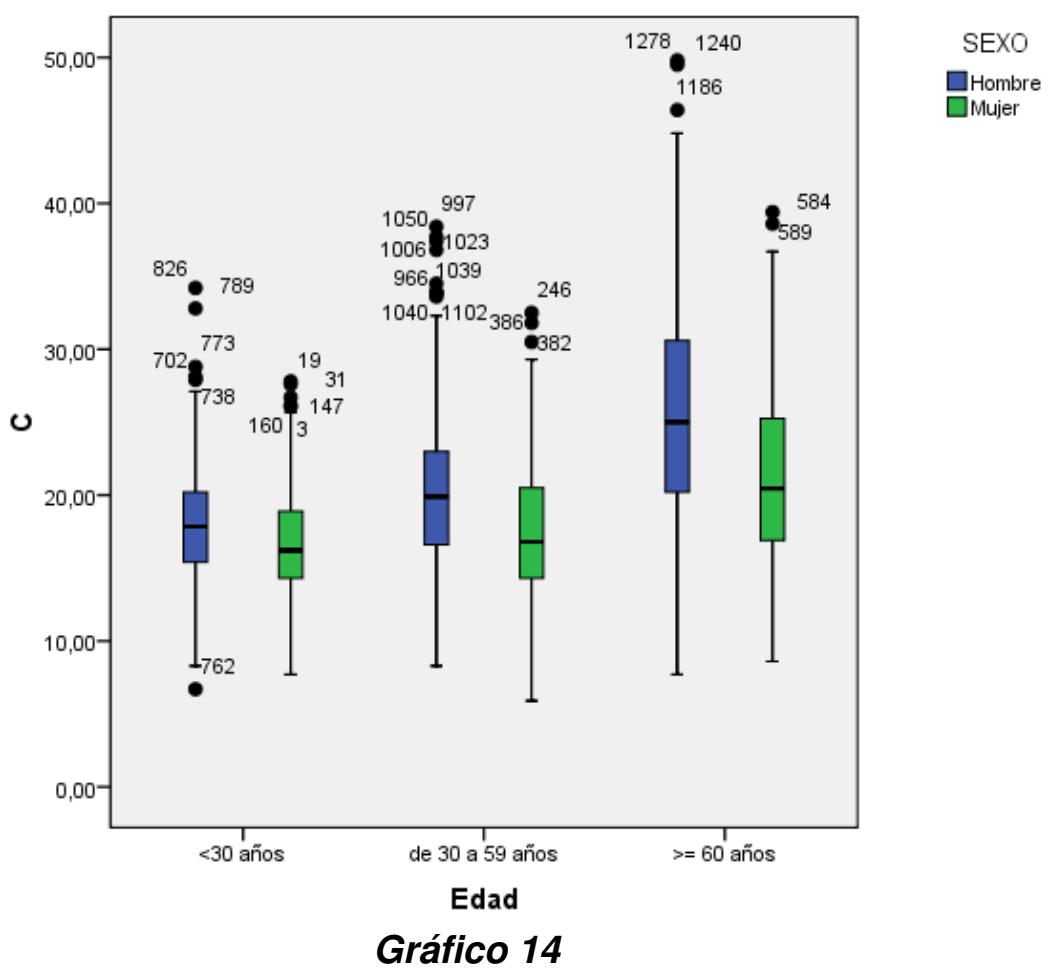

Se aprecia, en el gráfico 14, que la intensidad es bastante similar en los tres grupos de edad, el rango mayor de intensidades corresponde con el grupo de edad superior o igual a mayores de sesenta años; donde como el percentil mínimo 25 corresponde con $\mathrm{C}$ de aproximadamente 8 , y un percentil de 75 con un dato de 45 .

\subsubsection{Tinte (h)}

\subsubsection{1.-Tinte - Grupos de edad}

Con respecto al tinte y su modificación con el envejecimiento observamos en la tabla 54 , que difiere significativamente entre grupos de edad con una $p=, 000<0,05$. La potencia calculada para un nivel de confianza del $5 \%$ para esta conclusión es $>0,999$, es decir mayor al 99,99\% y por tanto muy elevada. Se estima que sólo un $22,6 \%$ de la variación de las cifras del tinte están explicados por la diferencia de edad. 


\begin{tabular}{|c|c|c|c|c|c|c|c|}
\hline \multicolumn{8}{|c|}{ Pruebas de los efectos inter-sujetos } \\
\hline Origen & Suma de cuadrados & $\mathrm{gl}$ & $\begin{array}{c}\text { Media } \\
\text { cuadrática }\end{array}$ & $\mathrm{F}$ & Sig. & $\begin{array}{c}\text { Eta al } \\
\text { cuadrado } \\
\text { parcial }\end{array}$ & $\begin{array}{c}\text { Potencia } \\
\text { observada }^{\text {b }}\end{array}$ \\
\hline $\begin{array}{l}\text { Intersección } \\
\text { edadc } \\
\text { sexo } \\
\text { edadc * sexo } \\
\text { Error } \\
\text { Total }\end{array}$ & $\begin{array}{r}11221285,451 \\
7173,445 \\
1205,588 \\
142,835 \\
24591,421 \\
11280178,360\end{array}$ & \begin{tabular}{r|}
1 \\
2 \\
1 \\
2 \\
1355 \\
1361
\end{tabular} & $\begin{array}{r}11221285,451 \\
3586,723 \\
1205,588 \\
71,418 \\
18,149\end{array}$ & $\begin{array}{r}618298,617 \\
197,630 \\
66,429 \\
3,935\end{array}$ & $\begin{array}{l}, 000 \\
, 000 \\
, 000 \\
, 020\end{array}$ & $\begin{array}{r}, 998 \\
, 226 \\
, 047 \\
, 006\end{array}$ & $\begin{array}{r}, 999 \\
, 999 \\
, 999 \\
, 709\end{array}$ \\
\hline
\end{tabular}

b.Calculado con alfa $=, 05$

Tabla 54

La media de $h$ desciende significativamente con la edad con una $p=, 000<0,05$. La potencia calculada para un nivel de confianza del $5 \%$ para esta conclusión es $>0,999$, es decir mayor al $99,99 \%$ y por tanto muy elevada. Analizando el valor de Eta cuadrado parcial, que es el porcentaje de los cambios de la variable dependiente estimamos que un $22.6 \%$ de el descenso de los resultados de h están explicados por la diferencia de edad entre los tres grupos.

Hay diferencias significativas en h entre las tres categorías de edad, entre sexos, pero no así en la interacción de ambos factores $(p=0.20)$.

Seguidamente se expondrá la representación gráfica de la evolución de la media de h con respecto a los tres grupos de edad (Gráfico15). Se aprecia que disminuye con la edad los datos medios del tinte.

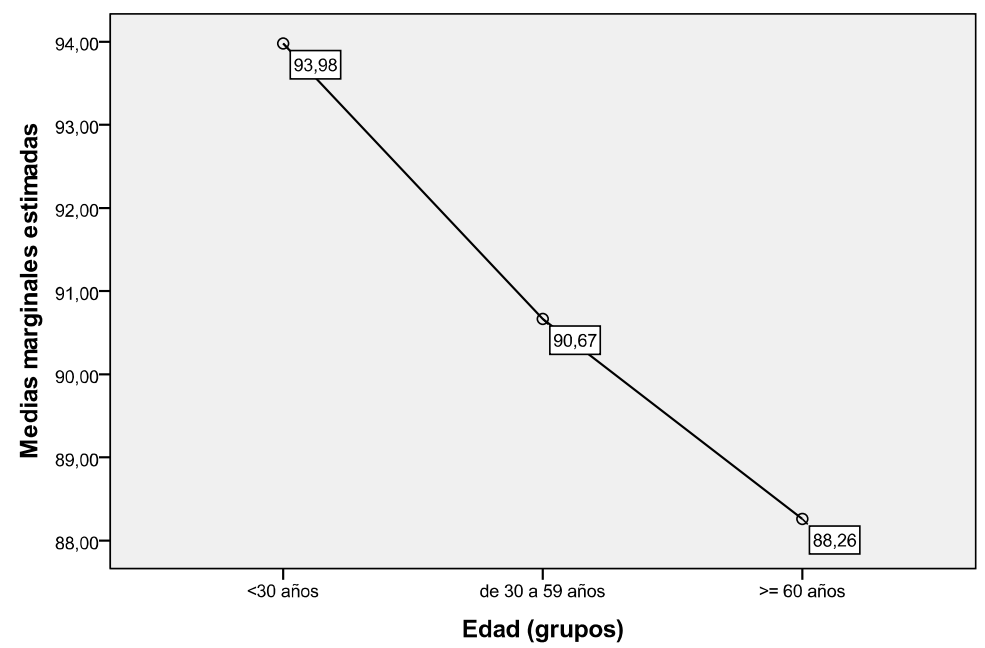

Gráfico 15

En la tabla 55, observamos como los valores medios del tinte disminuyen con la edad, evolucionan de 93.97 unidades para el grupo menor de treinta años, pasando por 
90.66 correspondiente al grupo de edad intermedia, hasta llegar a 88.26, media de tinte para la población mayor de sesenta años.

Variable dependiente:h
\begin{tabular}{|l|r|r|r|r|}
\hline Edad (grupos) & & & \multicolumn{2}{c|}{ Intervalo de confianza 95\% } \\
\cline { 4 - 5 } & Media & Error típ. & Límite inferior & Límite superior \\
\hline$<30$ años & 93,977 &, 207 & 93,570 & 94,383 \\
de 30 a 59 años & 90,665 &, 193 & 90,286 & 91,044 \\
$>=60$ años & 88,262 &, 200 & 87,869 & 88,655 \\
\hline
\end{tabular}

Tabla 55

A continuación, y como hemos venido realizando con las variables de valor e intensidad, comparamos las medias para cada grupo de edad y las comparamos con el resto de los grupos, lo que viene siendo una comparación por pares. Estos resultados quedan expuestos en la tabla 56.

\begin{tabular}{|c|c|c|c|c|c|c|c|}
\hline \multicolumn{8}{|c|}{ 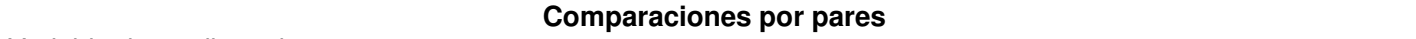 } \\
\hline \multirow{3}{*}{$\begin{array}{l}\text { (I)Edad } \\
\text { (grupos) }\end{array}$} & \multirow{3}{*}{\multicolumn{2}{|c|}{ (J)Edad (grupos) }} & \multirow{3}{*}{$\begin{array}{l}\text { Diferencia de } \\
\text { medias (I-J) }\end{array}$} & \multirow{3}{*}{$\begin{array}{l}\text { Error } \\
\text { típ. }\end{array}$} & \multirow[b]{3}{*}{ Sig. } & \multirow{2}{*}{\multicolumn{2}{|c|}{$\begin{array}{l}\text { Intervalo de confianza al } 95 \% \text { para } \\
\text { la diferencia }\end{array}$}} \\
\hline & & & & & & & \\
\hline & & & & & & Límite inferior & Límite superior \\
\hline \multirow[t]{2}{*}{$<30$ años } & dimension2 & $\begin{array}{l}\text { de } 30 \text { a } 59 \\
\text { años }\end{array}$ & 3,312 & ,283 &, 000 & 2,756 & 3,868 \\
\hline & & $>=60$ años & 5,715 & ,288 &, 000 & 5,149 & 6,280 \\
\hline \multirow{2}{*}{$\begin{array}{l}\text { de } 30 \text { a } 59 \\
\text { años }\end{array}$} & dimension2 & $<30$ años & $-3,312$ & ,283 &, 000 & $-3,868$ & $-2,756$ \\
\hline & & $>=60$ años & 2,403 & ,278 &, 000 & 1,857 & 2,949 \\
\hline \multirow[t]{2}{*}{$>=60$ años } & & $<30$ años & $-5,715$ & ,288 &, 000 & $-6,280$ & $-5,149$ \\
\hline & dimension2 & $\begin{array}{l}\text { de } 30 \text { a } 59 \\
\text { años }\end{array}$ & $-2,403$ & ,278 &, 000 & $-2,949$ & $-1,857$ \\
\hline
\end{tabular}

\section{Tabla 56}

En todas las comparaciones de las puntuaciones medias de cada grupo de edad y comparando con las respectivas de los grupos restantes se han encontrado diferencias estadísticamente significativas entre todos ellos con un p-valor $<0.0001$.

\subsubsection{2.-Tinte - Sexo}

La puntuación media de $\mathrm{h}$ también difiere significativamente entre sexos con una $p=, 000<0,05$. La potencia calculada para un nivel de confianza del $5 \%$ para esta conclusión es >0,999, es decir mayor al 99,99\% y por tanto muy elevada. Se estima que sólo un $4.7 \%$ de la variación de h están explicados por la diferencia entre sexos.

Medias por Sexo

Variable dependiente: $\mathrm{h}$

\begin{tabular}{|l|l|l|l|l|}
\hline SEXO & & \multirow{2}{*}{} & & Intervalo de confianza 95\% \\
\cline { 4 - 5 } & Media & Error típ. & Límite inferior & Límite superior \\
\hline Hombre & 90,025 &, 165 & 89,702 & 90,348 \\
Mujer & 91,911 &, 162 & 91,592 & 92,230 \\
\hline
\end{tabular}


Comparaciones por pares

Variable dependiente:h

\begin{tabular}{|c|c|c|c|c|c|c|}
\hline \multirow{2}{*}{\multicolumn{2}{|c|}{ (I)SEXO (J)SEXO }} & \multirow{2}{*}{$\begin{array}{l}\text { Diferencia } \\
\text { medias (I-J) }\end{array}$} & \multirow{2}{*}{$\begin{array}{l}\text { Error } \\
\text { típ. }\end{array}$} & \multirow[b]{2}{*}{ Sig } & \multicolumn{2}{|c|}{$\begin{array}{l}\text { Intervalo de confianza al } 95 \% \text { para la } \\
\text { diferencia }\end{array}$} \\
\hline & & & & & Límite inferior & Límite superior \\
\hline Hombre & Mujer & $-1,886$ & ,231 &, 000 & $-2,340$ & $-1,432$ \\
\hline Mujer & Hombre & 1,886 & 231 &, 000 & 1,432 & 2,340 \\
\hline
\end{tabular}

Tabla 57

Representación gráfica de los valores medios del tinte tanto en hombres como en mujeres (gráfico 16).

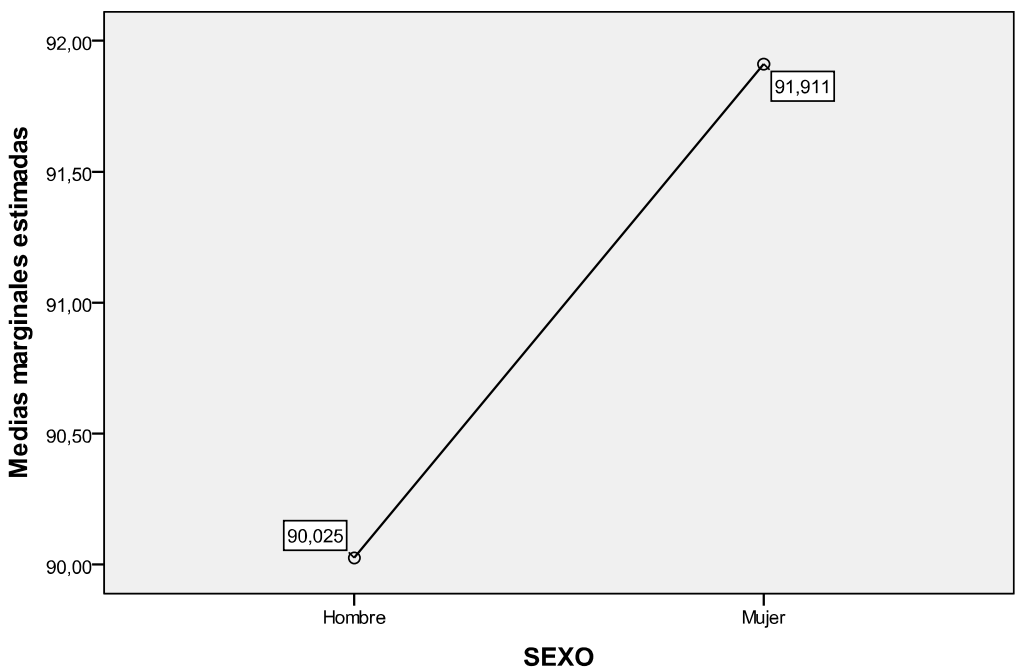

Gráfico 16

Observamos que con un intervalo de confianza del $95 \%$ el tinte (h) para un hombre estará entre el 89.70 y el 90.34 , mientras que para las mujeres estos números pasan a ser del 91.59 como límite interior y del 92.23 como límite superior. Señalamos que la diferencia de ambas medias es de 1.88 (tabla 58).

Estadísticos descriptivos

\begin{tabular}{|c|c|c|c|c|c|c|c|c|c|}
\hline \multirow[t]{2}{*}{ Edad (grupos) } & \multicolumn{3}{|c|}{$\begin{array}{l}\text { Media } \\
\text { SEXO }\end{array}$} & \multicolumn{3}{|c|}{$\begin{array}{c}\text { Desviación típica } \\
\text { SEXO }\end{array}$} & \multicolumn{3}{|c|}{$\begin{array}{c}\mathrm{N} \\
\text { SEXO }\end{array}$} \\
\hline & Hombre & Mujer & Total & Hombre & Mujer & Total & Hombre & Mujer & Total \\
\hline$<30$ años & 93,4456 & 94,5083 & 93,9908 & 3,78311 & 3,22252 & 3,54269 & 206 & 217 & 423 \\
\hline de 30 a 59 años & 89,7076 & 91,6225 & 90,6887 & 4,72548 & 4,29250 & 4,60495 & 237 & 249 & 486 \\
\hline$>=60$ años & 86,9224 & 89,6022 & 88,2504 & 5,17851 & 3,95460 & 4,79893 & 228 & 224 & 452 \\
\hline Total & 89,9088 & 91,8742 & 90,9052 & 5,31280 & 4,34001 & 4,94106 & 671 & 690 & 1,E3 \\
\hline
\end{tabular}

Tabla 58 


\subsubsection{3.- Tinte - Interacción de sexo y edad}

Evaluando la influencia del sexo y de la edad de manera conjunta sobre el tinte de la muestra observamos que el $p$ valor alcanza un valor de 0.20 , por ello podemos afirmar que la influencia es baja, de un $6 \%$.

En el siguiente gráfico, número 17, que engloba vemos la homogeneidad de la muestra y como el tinte evoluciona de manera muy similar en hombre y mujeres, siempre con cifras ligeramente superiores en mujeres.
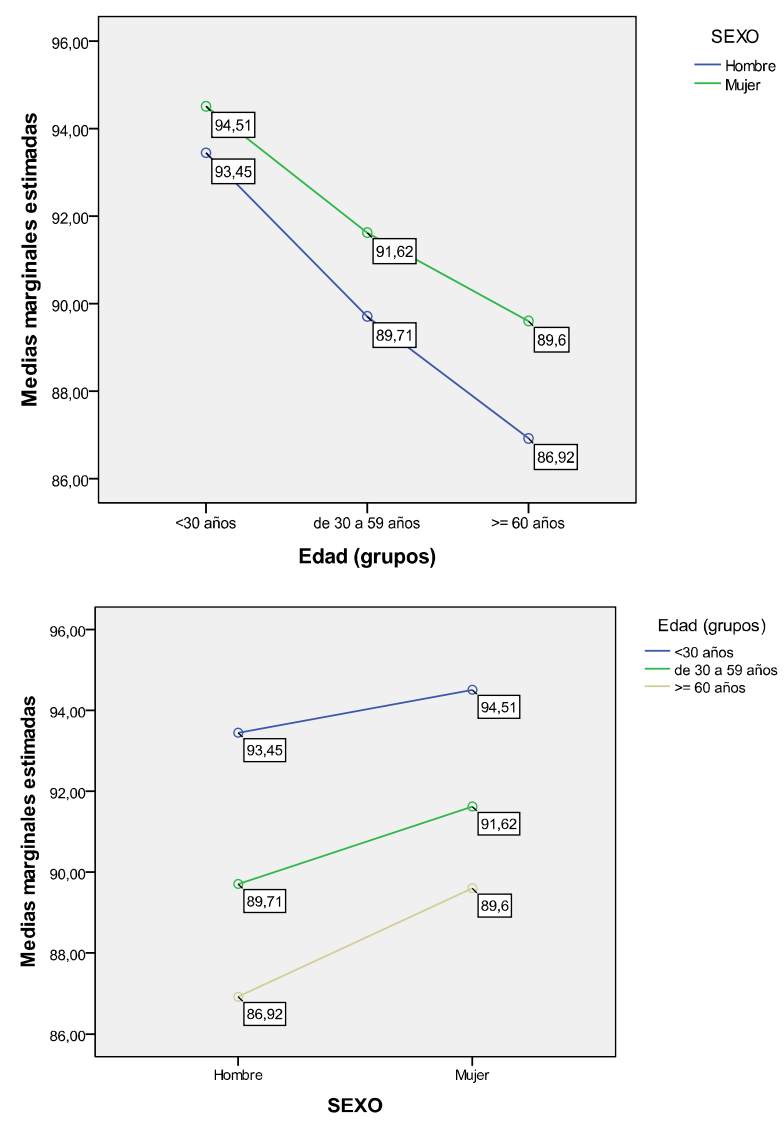

\section{Gráfico 17}

Tablas resumen de la aplicación del test no paramétrico de Kruskall-Wallis a la variable $\mathrm{h}$ tinte $(\mathrm{h})$, agrupadas en la tabla 59.

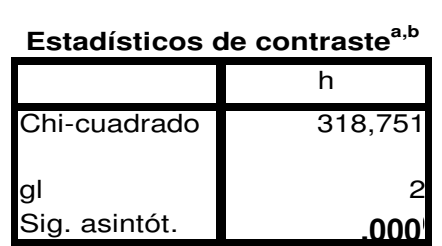

a. Prueba de Kruskal-Wallis

b. Variable de agrupación:

Edad (grupos)

Estadísticos de contraste ${ }^{\mathbf{a , b}}$
\begin{tabular}{|l|r|}
\hline & $\mathrm{h}$ \\
\hline Chi-cuadrado & 54,803 \\
gl & 1 \\
Sig. asintót. & \multicolumn{1}{c}{$\mathbf{0 0 0}$} \\
\hline
\end{tabular}
a. Prueba de Kruskal-Wallis
b. Variable de agrupación:
SEXO

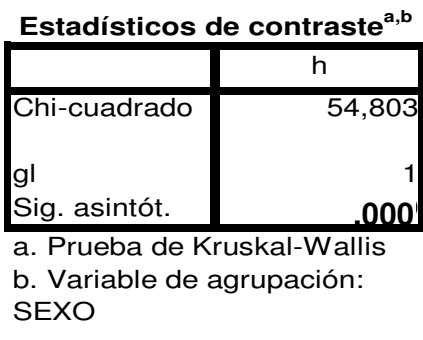

Tabla 59 
El test de Kruskal Wallis demuestra la veracidad de los resultados proporcionados en el test Anova, y por lo tanto su interpretación en las tres dimensiones del color estudiadas valor, tinte e intensidad.

Para terminar y como hemos venido realizando con el valor y la intensidad, en el siguiente diagrama de cajas (gráfico 18), se representa un gráfico de cajas del tinte (h), asociada a los tres grupo de edad y en cada uno de los sexos. Las cajas muestran el grado de dispersión del $50 \%$ de los valores centrales (valores entre el percentil 25 y 75) y los asteriscos y los círculos muestran los casos extremos (valores alejados más de 3 longitudes de caja del percentil 75 y 25) y los casos atípicos (valores alejados más de 1.5 longitudes de la caja del percentil 75 y 25), respectivamente.

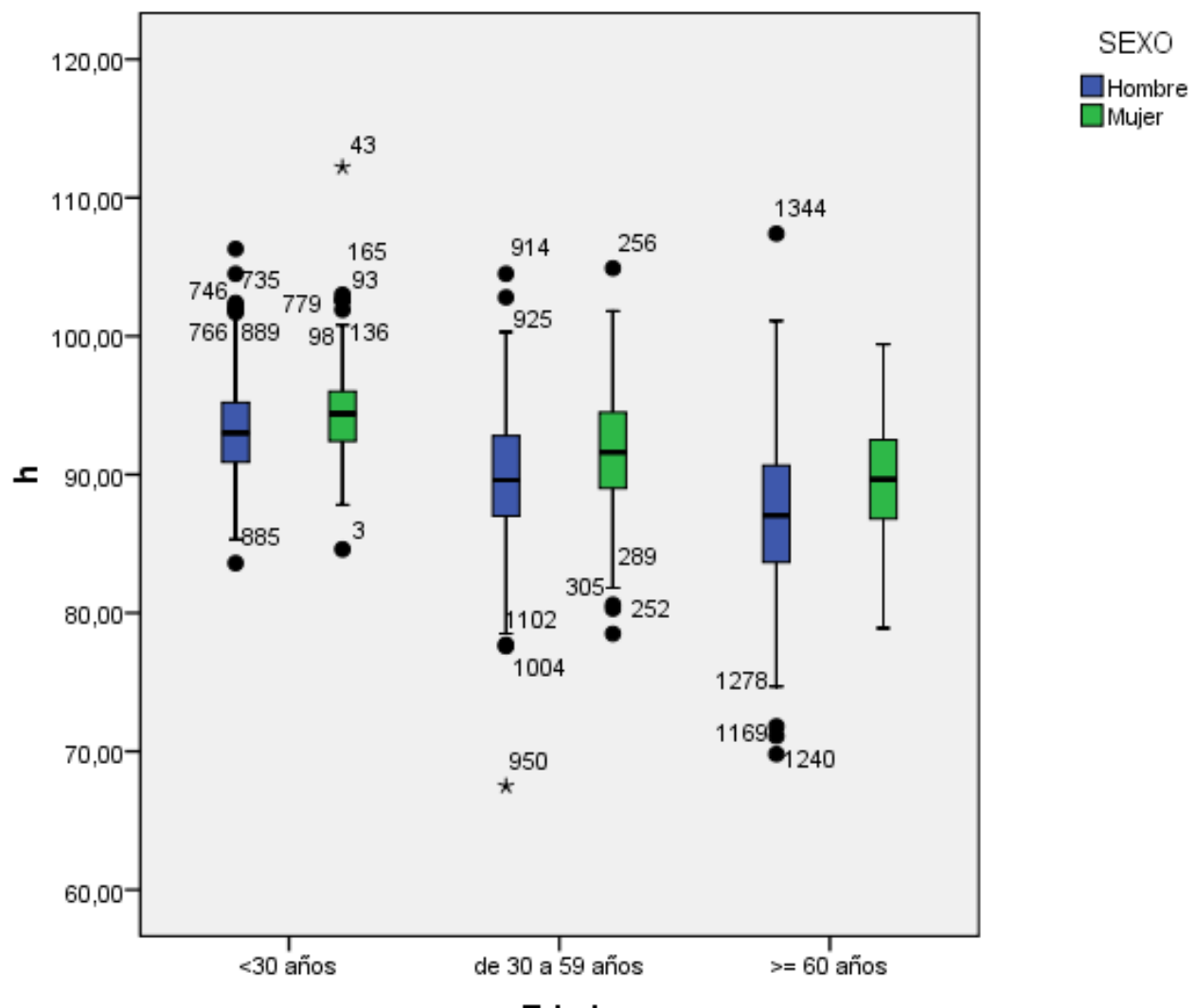

Edad

Gráfico 18

En la dimensión del color, tinte aparecen dos asteriscos como valores atípicos. El tinte no es uno de los factores que más se encuentra influido por la edad y por el sexo. Posteriormente estas tres dimensiones del color y su evolución con el tiempo serán estudiadas más en profundidad, al dividir nuestra muestra en décadas. 


\section{5.-EVOLUCIÓN DEL COLOR DENTAL CON EL ENVEJECIMIENTO DE LA POBLACIÓN}

\subsection{1.- Relación entre Valor o Luminosidad, Intensidad y Tinte con L, C y $\mathbf{h}$ respectivamente}

Las medias de las coordenadas de color, las desviaciones estándar, así como los límites del intervalo de confianza para la media al 95\% y los valores máximos mínimos y medianas se muestran en las siguientes figuras. Con estas tablas se asocia la variable ordinal numérica $L$ (método objetivo), su valor correspondiente como variable cualitativa, el mismo proceso lo exponemos para C (intensidad) y para h, asociada a la letra del tinte.

Esta representación tiene como fin la mejor comprensión de la relación entre las variables cualitativas que aparecen en la guía de color 3D Master y las variables continuas ordinales vinculadas a las mismas que proporciona el espectrofotómetro dentro del espacio de color tridimensional descrita en la tabla 60.

\begin{tabular}{|c|c|c|c|c|c|c|}
\hline \multicolumn{7}{|c|}{ DESCRIPTIVA DEL L*ASOCIADA AL VALOR } \\
\hline valor & $\mathrm{n}$ & mínimo & máximo & media \pm DS & mediana & inf 95\% - sup95\% \\
\hline $\mathbf{1}$ & 198 & 80.3 & 91.3 & $85.2 \pm 2.23$ & 84.9 & $84.9-85.5$ \\
\hline $\mathbf{1 . 5}$ & 100 & 78.5 & 94.3 & $84.8 \pm 2.73$ & 85.6 & $84.2-85.3$ \\
\hline $\mathbf{2}$ & 244 & 71.2 & 89.9 & $80.3 \pm 2.76$ & 80.3 & $79.9-80.6$ \\
\hline $\mathbf{2 . 5}$ & 201 & 72.4 & 79.7 & $77.6 \pm 2.44$ & 77.0 & $77.2-77.9$ \\
\hline $\mathbf{3}$ & 191 & 66.1 & 81.0 & $74.4 \pm 2.77$ & 74.6 & $74.0-74.8$ \\
\hline $\mathbf{3 . 5}$ & 192 & 63.4 & 86.4 & $71.3 \pm 2.65$ & 71.2 & $70.9-71.7$ \\
\hline $\mathbf{4}$ & 87 & 61.6 & 73.8 & $68.5 \pm 1.91$ & 68.5 & $68.0-68.9$ \\
\hline $\mathbf{4 . 5}$ & 108 & 56.0 & 70.1 & $64.6 \pm 2.15$ & 65.3 & $64.2-65.0$ \\
\hline $\mathbf{5}$ & 36 & 47.0 & 63.2 & $57.3 \pm 4.37$ & 58.3 & $55.8-58.8$ \\
\hline
\end{tabular}

Tabla 60

Por ejemplo, el valor o luminosidad 3, le corresponde una luminosidad (L) mínima de 66.1 y máxima de 81.0 , así con un 95\% de confianza estará comprendida entre 74.0 y 74.8. Además su media será 74.4, y su mediana 74.6.

Para un tinte R, por ejemplo, la variable continua ordinal h, se encuentra en un mínimo de 77.7 y un máximo de 91.1 como nos revela la tabla 61 . 


\begin{tabular}{|c|c|c|c|c|c|c|}
\hline \multicolumn{7}{|c|}{ DESCRIPTIVA DE $\boldsymbol{h}^{*}$ ASOCIADA AL TINTE } \\
\hline intensidad & $\mathrm{n}$ & mínimo & máximo & media \pm DS & mediana & inf $95 \%$ - sup95\% \\
\hline $\mathbf{L}$ & 359 & 87.2 & 102 & $92.2 \pm 2.55$ & 92.1 & $91.9-92.4$ \\
\hline $\mathbf{M}$ & 888 & 67.5 & 112 & $91.0 \pm 5.50$ & 91.4 & $90.6-91.3$ \\
\hline $\mathbf{R}$ & 114 & 77.7 & 91.1 & $86.3 \pm 2.97$ & 86.5 & $85.7-86.8$ \\
\hline
\end{tabular}

\section{Tabla 61}

En el caso de la intensidad, la intensidad número 2 de la guía Toothguide 3 D Master, tiene una media de $C$ de 22.0 y una mediana de $C$ de 21.9. La lectura análoga se aplica al resto de la tabla 62.

\begin{tabular}{|c|c|c|c|c|c|c|}
\hline \multicolumn{1}{|c|}{ DESCRIPTIVA DE C*ASOCIADA A LA INTENSIDAD } \\
\hline intensidad & $\mathrm{n}$ & mínimo & máximo & media \pm DS & mediana & inf 95\% - sup95\% \\
\hline $\mathbf{1}$ & 364 & 5.90 & 23.7 & $14.5 \pm 3.09$ & 14.5 & $14.2-14.8$ \\
\hline $\mathbf{1 . 5}$ & 482 & 7.70 & 28.6 & $18.0 \pm 3.26$ & 17.6 & $17.8-18.3$ \\
\hline $\mathbf{2}$ & 276 & 13.7 & 33.1 & $22.0 \pm 2.75$ & 21.9 & $21.6-22.3$ \\
\hline $\mathbf{2 . 5}$ & 156 & 19.1 & 37.7 & $27.7 \pm 4.13$ & 27.5 & $27.0-28.3$ \\
\hline $\mathbf{3}$ & 83 & 16.3 & 49.8 & $33.3 \pm 6.47$ & 33.0 & $31.9-37.7$ \\
\hline
\end{tabular}

Tabla 62

\subsubsection{Estudio de la evolución del color por décadas}

Con el fin de visualizar como el valor, el tinte y la intensidad se van modificando con la edad en los dos sexos hemos separado nuestra muestra no en los tres grupos de edad con los que hemos trabajado hasta ahora, sino con las diferentes décadas que abarca este estudio.

El gráfico 19, que aparece a continuación representa con una confianza del $95 \%$ a la variable valor $(L)$ en las diferentes décadas.

En estos rangos de valor se puede apreciar como disminuye de una forma progresiva con el paso del tiempo tanto para hombres como para mujeres. También se observa como la luminosidad o valor es ligeramente mayor en mujeres que en hombres en todas las décadas estudiadas, excepto para los menores de 19 años, donde aparecen como prácticamente iguales. 


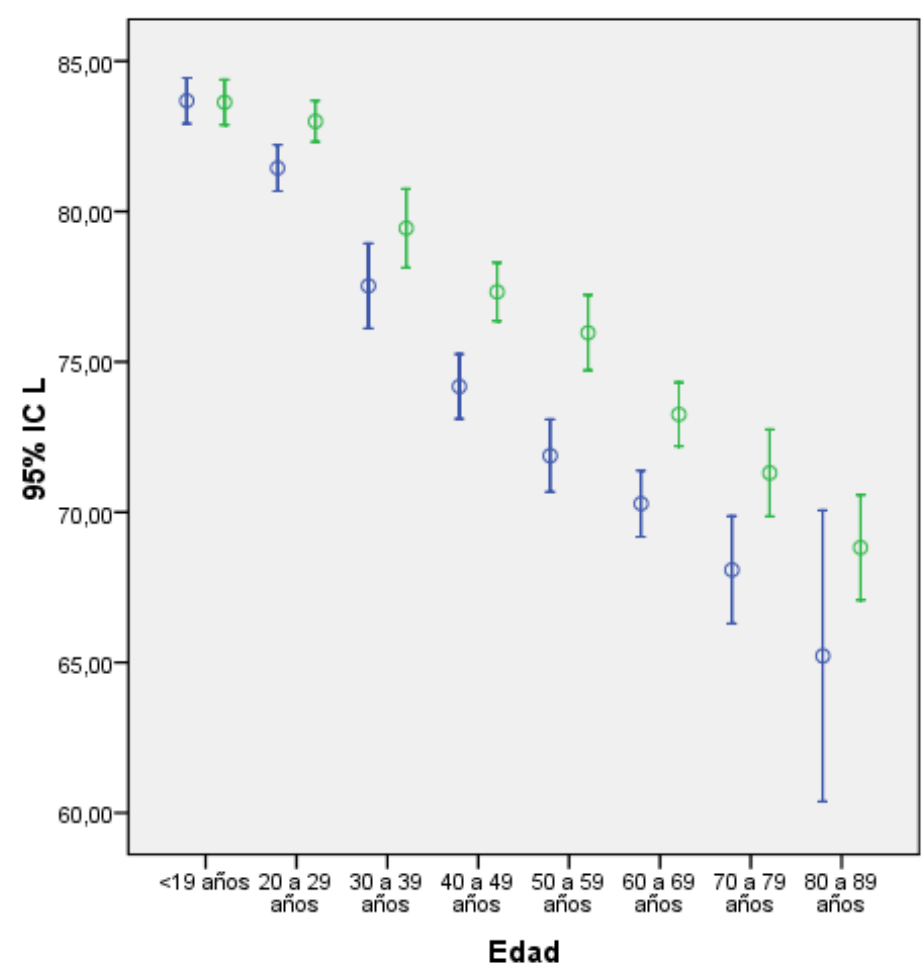

\section{Gráfico 19}

El tinte, representado por la variable h (Gráfico 20), hasta los treinta años va aumentando, posteriormente de manera homogénea disminuye. Al igual que ocurre con el valor, las mujeres tienen cifras ligeramente superiores.

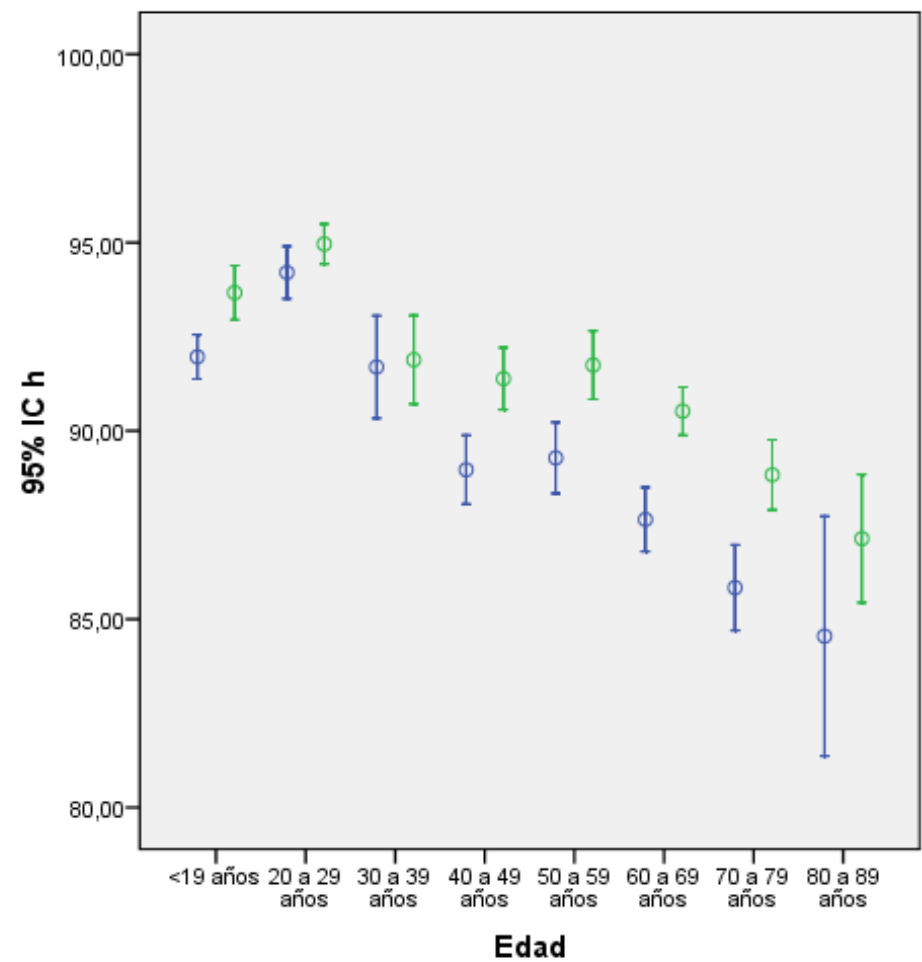


Por último analizaremos la variable intensidad en el gráfico 21. El intervalo de confianza del 95\% disminuye hasta los treinta años, y a partir de esa edad aumenta, progresivamente. En este caso la intensidad aparece ligeramente más alta aparece en hombres y no en mujeres.

Como observación el índice de confianza para el grupo de edad de 80-89 años en hombres que da en un intervalo muy amplio.

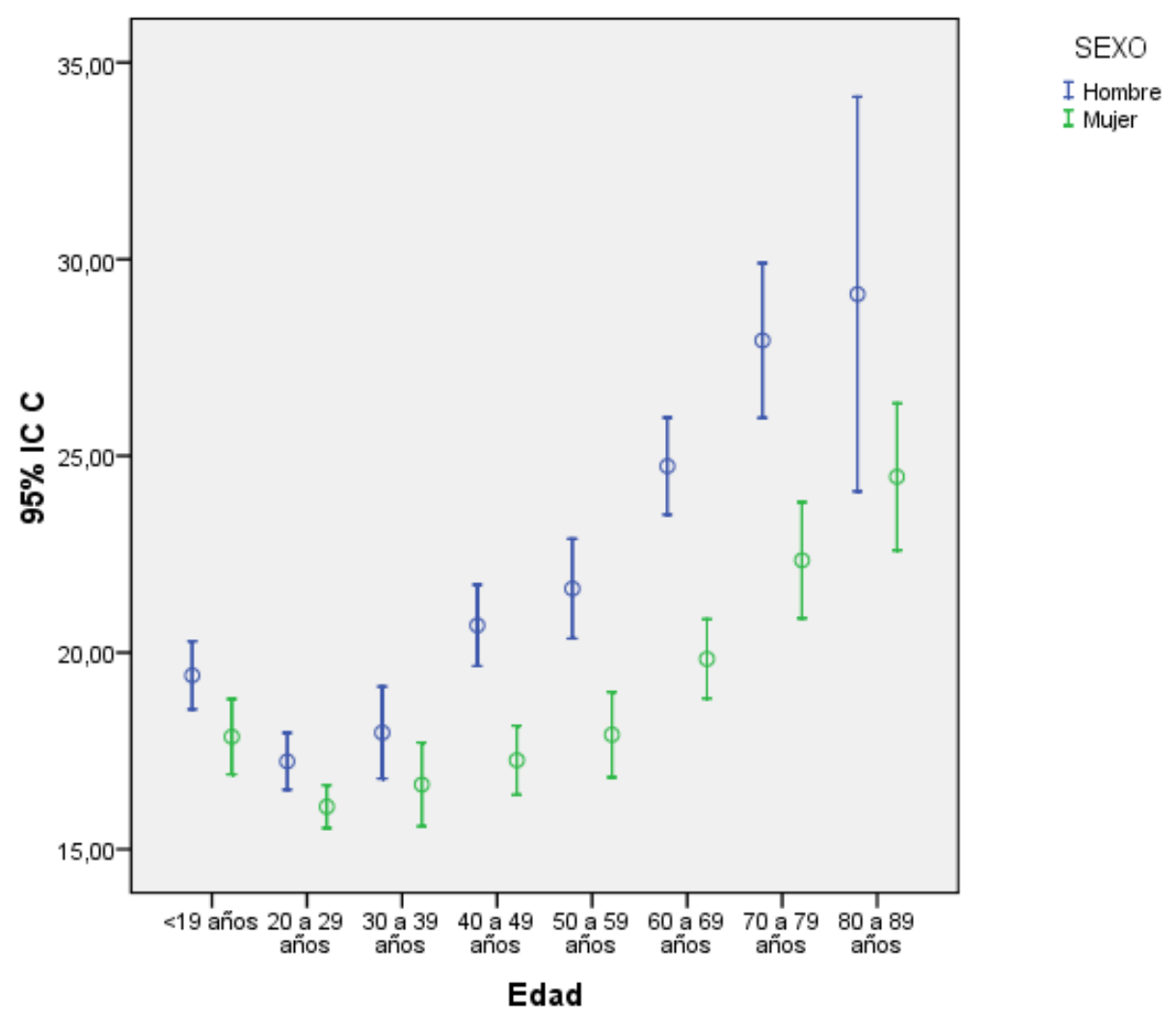

Gráfico 21

Las distancias absolutas entre las diferentes décadas, las hallamos aplicando la ecuación euclidiana de $\Delta \mathrm{E}$ (incremento de $\mathrm{E}$ ), explicada ya anteriormente utilizando la mediana como medida de referencia central. Con el fin de obtener un valor numérico más representativo de cada una de las décadas se opta por utilizar la mediana para que los valores extremos estén representados en menor medida.

Nos indica que según aumenta la diferencia de edad, la distancia absoluta espacial entre los las tres dimensiones del color se van acentuando. 
Comenzamos desarrollando la tabla 63 , que representa la distancia absoluta entre décadas, sin tener en cuenta la variable sexo.

Por ejemplo, la distancia ente la mediana de $L, a, b$ de la década de menores de 19 años y la mediana de L,a,b para la década entre 80 y 89 años, es decir las distancias extremas es de 16.98 unidades, mientras que la distancia con la mediana de (L,a,b) para la década de entre 20 y 29 años es de tan solo 2.66 .

\begin{tabular}{|c|c|c|c|c|c|c|c|c|}
\hline \multicolumn{7}{|c|}{ DISTANCIAS EUCLIDIANAS (L,a,b) } \\
BASADAS EN MEDIANAS DE LA POBLACIÓN TOTAL \\
\hline EDAD (Años) & $<19$ & $\mathbf{2 0 - 2 9}$ & $\mathbf{3 0 - 3 9}$ & $\mathbf{4 0 - 4 9}$ & $\mathbf{5 0 - 5 9}$ & $\mathbf{6 0 - 6 9}$ & $\mathbf{7 0 - 7 9}$ & $\mathbf{8 0 - 8 9}$ \\
\hline$<\mathbf{1 9}$ años & 0 & & & & & & & \\
\hline $\mathbf{2 0 - 2 9}$ años & 2.66 & 0 & & & & & & \\
\hline $\mathbf{3 0 - 3 9}$ años & 5.39 & 4.17 & 0 & & & & & \\
\hline $\mathbf{4 0 - 4 9}$ años & 7.65 & 7.05 & 3.02 & 0 & & & & \\
\hline $\mathbf{5 0 - 5 9}$ años & 10.06 & 9.57 & 5.48 & 2.53 & 0 & & & \\
\hline $\mathbf{6 0 - 6 9}$ años & 12.95 & 12.89 & 8.96 & 5.99 & 3.64 & 0 & & \\
\hline $\mathbf{7 0 - 7 9}$ años & 14.59 & 14.74 & 10.91 & 7.94 & 5.67 & 2.10 & 0 & \\
\hline $\mathbf{8 0 - 8 9}$ años & 16.98 & 17.40 & 13.74 & 10.80 & 8.64 & 5.09 & 3.00 & 0 \\
\hline
\end{tabular}

\section{Tabla 63}

A continuación y utilizando también la media de las medianas correspondientes, se describen la distancias existentes entre décadas para los hombres. Al igual que ocurría en la población total, las distancias aumentan según se distancias cronológicamente (tabla 64).

\begin{tabular}{|c|c|c|c|c|c|c|c|c|}
\hline \multicolumn{10}{|c|}{ DISTANCIAS EUCLIDIANAS (L,a,b) } \\
\hline EDAD (Años) & $<\mathbf{1 9}$ & $\mathbf{2 0 - 2 9}$ & $\mathbf{3 0 - 3 9}$ & $\mathbf{4 0 - 4 9}$ & $\mathbf{5 0 - 5 9}$ & $\mathbf{6 0 - 6 9}$ & $\mathbf{7 0 - 7 9}$ & $\mathbf{8 0 - 8 9}$ \\
\hline$<\mathbf{1 9}$ años & 0 & & & & & & & \\
\hline $\mathbf{2 0 - 2 9}$ años & 3.13 & 0 & & & & & & \\
\hline $\mathbf{3 0 - 3 9}$ años & 6.15 & 3.84 & 0 & & & & & \\
\hline $\mathbf{4 0 - 4 9}$ años & 9.10 & 7.81 & 4.32 & 0 & & & & \\
\hline $\mathbf{5 0 - 5 9}$ años & 12.00 & 10.63 & 6.97 & 2.90 & 0 & & & \\
\hline $\mathbf{6 0 - 6 9}$ años & 15.34 & 14.51 & 11.09 & 6.75 & 4.34 & 0 & & \\
\hline $\mathbf{7 0 - 7 9}$ años & 17.34 & 16.90 & 13.71 & 9.36 & 7.27 & 3.03 & 0 & \\
\hline $\mathbf{8 0 - 8 9}$ años & 18.71 & 18.67 & 15.79 & 11.52 & 9.79 & 5.81 & 2.95 & 0 \\
\hline
\end{tabular}

Tabla 64 
La última tabla de este apartado, tabla 65 , de esta apartado representa la población femenina. Como era de esperar la distancia menor entre décadas aparece entre los menores de 19 años y el grupo de edad siguiente, entre 20 y 29 años. La distancia superior esperaríamos encontrarla entre el grupo de edad inferior y el grupo de edad superior, distancia 16.75, pero en este caso existe una distancia superior situada entre el grupo de 20-29 años y el grupo de 80-89 años.

\begin{tabular}{|c|c|c|c|c|c|c|c|c|}
\hline \multicolumn{7}{|c|}{ DISTANCIAS EUCLIDIANAS (L,a,b) } \\
\hline BASADAS EN MEDIANAS EN MUJERES \\
\hline EDAD (Años) & $<\mathbf{1 9}$ & $\mathbf{2 0 - 2 9}$ & $\mathbf{3 0 - 3 9}$ & $\mathbf{4 0 - 4 9}$ & $\mathbf{5 0 - 5 9}$ & $\mathbf{6 0 - 6 9}$ & $\mathbf{7 0 - 7 9}$ & $\mathbf{8 0 - 8 9}$ \\
\hline $\mathbf{< 1 9}$ años & 0 & & & & & & & \\
\hline $\mathbf{2 0 - 2 9}$ años & 1.21 & 0 & & & & & & \\
\hline $\mathbf{3 0 - 3 9}$ años & 3.49 & 3.43 & 0 & & & & & \\
\hline $\mathbf{4 0 - 4 9}$ años & 6.21 & 6.08 & 2.72 & 0 & & & & \\
\hline $\mathbf{5 0 - 5 9}$ años & 7.60 & 7.52 & 4.13 & 1.44 & 0 & & & \\
\hline $\mathbf{6 0 - 6 9}$ años & 10.14 & 10.28 & 6.86 & 4.47 & 3.15 & 0 & & \\
\hline $\mathbf{7 0 - 7 9}$ años & 13.03 & 13.36 & 10.00 & 7.83 & 6.56 & 3.46 & 0 & \\
\hline $\mathbf{8 0 - 8 9}$ años & 16.75 & 17.22 & 13.97 & 11.98 & 10.76 & 7.69 & 4.22 & 0 \\
\hline
\end{tabular}

\section{Tabla 65}

Podemos generalizar que prácticamente, todas las distancias entre las décadas tomando como referencia la media de medianas, son crecientes, es decir, según aumenta la diferencia de edad, la distancia entre colores representado en la misma también aumenta, tanto en hombres como en mujeres y también en la población total. 


\section{6.-ESTUDIO DE LAS TABLILLAS DE COLOR DE LA GUÍA 3D MASTER}

En este apartado vamos a estudiar la relación entre las características de las tablillas de la guía de color 3D Master (Vita Zahnfabrik), en relación con sus variables ordinales continuas, Valor o luminosidad (L), Intensidad o Croma (C), y Tinte o tono (h), proporcionadas por el espectrofotómetro Vita Easyshade Compact (Vita Zahnfabrik). Además vamos a visualizar su ubicación en las tres dimensiones del espacio, y a su vez comprobar la ordenación de la misma.

\subsection{1.- Características descriptivas de las 26 tablillas de color}

A continuación vamos a exponer las veintiséis tablillas correspondientes a la guía de color empleada en este estudio, sin los colores intermedios obtenidos por el espectrofotómetro. Para conocer los valores de las tablillas intermedias, será necesario consultar el Anexo III.

Señalamos en cada tablilla el resultado mínimo, el máximo, la media y la desviación estándar, la mediana y los límites superior e inferior con un índice de confianza al 95\%. Existen tablillas con datos insuficientes para un estudio estadístico sólido, pero el texto las refleja para mantener la uniformidad de la exposición (Ejemplo: 4R1,5).

Las siguientes 26 tablas, quedaran agrupadas bajo el nombre de tabla resumen 66 .

\begin{tabular}{|c|c|c|c|c|c|c|}
\cline { 2 - 6 } \multicolumn{1}{c|}{} & \multicolumn{5}{c|}{ TABLILLA 1M1 $(\mathrm{n}=45)$} \\
\cline { 2 - 6 } \multicolumn{1}{c|}{} & mínimo & máximo & media \pm SD & mediana & inf 95\% & sup 95\% \\
\hline L & 80.3 & 89.5 & $84.4 \pm 2.46$ & 83.8 & $83.6-85.1$ \\
\hline C & 9.40 & 14.3 & $12.1 \pm 1.57$ & 12.4 & $11.6-12.6$ \\
\hline h & 90.1 & 103 & $97.4 \pm 2.91$ & 97.4 & $96.6-98.3$ \\
\hline a & -2.3 & 0 & $-1.5 \pm 0.48$ & -1.6 & $-1.7 /-1.4$ \\
\hline b & 9.20 & 14.2 & $12.0 \pm 1.61$ & 12.3 & $11.5-12.5$ \\
\hline
\end{tabular}

\begin{tabular}{|c|c|c|c|c|c|c|}
\cline { 2 - 6 } \multicolumn{1}{c|}{} & \multicolumn{5}{c|}{ TABLILLA 1M2 $(\mathrm{n}=59)$} \\
\cline { 2 - 6 } \multicolumn{1}{c|}{} & mínimo & máximo & media \pm SD & mediana & inf 95\% & sup 95\% \\
\hline L & 82.2 & 91.3 & $85.5 \pm 2.17$ & 84.9 & $85.0-86.1$ \\
\hline C & 16.2 & 23.0 & $20.1 \pm 1.50$ & 19.8 & $19.7-20.5$ \\
\hline h & 88.6 & 96.0 & $92.8 \pm 1.84$ & 93.1 & $92.3-93.3$ \\
\hline a & -2.1 & 0.50 & $-0.96 \pm 0.63$ & -1.1 & $-1.1 /-0.79$ \\
\hline b & 16.1 & 23.0 & $20.1 \pm 1.51$ & 19.7 & $19.7-20.5$ \\
\hline
\end{tabular}




\begin{tabular}{|c|c|c|c|c|c|c|}
\cline { 2 - 6 } \multicolumn{1}{c|}{} & \multicolumn{6}{c|}{ TABLILLA 2 1,5 $(\mathrm{n}=82)$} \\
\cline { 2 - 7 } \multicolumn{1}{c|}{} & mínimo & máximo & media \pm SD & mediana & inf 95\% & sup 95\% \\
\hline L & 76.6 & 83.9 & $79.5 \pm 1.78$ & 79.0 & $79.2-79.9$ \\
\hline C & 10.1 & 21.0 & $15.6 \pm 2.28$ & 15.7 & $15.1-16.1$ \\
\hline h & 91.1 & 102 & $94.5 \pm 2.20$ & 94.0 & $94.0-95.0$ \\
\hline a & -2.4 & -0.40 & $-1.2 \pm 0.44$ & -1.1 & $-1.3 /-1.1$ \\
\hline b & 10.0 & 21.0 & $15.5 \pm 2.30$ & 15.3 & $15.0-16.0$ \\
\hline
\end{tabular}

\begin{tabular}{|c|c|c|c|c|c|c|}
\cline { 2 - 6 } \multicolumn{1}{c|}{} & \multicolumn{5}{c|}{ TABLILLA 2L2,5 $(\mathrm{n}=14)$} \\
\cline { 2 - 6 } \multicolumn{1}{c|}{} & mínimo & máximo & media \pm SD & mediana & inf 95\% & sup 95\% \\
\hline L & 79.8 & 81.8 & $80.8 \pm 1.79$ & 80.5 & $79.8-81.8$ \\
\hline C & 20.7 & 22.6 & $21.6 \pm 1.57$ & 21.2 & $20.7-22.6$ \\
\hline h & 91.9 & 94.1 & $93.0 \pm 1.92$ & 92.1 & $91.9-94.1$ \\
\hline a & -1.5 & -0.24 & $-0.89 \pm 1.11$ & -0.70 & $-1.5 /-0.24$ \\
\hline b & 20.7 & 22.5 & $21.6 \pm 1.54$ & 21.2 & $20.7-22.5$ \\
\hline
\end{tabular}

\begin{tabular}{|c|c|c|c|c|c|c|}
\cline { 2 - 6 } \multicolumn{1}{c|}{} & \multicolumn{5}{c|}{ TABLILLA $2 M 1(\mathrm{n}=65)$} \\
\cline { 2 - 6 } \multicolumn{1}{c|}{} & mínimo & máximo & media \pm SD & mediana & inf 95\% & sup 95\% \\
\hline L & 71.2 & 84.6 & $79.6 \pm 3.80$ & 80.6 & $78.6-80.5$ \\
\hline C & 7.60 & 21.9 & $12.7 \pm 2.66$ & 12.5 & $12.1-13.4$ \\
\hline h & 88.7 & 107 & $95.9 \pm 4.35$ & 95.4 & $94.9-97.0$ \\
\hline a & -2.8 & 0.30 & $-1.2 \pm 0.74$ & -1.2 & $-1.3 /-0.98$ \\
\hline b & 7.30 & 21.8 & $12.6 \pm 2.71$ & 12.5 & $12.0-13.3$ \\
\hline
\end{tabular}

\begin{tabular}{|c|c|c|c|c|c|c|}
\cline { 2 - 7 } \multicolumn{1}{c|}{} & \multicolumn{6}{c|}{ TABLILLA 2M2 $(\mathrm{n}=6)$} \\
\cline { 2 - 7 } \multicolumn{1}{c|}{} & mínimo & máximo & media \pm SD & mediana & inf 95\% & sup 95\% \\
\hline $\mathbf{L}$ & 81.9 & 83.6 & $82.7 \pm 0.73$ & 82.7 & $81.9-83.5$ \\
\hline $\mathbf{C}$ & 19.5 & 26.1 & $21.4 \pm 2.46$ & 20.8 & $18.8-24.0$ \\
\hline $\mathbf{h}$ & 88.4 & 91.1 & $89.7 \pm 1.02$ & 89.6 & $88.6-90.8$ \\
\hline $\mathbf{a}$ & -0.40 & 0.70 & $0.13 \pm 0.40$ & 0.15 & $-0.28-0.55$ \\
\hline b & 19.5 & 26.1 & $21.4 \pm 2.46$ & 20.8 & $18.8-24.0$ \\
\hline
\end{tabular}

\begin{tabular}{|c|c|c|c|c|c|c|}
\cline { 2 - 7 } \multicolumn{1}{c|}{} & \multicolumn{6}{c|}{ TABLILLA 2M3 $(\mathrm{n}=21)$} \\
\cline { 2 - 7 } \multicolumn{1}{c|}{} & mínimo & máximo & media \pm SD & mediana & inf 95\% & sup 95\% \\
\hline L & 79.0 & 89.9 & $82.4 \pm 5.59$ & 82.1 & $81.2-83.6$ \\
\hline C & 25.3 & 32.5 & $26.9 \pm 1.73$ & 26.4 & $26.1-27.7$ \\
\hline h & 83.0 & 90.2 & $87.7 \pm 2.20$ & 88.3 & $86.7-88.7$ \\
\hline a & -0.10 & 3.80 & $1.10 \pm 1.12$ & 0.80 & $0.58-1.61$ \\
\hline b & 25.3 & 32.2 & $26.8 \pm 1.68$ & 26.3 & $26.1-27.6$ \\
\hline
\end{tabular}




\begin{tabular}{|c|c|c|c|c|c|c|}
\cline { 2 - 7 } \multicolumn{1}{c|}{} & \multicolumn{6}{c|}{ TABLILLA $2 R 1,5(n=6)$} \\
\cline { 2 - 7 } \multicolumn{1}{c|}{} & mínimo & máximo & media $\pm S D$ & mediana & inf 95\% & sup 95\% \\
\hline L & 76.4 & 80.4 & $78.0 \pm 1.49$ & 78.0 & $76.5-79.6$ \\
\hline C & 15.7 & 18.8 & $17.2 \pm 1.02$ & 17.3 & $16.2-18.3$ \\
\hline h & 86.7 & 91.1 & $89.3 \pm 1.70$ & 89.5 & $87.5-91.0$ \\
\hline a & -0.30 & 1.00 & $0.22 \pm 0.49$ & 0.15 & $-0.29-0.73$ \\
\hline b & 15.7 & 18.8 & $17.2 \pm 1.01$ & 17.2 & $16.2-18.3$ \\
\hline
\end{tabular}

\begin{tabular}{|c|c|c|c|c|c|c|}
\cline { 2 - 7 } \multicolumn{1}{c|}{} & \multicolumn{6}{c|}{ TABLILLA 2 2,5 $(\mathrm{n}=6)$} \\
\cline { 2 - 7 } \multicolumn{1}{c|}{} & mínimo & máximo & media \pm SD & mediana & inf 95\% & sup 95\% \\
\hline L & 78.9 & 81.2 & $80.1 \pm 1.16$ & 80.1 & $78.8-81.3$ \\
\hline C & 22.3 & 24.9 & $23.4 \pm 0.92$ & 23.4 & $22.5-24.4$ \\
\hline h & 85.3 & 90.5 & $88.4 \pm 1.93$ & 88.4 & $86.4-90.4$ \\
\hline a & -0.20 & 1.90 & $0.65 \pm 0.78$ & 0.65 & $-0.16-1.46$ \\
\hline b & 22.3 & 24.9 & $23.4 \pm 0.93$ & 23.4 & $22.4-24.4$ \\
\hline
\end{tabular}

\begin{tabular}{|c|c|c|c|c|c|c|}
\cline { 2 - 6 } \multicolumn{1}{c|}{} & \multicolumn{5}{c|}{ TABLILLA 3L1,5 $(\mathrm{n}=24)$} \\
\cline { 2 - 6 } \multicolumn{1}{c|}{} & mínimo & máximo & media \pm SD & mediana & inf 95\% & sup 95\% \\
\hline L & 70.9 & 78.3 & $73.2 \pm 2.15$ & 72.5 & $72.3-74.2$ \\
\hline C & 14.1 & 21.5 & $18.2 \pm 2.22$ & 18.4 & $17.3-19.2$ \\
\hline h & 89.5 & 95.5 & $91.9 \pm 1.69$ & 91.4 & $91.2-92.7$ \\
\hline a & -1.4 & 1.10 & $-0.49 \pm 0.58$ & -0.45 & $-0.74 /-0.25$ \\
\hline b & 14.0 & 21.5 & $18.2 \pm 2.24$ & 18.3 & $17.3-19.2$ \\
\hline
\end{tabular}

\begin{tabular}{|c|c|c|c|c|c|c|}
\cline { 2 - 7 } \multicolumn{1}{c|}{} & \multicolumn{6}{c|}{ TABLILLA 3L2,5 $(\mathrm{n}=10)$} \\
\cline { 2 - 7 } \multicolumn{1}{c|}{} & mínimo & máximo & media SD & mediana & inf 95\% & sup 95\% \\
\hline L & 72.6 & 77.8 & $74.8 \pm 1.84$ & 74.4 & $73.5-76.1$ \\
\hline C & 23.0 & 29.3 & $26.3 \pm 2.05$ & 26.5 & $24.8-27.8$ \\
\hline h & 88.9 & 95.8 & $90.5 \pm 2.09$ & 89.9 & $89.0-92.0$ \\
\hline a & -2.3 & 0.40 & $-0.24 \pm 0.86$ & 0 & $-0.86-0.38$ \\
\hline b & 22.9 & 29.3 & $26.3 \pm 2.06$ & 26.5 & $24.8-27.8$ \\
\hline
\end{tabular}

\begin{tabular}{|c|c|c|c|c|c|c|}
\cline { 2 - 6 } \multicolumn{1}{c|}{} & \multicolumn{5}{c|}{ TABLILLA 3M1 $(\mathrm{n}=96)$} \\
\cline { 2 - 6 } \multicolumn{1}{c|}{} & mínimo & máximo & media \pm SD & mediana & inf 95\% & sup 95\% \\
\hline L & 66.1 & 78.5 & $74.0 \pm 2.99$ & 74.3 & $73.3-74.6$ \\
\hline C & 8.90 & 18.1 & $14.8 \pm 2.03$ & 15.0 & $14.4-15.2$ \\
\hline h & 80.3 & 101 & $92.2 \pm 3.64$ & 92.6 & $91.5-93.0$ \\
\hline a & -2.7 & 2.50 & $-0.48 \pm 0.96$ & -0.60 & $-0.68 /-0.29$ \\
\hline b & 8.80 & 18.1 & $14.7 \pm 2.04$ & 15.0 & $14.3-15.1$ \\
\hline
\end{tabular}




\begin{tabular}{|c|c|c|c|c|c|c|}
\cline { 2 - 6 } \multicolumn{1}{c|}{} & \multicolumn{6}{c|}{ TABLILLA 3M2 $(\mathrm{n}=7)$} \\
\cline { 2 - 7 } \multicolumn{1}{c|}{} & mínimo & máximo & media \pm SD & mediana & inf 95\% & sup 95\% \\
\hline L & 72.8 & 78.6 & $75.4 \pm 2.04$ & 75.6 & $73.5-77.3$ \\
\hline C & 22.4 & 24.4 & $23.3 \pm 0.79$ & 23.2 & $22.5-24.0$ \\
\hline h & 87.2 & 88.7 & $88.1 \pm 0.57$ & 88.2 & $87.6-88.6$ \\
\hline a & 0.50 & 1.20 & $0.79 \pm 0.25$ & 0.80 & $0.56-1.01$ \\
\hline b & 22.4 & 24.4 & $23.2 \pm 0.78$ & 23.2 & $22.5-24.0$ \\
\hline
\end{tabular}

\begin{tabular}{|c|c|c|c|c|c|c|}
\cline { 2 - 6 } \multicolumn{1}{c|}{} & \multicolumn{5}{c|}{ TABLILLA 3M3 $(\mathrm{n}=16)$} \\
\cline { 2 - 7 } \multicolumn{1}{c|}{} & mínimo & máximo & media $\pm S D$ & mediana & inf 95\% & sup 95\% \\
\hline L & 74.1 & 81.0 & $77.5 \pm 2.02$ & 77.2 & $76.4-78.6$ \\
\hline C & 29.0 & 38.4 & $32.4 \pm 2.37$ & 32.8 & $31.1-33.6$ \\
\hline h & 82.9 & 92.1 & $86.6 \pm 2.28$ & 86.4 & $85.3-87.8$ \\
\hline a & -0.50 & 4.80 & $2.13 \pm 1.15$ & 1.95 & $1.51-2.74$ \\
\hline b & 28.9 & 38.1 & $32.3 \pm 2.34$ & 32.7 & $31.0-33.5$ \\
\hline
\end{tabular}

\begin{tabular}{|c|c|c|c|c|c|c|}
\cline { 2 - 7 } \multicolumn{1}{c|}{} & \multicolumn{6}{c|}{ TABLILLA 3R1,5 $(\mathrm{n}=3)$} \\
\cline { 2 - 7 } \multicolumn{1}{c|}{} & mínimo & máximo & media \pm SD & mediana & inf 95\% & sup 95\% \\
\hline $\mathbf{L}$ & 72.9 & 74.9 & $74.0 \pm 1.01$ & 74.2 & $71.5-76.5 .1$ \\
\hline $\mathbf{C}$ & 18.3 & 21.1 & $19.7 \pm 1.40$ & 19.6 & $16.2-23.1$ \\
\hline $\mathbf{h}$ & 85.7 & 87.3 & $86.6 \pm 0.82$ & 86.8 & $84.6-88.6$ \\
\hline $\mathbf{a}$ & 1.00 & 1.50 & $1.17 \pm 0.29$ & 1.00 & $0.45-1.88$ \\
\hline $\mathbf{b}$ & 18.3 & 21.1 & $19.6 \pm 1.40$ & 19.5 & $16.1-23.1$ \\
\hline
\end{tabular}

\begin{tabular}{|c|c|c|c|c|c|c|}
\cline { 2 - 6 } \multicolumn{1}{c|}{} & \multicolumn{6}{c|}{ TABLILLA $3 \mathbf{3 R}(\mathrm{n}=2)$} \\
\cline { 2 - 6 } \multicolumn{1}{c|}{} & mínimo & máximo & media \pm SD & mediana & inf 95\% & sup 95\% \\
\hline L & 74.1 & 74.2 & $74.2 \pm 0.07$ & 74.1 & $73.5-74.8$ \\
\hline C & 26.7 & 27.0 & $26.9 \pm 0.21$ & 26.7 & $24.9-28.8$ \\
\hline h & 78.5 & 83.8 & $81.2 \pm 3.75$ & 78.5 & $47.5-115$ \\
\hline a & 2.90 & 5.30 & $4.10 \pm 1.70$ & 2.90 & $-11-19.3$ \\
\hline b & 26.2 & 26.8 & $26.5 \pm 0.42$ & 26.2 & $22.7-30.3$ \\
\hline
\end{tabular}

\begin{tabular}{|c|c|c|c|c|c|c|}
\cline { 2 - 6 } \multicolumn{1}{c|}{} & \multicolumn{6}{c|}{ TABLILLA 4L1,5 $(\mathrm{n}=15)$} \\
\cline { 2 - 7 } \multicolumn{1}{c|}{} & mínimo & máximo & media \pm SD & mediana & inf 95\% & sup 95\% \\
\hline L & 67.2 & 70.3 & $68.4 \pm 0.92$ & 68.5 & $67.9-68.9$ \\
\hline C & 19.6 & 23.8 & $21.6 \pm 1.32$ & 21.3 & $20.9-22.4$ \\
\hline h & 87.5 & 92.1 & $89.7 \pm 1.54$ & 89.4 & $88.8-90.5$ \\
\hline a & -0.80 & 1.00 & $0.15 \pm 0.60$ & 0.20 & $-0.19-0.48$ \\
\hline b & 19.6 & 23.8 & $21.6 \pm 1.31$ & 21.3 & $20.9-22.3$ \\
\hline
\end{tabular}


RESULTADOS

\begin{tabular}{|c|c|c|c|c|c|}
\cline { 2 - 5 } \multicolumn{1}{c|}{} & \multicolumn{5}{c|}{ TABLILLA 4L2,5 $(\mathrm{n}=1)$} \\
\cline { 2 - 6 } \multicolumn{1}{c|}{} & mínimo & máximo & media/mediana & inf 95\% & sup 95\% \\
\hline L & 70.2 & 70.2 & 70.2 & \\
\hline C & 28.6 & 28.6 & 28.6 & \\
\hline h & 88.2 & 88.2 & 88.2 & \\
\hline a & 0.90 & 0.90 & 0.90 & \\
\hline b & 28.6 & 28.6 & 28.6 & \\
\hline
\end{tabular}

\begin{tabular}{|c|c|c|c|c|c|c|}
\cline { 2 - 7 } \multicolumn{1}{c|}{} & \multicolumn{6}{c|}{ TABLILLA 4M1 $(\mathrm{n}=22)$} \\
\cline { 2 - 7 } \multicolumn{1}{c|}{} & mínimo & máximo & media \pm SD & mediana & inf 95\% & sup 95\% \\
\hline L & 61.6 & 70.5 & $67.1 \pm 2.36$ & 67.8 & $66.0-68.1$ \\
\hline C & 12.3 & 21.2 & $17.7 \pm 2.47$ & 18.6 & $16.6-18.8$ \\
\hline h & 83.2 & 94.4 & $89.7 \pm 3.18$ & 90.2 & $88.3-91.1$ \\
\hline a & -1.1 & 2.30 & $0.17 \pm 1.01$ & -0.5 & $-0.28-0.62$ \\
\hline b & 12.3 & 21.1 & $17.7 \pm 2.46$ & 18.6 & $16.6-18.8$ \\
\hline
\end{tabular}

\begin{tabular}{|c|c|c|c|c|c|c|}
\cline { 2 - 6 } \multicolumn{1}{c|}{} & \multicolumn{6}{c|}{ TABLILLA 4M2 $(\mathrm{n}=3)$} \\
\cline { 2 - 7 } \multicolumn{1}{c|}{} & mínimo & máximo & media \pm SD & mediana & inf 95\% & sup 95\% \\
\hline $\mathbf{L}$ & 67.7 & 69.1 & $68.3 \pm 0.71$ & 68.2 & $66.6-70.1$ \\
\hline $\mathbf{C}$ & 26.5 & 27.5 & $27.0 \pm 0.50$ & 26.9 & $25.7-28.2$ \\
\hline $\mathbf{h}$ & 86.2 & 87.0 & $86.6 \pm 0.40$ & 86.5 & $85.6-87.6$ \\
\hline $\mathbf{a}$ & 1.40 & 1.80 & $1.63 \pm 0.21$ & 1.70 & $1.12-2.15$ \\
\hline $\mathbf{b}$ & 26.4 & 27.4 & $26.9 \pm 0.50$ & 26.8 & $25.6-28.1$ \\
\hline
\end{tabular}

\begin{tabular}{|c|c|c|c|c|c|c|}
\cline { 2 - 7 } \multicolumn{1}{c|}{} & \multicolumn{6}{c|}{ TABLILLA 4M3 $(\mathrm{n}=16)$} \\
\cline { 2 - 7 } \multicolumn{1}{c|}{} & mínimo & máximo & media \pm SD & mediana & inf 95\% & sup 95\% \\
\hline $\mathbf{L}$ & 67.0 & 73.8 & $69.8 \pm 1.97$ & 69.5 & $68.8-70.8$ \\
\hline $\mathbf{C}$ & 32.8 & 41.6 & $36.1 \pm 2.28$ & 36.3 & $34.9-37.3$ \\
\hline $\mathbf{h}$ & 79.7 & 87.7 & $83.6 \pm 2.39$ & 83.1 & $82.3-84.8$ \\
\hline $\mathbf{a}$ & 1.30 & 6.80 & $4.12 \pm 1.62$ & 4.45 & $3.25-4.98$ \\
\hline $\mathbf{b}$ & 32.7 & 41.3 & $35.8 \pm 2.18$ & 35.9 & $34.6-37.0$ \\
\hline
\end{tabular}

\begin{tabular}{|c|c|c|c|c|c|c|}
\cline { 2 - 7 } \multicolumn{1}{c|}{} & \multicolumn{6}{c|}{ TABLILLA 4R1,5 $(\mathrm{n}=2)$} \\
\cline { 2 - 7 } \multicolumn{1}{c|}{} & mínimo & máximo & media \pm SD & mediana & inf 95\% & sup 95\% \\
\hline L & 68.1 & 73.2 & $70.7 \pm 3.61$ & 70.7 & & \\
\hline C & 20.8 & 22.2 & $21.5 \pm 0.99$ & 21.5 & \\
\hline h & 80.6 & 88.7 & $84.7 \pm 5.73$ & 84.7 & \\
\hline a & 0.50 & 3.40 & $1.95 \pm 2.05$ & 1.95 & \\
\hline b & 20.5 & 22.2 & $21.4 \pm 1.20$ & 21.4 & \\
\hline
\end{tabular}




\begin{tabular}{|c|c|c|c|c|c|c|}
\cline { 2 - 6 } \multicolumn{1}{c|}{} & \multicolumn{6}{c|}{ TABLILLA 4R2,5 $(\mathrm{n}=6)$} \\
\cline { 2 - 7 } \multicolumn{1}{c|}{} & mínimo & máximo & media $\pm S D$ & mediana & inf 95\% & sup 95\% \\
\hline L & 67.3 & 70.5 & $68.9 \pm 1.15$ & 69.0 & $67.7-70.1$ \\
\hline C & 29.5 & 31.6 & $30.7 \pm 0.87$ & 30.8 & $29.7-31.6$ \\
\hline h & 81.8 & 84.9 & $83.9 \pm 1.08$ & 84.2 & $82.8-85.1$ \\
\hline a & 2.70 & 4.30 & $3.25 \pm 0.55$ & 3.10 & $2.67-3.83$ \\
\hline b & 29.4 & 31.4 & $30.5 \pm 0.85$ & 30.5 & $29.6-31.4$ \\
\hline
\end{tabular}

\begin{tabular}{|c|c|c|c|c|c|c|}
\cline { 2 - 7 } \multicolumn{1}{c|}{} & \multicolumn{6}{c|}{ TABLILLA 5M1 $(\mathrm{n}=9)$} \\
\cline { 2 - 7 } \multicolumn{1}{c|}{} & mínimo & máximo & media \pm SD & mediana & inf 95\% & sup 95\% \\
\hline L & 54.8 & 61.9 & $59.4 \pm 2.30$ & 60.1 & $57.6-61.1$ \\
\hline C & 18.7 & 23.7 & $21.6 \pm 2.03$ & 22.6 & $20.0-23.2$ \\
\hline h & 80.0 & 89.8 & $85.7 \pm 3.04$ & 85.8 & $83.3-88.3$ \\
\hline a & 0.10 & 3.20 & $1.56 \pm 1.01$ & 1.70 & $0.78-2.33$ \\
\hline b & 18.4 & 23.7 & $21.5 \pm 2.09$ & 22.5 & $19.9-23.1$ \\
\hline
\end{tabular}

\begin{tabular}{|c|c|c|c|c|c|c|}
\cline { 2 - 7 } \multicolumn{1}{c|}{} & \multicolumn{6}{c|}{ TABLILLA 5M2 $(\mathrm{n}=3)$} \\
\cline { 2 - 7 } \multicolumn{1}{c|}{} & mínimo & máximo & media \pm SD & mediana & inf 95\% & sup 95\% \\
\hline $\mathbf{L}$ & 47.9 & 53.6 & $51.5 \pm 3.13$ & 53.0 & $47.9-53.6$ \\
\hline $\mathbf{C}$ & 29.6 & 33.1 & $31.1 \pm 1.80$ & 30.6 & $29.6-33.1$ \\
\hline $\mathbf{h}$ & 77.6 & 80.5 & $79.0 \pm 1.45$ & 79.0 & $77.6-80.5$ \\
\hline $\mathbf{a}$ & 4.90 & 7.10 & $5.93 \pm 1.11$ & 5.80 & $4.90-7.10$ \\
\hline $\mathbf{b}$ & 29.2 & 32.4 & $30.5 \pm 1.67$ & 30.0 & $29.2-32.4$ \\
\hline
\end{tabular}

\begin{tabular}{|c|c|c|c|c|c|c|}
\cline { 2 - 7 } \multicolumn{1}{c|}{} & \multicolumn{6}{c|}{ TABLILLA 5M3 $(\mathrm{n}=6)$} \\
\cline { 2 - 7 } \multicolumn{1}{c|}{} & mínimo & máximo & media \pm SD & mediana & inf 95\% & sup 95\% \\
\hline L & 47.0 & 63.2 & $55.5 \pm 7.27$ & 55.1 & $47.7-62.9$ \\
\hline C & 39.4 & 49.8 & $45.2 \pm 3.92$ & 44.3 & $41.1-49.3$ \\
\hline h & 69.8 & 80.7 & $74.0 \pm 3.97$ & 73.3 & $69.8-78.1$ \\
\hline a & 6.30 & 16.1 & $12.6 \pm 3.80$ & 13.6 & $8.64-16.6$ \\
\hline b & 38.9 & 47.3 & $43.3 \pm 3.19$ & 42.4 & $40.0-46.7$ \\
\hline
\end{tabular}

\section{Tabla 66}

De los 1361 participantes en este estudio, tan solo 545 (40\%), tenían un color dentro de las 26 tablillas de color dela guía 3D Master. El color dental del 60\% restante estaba incluido en las denominadas "tablillas intermedias" (Anexo III). 


\subsection{2.- Distancias de L, C, h, a y b entre las 26 tablillas de color}

Vamos a utilizar los resultados obtenidos en el apartado anterior para conocer las distancia que existe entre las tablillas, tanto la distancia euclidiana $\Delta \mathrm{E}$, como la distancia en las tres dimensiones del color representadas como variables continuas ordinales, $\Delta \mathrm{L}$ (tabla 67 ), $\Delta \mathrm{a}$ (tabla 68 ), $\Delta \mathrm{b}$ (tabla 69 ), $\Delta \mathrm{C}$ (tabla 70 ) e $\Delta \mathrm{h}$ (tabla 71 ).

Para ello vamos a utilizar la mediana, como valor de referencia central.

En la tabla 72 que representa la distancia euclidiana entre los colores de la guía Toothguide 3D Master, aparecen casillas coloreadas, para su mejor discriminación cuando se aborde dicha tabla en el apartado de discusión.

Todos los cálculos que se han realizado para medir la diferencia entre dos colores $(\Delta \mathrm{E})$ se ha realizado con la fórmula desarrollada a continuación.

\section{Diferencia de color entre dos objetos:}

$$
\Delta E^{\star}=\left[\left(\Delta L^{*}\right)^{2}+\left(\Delta a^{*}\right)^{2}+\left(\Delta b^{*}\right)^{2}\right]^{1 / 2}
$$

$\Delta \mathbf{E}^{\star}$ Representa la magnitud de la diferencia de color, pero no indica la dirección en los ejes de coordenadas. 


\section{DISTANCIA DE LAS MEDIANAS DE L* ENTRE LAS TABLILLAS GUIA 3D MASTER}

\begin{tabular}{|c|c|c|c|c|c|c|c|c|c|c|c|c|c|c|c|c|c|c|c|c|c|c|c|c|c|c|}
\hline & 1M1 & 1M2 & 2L1,5 & 2L2,5 & 2M1 & 2M2 & $2 \mathrm{M} 3$ & 2R1,5 & 2R2,5 & 3L1,5 & 3L2,5 & 3M1 & 3M2 & 3M3 & 3R1,5 & 3R2,5 & 4L1,5 & 4L2,5 & 4M1 & 4M2 & 4M3 & 4R1,5 & 4R2,5 & 5M1 & $5 \mathrm{M} 2$ & 5M3 \\
\hline $1 \mathrm{M} 1$ & 0 & & & & & & & & & & & & & & & & & & & & & & & & & \\
\hline 1M2 & 1.10 & 0 & & & & & & & & & & & & & & & & & & & & & & & & \\
\hline $2 L 1,5$ & 4.80 & 5.90 & 0 & & & & & & & & & & & & & & & & & & & & & & & \\
\hline 2L2,5 & 3.35 & 4.45 & 1.45 & 0 & & & & & & & & & & & & & & & & & & & & & & \\
\hline 2M1 & 3.20 & 4.30 & 1.60 & 0.15 & 0 & & & & & & & & & & & & & & & & & & & & & \\
\hline $2 \mathrm{M} 2$ & 1.10 & 2.20 & 3.70 & 2.25 & 2.10 & 0 & & & & & & & & & & & & & & & & & & & & \\
\hline $2 \mathrm{M} 3$ & 1.70 & 2.80 & 3.10 & 1.65 & 1.50 & 0.60 & 0 & & & & & & & & & & & & & & & & & & & \\
\hline 2R1,5 & 5.80 & 6.90 & 1.00 & 2.45 & 2.60 & 4.70 & 4.10 & 0 & & & & & & & & & & & & & & & & & & \\
\hline 2R2,5 & 3.70 & 4.80 & 1.10 & 0.35 & 0.50 & 2.60 & 2.00 & 2.10 & 0 & & & & & & & & & & & & & & & & & \\
\hline $3 L 1,5$ & 11.30 & 12.40 & 6.50 & 7.95 & 8.10 & 10.20 & 9.60 & 5.50 & 7.60 & 0 & & & & & & & & & & & & & & & & \\
\hline 3L2,5 & 9.40 & 10.50 & 4.60 & 6.05 & 6.20 & 8.30 & 7.70 & 3.60 & 5.70 & 1.90 & 0 & & & & & & & & & & & & & & & \\
\hline 3M1 & 9.50 & 10.60 & 4.70 & 6.15 & 6.30 & 8.40 & 7.80 & 3.70 & 5.80 & 1.80 & 0.10 & 0 & & & & & & & & & & & & & & \\
\hline $3 \mathrm{M} 2$ & 8.20 & 9.30 & 3.40 & 4.85 & 5.00 & 7.10 & 6.50 & 2.40 & 4.50 & 3.10 & 1.20 & 1.30 & 0 & & & & & & & & & & & & & \\
\hline 3M3 & 6.65 & 7.75 & 1.85 & 3.30 & 3.45 & 5.55 & 4.95 & 0.85 & 2.95 & 4.65 & 2.75 & 2.85 & 1.55 & 0 & & & & & & & & & & & & \\
\hline 3R1,5 & 9.60 & 10.70 & 4.80 & 6.25 & 6.40 & 8.50 & 7.90 & 3.80 & 5.90 & 1.70 & 0.20 & 0.10 & 1.40 & 2.95 & 0 & & & & & & & & & & & \\
\hline 3R2,5 & 9.65 & 10.75 & 4.85 & 6.30 & 6.45 & 8.55 & 7.95 & 3.85 & 5.95 & 1.65 & 0.25 & 0.15 & 1.45 & 3.00 & 0.05 & 0 & & & & & & & & & & \\
\hline 4L1,5 & 15.30 & 16.40 & 10.50 & 11.95 & 12.10 & 14.20 & 13.60 & 9.50 & 11.60 & 4.00 & 5.90 & 5.80 & 7.10 & 8.65 & 5.70 & 5.65 & 0 & & & & & & & & & \\
\hline 4L2,5 & 13.60 & 14.70 & 8.80 & 10.25 & 10.40 & 12.50 & 11.90 & 7.80 & 9.90 & 2.30 & 4.20 & 4.10 & 5.40 & 6.95 & 4.00 & 3.95 & 1.70 & 0 & & & & & & & & \\
\hline 4M1 & 16.05 & 17.15 & 11.25 & 12.70 & 12.85 & 14.95 & 14.35 & 10.25 & 12.35 & 4.75 & 6.65 & 6.55 & 7.85 & 9.40 & 6.45 & 6.40 & 0.75 & 2.45 & 0 & & & & & & & \\
\hline 4M1 & 15.60 & 16.70 & 10.80 & 12.25 & 12.40 & 14.50 & 13.90 & 9.80 & 11.90 & 4.30 & 6.20 & 6.10 & 7.40 & 8.95 & 6.00 & 5.95 & 0.30 & 2.00 & 0.45 & 0 & & & & & & \\
\hline 4M3 & 14.35 & 15.45 & 9.55 & 11.00 & 11.15 & 13.25 & 12.65 & 8.55 & 10.65 & 3.05 & 4.95 & 4.85 & 6.15 & 7.70 & 4.75 & 4.70 & 0.95 & 0.75 & 1.70 & 1.25 & 0 & & & & & \\
\hline 4R1,5 & 13.15 & 14.25 & 8.35 & 9.80 & 9.95 & 12.05 & 11.45 & 7.35 & 9.45 & 1.85 & 3.75 & 3.65 & 4.95 & 6.50 & 3.55 & 3.50 & 2.15 & 0.45 & 2.90 & 2.45 & 1.20 & 0 & & & & \\
\hline $4 \mathrm{R} 2,5$ & 14.80 & 15.90 & 10.00 & 11.45 & 11.60 & 13.70 & 13.10 & 9.00 & 11.10 & 3.50 & 5.40 & 5.30 & 6.60 & 8.15 & 5.20 & 5.15 & 0.50 & 1.20 & 1.25 & 0.80 & 0.45 & 1.65 & 0 & & & \\
\hline $5 \mathrm{M} 1$ & 23.70 & 24.80 & 18.90 & 20.35 & 20.50 & 22.60 & 22.00 & 17.90 & 20.00 & 12.40 & 14.30 & 14.20 & 15.50 & 17.05 & 14.10 & 14.05 & 8.40 & 10.10 & 7.65 & 8.10 & 9.35 & 10.55 & 8.9 & 0 & & \\
\hline $5 \mathrm{M} 2$ & 30.80 & 31.90 & 26.00 & 27.45 & 27.60 & 29.70 & 29.10 & 25.00 & 27.10 & 19.50 & 21.40 & 21.30 & 22.60 & 24.15 & 21.20 & 21.15 & 15.50 & 17.20 & 14.75 & 15.20 & 16.45 & 17.65 & 16.0 & 7.1 & 0 & \\
\hline $5 \mathrm{M} 3$ & 28.70 & 29.80 & 23.90 & 25.35 & 25.50 & 27.60 & 27.00 & 22.90 & 25.00 & 17.40 & 19.30 & 19.20 & 20.50 & 22.05 & 19.10 & 19.05 & 13.40 & 15.10 & 12.65 & 13.10 & 14.35 & 15.55 & 13.9 & 5.0 & 2.1 & 0 \\
\hline
\end{tabular}

Tabla 67 


\section{DISTANCIA DE LAS MEDIANAS DE a* ENTRE LAS TABLILLAS GUIA 3D MASTER}

\begin{tabular}{|c|c|c|c|c|c|c|c|c|c|c|c|c|c|c|c|c|c|c|c|c|c|c|c|c|c|c|}
\hline & \\
\hline & 1M1 & 1M2 & $2 \mathrm{~L} 1,5$ & 2L2,5 & 2M1 & 2M2 & $2 \mathrm{M} 3$ & 2R1,5 & 2R2,5 & 3L1,5 & 3L2,5 & 3M1 & 3M2 & 3M3 & 3R1,5 & 3R2,5 & 4L1,5 & 4L2,5 & 4M1 & 4M2 & 4M3 & 4R1,5 & 4R2,5 & $5 \mathrm{M1}$ & 5M2 & $5 \mathrm{M} 3$ \\
\hline 1M1 & 0 & & & & & & & & & & & & & & & & & & & & & & & & & \\
\hline 1M2 & 0.50 & 0 & & & & & & & & & & & & & & & & & & & & & & & & \\
\hline 2L1,5 & 0.50 & 0 & 0 & & & & & & & & & & & & & & & & & & & & & & & \\
\hline $2 \mathrm{~L} 2,5$ & 0.90 & 0.40 & 0.40 & 0 & & & & & & & & & & & & & & & & & & & & & & \\
\hline 2M1 & 0.40 & 0.10 & 0.10 & 0.50 & 0 & & & & & & & & & & & & & & & & & & & & & \\
\hline 2M2 & 1.75 & 1.25 & 1.25 & 0.85 & 1.35 & 0 & & & & & & & & & & & & & & & & & & & & \\
\hline $2 \mathrm{M} 3$ & 2.40 & 1.90 & 1.90 & 1.50 & 2.00 & 0.65 & 0 & & & & & & & & & & & & & & & & & & & \\
\hline 2R1,5 & 1.75 & 1.25 & 1.25 & 0.85 & 1.35 & 0.00 & 0.65 & 0 & & & & & & & & & & & & & & & & & & \\
\hline $2 \mathrm{R} 2,5$ & 2.25 & 1.75 & 1.75 & 1.35 & 1.85 & 0.50 & 0.15 & 0.50 & 0 & & & & & & & & & & & & & & & & & \\
\hline $3 \mathrm{~L} 1,5$ & 1.15 & 0.65 & 0.65 & 0.25 & 0.75 & 0.60 & 1.25 & 0.60 & 1.10 & 0 & & & & & & & & & & & & & & & & \\
\hline 3L2,5 & 1.60 & 1.10 & 1.10 & 0.70 & 1.20 & 0.15 & 0.80 & 0.15 & 0.65 & 0.45 & 0 & & & & & & & & & & & & & & & \\
\hline 3M1 & 1.00 & 0.50 & 0.50 & 0.10 & 0.60 & 0.75 & 1.40 & 0.75 & 1.25 & 0.15 & 0.60 & 0 & & & & & & & & & & & & & & \\
\hline 3M2 & 2.40 & 1.90 & 1.90 & 1.50 & 2.00 & 0.65 & 0.00 & 0.65 & 0.15 & 1.25 & 0.80 & 1.40 & 0 & & & & & & & & & & & & & \\
\hline 3M3 & 3.55 & 3.05 & 3.05 & 2.65 & 3.15 & 1.80 & 1.15 & 1.80 & 1.30 & 2.40 & 1.95 & 2.55 & 1.15 & 0 & & & & & & & & & & & & \\
\hline $3 R 1,5$ & 2.60 & 2.10 & 2.10 & 1.70 & 2.20 & 0.85 & 0.20 & 0.85 & 0.35 & 1.45 & 1.00 & 1.60 & 0.20 & 0.95 & 0 & & & & & & & & & & & \\
\hline $3 R 2,5$ & 5.70 & 5.20 & 5.20 & 4.80 & 5.30 & 3.95 & 3.30 & 3.95 & 3.45 & 4.55 & 4.10 & 4.70 & 3.30 & 2.15 & 3.10 & 0 & & & & & & & & & & \\
\hline 4L1,5 & 1.80 & 1.30 & 1.30 & 0.90 & 1.40 & 0.05 & 0.60 & 0.05 & 0.45 & 0.65 & 0.20 & 0.80 & 0.60 & 1.75 & 0.80 & 3.90 & 0 & & & & & & & & & \\
\hline $4 \mathrm{~L} 2,5$ & 2.50 & 2.00 & 2.00 & 1.60 & 2.10 & 0.75 & 0.10 & 0.75 & 0.25 & 1.35 & 0.90 & 1.50 & 0.10 & 1.05 & 0.10 & 3.20 & 0.70 & 0 & & & & & & & & \\
\hline 4M1 & 1.55 & 1.05 & 1.05 & 0.65 & 1.15 & 0.20 & 0.85 & 0.20 & 0.70 & 0.40 & 0.05 & 0.55 & 0.85 & 2.00 & 1.05 & 4.15 & 0.25 & 0.95 & 0 & & & & & & & \\
\hline 4M1 & 3.30 & 2.80 & 2.80 & 2.40 & 2.90 & 1.55 & 0.90 & 1.55 & 1.05 & 2.15 & 1.70 & 2.30 & 0.90 & 0.25 & 0.70 & 2.40 & 1.50 & 0.80 & 1.75 & 0 & & & & & & \\
\hline 4M3 & 6.05 & 5.55 & 5.55 & 5.15 & 5.65 & 4.30 & 3.65 & 4.30 & 3.80 & 4.90 & 4.45 & 5.05 & 3.65 & 2.50 & 3.45 & 0.35 & 4.25 & 3.55 & 4.50 & 2.75 & 0 & & & & & \\
\hline $4 R 1,5$ & 3.55 & 3.05 & 3.05 & 2.65 & 3.15 & 1.80 & 1.15 & 1.80 & 1.30 & 2.40 & 1.95 & 2.55 & 1.15 & 0.00 & 0.95 & 2.15 & 1.75 & 1.05 & 2.00 & 0.25 & 2.50 & 0 & & & & \\
\hline $4 \mathrm{R} 2,5$ & 4.70 & 4.20 & 4.20 & 3.80 & 4.30 & 2.95 & 2.30 & 2.95 & 2.45 & 3.55 & 3.10 & 3.70 & 2.30 & 1.15 & 2.10 & 1.00 & 2.90 & 2.20 & 3.15 & 1.40 & \begin{tabular}{|l|}
1.35 \\
\end{tabular} & 1.15 & 0 & & & \\
\hline 5M1 & 3.30 & 2.80 & 2.80 & 2.40 & 2.90 & 1.55 & 0.90 & 1.55 & 1.05 & 2.15 & 1.70 & 2.30 & 0.90 & 0.25 & 0.70 & 2.40 & 1.50 & 0.80 & 1.75 & 0.00 & 2.75 & 0.25 & 1.40 & 0 & & \\
\hline $5 \mathrm{M} 2$ & 7.40 & 6.90 & 6.90 & 6.50 & 7.00 & 5.65 & 5.00 & 5.65 & 5.15 & 6.25 & 5.80 & 6.40 & 5.00 & \begin{tabular}{|l|}
3.85 \\
\end{tabular} & 4.80 & 1.70 & 5.60 & 4.90 & 5.85 & 4.10 & 1.35 & 3.85 & 2.70 & \begin{tabular}{|l|}
4.10 \\
\end{tabular} & 0 & \\
\hline $5 \mathrm{M} 3$ & 15.15 & 14.65 & 14.65 & 14.25 & 14.75 & 13.40 & 12.75 & 13.40 & 12.90 & 14.00 & 13.55 & 14.15 & 12.75 & 11.60 & 12.55 & 9.45 & 13.35 & 12.65 & 13.60 & 11.85 & 9.10 & 11.60 & 10.45 & 11.85 & 7.75 & 0 \\
\hline
\end{tabular}

Tabla 68 


\section{DISTANCIA DE LAS MEDIANAS DE b* ENTRE LAS TABLILLAS GUIA 3D MASTER}

\begin{tabular}{|c|c|c|c|c|c|c|c|c|c|c|c|c|c|c|c|c|c|c|c|c|c|c|c|c|c|c|}
\hline & \multicolumn{26}{|c|}{ DISTANCIA DE LAS MEDIANAS DE b* ENTRE LAS TABLILLAS GUIA 3D MASTER } \\
\hline & 1M1 & 1M2 & 2L1,5 & $2 \mathrm{~L} 2,5$ & 2M1 & 2M2 & $2 \mathrm{M} 3$ & 2R1,5 & 2R2,5 & $3 L 1,5$ & $3 \mathrm{~L} 2,5$ & 3M1 & 3M2 & 3M3 & 3R1,5 & $3 R 2,5$ & $4 L 1,5$ & 4L2,5 & 4M1 & 4M2 & 4M3 & 4R1,5 & 4R2,5 & 5M1 & $5 \mathrm{M} 2$ & $5 \mathrm{M} 3$ \\
\hline 1M1 & 0 & & & & & & & & & & & & & & & & & & & & & & & & & \\
\hline $1 \mathrm{M} 2$ & 7.40 & 0 & & & & & & & & & & & & & & & & & & & & & & & & \\
\hline 2L1,5 & 3.00 & 4.40 & 0 & & & & & & & & & & & & & & & & & & & & & & & \\
\hline 2L2,5 & 8.90 & 1.50 & 5.90 & 0 & & & & & & & & & & & & & & & & & & & & & & \\
\hline $2 \mathrm{M} 1$ & 0.20 & 7.20 & 2.80 & 8.70 & 0 & & & & & & & & & & & & & & & & & & & & & \\
\hline 2M2 & 8.45 & 1.05 & 5.45 & 0.45 & 8.25 & 0 & & & & & & & & & & & & & & & & & & & & \\
\hline $2 \mathrm{M} 3$ & 14.00 & 6.60 & 11.00 & 5.10 & 13.80 & 5.55 & 0 & & & & & & & & & & & & & & & & & & & \\
\hline 2R1,5 & 4.90 & 2.50 & 1.90 & 4.00 & 4.70 & 3.55 & 9.10 & 0 & & & & & & & & & & & & & & & & & & \\
\hline 2R2,5 & 11.05 & 3.65 & 8.05 & 2.15 & 10.85 & 2.60 & 2.95 & 6.15 & 0 & & & & & & & & & & & & & & & & & \\
\hline 3L1,5 & 6.00 & 1.40 & 3.00 & 2.90 & 5.80 & 2.45 & 8.00 & 1.10 & 5.05 & 0 & & & & & & & & & & & & & & & & \\
\hline 3L2,5 & 14.15 & 6.75 & 11.15 & 5.25 & 13.95 & 5.70 & 0.15 & 9.25 & 3.10 & 8.15 & 0 & & & & & & & & & & & & & & & \\
\hline 3M1 & 2.65 & 4.75 & 0.35 & 6.25 & 2.45 & 5.80 & 11.35 & 2.25 & 8.40 & 3.35 & 11.50 & 0 & & & & & & & & & & & & & & \\
\hline 3M2 & 10.90 & 3.50 & 7.90 & 2.00 & 10.70 & 2.45 & 3.10 & 6.00 & 0.15 & 4.90 & 3.25 & 8.25 & 0 & & & & & & & & & & & & & \\
\hline 3M3 & 20.40 & 13.00 & 17.40 & 11.50 & 20.20 & 11.95 & 6.40 & 15.50 & 9.35 & 14.40 & 6.25 & 17.75 & 9.50 & 0 & & & & & & & & & & & & \\
\hline 3R1,5 & 7.20 & 0.20 & 4.20 & 1.70 & 7.00 & 1.25 & 6.80 & 2.30 & 3.85 & 1.20 & 6.95 & 4.55 & 3.70 & 13.20 & 0 & & & & & & & & & & & \\
\hline $3 R 2,5$ & 14.20 & 6.80 & 11.20 & 5.30 & 14.00 & 5.75 & 0.20 & 9.30 & 3.15 & 8.20 & 0.05 & 11.55 & 3.30 & 6.20 & 7.00 & 0 & & & & & & & & & & \\
\hline 4L1,5 & 9.00 & 1.60 & 6.00 & 0.10 & 8.80 & 0.55 & 5.00 & 4.10 & 2.05 & 3.00 & 5.15 & 6.35 & 1.90 & 11.40 & 1.80 & 5.20 & 0 & & & & & & & & & \\
\hline 4L2,5 & 16.30 & 8.90 & 13.30 & 7.40 & 16.10 & 7.85 & 2.30 & 11.40 & 5.25 & 10.30 & 2.15 & 13.65 & 5.40 & 4.10 & 9.10 & 2.10 & 7.30 & 0 & & & & & & & & \\
\hline 4M1 & 6.30 & 1.10 & 3.30 & 2.60 & 6.10 & 2.15 & 7.70 & 1.40 & 4.75 & 0.30 & 7.85 & 3.65 & 4.60 & 14.10 & 0.90 & 7.90 & 2.70 & 10.00 & 0 & & & & & & & \\
\hline 4M1 & 14.50 & 7.10 & 11.50 & 5.60 & 14.30 & 6.05 & 0.50 & 9.60 & 3.45 & 8.50 & 0.35 & 11.85 & 3.60 & 5.90 & 7.30 & 0.30 & 5.50 & 1.80 & 8.20 & 0 & & & & & & \\
\hline 4M3 & 23.60 & 16.20 & 20.60 & 14.70 & 23.40 & 15.15 & 9.60 & 18.70 & 12.55 & 17.60 & 9.45 & 20.95 & 12.70 & 3.20 & 16.40 & 9.40 & 14.60 & 7.30 & 17.30 & 9.10 & 0 & & & & & \\
\hline 4R1,5 & 9.05 & 1.65 & 6.05 & 0.15 & 8.85 & 0.60 & 4.95 & 4.15 & 2.00 & 3.05 & 5.10 & 6.40 & 1.85 & 11.35 & 1.85 & 5.15 & 0.05 & 7.25 & 2.75 & 5.45 & 14.55 & 0 & & & & \\
\hline 4R2,5 & 18.20 & 10.80 & 15.20 & 9.30 & 18.00 & 9.75 & 4.20 & 13.30 & 7.15 & 12.20 & 4.05 & 15.55 & 7.30 & 2.20 & 11.00 & 4.00 & 9.20 & 1.90 & 11.90 & 3.70 & 5.40 & 9.15 & 0 & & & \\
\hline $5 \mathrm{M} 1$ & 10.20 & 2.80 & 7.20 & 1.30 & 10.00 & 1.75 & 3.80 & 5.30 & 0.85 & 4.20 & 3.95 & 7.55 & 0.70 & 10.20 & 3.00 & 4.00 & 1.20 & 6.10 & 3.90 & 4.30 & 13.40 & 1.15 & 8.0 & 0 & & \\
\hline $5 \mathrm{M} 2$ & 17.70 & 10.30 & 14.70 & 8.80 & 17.50 & 9.25 & 3.70 & 12.80 & 6.65 & 11.70 & 3.55 & 15.05 & 6.80 & 2.70 & 10.50 & 3.50 & 8.70 & 1.40 & 11.40 & 3.20 & 5.90 & 8.65 & 0.5 & 7.5 & 0 & \\
\hline $5 \mathrm{M} 3$ & 30.10 & 22.70 & 27.10 & 21.20 & 29.90 & 21.65 & 16.10 & 25.20 & 19.05 & 24.10 & 15.95 & 27.45 & 19.20 & 9.70 & 22.90 & 15.90 & 21.10 & 13.80 & 23.80 & 15.60 & 6.50 & 21.05 & 11.9 & 19.9 & 12.4 & 0 \\
\hline
\end{tabular}

Tabla 69 


\section{DISTANCIA DE LAS MEDIANAS DE C* ENTRE LAS TABLILLAS GUIA 3D MASTER}

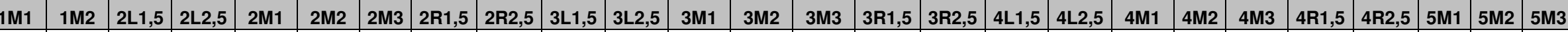

Tabla 70 
RESULTADOS

\section{DISTANCIA DE LAS MEDIANAS DE $h$ * ENTRE LAS TABLILLAS GUIA 3D MASTER}

\begin{tabular}{|c|c|c|c|c|c|c|c|c|c|c|c|c|c|c|c|c|c|c|c|c|c|c|c|c|c|c|}
\hline & \multicolumn{26}{|c|}{ DISTANCIA DE LAS MEDIANAS DE $h$ * ENTRE LAS TABLILLAS GUIA 3D MASTER } \\
\hline & 1M1 & $1 \mathrm{M} 2$ & $2 \mathrm{~L} 1,5$ & $2 \mathrm{~L} 2,5$ & 2M1 & $2 \mathrm{M} 2$ & $2 \mathrm{M} 3$ & 2R1,5 & 2R2,5 & $3 L 1,5$ & $3 L 2,5$ & 3M1 & 3M2 & 3M3 & 3R1,5 & $3 R 2,5$ & $4 L 1,5$ & $4 \mathrm{~L} 2,5$ & 4M1 & $4 \mathrm{M} 2$ & 4M3 & 4R1,5 & 4R2,5 & $5 \mathrm{M} 1$ & $5 \mathrm{M} 2$ & 5M3 \\
\hline 1M1 & 0 & & & & & & & & & & & & & & & & & & & & & & & & & \\
\hline $1 \mathrm{M} 2$ & 4 & 0 & & & & & & & & & & & & & & & & & & & & & & & & \\
\hline 2L1,5 & 3,4 & 0,9 & 0 & & & & & & & & & & & & & & & & & & & & & & & \\
\hline $2 \mathrm{~L} 2,5$ & 5,3 & 1 & 1,9 & 0 & & & & & & & & & & & & & & & & & & & & & & \\
\hline 2M1 & 2 & 2,3 & 1,4 & 3,3 & 0 & & & & & & & & & & & & & & & & & & & & & \\
\hline 2M2 & 7,8 & 3,5 & 4,4 & 2,5 & 5,8 & 0 & & & & & & & & & & & & & & & & & & & & \\
\hline $2 \mathrm{M} 3$ & 9,1 & 4,8 & 5,7 & 3,8 & 7,1 & 1,3 & 0 & & & & & & & & & & & & & & & & & & & \\
\hline 2R1,5 & 7,9 & 3,6 & 4,5 & 2,6 & 5,9 & 0,1 & 1,2 & 0 & & & & & & & & & & & & & & & & & & \\
\hline 2R2,5 & 9 & 4,7 & 5,6 & 3,7 & 7 & 1,2 & 0,1 & 1,1 & 0 & & & & & & & & & & & & & & & & & \\
\hline 3L1,5 & 6 & 1,7 & 2,6 & 0,7 & 4 & 1,8 & 3,1 & 1,9 & 3 & 0 & & & & & & & & & & & & & & & & \\
\hline $3 \mathrm{~L} 2,5$ & 7,5 & 3,2 & 4,1 & 2,2 & 5,5 & 0,3 & 1,6 & 0,4 & 1,5 & 1,5 & 0 & & & & & & & & & & & & & & & \\
\hline 3M1 & 4,8 & 0,5 & 1,4 & 0,5 & 2,8 & 3 & 4,3 & 3,1 & 4,2 & 1,2 & 2,7 & 0 & & & & & & & & & & & & & & \\
\hline 3M2 & 9,2 & 4,9 & 5,8 & 3,9 & 7,2 & 1,4 & 0,1 & 1,3 & 0,2 & 3,2 & 1,7 & 4,4 & 0 & & & & & & & & & & & & & \\
\hline $3 \mathrm{M} 3$ & 11,05 & 6,75 & 7,65 & 5,75 & 9,05 & 3,25 & 1,95 & 3,15 & 2,05 & 5,05 & 3,55 & 6,25 & 1,85 & 0 & & & & & & & & & & & & \\
\hline 3R1,5 & 10,6 & 6,3 & 7,2 & 5,3 & 8,6 & 2,8 & 1,5 & 2,7 & 1,6 & 4,6 & 3,1 & 5,8 & 1 & 0,45 & 0 & & & & & & & & & & & \\
\hline 3R2,5 & 16,25 & 11,95 & 12,85 & 10,95 & 14,25 & 8,45 & 7,15 & 8,35 & 7,25 & 10,25 & 8,75 & 11,45 & 7 & 5 & 5,65 & 0 & & & & & & & & & & \\
\hline 4L1,5 & 8 & 3,7 & 4,6 & 2,7 & 6 & 0,2 & 1,1 & 0,1 & 1 & 2 & 0,5 & 3,2 & 1 & 3,05 & 2,6 & 8,25 & 0 & & & & & & & & & \\
\hline 4L2,5 & 9,2 & 4,9 & 5,8 & 3,9 & 7,2 & 1,4 & 0,1 & 1,3 & 0,2 & 3,2 & 1,7 & 4,4 & 0 & 2 & 1,4 & 7 & 1,2 & 0 & & & & & & & & \\
\hline 4M1 & 7,25 & 2,95 & 3,85 & 1,95 & 5,25 & 0,55 & 1,85 & 0,65 & 1,75 & 1,25 & 0,25 & 2,45 & 2 & 4 & 3 & 9 & 1 & 1,95 & 0 & & & & & & & \\
\hline 4M1 & 10,9 & 6,6 & 7,5 & 5,6 & 8,9 & 3,1 & 1,8 & 3 & 1,9 & 4,9 & 3,4 & 6,1 & 2 & 0,15 & 0,3 & 5,35 & 3 & 2 & 3,65 & 0 & & & & & & \\
\hline $4 \mathrm{M} 3$ & 14,3 & 10 & 10,9 & 9 & 12,3 & 6,5 & 5,2 & 6,4 & 5,3 & 8,3 & 6,8 & 9,5 & 5,1 & 3,25 & 3,7 & 1,95 & 6,3 & 5,1 & 7,05 & 3,4 & 0 & & & & & \\
\hline 4R1,5 & 12,75 & 8,45 & 9,35 & 7,45 & 10,75 & 4,95 & 3,65 & 4,85 & 3,75 & 6,75 & 5,25 & 7,95 & 3,55 & 1,7 & 2,15 & 3,5 & 4,75 & 3,55 & 5,5 & 1,85 & 1,55 & 0 & & & & \\
\hline 4R2,5 & 13,2 & 8,9 & 9,8 & 7,9 & 11,2 & 5,4 & 4,1 & 5,3 & 4,2 & 7,2 & 5,7 & 8,4 & 4 & 2,15 & 2,6 & 3,05 & 5,2 & 4 & 5,95 & 2,3 & 1,1 & 0,45 & 0 & & & \\
\hline $5 \mathrm{M} 1$ & 11,6 & 7,3 & 8,2 & 6,3 & 9,6 & 3,8 & 2,5 & 3,7 & 2,6 & 5,6 & 4,1 & 6,8 & 2,4 & 0,55 & 1 & 4,65 & 3,6 & 2,4 & 4,35 & 0,7 & 2,7 & 1,15 & 1,6 & 0 & & \\
\hline $5 \mathrm{M} 2$ & 18,4 & 14,1 & 15 & 13,1 & 16,4 & 10,6 & 9,3 & 10,5 & 9,4 & 12,4 & 10,9 & 13,6 & 9,2 & 7,35 & 7,8 & 2,15 & 10,4 & 9,2 & 11,15 & 7,5 & 4,1 & 5,65 & 5,2 & 6,8 & 0 & \\
\hline $5 \mathrm{M} 3$ & 24,15 & 19,85 & 20,75 & 18,85 & 22,15 & 16,35 & 15,05 & 16,25 & 15,15 & 18,15 & 16,65 & 19,35 & 14,95 & 13,1 & 13,55 & 7,9 & 16,15 & 14,95 & 16,9 & 13,25 & 9,85 & 11,4 & 10,95 & 12,55 & 5,75 & 0 \\
\hline
\end{tabular}

Tabla 71 
DISTANCIA DE LAS MEDIANA DE $\triangle E$ ENTRE LOS COLORES GUIA 3D MASTER

\begin{tabular}{|c|c|c|c|c|c|c|c|c|c|c|c|c|c|c|c|c|c|c|c|c|c|c|c|c|c|c|}
\hline & \\
\hline & 1M1 & $1 \mathrm{M} 2$ & $2 \mathrm{~L} 1,5$ & 2L2,5 & $2 \mathrm{M} 1$ & 2M2 & $2 \mathrm{M} 3$ & 2R1,5 & 2R2,5 & 3L1,5 & 3L2,5 & 3M1 & 3M2 & 3M3 & 3R1,5 & 3R2,5 & 4L1,5 & 4L2,5 & 4M1 & 4M2 & 4M3 & 4R1,5 & 4R2,5 & $5 \mathrm{M} 1$ & 5M2 & $5 \mathrm{M3}$ \\
\hline $1 \mathrm{M} 1$ & 0 & & & & & & & & & & & & & & & & & & & & & & & & & \\
\hline $1 \mathrm{M} 2$ & 7.49 & 0 & & & & & & & & & & & & & & & & & & & & & & & & \\
\hline 2L1,5 & 5.68 & 7.36 & 0 & & & & & & & & & & & & & & & & & & & & & & & \\
\hline 2L2,5 & 9.55 & 4.71 & 6.08 & 0 & & & & & & & & & & & & & & & & & & & & & & \\
\hline 2M1 & 3.23 & 8.38 & 3.22 & 8.71 & 0 & & & & & & & & & & & & & & & & & & & & & \\
\hline 2M2 & 8.69 & 2.73 & 6.70 & 2.44 & 8.61 & 0 & & & & & & & & & & & & & & & & & & & & \\
\hline $2 \mathrm{M3}$ & 14.30 & 7.41 & 11.58 & 5.56 & 14.02 & 5.62 & 0 & & & & & & & & & & & & & & & & & & & \\
\hline 2R1,5 & 7.79 & 7.44 & 2.48 & 4.76 & 5.53 & 5.89 & 10.00 & 0 & & & & & & & & & & & & & & & & & & \\
\hline $2 \mathrm{R} 2,5$ & 11.86 & 6.27 & 8.31 & 2.56 & 11.01 & 3.71 & 3.56 & 6.51 & 0 & & & & & & & & & & & & & & & & & \\
\hline 3L1,5 & 12.84 & 12.49 & 7.18 & 8.46 & 9.99 & 10.50 & 12.55 & 5.64 & 9.19 & 0 & & & & & & & & & & & & & & & & \\
\hline $3 L 2,5$ & 17.06 & 12.53 & 12.11 & 8.04 & 15.31 & 10.06 & 7.74 & 9.92 & 6.52 & 8.38 & 0 & & & & & & & & & & & & & & & \\
\hline 3M1 & 9.91 & 11.62 & 4.73 & 8.76 & 6.78 & 10.23 & 13.84 & 4.39 & 10.28 & 3.80 & 11.51 & 0 & & & & & & & & & & & & & & \\
\hline 3M2 & 13.84 & 10.11 & 8.80 & 5.45 & 11.97 & 7.53 & 7.20 & 6.49 & 4.50 & 5.93 & 3.55 & 8.46 & 0 & & & & & & & & & & & & & \\
\hline 3M3 & 21.74 & 15.43 & 17.76 & 12.25 & 20.73 & 13.29 & 8.17 & 15.62 & 9.89 & 15.32 & 7.10 & 18.15 & 9.69 & 0 & & & & & & & & & & & & \\
\hline 3R1,5 & 12.27 & 10.90 & 6.71 & 6.69 & 9.73 & 8.63 & 10.42 & 4.52 & 7.05 & 2.53 & 7.02 & 4.82 & 3.96 & 13.55 & 0 & & & & & & & & & & & \\
\hline 3R2,5 & 18.09 & 13.74 & 13.26 & 9.53 & 16.30 & 11.03 & 8.61 & 10.81 & 7.56 & 9.52 & 4.10 & 12.47 & 4.88 & 7.21 & 7.65 & 0 & & & & & & & & & & \\
\hline 4L1,5 & 17.84 & 16.52 & 12.16 & 11.98 & 15.02 & 14.21 & 14.50 & 10.34 & 11.78 & 5.04 & 7.83 & 8.63 & 7.37 & 14.41 & 6.03 & 8.61 & 0 & & & & & & & & & \\
\hline $4 \mathrm{~L} 2,5$ & 21.37 & 17.30 & \begin{tabular}{|l|}
16.07 \\
\end{tabular} & 12.74 & 19.28 & \begin{tabular}{|l|}
14.77 \\
\end{tabular} & 12.12 & 13.83 & 11.20 & \begin{tabular}{|l|}
10.63 \\
\end{tabular} & 4.80 & 14.33 & 7.63 & 8.13 & 9.94 & 5.50 & 7.52 & 0 & & & & & & & & \\
\hline 4M1 & 17.31 & 17.21 & 11.77 & 12.97 & 14.27 & 15.10 & 16.30 & 10.34 & 13.25 & 4.77 & 10.28 & 7.51 & 9.13 & 17.06 & 6.59 & 10.98 & 2.81 & 10.33 & 0 & & & & & & & \\
\hline 4M1 & 21.55 & 18.36 & 16.02 & 13.68 & 19.14 & 15.78 & 13.93 & 13.80 & 12.43 & 9.76 & 6.43 & 13.52 & 8.27 & 10.72 & 9.47 & 6.42 & 5.70 & 2.80 & 8.39 & 0 & & & & & & \\
\hline 4M3 & 28.27 & 23.06 & 23.37 & 19.06 & 26.52 & 20.58 & 16.29 & 21.00 & 16.89 & 18.52 & 11.55 & 22.08 & 14.57 & 8.70 & 17.41 & 10.51 & 15.23 & 8.15 & 17.95 & 9.58 & 0 & & & & & \\
\hline 4R1,5 & 16.35 & 14.66 & 10.75 & 10.15 & 13.68 & 12.19 & 12.52 & 8.63 & 9.74 & 4.29 & 6.62 & 7.79 & 5.40 & 13.07 & 4.11 & 6.58 & 2.77 & 7.33 & 4.46 & 5.98 & 14.81 & 0 & & & & \\
\hline $4 \mathrm{R} 2,5$ & 23.92 & 19.67 & \begin{tabular}{|l|}
18.67 \\
\end{tabular} & 15.23 & 21.84 & \begin{tabular}{|l|}
17.07 \\
\end{tabular} & 13.94 & \begin{tabular}{|l|}
16.32 \\
\end{tabular} & 13.42 & \begin{tabular}{|l|}
13.17 \\
\end{tabular} & 7.42 & 16.83 & 10.10 & 8.51 & \begin{tabular}{|l|}
12.34 \\
\end{tabular} & 6.59 & 9.65 & 3.14 & \begin{tabular}{|l|}
12.37 \\
\end{tabular} & \begin{tabular}{|l|}
4.03 \\
\end{tabular} & 5.58 & 9.36 & 0 & & & \\
\hline 5M1 & 26.01 & 25.11 & 20.41 & 20.53 & 22.99 & 22.72 & 22.34 & 18.73 & 20.04 & 13.26 & 14.93 & 16.24 & 15.54 & 19.86 & 14.43 & 14.80 & 8.61 & 11.82 & 8.67 & 9.17 & 16.56 & 10.61 & 12.04 & 0 & & \\
\hline $5 \mathrm{M} 2$ & 36.28 & 34.22 & 30.65 & 29.54 & 33.42 & 31.61 & 29.75 & 28.64 & 28.37 & 23.58 & 22.45 & 26.85 & 24.12 & 24.60 & 24.13 & 21.50 & |16.83 & 17.93 & 19.53 & 16.06 & \begin{tabular}{|l|}
17.52 \\
\end{tabular} & 20.02 & 16.23 & 11.11 & 0 & \\
\hline $5 \mathrm{M3}$ & 44.26 & 40.22 & 38.99 & 35.98 & 41.97 & 37.55 & 33.92 & 36.59 & 33.97 & \begin{tabular}{|l|}
32.85 \\
\end{tabular} & 28.46 & 36.36 & 30.84 & 26.73 & 32.35 & 26.55 & 28.33 & 24.05 & 30.18 & 23.56 & $\mid 18.19$ & 28.62 & 21.07 & 23.69 & $\mid$\begin{tabular}{|l|}
$\mid 14.77$ \\
\end{tabular} & 0 \\
\hline
\end{tabular}

Tabla 72 
Al observar las cifras que aporta la tabla 72 que mide las diferencia absolutas entre dos colores $(\Delta E)$, observamos que la diferencia menor de los colores posee una puntuación de 2.44 y se encuentra entre el color $2 \mathrm{~L} 2,5$ y $2 \mathrm{M} 2$. Por el contrario la máxima diferencia de color aparece entre la tablill1M1 y $5 \mathrm{M} 3$, es decir los colores más extremos de la guía 3D Master (Vita- Zahnfabrik).

En la tabla 72 en color azul señalamos las diferencias de color comprendidas entre 2.6 e inferiores a 5.5, un total de 31 pares (9.53\%); en color naranja señalamos las diferencia de color con un valor inferior a 2.6 y son 4 pares $(1.24 \%)$.

Podemos observar que como norma los colores que tienen luminosidades o valores diferentes $(\Delta \mathrm{L})$ son donde las diferencias entre sus colores son mayores. De manera aproximada según se alejan los colores $\Delta \mathrm{E}$ aumenta, aunque no siguen una ordenación matemática constante. De las tres coordenadas de color, el valor, es la que presenta una ordenación mayor.

Las coordenadas a y b, no tienen correlación con respecto a la intensidad y croma, pero son necesarias al ser las coordenadas ordinales para calcular la diferencia absoluta entre dos colores. En el apartado siguiente estudiaremos las variables luminosidad o valor $(\mathrm{L})$, intensidad o croma $(\mathrm{C})$ y tinte $(\mathrm{h})$ para analizar de manera más relacionada con la disposición de las colores en la guía 3D Master y poder interpretar con mayor facilidad sus resultados y aportaremos tridimensionalmente sus representaciones gráficas.

\subsection{3.- Estudio de la ordenación de la guía 3D Master según las tres dimensiones del color}

En este apartado vamos a estudiar la distribución de L, C, h en las 26 tablillas de color pertenecientes a la guía 3D Master (observar los valores en negrita dentro de la tabla correspondiente).

A continuación, en la tabla 73 , vamos a observar el valor (L) como variable cuantitativa continua numérica, y como según aumenta el número de valor de la guía 3D Master $(1,2,3,4,5)$ que corresponde al valor estudiado, disminuye $\mathrm{L}$.

Desde la luminosidad o valor $L$ con la mediana menor 53.00, que corresponde a la tablilla 5M2, a la siguiente tablilla 5M3 que la corresponde una cifra de 55.00, pasando 
por el valor 4, con luminosidades (L) comprendidas entre 68.20 y 70.20 , según muestra la tabla 75 .

Posteriormente y ocupando la parte central de la tabla tenemos la luminosidad o valor 3 , cuya menor luminosidad es de 77.15. Seguidamente el valor 2, y por último el valor 1 , pertenecen al grupo de las tablillas más luminosas o con mayor valor con cifras de $83.80(1 \mathrm{M} 2)$ y de $84.90(1 \mathrm{M} 1)$.

\begin{tabular}{|c|c|c|c|c|}
\hline \multicolumn{5}{|c|}{ MEDIANAS TABLILLAS GUIA 3D MASTER } \\
\hline Tablilla & $\mathbf{n}$ & $\mathbf{L}^{*}$ & $\mathbf{C}^{*}$ & $\mathbf{h}^{*}$ \\
\hline 5M2 & 3 & $\mathbf{5 3 . 0 0}$ & 30.60 & 79.00 \\
\hline 5M3 & 6 & $\mathbf{5 5 . 1 0}$ & 44.50 & 73.25 \\
\hline 5M1 & 9 & $\mathbf{6 0 . 1 0}$ & 22.60 & 85.80 \\
\hline 4M1 & 22 & $\mathbf{6 7 . 7 5}$ & 18.60 & 90.15 \\
\hline 4M2 & 3 & $\mathbf{6 8 . 2 0}$ & 26.90 & 86.50 \\
\hline 4L1,5 & 15 & $\mathbf{6 8 . 5 0}$ & 21.30 & 89.40 \\
\hline 4R2,5 & 6 & $\mathbf{6 9 . 0 0}$ & 30.75 & 84.20 \\
\hline 4M3 & 16 & $\mathbf{6 9 . 4 5}$ & 36.25 & 83.10 \\
\hline 4L2,5 & 1 & $\mathbf{7 0 . 2 0}$ & 28.60 & 88.20 \\
\hline 4R1,5 & 2 & $\mathbf{7 0 . 6 5}$ & 21.50 & 84.65 \\
\hline 3L1,5 & 24 & $\mathbf{7 2 . 5 0}$ & 18.35 & 91.40 \\
\hline 3R2,5 & 2 & $\mathbf{7 4 . 1 5}$ & 26.85 & 81.15 \\
\hline 3R1,5 & 3 & $\mathbf{7 4 . 2 0}$ & 19.60 & 86.80 \\
\hline 3M1 & 96 & $\mathbf{7 4 . 3 0}$ & 15.00 & 92.60 \\
\hline 3L2,5 & 10 & $\mathbf{7 4 . 4 0}$ & 26.45 & 89.90 \\
\hline 3M2 & 7 & $\mathbf{7 5 . 6 0}$ & 23.20 & 88.20 \\
\hline 3M3 & 16 & $\mathbf{7 7 . 1 5}$ & 32.75 & 86.35 \\
\hline 2R1,5 & 6 & $\mathbf{7 8 . 0 0}$ & 17.25 & 89.50 \\
\hline 2L1,5 & 82 & $\mathbf{7 9 . 0 0}$ & 15.70 & 94.00 \\
\hline 2R2,5 & 6 & $\mathbf{8 0 . 1 0}$ & 23.35 & 88.40 \\
\hline 2L2,5 & 14 & $\mathbf{8 0 . 4 5}$ & 21.20 & 92.10 \\
\hline 2M1 & 65 & $\mathbf{8 0 . 6 0}$ & 12.50 & 95.40 \\
\hline 2M3 & 21 & $\mathbf{8 2 . 1 0}$ & 26.40 & 88.30 \\
\hline 2M2 & 6 & $\mathbf{8 2 . 7 0}$ & 20.75 & 89.60 \\
\hline 1M1 & 45 & $\mathbf{8 3 . 8 0}$ & 12.40 & 97.40 \\
\hline 1M2 & 59 & $\mathbf{8 4 . 9 0}$ & 19.80 & 93.10 \\
\hline & & $\mathbf{7 a b l a 7 3}$ & & \\
\hline
\end{tabular}

Tabla 73

En la tabla siguiente, vamos a estudiar la intensidad (C), donde apreciamos que no existe tanto rigor en la ordenación como en el valor. Según nuestros resultados la mediana de la intensidad de las tablillas $4 \mathrm{~L} 1,5,4 \mathrm{R} 1,5$, y $5 \mathrm{M} 1$, se encuentra ubicada en la zona de intensidad 2, y deberían de aparecer en la parte superior de la tabla en la zona de los 1. 
Por lo demás existe bastante homogeneidad en el resto de las tablillas con respecto a la intensidad, según la tabla 74.

\begin{tabular}{|c|c|c|c|c|}
\hline \multicolumn{5}{|c|}{ MEDIANAS TABLILLAS GUIA 3D MASTER } \\
\hline Tablilla & $\mathbf{n}$ & $\mathbf{L}^{*}$ & $\mathbf{C}^{*}$ & $\mathbf{h}^{*}$ \\
\hline 1M1 & 45 & 83.80 & $\mathbf{1 2 . 4 0}$ & 97.40 \\
\hline 2M1 & 65 & 80.60 & $\mathbf{1 2 . 5 0}$ & 95.40 \\
\hline 3M1 & 96 & 74.30 & $\mathbf{1 5 . 0 0}$ & 92.60 \\
\hline 2L1,5 & 82 & 79.00 & $\mathbf{1 5 . 7 0}$ & 94.00 \\
\hline 2R1,5 & 6 & 78.00 & $\mathbf{1 7 . 2 5}$ & 89.50 \\
\hline 3L1,5 & 24 & 72.50 & $\mathbf{1 8 . 3 5}$ & 91.40 \\
\hline 4M1 & 22 & 67.75 & $\mathbf{1 8 . 6 0}$ & 90.15 \\
\hline 3R1,5 & 3 & 74.20 & $\mathbf{1 9 . 6 0}$ & 86.80 \\
\hline 1M2 & 59 & 84.90 & $\mathbf{1 9 . 8 0}$ & 93.10 \\
\hline 2M2 & 6 & 82.70 & $\mathbf{2 0 . 7 5}$ & 89.60 \\
\hline 2L2,5 & 14 & 80.45 & $\mathbf{2 1 . 2 0}$ & 92.10 \\
\hline 4L1,5 & 15 & 68.50 & $\mathbf{2 1 . 3 0}$ & 89.40 \\
\hline 4R1,5 & 2 & 70.65 & $\mathbf{2 1 . 5 0}$ & 84.65 \\
\hline 5M1 & 9 & 60.10 & $\mathbf{2 2 . 6 0}$ & 85.80 \\
\hline 3M2 & 7 & 75.60 & $\mathbf{2 3 . 2 0}$ & 88.20 \\
\hline 2R2,5 & 6 & 80.10 & $\mathbf{2 3 . 3 5}$ & 88.40 \\
\hline 2M3 & 21 & 82.10 & $\mathbf{2 6 . 4 0}$ & 88.30 \\
\hline 3L2,5 & 10 & 74.40 & $\mathbf{2 6 . 4 5}$ & 89.90 \\
\hline 3R2,5 & 2 & 74.15 & $\mathbf{2 6 . 8 5}$ & 81.15 \\
\hline 4M2 & 3 & 68.20 & $\mathbf{2 6 . 9 0}$ & 86.50 \\
\hline 4L2,5 & 1 & 70.20 & $\mathbf{2 8 . 6 0}$ & 88.20 \\
\hline 5M2 & 3 & 53.00 & $\mathbf{3 0 . 6 0}$ & 79.00 \\
\hline 4R2,5 & 6 & 69.00 & $\mathbf{3 0 . 7 5}$ & 84.20 \\
\hline 3M3 & 16 & 77.15 & $\mathbf{3 2 . 7 5}$ & 86.35 \\
\hline 4M3 & 16 & 69.45 & $\mathbf{3 6 . 2 5}$ & 83.10 \\
\hline 5M3 & 6 & 55.10 & $\mathbf{4 4 . 5 0}$ & 73.25 \\
\hline
\end{tabular}

Tabla 74

Por último vamos a desarrollar el tinte (h) en la tabla 75. En este elemento, prácticamente no existe ningún grado de orden con respecto a $L, M$, y $R$. Vemos como se intercambian a lo largo de la tabla, sin obtener grupos claros.

\begin{tabular}{|c|c|c|c|c|}
\hline \multicolumn{5}{|c|}{ MEDIANAS TABLILLAS GUIA 3D MASTER } \\
\hline Tablilla & $\mathbf{n}$ & $\mathbf{L}^{*}$ & $\mathbf{C}^{*}$ & $\mathbf{h}^{*}$ \\
\hline 5 M3 & 6 & 55.10 & 44.50 & $\mathbf{7 3 . 2 5}$ \\
\hline 5 M2 & 3 & 53.00 & 30.60 & $\mathbf{7 9 . 0 0}$ \\
\hline $3 \mathbf{R} 2,5$ & 2 & 74.15 & 26.85 & $\mathbf{8 1 . 1 5}$ \\
\hline 4 M3 & 16 & 69.45 & 36.25 & $\mathbf{8 3 . 1 0}$ \\
\hline $4 \mathbf{R} 2,5$ & 6 & 69.00 & 30.75 & $\mathbf{8 4 . 2 0}$ \\
\hline $4 \mathbf{R} 1,5$ & 2 & 70.65 & 21.50 & $\mathbf{8 4 . 6 5}$ \\
\hline 5 M1 & 9 & 60.10 & 22.60 & $\mathbf{8 5 . 8 0}$ \\
\hline 3M3 & 16 & 77.15 & 32.75 & $\mathbf{8 6 . 3 5}$ \\
\hline
\end{tabular}




\begin{tabular}{|c|c|c|c|c|}
\hline \multicolumn{5}{|c|}{ MEDIANAS TABLILLAS GUIA 3D MASTER } \\
\hline Tablilla & $\mathbf{n}$ & $\mathbf{L}^{*}$ & $\mathbf{C}^{*}$ & $\mathbf{h}^{*}$ \\
\hline 4M2 & 3 & 68.20 & 26.90 & $\mathbf{8 6 . 5 0}$ \\
\hline 3R1,5 & 3 & 74.20 & 19.60 & $\mathbf{8 6 . 8 0}$ \\
\hline 4L2,5 & 1 & 70.20 & 28.60 & $\mathbf{8 8 . 2 0}$ \\
\hline 3M2 & 7 & 75.60 & 23.20 & $\mathbf{8 8 . 2 0}$ \\
\hline 2M3 & 21 & 82.10 & 26.40 & $\mathbf{8 8 . 3 0}$ \\
\hline 2R2,5 & 6 & 80.10 & 23.35 & $\mathbf{8 8 . 4 0}$ \\
\hline 4L1,5 & 15 & 68.50 & 21.30 & $\mathbf{8 9 . 4 0}$ \\
\hline 2R1,5 & 6 & 78.00 & 17.25 & $\mathbf{8 9 . 5 0}$ \\
\hline 2M2 & 6 & 82.70 & 20.75 & $\mathbf{8 9 . 6 0}$ \\
\hline 3L2,5 & 10 & 74.40 & 26.45 & $\mathbf{8 9 . 9 0}$ \\
\hline 4M1 & 22 & 67.75 & 18.60 & $\mathbf{9 0 . 1 5}$ \\
\hline 3L1,5 & 24 & 72.50 & 18.35 & $\mathbf{9 1 . 4 0}$ \\
\hline 2L2,5 & 14 & 80.45 & 21.20 & $\mathbf{9 2 . 1 0}$ \\
\hline 3M1 & 96 & 74.30 & 15.00 & $\mathbf{9 2 . 6 0}$ \\
\hline 1M2 & 59 & 84.90 & 19.80 & $\mathbf{9 3 . 1 0}$ \\
\hline 2L1,5 & 82 & 79.00 & 15.70 & $\mathbf{9 4 . 0 0}$ \\
\hline 2M1 & 65 & 80.60 & 12.50 & $\mathbf{9 5 . 4 0}$ \\
\hline 1M1 & 45 & 83.80 & 12.40 & $\mathbf{9 7 . 4 0}$ \\
\hline
\end{tabular}

Tabla 75

A continuación vamos a exponer para los tres componentes del color, valor 0 luminosidad (Grafico 22), tinte (Grafico 23) e intensidad (Grafico 24) la representación gráfica en tres dimensiones para visualizar los datos anteriormente expuestos. Para confeccionar dichos gráficos se han utilizado la media de las medianas implicadas dentro de las variables $L$, a y b que, señalan las dimensiones en los tres ejes de coordenadas ordinales espaciales.

En primer lugar aparece el gráfico correspondiente al valor, en el que claramente podemos apreciar una ordenación espacial en torno al valor $(\mathrm{L})$.

La distancia entre los grados de luminosidad o valor, son similares, excepto para el valor número 5 , que queda más alejado de los otros cuatro grados de luminosidad.

Los gráficos en tres dimensiones han sido desarrollados con el programa R 2.7.2. 


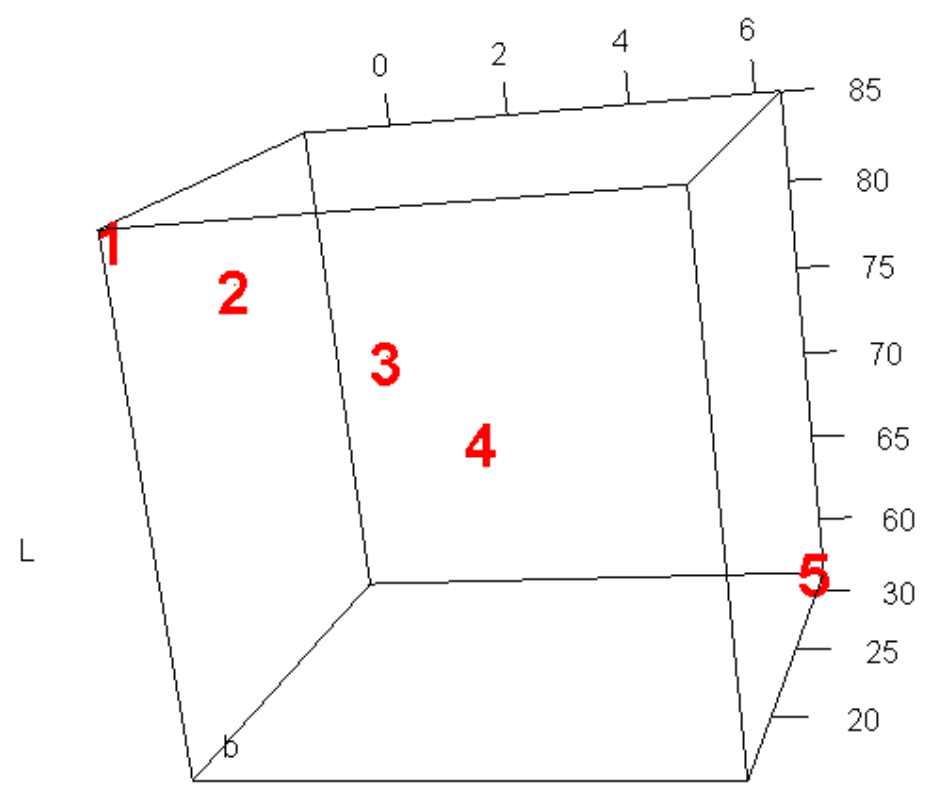

a

\section{Gráfico 22}

A continuación representamos la intensidad (C), en los tres ejes del espacio, de manera similar a la empleada en el caso del valor o luminosidad en el gráfico 23 . En este grafico debemos de fijarnos en el eje de coordenadas a para conocer su ubicación espacial correspondiente, y observar que no se encuentran distribuidos de forma tan rigurosa como en el caso del valor y que además, el grado 3 de intensidad se encuentra separado del resto.

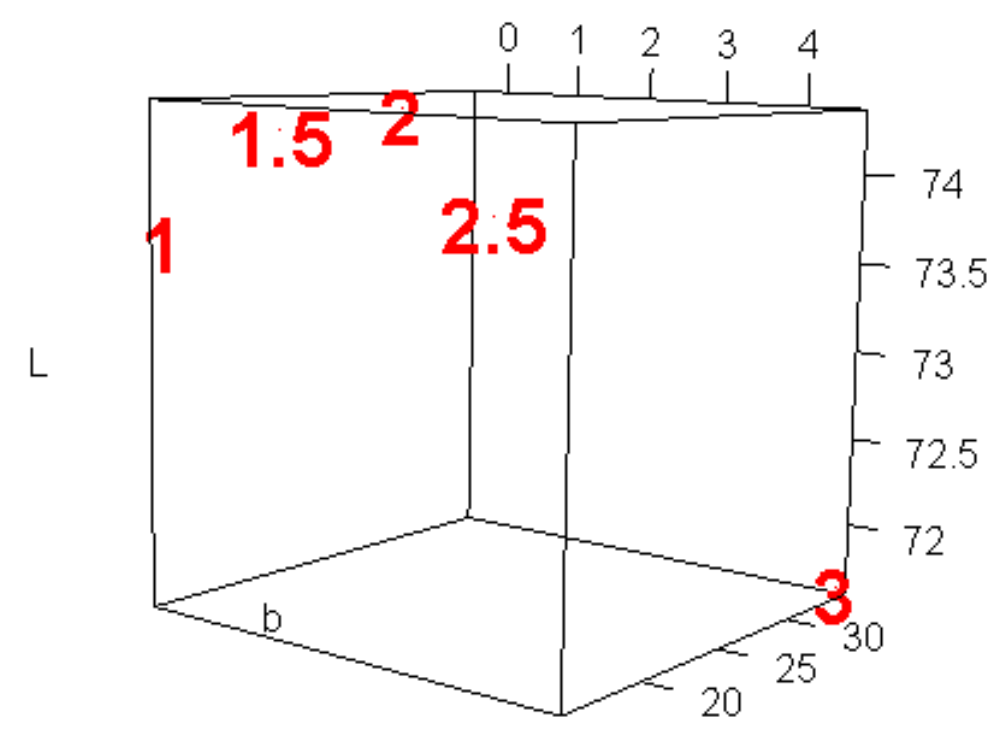

a

Gráfico 23 
En último lugar el gráfico 24, que corresponde a la representación tridimensional del tinte, donde se diferencian claramente las tres categorías estudiadas. Esta vez las tres categorías están claramente definidas y separadas de una manera uniforme y armoniosa en los tres eje de coordenadas ordinales.

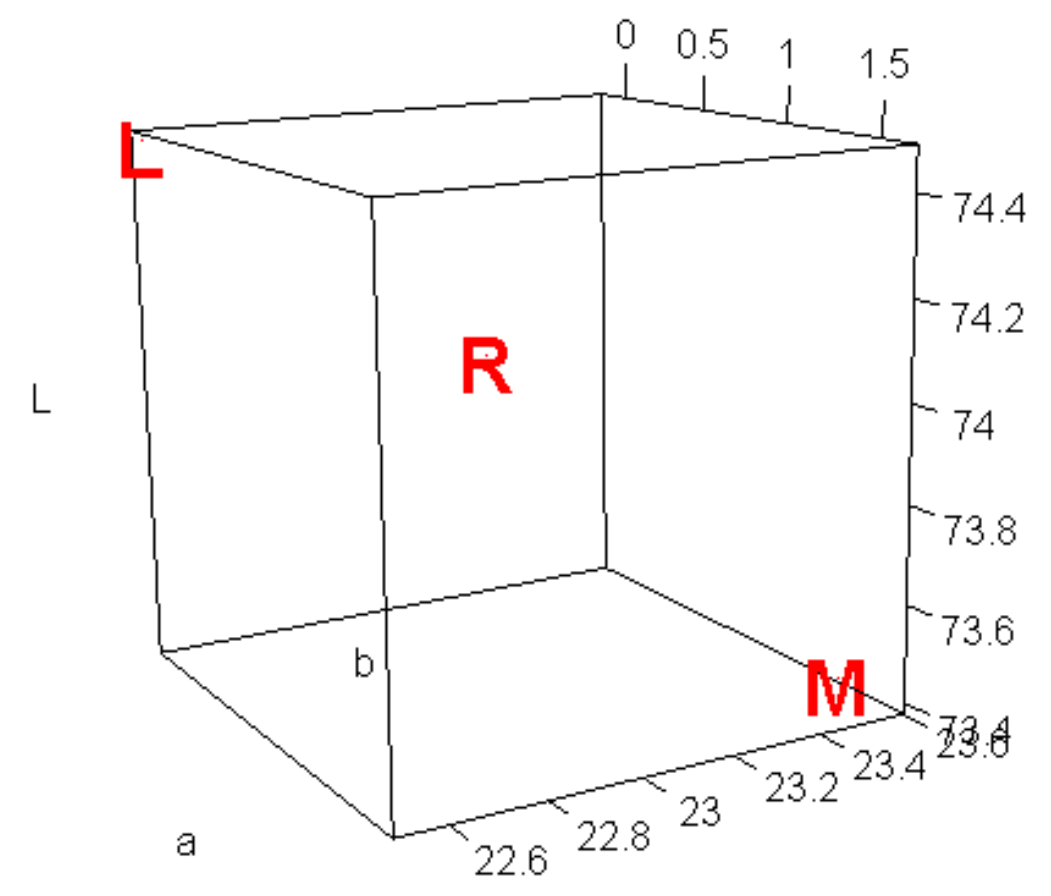

\section{Gráfico 24}

A continuación, el grafico siguiente, gráfico 25, integra las tres dimensiones del color representadas anteriormente por separado. Aparecen las 26 tablillas de la guía de color 3D Master, en este caso los datos utilizados han sido también las medias de las medianas de dichas tablillas. Podemos resaltar dentro de la imagen, como los cinco planos de valor o luminosidad, situados a lo largo del eje de coordenadas L, se aprecia perfectamente, y las 26 tablillas de la guía de color 3D Master (VitaZahnfabrik) siguen el orden esperado.

En la parte inferior de dicho gráfico se encuentra el grado de luminosidad 5, este grado de valor, engloba a las tablillas $5 \mathrm{M} 1,5 \mathrm{M} 2,5 \mathrm{M} 3$. Están más separadas del resto de tablillas y entre sí, también existe mayor distancia en comparación con el resto de tablillas. 
Observar, como tablillas extremas, el $1 \mathrm{M} 1$ y el $5 \mathrm{M} 3$, se encuentran prácticamente en los ángulos opuestos del cubo tridimensional que empleamos como marco de referencia.

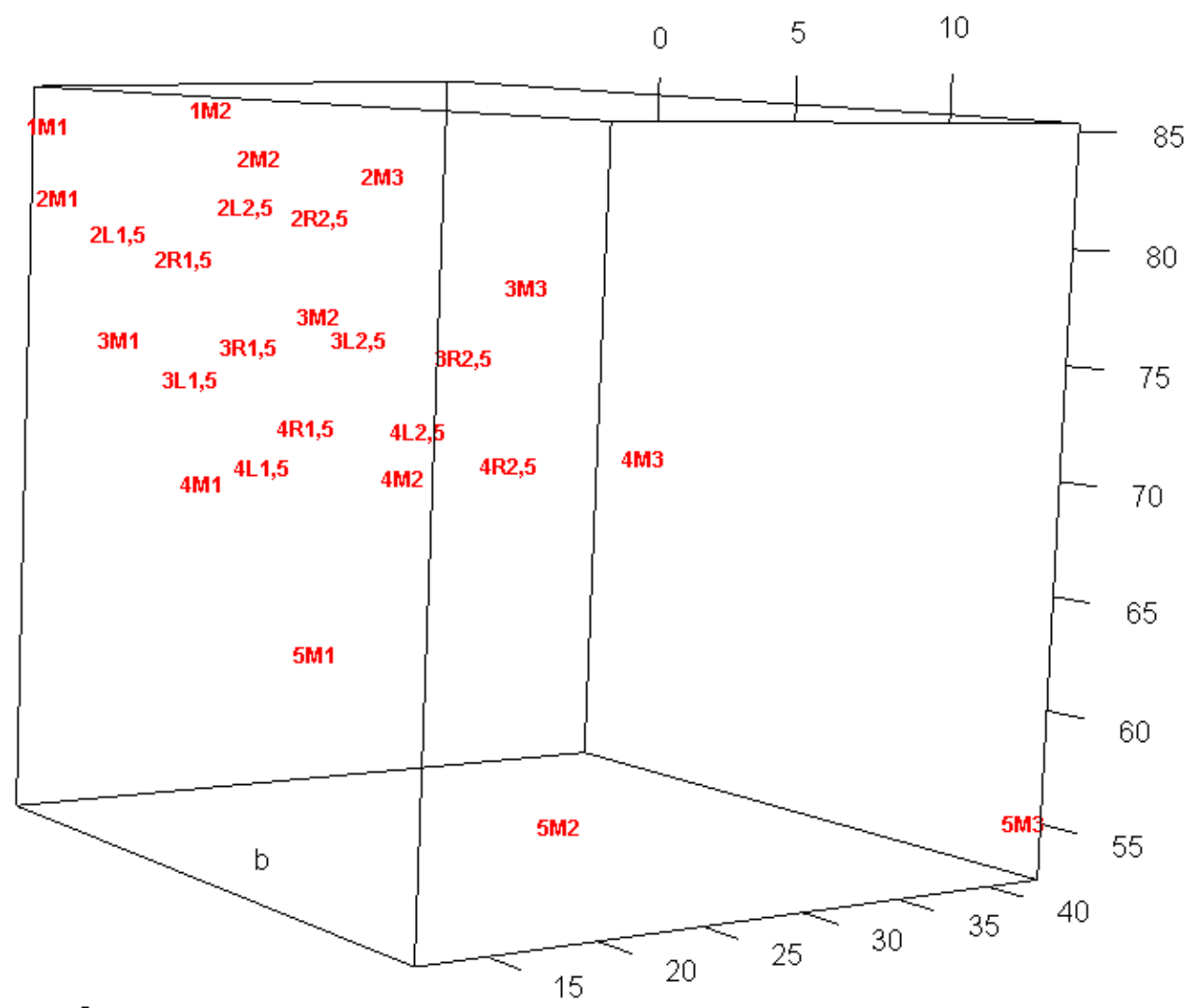

Gráfico 25

Esto quiere decir que las tablillas del valor 5 están distribuidas de forma no equiparable, es decir, quedan más alejadas del resto y además entre ellas la distancia aumenta en comparación con el resto de las tablillas de color. 
6.- DISCUSIÓN 



\section{6.- DISCUSIÓN}

La sonrisa es una de las comunicaciones interpersonales más importantes ${ }^{41}$. El último objetivo en Odontología es crear una sonrisa bonita, con dientes proporcionados, en armonía con la encía, labios y rostro del paciente ${ }^{83}$. Además, cualquier restauración estética necesita considerar los parámetros de forma, superficie, translucidez y color $83,142,143$

En la Odontología Restauradora, el clínico se encuentra con el desafío común de reproducir el color de los dientes naturales. El objetivo de una restauración estética es lograr la belleza morfológica, óptica y biológica que se traduce en la aceptación social 144,145

El primer autor del que tenemos constancia que se interesó en determinar el color del diente, fue Clark EB. en 1931 y desarrolló un sistema de tablas de porcelana para la designación de los colores. También se percató, de que cada región del diente tenía un color diferente ${ }^{44}$.

Tal y como queda reflejado en la introducción, el color es un fenómeno complejo de percepción visual que responde a la luz reflejada y transmitida por un objeto. Cuando la luz contacta con un objeto, ésta puede ser reflejada, absorbida, dispersada o transmitida por él ${ }^{146}$.

Los dientes naturales, tienen características que hacen difícil la selección de su color, debido a que son policromáticos. Además, son varios los factores que influyen como, textura superficial, translucidez y color del entorno. El efecto de varias capas causado por varios grados de esmalte translúcido y dentina opaca, crean un cambio de color a lo largo de toda la superficie del diente ${ }^{146}$.

El Dr. Martínez Vázquez de Parga afirma que hay que tener en cuenta los tres ejes del diente en la toma de color $^{18}$ :

-Eje antero-posterior: debemos tener en cuenta que la percepción del color viene determinada por el grosor del diente, ya que con mayor espesor, tiene mayor opacidad e intensidad de color. 
-Eje Vertical: el tercio cervical es el que tiene mayor intensidad y el tercio incisal es el más transparente.

-Eje Transversal: el diente tiende a tener una mayor difuminación del color, sobre todo en las áreas interproximales y el valor del mismo tiende hacia el negro ${ }^{10}$.

Estas diferencias entre los ejes del diente junto con la estructura semitraslúcida, el pequeño tamaño de los dientes, la superficie irregular del diente natural contribuyen a la complejidad de la toma de color tanto por el método objetivo como por el método subjetivo $^{147}$.

En un estudio publicado por Gaceta Dental en Junio de 2008, dirigido por la Dra. Celemín Viñuela y realizado por Prieto Álvarez M., se afirma que el $50 \%$ de los odontólogos consulta a sus pacientes para elegir el color "a menudo" y un $39 \%$ "siempre". A pesar de estos datos, paradójicamente un bajo porcentaje de las prótesis tienen que ser repetidas por insatisfacción con el color ${ }^{124}$.

Se ha documentado que el $23 \%$ de los adultos británicos no están satisfechos con el color de sus dientes ${ }^{42}$, en Estados Unidos, el 34\% ${ }^{148,} 149$.

No solo el color dental afecta a la estética, sino que la idea de que el color dental podría afectar nuestra percepción sobre otra persona y sus rasgos personales, podría añadir otra dimensión a la cuestión de la sonrisa perfecta. En un estudio publicado en British Dental Journal en el año 2008 por Kershaw S. y colaboradores, se estudió la posible relación entre percepciones sociales y color dental. A las participantes (mujeres jóvenes) se las enseñaron varias fotos de sonrisas con dientes blanqueados, sin blanquear y con alteraciones del color. Los resultados mostraron que a los pacientes con alteraciones en el color, se les asociaron pobres rangos en competencias sociales (amable, sincero,...), en capacidad intelectual, en ajustes psicológicos (introvertido, feliz,...), y en relaciones personales. De esta manera el color dental no solo serviría para valorar cuestiones estéticas, sino también implicaciones personales, es decir, prejuzgar la personalidad de otra persona. Los autores concluyen en la necesidad de estudios a largo plazo para concretar estos resultados ${ }^{150}$. 


\section{1.- COLOR DENTAL}

Ya Lemiere y Burk en 1975 investigaron la frecuencia y distribución del espacio del diente natural usando un espectrofotómetro y afirmaron que la variabilidad de color de los dientes naturales era mayor que la que proporcionaban las guías de color. Estos autores reconocen que el color del diente no es uniforme ${ }^{67}$.

El rango de coordenadas cromáticas y su distribución dentro del espacio cromático de los dientes han sido descritos en numerosas investigaciones, y la mayoría de los autores han seleccionado el incisivo central superior como referencia ${ }^{6}$.

O’Brien WJ. en 1997 publicó un estudio donde estudió 95 dientes anteriores extraídos y sometió los tres tercios del diente a la medición espectrofotométrica. Sus resultados a través del test estadístico Anova aportaron que no había diferencias estadísticamente significativas para el valor $(L)$ entre los tres tercios del diente. Por el contrario, sí que encontraron diferencias estadísticamente significativas para el parámetro a y $\mathrm{b}$ entre los tercios en los que se dividió a cada diente. A través del Test de Scheffe's se afirmó que existía en la región gingival mayor cantidad de a y b que en el resto del diente. Si calculamos la diferencia de color entre los tres tercios del diente aplicando la ecuación euclidiana de $(\Delta \mathrm{E})$, vemos que entre la región gingival y la región incisal había una diferencia de 8,2 unidades, 4,4 entre la región gingival y el tercio medio y de 4,9 entre el tercio medio y el tercio incisal. Resumiendo la mayoría de los autores encuentran diferencias de intensidad para la región cervical donde las coordenadas de $\mathrm{C}$ son mayores que en el resto del diente ${ }^{151}$.

Por eso, para la mayoría de los autores consultados, el tercio medio del diente es el sitio que ha sido descrito como el que mejor representa el color dental ${ }^{152}$. Así también, en este estudio el tercio elegido para representar el color dental de cada participante ha sido el tercio medio. Esto ocurre porque el tercio incisal es más translúcido y está más afectado por el fondo de la cavidad y el tercio cervical está modificado por la dispersión de la luz de la encía ${ }^{151,153}$.

Como hemos visto anteriormente, el incisivo central superior ha sido frecuentemente usado en evaluaciones del color dental $44,152,154,155$, ése ha sido también el diente utilizado en nuestro estudio. 
Los caninos son los dientes más rojos, luego los incisivos centrales y después los laterales ${ }^{156}$. El color del tercio cervical suele tener un tinte más rojizo que los tercios medio e incisal de los dientes anteriores a causa de la pérdida de espesor y opacidad del esmalte ${ }^{152}$. No podemos comparar nuestros resultados con los anteriormente mencionados, ya que únicamente medimos el incisivo central superior.

En el año 2000, Hasegawa A. también afirmó que el incisivo central superior en el tercio medio es más luminoso que el incisivo lateral superior y el canino, y que el canino es más oscuro que los otros dos incisivos ${ }^{157}$. El canino también fue más rojizo que los dos incisivos, incisivo lateral e incisivo central. Estos resultados son idénticos a los aportados por estudios anteriores como los de, Kato A. en 1976, Goodking RJ en $1987^{152,158}$.

Eiffer C. y colaboradores en el año 2009, también igualmente encontraron diferencias entre distintos dientes. Los caninos superiores son más oscuros que los caninos inferiores, a su vez, están más saturados que los incisivos laterales y tienden más a rojizos que a verdes ${ }^{159}$. Estos mismos resultados están respaldados en el año 2005 por Dozic A. ${ }^{160}$.

En general, los dientes anteriores maxilares son ligeramente más amarillos que los mandibulares ${ }^{152}$ y el incisivo central maxilar presenta mayor valor que el lateral y el canino ${ }^{152,156,157,161 .}$

Al igual que para los autores citados en la tabla 76, coincidimos en que el incisivo central tiene un buen acceso y su cara vestibular es menos convexa que la de los caninos, éstas han sido las razones que nos han llevado a tomarlo como diente representativo de cada sujeto estudiado.

Como se ha indicado anteriormente, el rango de coordenadas cromáticas y su distribución dentro del espacio cromático de los dientes han sido descritas en numerosas investigaciones. Hay publicados estudios ${ }^{152,162}$ que realizaron medidas in vivo en el que, empleando un colorímetro de fibra óptica calibrado, midieron las coordenadas cromáticas en el tercio medio vestibular de 2832 dientes anteriores. Encontraron, para el tinte un rango de 4.49YR a 2.26Y, para el valor 5.66-8.48 y para la intensidad de 1.09-4.96. Otros estudios han empleado el sistema Munsell para la evaluación de la distribución del espacio cromático de los dientes o, incluso, los 
valores triestímulo. Un compendio de estos trabajos se puede encontrar en las publicaciones de Miller LL. en 1987, y O'Brien WJ. en $1997^{90,151 .}$

Un resumen de los numerosos trabajos sobre el color de los dientes in vivo midiendo incisivos centrales superiores y empleando para su especificación el espacio CIELab pueden consultarse en la Tabla 76. Los resultados de estos trabajos muestran el rango del color de los dientes naturales en este espacio cromático.

\begin{tabular}{|c|c|c|c|c|c|c|c|}
\hline AUTORES & MÉTODO & PAíS & $\mathbf{n}$ & EDAD & L & a & b \\
\hline Gegauff y cols,1993 & Colorímetro & USA & 20 & $20-27$ & 51.1 & -0.1 & -0.2 \\
\hline Rubiño y cols, 1994 & Colorímetro & España & 600 & $15-50$ & $67.6 \pm 7.0$ & $4.3 \pm 2.1$ & $12.1 \pm 3.3$ \\
\hline Zhao y Zhu, 1998 & Espectrof. & China & 70 & $18-70$ & $51.48 \pm 8.02$ & $0.62 \pm 0.14$ & $0.15 \pm 0.02$ \\
\hline Odiosso y cols, 2000 & Espectrof. & USA & 180 & $13-64$ & $69.3 \pm 5.92$ & $5.40 \pm 1.33$ & $18.7 \pm 3.37$ \\
\hline Russell y cols, 2000 & Espectrof. & Irlanda & 7 & estudiantes & 48.31 & 1.35 & 2.73 \\
\hline Russell y cols, 2000 & Espectrof. & Irlanda & 7 & estudiantes & 41.31 & -0.91 & 4.91 \\
\hline Hasegawa y cols, 2000 & Espectrof. & Japón & 87 & $13-84$ & $73.0 \pm 8.0$ & $3.5 \pm 1.5$ & $16.5 \pm 5.0$ \\
\hline
\end{tabular}

Tabla 76: Valores $L$, a y b registrados en incisivos centrales superiores in vivo

A diferencia de nuestro estudio, Hasegawa A. y colaboradores (2000) y Hasegawa A. e Ikeda I. (2000), miden el color del diente en cinco diferentes posiciones del eje vertical de la superficie vestibular del incisivo central superior empleando un colorímetro, encontrando que existen variaciones significativas de los valores de $L$, a y b a lo largo de dicho eje ${ }^{157,161}$. Para $L$, los valores máximos se encuentran en el tercio medio ${ }^{163}$. El valor de $L$ fue inferior en la zona cervical ${ }^{29}$ y significativamente menor en el tercio incisal ${ }^{156}$. Por lo que se refiere a la variable a, los valores más altos se encontraron en la zona cervical disminuyendo de una forma progresiva y significativa en dirección incisal. Para la variable b, la zona cervical, de nuevo fue la que presentaba los valores más elevados cayendo de forma gradual y significativa, igualmente, en dirección incisal. En cuanto a la translucidez, se ha demostrado que disminuye desde incisal al tercio medio ${ }^{157}$.

La variabilidad de las coordenadas de color que, según la casa comercial, Vita Zahnfabrik ofrece la dentición natural se encuentra en unas cifras de Valor o luminosidad representado en la variable $L$, de 65 a 90 unidades, una intensidad representada por $\mathrm{C}$ de 5 a 30 unidades y el tinte representado por la variable $\mathrm{h}$, entre $70^{\circ}$ y $90^{\circ}$. 
Como vemos en la tabla 77 , no podemos realizar una comparación estadística rigurosa entre nuestros resultados y las coordenadas CIELab medias de otros estudios (tabla 76) debido a las particularidades metodológicas, que varían tanto en el número de sujetos, como en el rango de edad y el método de medida empleado.

\begin{tabular}{|c|c|c|c|c|c|c|c|}
\hline \multicolumn{7}{|c|}{ VALORES MEDIOS DE $\mathbf{L}, \mathbf{C}, \boldsymbol{h}$ a y b SEGÚN GÉNERO } \\
\hline & $\mathrm{n}$ & edad & $\mathbf{L}$ & $\mathbf{C}$ & $\mathbf{h}$ & $\mathbf{a}$ & $\mathbf{b}$ \\
\hline HOMBRES & 671 & $16-89$ & 74,98 & 21,53 & 89.90 & 0.59 & 21.42 \\
\hline MUJERES & 690 & $16-89$ & 77.51 & 18.37 & 91.87 & -0.32 & 18.31 \\
\hline
\end{tabular}

Tabla 77: Valores medios obtenidos en este estudio $L, C, h$, a y $b$

Con nuestros resultados encontramos unos valores mínimos de valor de 47.0, perteneciente al color $5 \mathrm{M} 3$, y un valor máximo de 91.3 perteneciente al color $1 \mathrm{M} 2$, exceptuando aquel valor de 100.0 perteneciente al color 0M1,5 que según la casa comercial está dentro del grupo de "bleaching teeth" o dientes blanqueados.

La intensidad o croma en nuestros resultados ofrece unos valores extremos de 49.8, perteneciente al color 5M3 y 7.60 perteneciente al color 2M1.

A continuación el tinte, según nuestros resultados alcanzó el pico máximo en 107º en el color 2M1, y el suelo en 69\%, dentro del color 5M3. Como se observa nuestros resultados amplían ligeramente la horquilla de datos donde se encuentra la dentición natural con respecto a los datos de la casa Vita Zahnfabrik.

Nuestros resultados se ven también respaldados por el estudio de Zaira $\mathrm{H}$. en el año 2009, que encontró midiendo con el espectrofotómetro Easyshade, colores naturales que sobrepasaban dichos umbrales aportados por la casa comercial Vita-Zahnfabrik, concretamente para la intensidad sus resultados encontraron valores de 35.8 y para el tinte de $115.5^{\circ}{ }^{43}$.

Como ya hemos comentado anteriormente, los colores de los dientes naturales cambian con la edad, se vuelven más oscuros debido a una serie de factores: durante la juventud, las cámaras pulpares son amplias y el color rojo de la pulpa influye sobre el color total del diente. Con la edad, se va depositando dentina secundaria en su interior y esto hace que la dentina se vuelva más opaca y atenúa el efecto de la pulpa. 
A medida que los dientes se desgastan con el cepillado la superficie dentaria se vuelve lisa y refleja más la luz; la abrasión de los bordes incisales de los dientes hace que se pierda esmalte $y$, con ello se pierde la translucidez de los mismos al exponerse la dentina ${ }^{10}$. Los dientes también se oscurecen como consecuencia de la placa bacteriana, depósitos, restos de alimentos y absorción de fluidos orales ${ }^{10}$.

Al envejecer, se produce una mayor intensidad en el color de los dientes y además tienen un menor valor ${ }^{18,164}$, nuestros resultados concuerdan plenamente con estas afirmaciones.

En general, el color de los dientes naturales tiene una significativa tendencia a cambiar con la edad del sujeto, generalmente se vuelven más oscuros y más amarillos ${ }^{148,152,}$ $156,157,165,166$

El impacto de la edad sobre el color del diente es debido a varios factores:

- La cámara pulpar se retrae dejando en su lugar dentina secundaria ${ }^{167}$.

- La dentina secundaria se vuelve más dura y menos permeable.

- Existe la hipótesis de que los pigmentos e iones amorfos orgánicos e inorgánicos penetran a través del esmalte depositándose en la unión amelocementaria en la estructura dentinaria ${ }^{167}$.

- La intensidad de la dentina se vuelve más saturada y el valor del diente disminuye combinado con la disminución del espesor del esmalte, como resultado del uso normal de los dientes, el color dentinario se vuelve más dominante en el color dental. Con el aumento de la edad, la superficie de los dientes se desgasta gradualmente.

Estos mecanismos también han sido objeto de estudio por otros autores ${ }^{152,168}$. El resultado es un progresivo oscurecimiento del diente, sin tener en cuenta las características genéticas de cada individuo ${ }^{168}$. Este proceso también lo refleja Goodkind y Schwabacher en sus artículos, explicando que el oscurecimiento de los dientes a partir de los treinta y cinco años se produce por la aparición de dentina secundaria, y al ser la dentina más oscura que el esmalte, y éste al estar disminuido hace que haya una disminución del valor con la edad ${ }^{152}$. 
Como estamos observando, podemos afirmar que existe un amplio acuerdo por parte de los investigadores de que los dientes presentan una tendencia significativa hacia el amarillo y oscurecen con la edad 148, 156, 157, 166, 169 . El impacto de la edad sobre el color del diente es debido, como ya hemos comentado, a la variación del espesor, composición y estructura de los tejidos dentarios a lo largo de la vida.

La intensidad de un diente, procede principalmente de la dentina, será menor en un diente joven a causa del efecto máscara del esmalte. El espesor natural del esmalte es mayor por incisal que por la zona cervical, por lo que la intensidad será mayor por cervical y disminuirá hacia la zona incisal. A medida que el esmalte se adelgaza con el tiempo, se hace más evidente la dentina y el diente se vuelve menos monocromático. El esmalte joven también es más permeable y se deshidratará más rápidamente. Las capas más profundas del esmalte tienen menos espacios de aire y están más mineralizadas. Este esmalte más profundo es más translúcido ${ }^{50}$.

En estudio en 180 adultos y adolescentes en USA se midieron sus incisivos centrales superiores con espectrofotómetro, se mostró que cada año de vida, el rango de amarillo aumento $0.10 \mathrm{~b}$ unidades y la luminosidad disminuyó en $0.22 \mathrm{~L}$ unidades. Este mismo estudio reveló que según aumenta la edad el nivel de b aumenta más rápidamente en hombres que en mujeres. También se afirmó que el consumo de bebidas cromógenas, café, té, vino tinto, etc. afecta de forma significativa al valor de las coordenadas cromáticas. Individuos que consumen diariamente café 0 té presentan, de media, un crecimiento de 1.2 unidades en $\mathrm{b}$ y un decrecimiento de 1.5 unidades en $L^{148}$. No hemos encontrado estudios similares sobre población española en la que el color dental se mida con espectrofotometría.

Al igual que en el presente estudio, Gozalo Díaz G. en el año 2008 planteó la hipótesis de que la edad de los sujetos y el sexo pueden ser usados para estimar el valor CIELab de sus incisivos centrales superiores. Esta hipótesis sería muy útil a la hora de determinar el color dental en pacientes totalmente edéntulos. Se encontró que la edad y el género son determinantes estadísticamente significativos en predecir los tres parámetros del color de los incisivos superiores; el modelo de regresión lineal explicó un $36 \%$ de variabilidad para $L$, un $16 \%$ para la variable a, y un $21 \%$ para b. Fue capaz de predecir el color dental con un rango de 5,8 unidades CIELab ${ }^{169}$. 
Un estudio realizado por Goodkind RJ. en 1987 coincide en algunos puntos con nuestros resultados. Este autor señala que, después de aproximadamente los 35 años de edad, los dientes suelen volverse más oscuros, rojizos y más saturados con la excepción de la localización cervical donde el color es aparentemente, más amarillo. La variación de la edad se hace notable en intensidad que aumenta con la edad, mientras que los valores de tinte y valor disminuyen ${ }^{152 .}$

A partir de los treinta años, el color de los dientes tiende a ser menos luminoso, mostrar colores rojizos y amarillentos, dando una medición de parámetros que reflejan un aumento de las variables intensidad (C), b, a, con la edad, no así con el tinte ( $h$ ) que tiene tendencia a disminuir, pero de manera más ligera ${ }^{43}$. A pesar de que dicho estudio, presenta una muestra significativamente inferior a la empleada en nuestro trabajo, nuestros resultados son muy similares.

Con respecto al valor, este no desciende cerca del borde incisal según aumenta la edad, esto puede ser debido a los efectos del negro del fondo de la boca a través del esmalte transparente ${ }^{157}$. El mismo autor afirma que la cantidad de rojo, medida por la variable a en la región incisal aumenta según avanza la edad, pero no se encontraron cambios en el eje del rojo en otras localizaciones, debido al desgaste de la región incisal según avanza la edad ${ }^{170}$.

En concordancia con nuestros resultados, Xiao J. y colaboradores que en el año 2007 encontraron como el valor $L$, del diente disminuía y valores como $b$, aumentaban a medida que avanzaba la edad. En general la variación de color del diente natural es un factor que influye en la personalidad del individuo, ya que con el paso de tiempo, los dientes se vuelven más oscuros y amarillentos influyendo negativamente en su autoestima $^{168}$.

Kato A. ya en 1976 afirmó que el valor en el tercio medio del diente y cerca de la raíz disminuye linealmente según avanza la edad. No podemos discutir esta afirmación, ya que en nuestro trabajo solo hemos medido el color del tercio medio ${ }^{171}$.

En contrapunto, Zhu H. en el año 2001 estudió a 163 personas asiáticas entre 20 y 73 años con un espectrofotómetro, afirmó que los valores de las variables $L$, y a no estaban relacionados con la edad. En cambio b, si fue relacionado con la edad tanto en el tercio medio como en el cervical ${ }^{172}$. Otro de los pocos autores que no ha 
encontrado diferencias significativas en el color dental entre el grupo de edad de 50 años y el grupo de edad de 70 años, ha sido Eiffer C. en el año $2009^{159}$.

Hasegawa A. en el año 2000 y Schawacher WB. en 1990 hacen referencia a la importancia de obtener una extensa base de datos de los colores de los dientes naturales "in vivo" por grupos de edad y sexo, donde se incluya todo el espectro de color de los dientes naturales, y estamos totalmente de acuerdo con esta afirmación ${ }^{153,161}$. Para ello, se necesitan estudios a través de espectrofotometría, con una muestra mayor, en diferentes países y con diferentes razas para intentar resolver esta cuestión que queda pendiente.

El sexo del paciente, la edad y la raza son factores importantes a tener en cuenta a la hora de tomar el color del diente. Otras variables como consumir té, café o tabaco, y la frecuencia del cepillado no son tan significativas ${ }^{168}$.

Si nos fijamos en la variable del género, en el varón hay una mayor intensidad en el color dental que en la mujer, en la cual hay un mayor valor y transparencia ${ }^{18,132,173 .}$

No hay diferencias significativas en el color dental entre hombres y mujeres de acuerdo con un número de estudios que envuelve el diente natural ${ }^{161,166}$. En el año 2000, Hasegawa A., no encontró diferencias estadísticamente significativas para L, a y b según el género al analizar sujetos japoneses ${ }^{161}$ En la población china, tampoco Zhu $\mathrm{H}$. en el año 2001 encontraron diferencias estadísticamente entre hombres y mujeres $^{172}$.

Por el contrario, y de acuerdo con nuestros resultados, un estudio publicado por Odioso LL. en el año 2000, ha mostrado que comparado con los hombres, las mujeres tienen estadísticamente dientes más claros y menos amarillos ${ }^{148}$. En sus resultados, los hombres tienen un valor promedio de $\mathrm{L}$ aproximado de 3,7 unidades menor comparado con mujeres para incisivos centrales superiores. En nuestro estudio la diferencia de promedios, entre hombres y mujeres es de aproximadamente 2.2 unidades, menor en hombres. Estos resultados se suman a otros estudios que han mostrado que las mujeres tienen los dientes más claros, menos amarillos y menos saturados que los hombres ${ }^{152,169,174 .}$ 
Nuestro estudio distingue variaciones del color dental entre los dos géneros, determinando que los valores del tinte (h), y valor $L$ son más altos en mujeres, mientras que la intensidad (C), la variable a y el parámetro b son más altos en hombres.

También en la población española, un estudio muy interesante fue el publicado por Rubiño M. y colaboradores en 1994 donde estudiaron in vivo a 600 personas, con edades comprendidas entre los 15 y los 50 años, tanto hombres como mujeres a los cuales se les midió el color del tercio medio del incisivo central superior derecho. Este diente debía de estar completamente sano y previamente limpio con pasta dental. Las mediciones de color se realizaron con el colorímetro Topcon BM-5, bajo condiciones de luz constante F2 de la CIE. Los resultados obtenidos fueron estudiados mediante el sistema de medición CIELab, y expresados en $\mathrm{L}, \mathrm{a}, \mathrm{b}$. De esta manera la media de los resultados obtenidos fue la siguiente: $L=67,6, a=4,3$ y $b=12,1^{72}$.

En el diseño del estudio no diferenció ni género, ni edades en la expresión de sus resultados. Así al ajustar el 95\% de sus resultados estadísticamente al espacio del color, se forma una elipse que se encuentra centrada en el punto $a=4,3$ y $b=12,1$, correspondiendo estos valores a intensidad $(C=12,84)$ y tinte $\left(h=70,4^{\circ}\right)$. Como nota los autores informan de que la elipse no contiene el punto $a=0$ y $b=0$, el cual correspondería al blanco, sino que, los dientes abarcan el espacio de color "más hacia el amarillo" 72.

A continuación vamos a exponer las tablas resumen de coordenadas $L, C, h$ a, y b, con el fin de poder comparar resultados, separando grupos de edad y sexo. Dichas tablas, corresponden a los resultados de Hernández Z. $2009^{43}$ y a nuestros propios resultados.

\begin{tabular}{|c|c|c|c|c|c|c|}
\hline \multicolumn{7}{|c|}{ Media de las variables L, C, h, a y b (Hernández Z. 2009) } \\
\hline Grupo de edad & & $\mathrm{L}$ & $\mathrm{C}$ & $\mathrm{h}$ & $\mathrm{a}$ & $\mathrm{b}$ \\
\hline \multirow{2}{*}{$<30$ años } & Mujeres & 82.78 & 15.99 & 99.88 & -2.49 & 15.79 \\
\cline { 2 - 7 } & Hombres & 80.57 & 18.80 & 97.20 & -2.08 & 18.63 \\
\hline \multirow{2}{*}{$30-59$ años } & Mujeres & 77.71 & 19.07 & 94.41 & -1.27 & 18.99 \\
\cline { 2 - 7 } & Hombres & 72.63 & 25.20 & 89.07 & 0.74 & 25.12 \\
\hline \multirow{2}{*}{$\geq 60$ años } & Mujeres & 77.18 & 24.09 & 91.50 & -0.43 & 23.96 \\
\cline { 2 - 7 } & Hombres & 71.02 & 27.08 & 89.91 & 0.73 & 28.36 \\
\hline
\end{tabular}

Tabla 78 


\begin{tabular}{|c|c|c|c|c|c|c|}
\hline \multicolumn{7}{|c|}{ Media de las variables aportadas en este estudio de $\mathrm{L}, \mathrm{C}, \mathrm{h}, \mathrm{a}$ y $\mathrm{b}$} \\
\hline Grupo de edad & & $\mathrm{L}$ & $\mathrm{C}$ & $\mathrm{h}$ & $\mathrm{a}$ & $\mathrm{b}$ \\
\hline \multirow{2}{*}{$<30$ años } & Mujeres & 83.22 & 16.71 & 94.51 & -1.19 & 16.64 \\
\cline { 2 - 7 } & Hombres & 82.21 & 17.98 & 93.45 & -0.80 & 17.93 \\
\hline \multirow{2}{*}{$30-59$ años } & Mujeres & 77.39 & 17.33 & 91.62 & -0.26 & 17.28 \\
\cline { 2 - 7 } & Hombres & 74.18 & 20.38 & 89.71 & 0.47 & 20.31 \\
\hline \multirow{2}{*}{$\geq 60$ años } & Mujeres & 72.30 & 21.16 & 89.62 & 0.43 & 21.09 \\
\cline { 2 - 7 } & Hombres & 69.31 & 25.94 & 86.92 & 1.98 & 25.75 \\
\hline
\end{tabular}

\section{Tabla 79}

Vemos el paralelismo existente en dichos resultados, ya que la metodología empleada ha sido muy parecida. La muestra de pacientes empleada tiene diferentes orígenes en ambos estudios, en el caso de Hernández Z., ha sido registrada en Madrid y el número de pacientes fue de $96^{43}$.

Si observamos ambas tablas, los resultados cambian de forma análoga para cada una de las variables. Exceptuando situaciones como que la media del valor o luminosidad (L), es muy similar en mujeres entre los grupos de edad de 30-59 años y del grupo de edad superior de sesenta años.

Analizando en profundidad el estudio publicado por Hasegawa A. en el año 2000, se ve que estudiaron las coordenadas de color L, C, h de 87 incisivos centrales superiores (42 hombres y 45 mujeres) de edades entre los 13 y los 84 años mediante colorimetría puntual de $1 \mathrm{~mm}$ de diámetro.

Como resultados publicaron que existe una correlación negativa entre edad y $L$, con relación positiva entre edad y $b$. Ambos parámetros, a y b aumentan cuando nos acercamos a cervical, pero la translucidez disminuye en dirección de la raíz. De esta forma concluyen que según aumenta la edad del sujeto, el tercio medio del diente natural se vuelve más oscuro y más amarillo. Tanto el color "rojo" como el "amarillo" presentes en los dientes naturales tiene tendencia a aumentar desde incisal a cervical mientras el grado de translucidez disminuye ${ }^{157}$. En su estudio la punta del colorímetro utilizado no se puso en contacto con el diente, (se aproximó al máximo) y esto puede conllevar varios errores como reflexión irregular, ligeros movimientos del rostro del paciente, y la reflexión de la luz sobre encía y labios. Nuestros resultados limitados, en este caso, al tercio medio, también corroboran dichas afirmaciones.

Las mediciones de las variables, $L$ y b eran las más cambiantes con la edad y con el género ${ }^{148,168}$. 
No todos los autores encuentran diferencias de color entre géneros, así, Eiffer C. en el año 2009 no encontró diferencias estadísticamente significativas entre hombres y mujeres $^{159}$.

Con nuestros datos, apuntamos que la cifra del valor medio objetivo y de valor medio subjetivo aumenta según aumenta la edad de los grupos establecidos de manera muy parecida. Para hacer inferencias a la población siempre utilizamos la medida del método objetivo que evita la subjetividad del ojo humano.

Vamos a desarrollar los resultados obtenidos a continuación utilizando la nomenclatura o referencia de la guía 3D Master. La media de luminosidad o valor objetiva en varones pasa de 1.71 en el grupo de menores de 30 años, a 3.06 en el grupo de edad intermedia a 3.69 en el grupo de mayores de treinta años. En mujeres los datos son similares, aunque ligeramente menores. La luminosidad o valor medio objetivo en mujeres pasa de 1.56 a 2.48 y 3.19 en los tres grupos de edad establecidos. Por lo que se aprecia un aumento proporcionado en ambos géneros, existiendo diferencias estadísticamente significativas entre los tres grupos de edad tanto en hombres como en mujeres.

Para la intensidad media seguimos en la misma línea de reflexión, los datos aportados por ambos métodos, son bastante similares, y prácticamente imperceptibles 29.

La intensidad media objetiva en hombres en los tres grupos de edad establecidos pasa de 1.68 a 1.65 y por último a 2.00. Apuntar que no existen diferencias estadísticamente significativas en varones entre los grupos de edad inferiores. Para las mujeres, la intensidad media evoluciona en los tres grupos de edad de 1.51 a 1.48 a 1.71, no alcanzando la intensidad 2 como ocurría en hombres. En el caso de los hombres existen diferencias estadísticamente significativas entre todos los grupos excepto en el grupo de menores de treinta años y el grupo de edad intermedia.

En los individuos de raza blanca los dientes tienen un menor valor e intensidad que en los individuos de raza negra ${ }^{18}$. Se deben tener en cuenta los pigmentos que determinan el color de la piel y que influyen en el color del diente como son ${ }^{10}$ : 
- Melanina: da una tonalidad negra a la cara. Cuando la piel es muy blanca, se produce un menor valor y translucidez en el color dentario.

- Hemoglobina: que es responsable del color rojo

- Colágeno: que se encuentra en la piel y da un color amarillo anaranjado ${ }^{18,175,176 .}$

También influye el pelo, ya que los morenos tienen mayor intensidad en el color dental que los rubios ${ }^{10}$.

Al analizar el color dental de la población africana, Esan TA. y colaboradores en el año 2006, señalaron la limitada información que relaciona color dental, edad y color de piel. Esta carencia limita a los prostodoncistas para seleccionar el diente artificial en pacientes totalmente edéntulos. Su artículo explora la posibilidad de relacionar estos factores $^{174}$.

Uno de los pocos estudios publicados, sobre la relación entre el color de piel y el color de los dientes, es el realizado por Jahangiri L. y colaboradores en el año 2002, donde concluyen que el color del diente y el color de piel está inversamente relacionados, y que los adultos con mayor edad tienen los dientes más oscuros (menor valor) ${ }^{166}$.

El color del diente varía según la región, por la diversidad racial y los factores del entorno. Odioso LL. y colaboradores en el año 2007 encontraron que las personas blancas tenían el color de los dientes menos amarillentos (aproximadamente 1-2 unidades menos de $\mathrm{b}$ que los negros e hispanos, al calcularlo a través de un colorímetro $^{148}$. Sin embargo eran los sujetos pertenecientes a la raza caucásica los que se encontraban menos satisfechos con su color dental ${ }^{168}$. Esta conclusión se atreve a cuantificar la diferencia de color dental entre población caucásica y población negra. Recordamos que, nuestros resultados se basan exclusivamente en población caucásica.

A continuación vamos a explicar porque nuestros resultados podrían llegar a representar a la población española utilizando para ello las posibilidades que nos ofrece el estudio estadístico. Trabajamos con una fórmula que mide una variable dicotómica cuya máxima variabilidad se obtiene cuando $p=q=0,50$.

Fijamos unas características del estudio estadístico, valores habituales: coeficiente de confianza del $95,5 \%$, precisión del $3 \%$ y $p=q=0,50$. 
Ahora veamos los datos poblacionales según el INE, censo oficial del 2011, por tanto datos válidos a 01/01/2012

1) Población de Castilla y León, mayor de 18 años: 2.048 .483 (en total: hombres y mujeres).Con las condiciones citadas arriba, el tamaño mínimo de muestra es: 1.116 personas (habría que repartir por sexos).

2) Población de España, mayor de 18 años: 35.297.301 (hombres y mujeres).

Con las mismas características estadísticas citadas anteriormente, el tamaño de muestra mínimo es también de 1.116 personas puesto que el factor de corrección es el mismo, cuando el tamaño de las poblaciones es tan grande, a partir de una población mayor a 8000 casos, aproximadamente, es indiferente que la población tenga 2 millones (Castilla y León) o que tenga 36 millones (España).

Así en el tamaño de nuestra muestra se ajusta al n mínimo necesario para cumplir las condiciones estadísticas fijadas. La carencia, no está en el número de sujetos incluidos en el estudio; sino en la composición real de la muestra.

Para que fuese representativa de España, se debería incluir en el estudio personas pertenecientes a todas las comunidades autónomas españolas. Y no solo a individuos Castellano leoneses. Por otra parte no encontramos motivos para pensar que el color dental de las personas pertenecientes a otras comunidades autónomas pueda diferir del estudiado en este trabajo, y por lo tanto las conclusiones del mismo puedan aplicarse con confianza al resto de los españoles.

\section{2.- FRECUENCIA DE COLORES}

Smith PW. y Wilson NH. en 1998 demostraron que, los colores más frecuentemente elegidos fueron $A 3$, seguido de cerca por los colores $A 2, C 2, B 2$ y B3 ${ }^{177}$. Estos resultados coinciden con los tintes marrones rojizos A3 y A2. Nuestros resultados no son totalmente equiparables ya que en nuestro estudio se utiliza la guía de color 3D Master, y aparece como color más frecuente el 3M1.

Años después, los resultados otro estudio indican que los colores más comunes son D3 (Vitapan Clasica), 410 (Cromascop), y 3R1, 5 (Vita 3D Master). Esto puede 
relacionarse con diferencias básicas en la tonalidad de los dientes entre los diferentes grupos de población ${ }^{178}$.

El color más frecuente en la muestra que analiza nuestro estudio es el 3M1 con 96 sujetos y representa un porcentaje de $7.05 \%$, seguido por el $1 \mathrm{M} 1,5$ con 94 casos representando un $6.91 \%$. El color 3R1,5 está representado con un porcentaje de $0.22 \%$. Para poder visualizar con mayor detalle, a continuación en la tabla 80 , representamos los colores encontrados:

\begin{tabular}{|c|c|c|c|c|c|c|}
\hline \multicolumn{7}{|c|}{ FRECUENCIA DE COLORES TOOTHGUIDE 3D MASTER } \\
\hline TOTAL & \multicolumn{3}{|c|}{ HOMBRES } & \multicolumn{3}{c|}{ MUJERES } \\
\hline & $<30$ años & $30-59$ años & $\geq 60$ años & $<30$ años & $30-59$ años & $\geq 60$ años \\
\hline \multirow{2}{*}{$3 \mathrm{M} 1(7.05 \%)$} & $1 \mathrm{M} 1,5$ & $3 \mathrm{M} 1$ & $4,5 \mathrm{M} 1,5$ & $1 \mathrm{M} 1,5$ & $2 \mathrm{M} 1$ & 3 \\
& $(14.56 \%)$ & $(10.13 \%)$ & $(8.77 \%)$ & $(6.91 \%)$ & $(10.84 \%)$ & $3 \mathrm{M} 1(9.82 \%)$ \\
\hline $1 \mathrm{M} 1,5$ & $1 \mathrm{M} 2$ & $2,5 \mathrm{~L} 1,5$ & $4,5 \mathrm{M} 2,5$ & $1 \mathrm{M} 1$ & $2 \mathrm{~L} 1,5$ & $2,5 \mathrm{~L} 15$ \\
$(6.91 \%)$ & $(13.59 \%)$ & $(5.91 \%)$ & $(7.89 \%)$ & $(13.82 \%)$ & $(10.04 \%)$ & $(5.80 \%)$ \\
\hline \multirow{2}{*}{$2 \mathrm{~L} 1(5.22 \%)$} & $1,5 \mathrm{M} 1,5$ & $3,5 \mathrm{~L} 1,5$ & $3 \mathrm{M} 1(4.82 \%)$ & $2 \mathrm{~L} 1,5$ & $3 \mathrm{M} 1$ & $3,5 \mathrm{M} 1$ \\
& $(9.71 \%)$ & $(5.06 \%)$ & & $(10.14 \%)$ & $(10.04 \%)$ & $(5.36 \%)$ \\
\hline
\end{tabular}

\section{Tabla 80}

En el año 2009, Hernández Z. encontró que los tres colores más frecuentes de la guía Toothguide 3D Master fueron el 2M1 (19.63\%), 3M1 (12.45\%) y por último 2R1,5 $(9.35 \%)^{43}$. Como curiosidad, apuntamos que el color más común en nuestra muestra (3M1) aparece en su segunda posición, y que el color 2R1,5, no aparece como color frecuente en ninguno de los tres grupos de edad estudiados.

Si estudiamos la frecuencia de colores analizando únicamente el género, nuestros colores más frecuentes serían para mujeres el 1M1,5 (8.84\%) y para hombres el 3M1 (6.26\%), mientras que para Hernández Z. y colaboradores, serían $2 \mathrm{M} 1$ (27.5\%) para el género femenino y de 3 L1,5 (19.05\%) para el género masculino ${ }^{43}$.

La opinión de la casa comercial con respecto a la tablilla seleccionada por su espectrofotómetro es que produce el efecto de redondeo y esto es más relevante cuando existen colores intermedios como en el caso de Easyshade ${ }^{96}$.

\section{3.- METODO SUBJETIVO}

En 1985, Jack Preston, resumió los problemas existentes en la determinación de los colores demostrando que en la captación del color intervienen diversos factores que interactúan entre sí. Además identificó varios problemas asociados a las guías de color 
dental, y describe la inevitable influencia del color gingival durante la selección del color, la diferencia de materiales de fabricación en las guías, con las que seleccionamos el color dental y las cerámicas que utilizamos para nuestras restauraciones ${ }^{79}$.

Posteriormente, se insistió en la idea de que la determinación visual del color dental está basada en la comparación con el diente remanente del paciente con las guías comerciales de color standard ${ }^{161}$. No obstante el rango de colores de las guía es inadecuado, no distribuido de una manera lógica, no concuerda con el color de los dientes $68,79,85$, y no cubre todos los colores posibles encontrados en los dientes naturales $^{72}$.

Por todo esto, la selección del color dental se considera un proceso subjetivo y difícil, porque la interpretación del observador está repleta de variables y factores ambientales tales como la fatiga del ojo humano, el envejecimiento, la emoción, condiciones de iluminación, nivel de experiencia, y de variables fisiológicas tales como la ceguera, o alteraciones de la percepción del color 10, 84, 179, 180, 181.

La selección del color de un diente al pertenecer al rango de las experiencias subjetivas tiene por parte del cerebro una interpretación única del color. El subjetivismo debido a las diferencias en el concepto de estética, a las funciones de respuesta visual del individuo o a experiencias pasadas ${ }^{182,183}$.

El cansancio visual alcanzado tras el trabajo visual profesional a lo largo de varias horas y tras mucho tiempo de observación de un mismo objeto pueden alterar de forma significativa la toma de color dental ${ }^{184}$.

Según hemos mencionado ya en la introducción, cuanto más tiempo se observa un determinado tinte, menos sensibilidad se tiene para advertir diferencias dentro de él, ya que existe saturación de receptores nerviosos. Para evitarlo conviene mirar un objeto color gris neutro ${ }^{185,186}$. Es recomendable realizar pequeños descansos de aproximadamente 5 segundos.

Los factores psicológicos, estados de ánimo por parte del observador, pueden llegar a provocar interpretaciones diferentes para una misma realidad, en este caso, el color dental. También existen las ilusiones ópticas, como por ejemplo, que un mismo objeto 
aparezca más oscuro sobre un fondo claro que sobre un fondo oscuro. Además, la comunicación visual de las características del color es limitada ${ }^{81}$.

La selección del color, aun bajo condiciones ideales es una valoración subjetiva, hasta con clínicos expertos ${ }^{82,87}$. Culpepper WD. en 1970 informó de la falta de acuerdo entre varios los dentistas, a la hora de realizar una toma de color a un diente natural y la incapacidad de algunos dentistas, para duplicar sus propias selecciones de color de una ocasión a otra ${ }^{87}$.

Por si estas limitaciones no fueran suficientes, se observa que las guías de color dentales, suministradas por el mismo fabricante podrían mostrar ligeras variaciones de color que podrían ser cuantificadas por métodos electrónicos. Esta falta de control de los lotes de un mismo fabricante ya ha sido descrita, es decir, existe una falta de estandarización $76,79,82,133$. Incluso un estudio concluyó después de trabajar con las coordenadas de color de 25 guías Vitapan Clasica, que estas podrían no considerarse intercambiables $^{187}$.

Los errores en la concordancia de color mencionados por Culpepper WD. en 1970 se atribuyen a las variables humanas, pero otros errores que se deben a la insuficiencia de las guías dentales disponibles ${ }^{178}$. Además, la diferencias entre el centro y los lados de un diente en términos de color, forma, estructura, y el brillo puede ser interpretado de manera diferente por cada observador ${ }^{178}$.

Hay varias desventajas sobre las guías de color, como el rango de tintes inadecuados disponibles y su falta de uniformidad ${ }^{18,84}$. Las guías de color más comúnmente utilizadas en el uso clínico diario, incluyen la guía Vitapan Clasica (Vita Zahnfabrik, Bad Säckingen, Alemania), guía Chromascop (Ivoclar Vivadent, Amherst, NY) y Toothguide 3D Master (Vita Zahnfabrik ).

El logro de un color clínicamente aceptable entre un diente y la restauración guarda estrecha relación con la cobertura de la guía de colores, la experiencia clínica, y las condiciones de iluminación en las que se produce el color ${ }^{188}$. Con frecuencia, la gama de colores disponibles en las guías de color no es adecuada, están ilógicamente distribuidos, son incompatibles con el color natural del diente, y no cubren todos los posibles valores encontrados para las cromacidades del diente natural ${ }^{12,73,87,90,189}$. 
Varios han sido los autores que han puesto el acento en la falta de tonalidades rojizas en las guías de color Vitapan Clasica, no cubriendo el espacio de color de los dientes naturales ${ }^{79,90,157}$. El ojo humano, no puede distinguir las longitudes de onda que componen una muestra de color. Debe ser señalado que los observadores son más sensibles y críticos con cambios de color en la franja del rojo que en la del amarillo, aunque corresponda con idénticos valores de $\Delta \mathrm{E}^{190}$.

Kenneth AK., en 2007 midió 25 guías dentales Vitapan Clasica mediante espectrofotometría, con el fin de valorar si el color de cada tablilla es estable entre una guía y otra. Así, concluye que las variaciones entre las guías de color Vitapan Clasica eran mayores que las variaciones introducidas por el método experimental ${ }^{187}$. Otros autores, sin embargo, como O'Keefe K. en 1988 y Paravina RD. En 2004, afirmaron que la guía Vitapan Clasica ha sido utilizada como el "Standard de las guías" 145, 191.

Cuando seleccionamos el color dental, es recomendable determinar primero el valor o luminosidad, seguido por la intensidad. El tinte es determinado en último lugar, cuando el valor y la intensidad están ya fijados ${ }^{192}$. Este protocolo de selección del color dental es en el que se basa la guía de color Vitapan 3D Master, según instrucciones del propio fabricante y es el que hemos utilizado en este estudio.

Al comparar la guía Vitapan Clasica y la guía 3D Master, se afirma que los rangos de intensidad y la gama de colores de la guía de color 3D Master tiende a cubrir los colores de los dientes naturales, siendo superior, por tanto a la guía Vitapan Clasica 193,194 .

En vista de estos resultados, parece que el uso único de la guía de color Toothguide 3D Master es tan eficaz como el uso de las 3 guías de color combinadas (Vitapan Clásica, Chromascop y Vitapan 3D Master). Por contrapunto vemos que todavía es menor su utilización en la práctica clínica. Dicho de otro modo, la guía Vitapan Clásica, la guía Chromascop no aumentan el espectro de cobertura de la guía 3D Master. Sin embargo, es importante señalar que ninguna de las guías de color, incluyendo la guía 3D Master, parecen abarcar de forma eficaz la zona roja del espectro de los dientes 178.

En otro sentido, un estudio comparativo de las guías dentales efectuado por Kim Pusateri S. y colaboradores en el año 2009 destacaron que la guía Vita Clásica (Vita- 
Zahnfabrik) tiene un promedio más alto de fiabilidad (95\%) que la guía 3D Master con un resultado inferior al $91.2 \%$, sin embargo la casa Vita Zahnfabrik llevó a cabo un control de sus productos y observaron que la guía 3D Master proporcionaba mayor seguridad dando resultados más precisos. Debemos tener en cuenta que la guía Vita Clásica maneja menor número de variables, por lo que el error es menor, pero obtenemos muestras con poca exactitud ${ }^{146}$.

Para otros autores sin embargo, no está claro que sistema de guía de color es el más representativo del amplio espectro del color de la dentición humana ${ }^{178}$. Por ejemplo, el uso de la guía 3D Master, en el trabajo de Klementi E. y colaboradores en el año 2006, era un obstáculo para lograr resultados estéticos, sobretodo en observadores nobeles ya que obtuvieron peores resultados que profesionales con experiencia ${ }^{195}$.

La selección del color se pueden hacer utilizando evaluación visual del color o el análisis instrumental ${ }^{196}$. Aunque el método más popular ${ }^{76} \mathrm{y}$ tradicional de selección de color en Odontología es a través del uso de la selección visual con una guía de colores prefabricados, la duplicación de color con este proceso está plagado de resultados poco fiables e inconsistentes ${ }^{84,87,133}$.

Si analizamos, dentro de la toma de color subjetiva la variable operador, podemos decir, que según las estadísticas, el $0,5 \%$ de las mujeres y el $8 \%$ de los hombres tienen una deficiencia para diferenciar los colores ${ }^{14,134,197}$. La deficiencia para los colores se manifiesta como una incapacidad para percibir determinados colores (protanopía, deuteranopía, tritanopía) o como una debilidad en la visión cromática (protanomalopía, deuteranomalopía, tritanomalopía). Las alteraciones congénitas en la percepción del color están ligadas al cromosoma X, y por tanto ocurren con una frecuencia superior en el sexo masculino ${ }^{14}$.

El enfoque de que las mujeres toman el color dental mejor que los hombres, es una conclusión a la que llegan varios autores ${ }^{87,198}$. En el año 2008 se evaluó la capacidad para seleccionar el color dental en 150 hombres y 150 mujeres sin alteraciones en la percepción del color, y no se encontraron diferencias estadísticamente significativas entre ambos grupos ${ }^{199}$. Similares resultados respaldan también dicha conclusión ${ }^{147}$, 173, 193, 200, 201 .En nuestro estudio la toma de color siempre fue realizada por una mujer. 
En contraposición, y referente al género del operador, Esthell J. y colaboradores en el año 2006 en sus conclusiones resaltan que las mujeres tienen mayor capacidad para captar los elementos del color ${ }^{202}$ y Donahue JL. y colaboradores en 1991 citan que las mujeres están más de acuerdo con las mediciones del espectrofotómetro que los hombres, pero que la diferencia es menos significativa ${ }^{88}$.

No solo el género se ha estudiado para saber si influye en la toma de color, sino también la edad, y la experiencia clínica. Varios estudios afirmaron que ninguna de estas variables influye en la toma de color dental ${ }^{134,173,200}$. Por el contrario Haddad HJ. en el año 2009 y Capa N. en el año 2010 sí que encontraron diferencias a tener en cuenta en la toma de color dental el grado de experiencia del clínico ${ }^{198,203 .}$

Al analizar qué factores individuales, podrían influir en la toma de color dental, Capa N. y colaboradores realizaron un estudio en el año 2010 cuyos resultados no mostraron diferencias estadísticamente significativas con respecto al sexo, color de ojos o el uso de anteojos o lentes de contacto entre los diferentes operadores ${ }^{203}$.

De este análisis podemos deducir que la evaluación del color dental por el método subjetivo es poco fiable, mientras que la esfera espectrofotométrica puede evidenciar una mayor predicción, y ser un método de evaluación más exacto ${ }^{204}$.

A continuación vamos a fijarnos en los tipos de fuentes de luz. El uso de lámparas de luz día ayuda a estandarizar las condiciones lumínicas y mejorar de manera significativa la realización de toma de color dental si la comparamos con las variaciones que presenta la luz del día natural ${ }^{205,206}$. Varios son los estudios que señalan la influencia de las condiciones de luz en la toma de color ${ }^{173,193,207 .}$

Si comparamos la luz fluorescente con la luz incandescente, la luz fluorescente tiende a acentuar el azul, y la luz incandescente acentúa el rango del amarillo-rojo ${ }^{77}$.

Cha HS., y Lee YK. en el año 2009 se propusieron como objetivo determinar la diferencia de color existente sobre las tablillas de las guías de color (Vita Lumin, Chromascop, y Vita 3D Master) al cambiar el tipo de luz incidente sobre ellas. Así utilizaron iluminación estándar CIE D65, A, y F2. Como resultado observaron que existía diferencias estadísticamente significativas en todas las guías de color entre los tres tipos de iluminación ${ }^{208}$. Un estudio publicado por Gokce HS. y colaboradores un 
año después, volvió a insistir en como el cambio en la temperatura de la luz puede influir la toma de color dental óptima ${ }^{209}$.

La luz incandescente es una luz que tenemos en el equipo dental y nos proporciona gran intensidad lumínica en un área determinada, aunque no es buena para la toma de color ya que tiene mucha cantidad de luz amarillo-naranja que puede inducir a error en la toma de color $210,211$.

Cuando no sea posible contar con la luz natural, ya sea por la hora o porque nos encontramos en una habitación interior, podemos optar por la utilización de lámparas de luz corregida. Estas lámparas nos proporcionan una iluminación con una temperatura parecida a la de la luz natural del mediodía entre los $5500^{\circ}$ y $6500^{\circ} \mathrm{K}$. Se han diseñado distintos dispositivos, uno de ellos es Shademat Visual + $(\mathrm{SV}+)$ que es un aparato nuevo diseñado para proporcionar unas condiciones ópticamente "ideales" para la determinación de los colores ${ }^{212}$.

Otra de las variables que influye en la toma de color, es el color reflejado o el color ambiente, nos referimos a los colores reflejados de los cuerpos más próximos por los que está rodeado ${ }^{18,175}$. Siempre se recomienda neutralizar dichos colores con un paño gris ${ }^{67}$, eliminar maquillajes, pintalabios,.....

Cuando un labio cubra de manera parcial el diente cambiará la claridad y el color percibidos por el observador, ya que la cantidad de luz que ilumina al diente está limitada ${ }^{54,213}$.

En el gabinete es importante que las paredes, el techo y el suelo sean de un color neutro ${ }^{8}$, el objetivo es conseguir que el gabinete sea lo más parecido a una cámara neutra ${ }^{10,77}$.

Si nos fijamos en el estado de hidratación del diente en el momento de toma de color, comprobamos que es una variable que afecta tanto a la toma de color objetiva, como a la toma de color subjetiva.

Cuando los dientes se deshidratan, el aire sustituye al agua entre las bandas de esmalte, cambiando el índice de refracción y haciendo que el esmalte parezca más opaco. El diente resecado se ha demostrado que tiene una apariencia más blanca ${ }^{81}$, 
214. Por ejemplo, Russel MD. y colaboradores en el año 2000 aplicaron un dique de goma en los dientes anteriores de 7 sujetos y resecaron el diente durante 15 minutos. El color del diente fue medido antes y después con un espectrofotómetro y fue demostrado que $\mathrm{L}$ significantemente aumentaba, la variable $a$, significantemente aumentaba hacia cero, mientras b, no mostró cambios significativos. Además el color de los dientes se había vuelto más claro y menos saturado. El color de los dientes volvió a sus valores iniciales después de 20 minutos de la retirada del dique de goma 214

Muchos han sido los autores que han estudiado el error de cobertura de las guías dentales a lo largo del tiempo.

El área de intervalo de error o la Cobertura de error, representa la media del valor de la mínima diferencia de color entre muestras de un set de cada espécimen y otro set, es un parámetro útil para comparar rangos de color y distribución de guías de color y dientes humanos ${ }^{123}$. Ha sido calculada como la diferencia de color representada por la media de valor de la mínima diferencia de color entre cada diente y la tablilla correspondiente Vita Clasica y la guía Vita 3D Master. Queda patente que para comparar la cobertura de error de las guías de color, las coordenadas de color $L$, a, y b de los dientes naturales deben de ser estudiadas $215,216$.

Es variada la cobertura de error propuesta por los diferentes autores tanto para la guía Vita Clásica como para la guía 3D Master:

- Guía Vita Clásica: cobertura de error 3,0 (SD $\pm 2,3)$ según O’Brien WJ en $1991^{123}$ y Boenke KM. $1999{ }^{217}$ y de 3,1 (SD $\left.\pm 1,7\right)$ para Analoui M. $2004{ }^{216}$. Paravina en el año 2007 estudió la cobertura de error de la guía Vitapan Clasica, a través de la medición de 1064 dientes naturales en el sistema CIELab, y ésta fue de 4.1 (SD \pm $1.8)^{215}$

- Guía 3D Master: cobertura de error 2,3 (SD \pm 1.5) según O’Brien WJ en $1991{ }^{123}$ y Boenke KM. $1999,{ }^{217}$ y de 2,6 (SD \pm 1.2$)$ para Analoui $M .2004{ }^{214}$, y según un cálculo aproximado de Paravina RD. en 2007 sería de $3,5^{215}$. Siendo una cobertura de error clínicamente aceptable para las guías clínicas según Paravina RD. 2007 de $\Delta \mathrm{E} \leq 2$ unidades $^{215}$. Lejos de nuestras guías dentales actuales. 
El sistema Toothguide 3D utiliza 26 tablillas de color en comparación con la Vitapan Clásica que posee 16 tablillas de color, lo que puede explicar la diferencia. De acuerdo con el fabricante de la guía 3D Master, fue diseñada para incluir una cobertura uniforme de las tablillas de color en casi todos los matices existentes del diente natural. Se pretendía ser sistemáticamente organizados en un espacio de color tridimensional que hace que la selección de la tablilla de color sea más sencilla y exacta. Además, varias características importantes se han mejorado con la guía de colores 3D Master: la gama de valor es más amplia, se incluyen más tablillas de color, que están espaciadas uniformemente, la gama de color se extiende en la dirección de los espectros de color rojizo, y aunque todavía existe cierta falta de armonía, el acuerdo de la tablillas de color general es mucho mejor en comparación con la guía de colores Vitapan Clásica ${ }^{145}$.

La comparación de las guías de color y la gama de colores de dientes naturales también se puede realizar utilizando el error de cobertura (CE) ${ }^{123}$. CE es el índice que muestra el valor medio de las diferencias de color entre las muestras de un mínimo de un conjunto (en este caso, las guías de color) a cada espécimen de otro conjunto (en este caso, los dientes). El promedio de estas diferencias de color se define como la CE. O'Brien en 1991 evaluaron 2 guías de color e informó de que los CE de Bioform $(2.99)$ y Vita Lumin $(3,02)$ guías de color no fueron significativamente diferentes entre sí, pero su combinación mostró un valor de 2,54 CE, que fue significativamente menor ${ }^{123}$. Limitaciones de este estudio incluyen el uso de una instrumentación de medición del color que resultará en la pérdida de precisión en la medición de tablillas de color con áreas translúcidas ${ }^{161}$.

Algunos errores de cobertura siempre existirán, porque las tablillas dentales son representaciones esquemáticas del espacio de color del diente, y el número de las tablillas de color es limitado ${ }^{196}$.

\section{4.- METODO OBJETIVO}

Con el fin de eliminar las variables subjetivas no controlables en la toma de color convencional, se han desarrollado los métodos electrónicos ${ }^{81}$.

Aparatos electrónicos, ópticos y tecnología computarizada, han proporcionado no solamente una determinación objetiva y rápida del color, sino que también han 
presentado la capacidad de detectar cambios sutiles del color. Colorímetros y espectrofotómetros han demostrado gran utilidad en la investigación dental ${ }^{133}$.

La esfera del análisis espectrofotométrico no está influenciada por variables humanas como fatiga ocular, edad, experiencia, factores psicológicos o fisiológicos como el daltonismo, exposición al humo del cigarro, sol, enfermedades crónicas como diabetes, glaucoma, enfermedad de Adisson, anemia perniciosa, y la toma de analgésicos, antibióticos y antihipertensivos que alteran la percepción del color ${ }^{133,173}$.

En 1984 la American Dental Association llegó a un consenso que dictaba los siguientes puntos:

- - Las escalas de colores disponibles en las guías de color no se corresponden con los colores de los dientes naturales.

- -Así mismo, tampoco se corresponden los materiales utilizados para la fabricación de las guías de color, con los materiales en que se confeccionan las restauraciones.

- -Para establecer unos colores dentales estándar, es preciso efectuar mediciones espectrofotométricas de los dientes naturales.

En el estudio de Carossa S. y colaboradores del año 2001, se observaron pequeñas diferencias, pero significativas, en las mediciones espectrofotométricas ${ }^{218}$. Da Silva J., en el año 2008 afirmó que las coronas fabricadas a través de una toma de color mediante espectrofotómetro tenían menos fallos de color y eran menos rechazadas por los pacientes, que las coronas confeccionadas a través de una toma de color convencional $^{219}$.

El alto coste y la manipulación más compleja, restringen el uso de estos sistemas digitales tanto para la clínica como para el laboratorio ${ }^{102,220 .}$

Todos estos dispositivos, incorporan una fuente de luz propia, para no depender de las condiciones de luz del entorno. Además tienen la capacidad de poder tomar el color de diferentes zonas de un diente (mediante una punta lectora pequeña).

Los espectrofotómetros son capaces de medir diferencias pequeñas de color entre ejemplos muy similares ${ }^{106,107}$. 
Una de las desventajas de los espectrofotómetros, es que son instrumentos diseñados para medir superficies lisas, y los dientes no son totalmente lisos y pueden tener en su superficie irregularidades. Una pequeña apertura en el colorímetro es propenso a significativos efectos de pérdida de límite en la determinación del color que conllevará errores ${ }^{76,}{ }^{105}$. Por eso siempre que sea posible, es recomendable el uso de posicionadores.

Los errores sistemáticos son difíciles de manejar y pueden estar asociados al instrumental afectando el grado de precisión ${ }^{106}$. Es decir, existe una pobre correlación entre varios colorímetros en comparación con la fiabilidad de otros instrumentos intraorales. Consecuentemente la comparación de datos entre colorímetros es desaconsejada y poco fiable ${ }^{106}$.

El espectrofotómetro Spectroshade Micro proporciona las medidas más repetibles e indica una mayor coherencia en comparación con Easyshade, ShadeVision y X -Rite 221. Dozic A. en el año 2007 concluyó después de analizar diferentes sistemas electrónicos en la toma de color in vitro sobre tablillas de color dentales que el dispositivo ShadeEye (Identa Color II) era menos fiable que el espectrofotómetro Easyshade, siendo este a su vez el más fiable, tanto en circunstancias in vitro como in vivo $^{222}$.

Los colorímetros a diferencia de los espectrofotómetros, solo tienen tres o cuatro filtros; el cuarto filtro es un filtro de densidad neutra para la escala del gris; los colorímetros solo arrojan datos triestímulos para un determinado objeto luminoso. Los espectrofotómetros despliegan una reflexión espectral o curva de transmisión que es en función de la longitud de onda. A partir de la curva de reflexión espectral pueden calcularse los datos con triple estímulo para un determinado objeto luminoso. Se han encontrado que las mediciones mediante espectrofotómetro bajo condiciones de luz estandarizadas son más fiables y exactas que las obtenidas por discriminación visual $82,111$.

En cuanto a la comparación entre colorímetros y espectrofotómetros, está claro que en teoría los segundos aportan más ventajas prácticas (como el sistema de guía de posicionamiento), aunque es necesaria la realización de más estudios en este sentido 100. 
Lagouvardos PE. en el año 2009 realizó un estudio comparando sistemas digitales de medida, Easyshade con ShadeEye midiendo 31 dientes exodonciados a través de sus coordenadas CIELab, L, a, y b. Afirmaron como conclusión, que los datos de dichas coordenadas fueron mayores con Easyshade que con ShadeEye, esta diferencia de color fue clínicamente inaceptable $\Delta E=10.01$, además la reproductibilidad de las medidas fue excelente para ambos sistemas y para todos los parámetros de color, pero significativamente mayor con Easyshade para el parámetro $L{ }^{223}$. Estos resultados coinciden con los resultados publicados por Joiner A. y colaboradores en el año 2008, donde el grado de concordancia se espera que sea menor que la fiabilidad entre el mismo aparato debido a la dificultad de controlar el error sistemático en estos dispositivos $^{224}$.

Con el fin de saber si existían diferencias en la toma de color dental entre varios examinadores, Hassel A.J. en el año 2007 publicó un estudio donde comparaba la fiabilidad intraexaminador, mediante un espectrofotómetro clínico. Así tres examinadores evaluaron los valores de L, C y h y el color dental empleando dos veces la guía vita 3D Master en 161 dientes anteriores de 19 pacientes mediante espectrofotómetro (Vita Easyshade, Vita Zahnfabrik). En un $48 \%$ de los casos se consiguió un acuerdo exacto de la tablilla de color escogida de la guía de color 3D Master. De esta manera el autor concluye que la fiabilidad intraexaminador fue aceptable en términos generales, aunque en ocasiones se observó alguna diferencia clínicamente importante entre las dos mediciones de un examinador ${ }^{190}$.

En el año 2009, Kim Pusateri S. y colaboradores, se propusieron como objetivo estudiar la fiabilidad y exactitud de 4 espectrofotómetros a la venta en el mercado para medir el color dental. La fiabilidad de los dispositivos fue la siguiente: ShadeVision, 99,0\%; SpectroShade, 96,9\%; Easyshade, el 96,4\%, y ShadeScan, 87,4\%. Una diferencia significativa en la fiabilidad se encontró entre ShadeVision y ShadeScan $(P=.008)$. Todas las otras comparaciones mostraron fiabilidad similar. La precisión de los dispositivos fue la siguiente: Vita Easyshade, el 92,6\%; ShadeVision, 84,8\%; SpectroShade, el $80,2 \%$, y ShadeScan, un $66,8 \%$. Se encontraron diferencias significativas en la precisión entre todos los pares de dispositivos $(P<.001)$ con la excepción de SpectroShade y ShadeVision $(P=.033){ }^{146}$. 
Sin embargo, estos estudios sobre fiabilidad de los aparatos electrónicos o de comparación de su fiabilidad con la del ojo humano carecen de una regla de oro. La fiabilidad puede ser buena, pero queda poco claro si la validez es alta, es decir, si lo que se ha medido es el color verdadero ${ }^{190}$.

Todavía no disponemos de muchos estudios que evalúen la efectividad de los espectrofotómetros en Odontología, pero la coincidencia de resultados es lo que es clara ${ }^{109,225}$.

Previamente ya hemos señalado que los espectrofotómetros y colorímetros, poseen la posibilidad de estandarizar, mediante posicionadores, la zona del diente en la que medimos el color ${ }^{101,102,103 .}$

El espectrofotómetro explora solo un área del diente con la punta de la sonda lectora. Debido a ello, siempre que en la medición del color se retiraba la punta de la sonda del diente, con lo que probablemente se colocaba en un área del diente diferente y un mismo diente puede presentar muchos colores. Se ha demostrado que las diferencias en el posicionamiento de la sonda, incluso pequeñas, afectan a la medición del color dentario, porque la reflexión espectral de una superficie contorneada no puede duplicarse a menos que se mida en el mismo punto exacto ${ }^{102,226}$.

Sobre los 1361 pacientes estudiados en esta tesis doctoral sería inviable confeccionar un posicionador individualizado para cada uno de ellos con un diámetro de $5 \mathrm{~mm}$, correspondiente al diámetro de la punta lectora del espectrofotómetro, por eso no podemos garantizar que las dos medidas mínimas realizas con el espectrofotómetro Easyshade Compact estuvieran situadas sobre el mismo área del diente.

Otro de los factores que impiden una exacta medida del color dental, es la superficie convexa de los dientes, lo que complica la correcta colocación de la punta lectora del espectrofotómetro (cuidado con los límites), lo que a su vez resulta esencial para poder obtener mediciones fiables. Sabemos que la punta lectora de los espectrofotómetros está diseñada para medir superficies lisas.

Para complicar el registro del color, mediante estas puntas lectoras, la mayor parte de los dientes tienen superficies irregulares con concavidades y convexidades. La topografía de la superficie de los dientes altera la cantidad y calidad de la luz reflejada 
directamente desde ellos y de la que atraviesa la superficie. La topografía del diente afecta al tinte percibido a la intensidad y al valor.

La morfología de la superficie dental afecta a la cantidad y tipo de reflexión; una superficie rugosa permite más difusión de la luz, mientras que una superficie lisa y pulida permite una reflexión de la luz más espectacular.

Un estudio donde podemos analizar este efecto, es el publicado por Karamouzos A. y colaboradores en Febrero del año 2007, con espectrofotometría donde las medidas que parecieron más estables fueron la de los incisivos centrales superiores y las que más variaron la de los premolares inferiores. La superficie curva de los premolares parece contribuir a errores adicionales inherentes durante el proceso de medida por el impacto negativo del reflejo de la luz en el área de medición del espectrofotómetro ${ }^{136}$.

Cabe esperar que las mediciones tiendan a ser menores para los caninos que para los incisivos centrales superiores, ya que tenemos en cuenta la superficie más convexa de los caninos y los problemas que conlleva la colocación de la punta lectora ${ }^{214}$. Se esperaría menos errores en el incisivo central superior por su superficie plana, pero la translucidez del incisivo central superior es mayor a la del canino, y esto podría aumentar el error de la medida del espectrofotómetro ${ }^{190}$.

El análisis instrumental de color ofrece datos objetivos cuantificados. Los dientes naturales y el color de las tablillas de color, se puede medir con un instrumento que posee una pequeña ventana para la iluminación y la medición, pero las muestras translúcidas están sujetas a la transmisión parcial de la luz, dando lugar a errores sistemáticos en las coordenadas de color ${ }^{105,123}$.

La pérdida de límite es el fenómeno que se produce cuando la luz difusa es transmitida a través de material translúcido, que originalmente sería visto por el ojo, simplemente no es medido por el instrumento debido a la configuración de la fuente luminosa, del sensor, la apertura y la configuración de la medida. Por lo tanto, estas pérdidas no se consideran en la comparación entre los métodos de medición diferentes. La pérdida de límites se podría evitar asegurándose de que no hay apertura entre la fuente de luz externa, espectrofotómetro y el objeto ${ }^{105,123}$. 
En un estudio más reciente, Analoui M. y colaboradores en el año 2004, estudiaron dientes extraídos, que tienen diferentes características espectrales y demostró que la guía Vita $3 \mathrm{D}$ Master tiene la menor diferencia de color media $(\Delta \mathrm{E})$. Aunque la configuración de la medición del color óptica era ideal en términos de medición de las muestras translúcidas sin pérdida de borde, dientes extraídos, como se mencionó anteriormente, tienen diferentes características espectrales en comparación con la dentición natural vital ${ }^{216}$.

Los errores de pérdida de límites ocurren, debido a la pequeña talla de la punta lectora y a la translucidez del diente ${ }^{215}$. Como resultado ocurre una sustancial cantidad de luz reflejada de la superficie del diente que emerge fuera de la superficie de la ventana de la punta lectora dando lugar a una medición demasiado oscura 76, 105, 227.

Para intentar corregir esta cobertura de error, Vita Easyshade diseñó diferentes modelos de medición, basado sobre el material de medida, bien sea, diente natural corona o tablilla.

No podemos olvidar que antes de la utilización del espectrofotómetro Easyshade Compact utilizado en este estudio, éste, se sometió a un test de validación. Este test de validación consiste en la medición de cinco incisivos centrales superiores extraídos. Este diente es medido por cinco operadores distintos, cinco veces cada día, entrenados en el uso del espectrofotómetro, cinco días diferentes, anotando sus coordenadas en el espacio CIELab bajo dos condiciones de luz distintas. Se analizaron los resultados obtenidos y se observó el alto grado de estabilidad temporal y concordancia interexaminador de los mismos. Dando por válido y fiable el espectrofotómetro utilizado (ver Anexo III).

\section{5.-COMPARATIVA ENTRE MÉTODO OBJETIVO Y MÉTODO SUBJETIVO}

Los resultados de las investigaciones de las relaciones entre el color percibido por el ojo humano y el color registrado por el espectrofotómetro no han sido concluyentes 102.

Algunos estudios han sugerido que existe correlación entre el ojo humano y el espectrofotómetro $^{29,76,81}$, otros autores no han encontrado relación 84, 108, 128, 195, 228. Mientras, otros autores, demostraron que, entre los observadores humanos y los 
aparatos electrónicos, se producían poca correlación positiva a la hora de determinar el color dentario $229,230$.

Yap Au. en el año 1999, realizó un estudio in vitro y concluyó que había una diferencia significativa entre la toma de color visual y las mediciones computarizadas a favor del colorímetro. Estas diferencias podrían ser clínicamente significativas en la toma de color si $\Delta E$ fuese superior a 3 unidades ${ }^{77}$. Es necesario tener en cuenta que la mayoría de los dispositivos electrónicos son más fiables en estudios in vitro que in vivo 222

De cualquier forma, la fiabilidad de las mediciones de color dentario mediante espectrofotómetro se consideran superiores a las del ojo humano. En un estudio de 3758 dientes se demostró que la valoración espectrofotométrica del color (SpectroShade, medial High Tecnologies) era idéntica en un $89.6 \%$ de los casos, mientras que la valoración visual del mismo sólo era de un $47.9 \%$ de los casos ${ }^{229}$. Se encontró la misma tendencia en un trabajo preliminar empleando el espectrofotómetro Easyshade ${ }^{231}$.

En el año 2009, Judeh A., y colaboradores, compararon la toma de color dental convencional con la toma de color mediante espectrofotometría (Easyshade) entre varios profesionales de la Odontología. Sí que se encontraron diferencias estadísticamente significativas entre ambos métodos de medición. El método digital fue cinco veces más preciso en la toma de color comparado con la toma de color visual. Los autores concluyen que la medición digital no resuelve todos los problemas generados en la determinación del color dental. Estos sistemas digitales necesitan más refinamiento, como softwares adaptados que ayudarían más a los clínicos en su difícil tarea de seleccionar el color correcto ${ }^{232}$.

El estudio realizado por Horn DJ. y colaboradores en 1998 concluía que la espectrofotometría es un método más predecible y fiable en la evaluación del color de los dientes humanos in vitro que el ojo humano. El espectrofotómetro alcanzaba una reproductibilidad del $80 \%$, mientras que los observadores se limitaban al $65 \%{ }^{233}$. A similares resultados llegaba el estudio realizado por Paul S. y colaboradores en el año 2002, que concluía que la medición con espectrofotómetro es más precisa y reproductible que la del ojo humano (los observadores coincidieron en un $26,6 \%$ y el 
espectrofotómetro en un $83,3 \%{ }^{82}$. El análisis espectrofotométrico parece ser más reproducible, incluso entre varios operadores, que la determinación visual ${ }^{82,229 .}$

Los resultados de Tung FF. en el año 2002 comparaban la toma de color entre diferentes observadores donde el $72 \%$ de las mediciones estaban de acuerdo y el colorímetro coincidía en un $82 \%{ }^{195}$. En esta misma línea de investigación se encuentra el trabajo de Klementti E. y colaboradores en el año 2006 que encontraron que los observadores solo obtuvieron un acierto del $48 \%$. Como vemos los porcentajes de coincidencias varían según los diferentes estudios, pero todos ellos coinciden que la superioridad encontrada en los dispositivos electrónicos.

La experiencia, como hemos visto anteriormente, es un factor determinante en la toma de color subjetiva, a mayor experiencia, mayor fiabilidad de resultados. Aun así, se investigó que observadores con experiencia clínica tuvieron un acierto del 55-64\%, frente a espectrofotómetros con un $83 \%$ de aciertos. ${ }^{84,195}$.

Además, la toma de color visual subjetiva tiene tendencia a seleccionar colores más oscuros que la determinación a través del espectrofotómetro ${ }^{82,229}$. Nuestros resultados no corroboran semejante afirmación ya que para la luminosidad o valor no se encuentran diferencias estadísticamente significativas entre las medias de valor del método objetivo y las del método subjetivo realizando un test t Student pareado. En cambio para la intensidad, sí que se encontraron diferencias estadísticamente significativas siendo la media de las observaciones objetivas ligeramente superior, siendo está una diferencia no perceptible por el ojo humano si nos ajustamos a los umbrales descritos por Kuehi RG. 1979 y Johnson WM. $1989^{28,29}$.

Si comparamos la sensibilidad de los colorímetros frente a un grupo de observadores, vemos que el colorímetro tiene mayor sensibilidad que los observadores expertos ${ }^{82}$, $100,102,128,168$.

El valor o luminosidad ha sido considerada la dimensión del color más altamente reconocible en la toma de color visual ${ }^{234}$. Esta afirmación coincide con nuestros resultados, donde según el índice de Kappa ponderado la luminosidad o valor es la coordenada de color donde existe mayor concordancia entre el método subjetivo y el método objetivo. 
A continuación, analizamos las coincidencias exactas para la totalidad de nuestra muestra. La coincidencia, para la variable valor fue de $38.58 \%$ y para la intensidad fue de $42.32 \%$. Como se puede comprobar, ha habido un $14,1 \%$ de coincidencias en tinte $\mathrm{L}$, un $56,7 \%$ en tinte $\mathrm{M}$ y un 2,1\% en tinte R. Con lo cual la tasa de coincidencia total alcanza casi el $73 \%$. Para la intensidad el porcentaje de coincidencias absoluto fue de $42.32 \%$, y para el valor de $38.58 \%$. Hemos de apuntar como importante la falta de posibilidad para elegir valores e intensidades intermedias, ya que el espectrofotómetro es capaz de señalarlas y con las tablillas de las guías 3D Master esta selección es imposible porque no existen como tablilla de color física.

Estas cifras aumentan de manera considerable para la intensidad y valor si consideramos el no acierto de valor e intensidad en medio punto como válido. Para el valor o luminosidad el porcentaje es de $80.82 \%$; y para la intensidad del $80.24 \%$.

Las coincidencias totales en el color entre el ojo humano y el espectrofotómetro, es decir valor, con tinte, e intensidad aparecieron en un $18.37 \%$ de la población total, este resultado se aproxima mucho al $20.56 \%$ de coincidencias absolutas encontradas en el estudio de Hernández Z. del año $2009^{43}$.

Para analizar el grado de concordancia entre el ojo humano y el dispositivo electrónico hemos utilizado el test estadístico Kappa simple y Kappa ponderado. Para una mejor interpretación de dichos datos nos hemos orientado según el criterio de Landis JR. y Koch GG. en el año 1977, conscientes de que no existen dos observadores (según aparece en dicho artículo). La relación entre las observaciones de varios experimentadores, según el estadístico Kappa, es de 0 si los criterios de los observadores son totalmente diferentes (al azar), superior al 0.4 si la concordancia es moderada, superior a 0.6 concordancia buena-sustancialmente importante, y superiores a 0.8 si la concordancia es muy buena, casi perfecta ${ }^{235}$.

En nuestros resultados el índice de Kappa ponderado mayor se obtuvo en el valor (Kappa ponderado de 0.65) seguido del tinte (Kappa simple 0.43) y por último la intensidad (Kappa ponderado de 0.35). Es decir, una relación buena entre el método objetivo y el método subjetivo para el valor, una relación moderada para el tinte, y ligeramente inferior a moderada para la intensidad.

En el año 2007, Hassel A., realizó un estudio donde comparó los colores aportados por tres examinadores distintos con las coordenadas de color y color resultante en la 
guía de color 3D Master (Vita Zahnfabrik) afirmó que un mismo examinador hubiera escogido exactamente el mismo color dental (3D Master) en un $48 \%$ de los casos; en la mayoría de los casos restantes, las diferencias hubieran quedado en medio punto en cuanto al valor e intensidad en la guía de colores 3D Master. Esto podría explicarse en parte por el algoritmo subyacente del aparato empleado para determinar la tablilla más parecida en la elección del color de los datos $L, C$, y h. La precisión de la tablilla elegida queda sometida al error de redondeo de las mediciones $L, C, y$, lo que resulta en la selección de colores diferentes y la capacidad de repetición es elevada $^{190}$.

\section{6.- DISTRIBUCIÓN DEL COLOR EN LA GUÍA 3D MASTER}

Para realizar el estudio comparativo de la distribución del color en la guía de color Toothguide 3D Master, básicamente nos hemos basado en el estudio publicado por Ahn JS. y Lee YK. en el año 2008. En dicho estudio, midieron 29 guías dentales 3D Master con un colorímetro con luz D65. Cada tablilla fue medida cinco veces en su tercio central y se estudiaron sus valores medios ${ }^{236}$.

Los autores afirman que la distribución de los tres parámetros de las tablillas de color (tinte, valor e intensidad) no está colocada de manera uniforme en el espacio del color con respecto a un criterio matemático. Aun así, están más ordenadas en la guía 3D Master, que en el resto de guías convencionales ${ }^{236}$.

Por si es del interés del lector, comparar los datos correspondientes a cada uno de las coordenadas de color de la guía 3D Master y sus $\Delta E$ entre las mismas ofrecidos por Ahn JS. y Lee YK. en el año 2008, con los resultados análogos ofrecidos en este trabajo se añaden las siguientes tablas (tablas 81 y 82 ) ${ }^{236}$.

En este artículo se estudia en profundidad la ordenación de la guía 3D Master (VitaZahnfabrik) por las variables ordinales continuas, L (valor o luminosidad), C (intensidad o croma), h (tinte o tono), y también se analiza la distancia de color entre tablillas adyacentes $(\Delta \mathrm{E})$. Primero vamos a comparar las coordenadas de color (L, $\mathrm{C}$ y h) y posteriormente nos fijaremos en la diferencia de color entre las tablillas $(\Delta E)^{236}$. 
A lo largo de todo el texto, hemos estudiado los colores intermedios de la guía de color 3D Master, por eso también se han establecido a través de sus coordenadas L, C, h a y b, y se pueden consultar en el Anexo III.

La siguiente tabla, tabla 81, resume las coordenadas de color obtenidas por Ahn y Lee correspondientes a cada una de las 29 tablillas de color pertenecientes a la guía de color 3D Master ${ }^{236}$.

Si comparamos la media de cada tablilla presentada en la tabla 81, para cada una de las coordenadas de color L, C, h, a y b con las aportadas en nuestro estudio (tabla 68), observamos que oscilan de manera clara. Esta diferencia, puede ser debida a que los autores utilizaban un colorímetro para recoger los datos, no especifican si las 29 tablillas de color procedían del mismo lote y que el espesor variable de las tablillas, no se encuentra estandarizado en el diente natural. Aunque lo que sí coincide, es en el orden y las conclusiones que se obtienen de dichos datos. La guía de color 3D Master está más ordenada por la luminosidad o valor, seguida de la intensidad o croma y por último el tinte.

No sólo los anteriores factores pueden condicionar los resultados, sino que además, la obtención de nuestros datos discrepa, ya que utilizamos incisivos centrales superiores "in vivo" en lugar de medir tablillas de color, utilizamos espectrofotómetro y que para evitar en lo posible los valores extremos, empleamos la mediana en lugar de la media. Todos estos factores pueden contribuir a que las coordenadas de color para cada una de las tablillas y las correspondientes diferencias entre ellas puedan variar entre nuestros resultados y los datos proporcionados por Ahn JS.y Lee YK. en el año 2008 236

Los valores extremos para las coordenadas de color según la tabla 81 son para Luminosidad o valor $L$ máxima de 64.7 y $L$ mínima de 50.3. Siguiendo el mismo razonamiento C máxima 19.7 y C mínima de 5.4, por último el tinte $\mathrm{h}$ máxima de 89.4 y h mínima de 75.8. Las cifras extremas en las variables se han encontrado en las tablillas también extremas, 1M1 y 5M3. Recordamos en este punto los extremos de dichas variables encontradas en este trabajo, para $L$ la cifra máxima fue de 91.3 y la mínima de 47.0 , para C, 49.8 y 7.60 y para $h, 107^{\circ}$ y $69^{\circ}$. 


\begin{tabular}{|c|c|c|c|c|c|}
\hline Shade & $\mathbf{L}^{*}$ & $\begin{array}{c}\text { Chroma } \\
\text { (C*ab) }\end{array}$ & h degrees & $a^{*}$ & b* \\
\hline OM1 (1)1 & $70.9(0.3) 2$ & $1.7(0.1) 2$ & $-74.6(1.9) 2$ & $-0.4(0.0) 2$ & $1.6(0.1) 2$ \\
\hline 0M2 (2) & $67.8(0.2)$ & $2.8(0.0)$ & $-86.1(0.1)$ & $-0.2(0.0)$ & $2.8(0.0)$ \\
\hline 0M3 (3) & $66.8(0.3)$ & $3.3(0.0)$ & $-83.7(0.2)$ & $-0.4(0.0)$ & $3.3(0.0)$ \\
\hline $1 \mathrm{M} 1$ (4) & $64.7(0.5)$ & $5.4(0.1)$ & $89.2(0.2)$ & $-0.1(0.0)$ & $5.4(0.1)$ \\
\hline 1M2 (5) & $65.0(0.5)$ & $8.7(0.1)$ & $89.4(0.2)$ & $0.1(0.0)$ & $8.7(0.1)$ \\
\hline 2L1.5 (6) & $61.8(0.2)$ & $8.7(0.0)$ & $88.9(0.1)$ & $0.2(0.0)$ & $8.7(0.0)$ \\
\hline 2L2.5 (7) & $61.3(0.3)$ & $13.5(0.3)$ & $86.5(0.1)$ & $0.8(0.0)$ & $13.5(0.3)$ \\
\hline $2 \mathrm{M} 1$ (8) & $60.6(0.5)$ & $6.5(0.0)$ & $86.8(0.1)$ & $0.4(0.0)$ & $6.5(0.0)$ \\
\hline 2M2 (9) & $61.7(0.3)$ & $10.1(0.1)$ & $85.5(0.1)$ & $0.8(0.0)$ & $10.0(0.1)$ \\
\hline $2 \mathrm{M} 3$ (10) & $61.6(0.1)$ & $14.3(0.1)$ & $85.4(0.1)$ & $1.1(0.0)$ & $14.2(0.1)$ \\
\hline 2R1.5 (11) & $62.0(0.3)$ & $8.7(0.0)$ & $83.5(0.1)$ & $1.0(0.0)$ & $8.7(0.0)$ \\
\hline 2R2.5 (12) & $61.8(0.8)$ & $11.8(0.2)$ & $83.6(0.2)$ & $1.3(0.1)$ & $11.7(0.2)$ \\
\hline 3L1.5 (13) & $56.4(0.4)$ & $10.5(0.2)$ & $83.2(0.1)$ & $1.3(0.0)$ & $10.5(0.2)$ \\
\hline 3L2.5 (14) & $57.3(0.4)$ & $14.8(0.3)$ & $83.2(0.0)$ & $1.8(0.0)$ & $14.7(0.3)$ \\
\hline 3M1 (15) & $56.6(0.5)$ & $6.7(0.0)$ & $81.9(0.1)$ & $0.9(0.0)$ & $6.6(0.0)$ \\
\hline $3 \mathrm{M} 2$ (16) & $58.1(0.2)$ & $11.0(0.1)$ & $81.9(0.1)$ & $1.6(0.0)$ & $10.9(0.1)$ \\
\hline 3M3 (17) & $59.3(0.5)$ & $16.2(0.1)$ & $81.7(0.0)$ & $2.3(0.0)$ & $16.0(0.1)$ \\
\hline 3R1.5 (18) & $56.3(0.1)$ & $8.6(0.2)$ & $79.4(0.2)$ & $1.6(0.0)$ & $8.5(0.2)$ \\
\hline 3R2.5 (19) & $57.1(0.6)$ & $14.5(0.1)$ & $80.1(0.1)$ & $2.5(0.0)$ & $14.3(0.1)$ \\
\hline 4L1.5 (20) & $54.3(0.5)$ & $11.6(0.1)$ & $79.6(0.1)$ & $2.1(0.1)$ & $11.4(0.1)$ \\
\hline 4L2.5 (21) & $54.9(0.4)$ & $15.5(0.3)$ & $80.2(0.1)$ & $2.6(0.1)$ & $15.3(0.3)$ \\
\hline 4M1 (22) & $53.3(0.6)$ & $8.8(0.2)$ & $77.2(0.1)$ & $2.0(0.0)$ & $8.6(0.2)$ \\
\hline 4M2 (23) & $54.7(0.1)$ & $13.3(0.0)$ & $78.3(0.0)$ & $2.7(0.0)$ & $13.0(0.1)$ \\
\hline $4 \mathrm{M} 3(24)$ & $54.6(0.0)$ & $17.3(0.1)$ & $78.2(0.1)$ & $3.6(0.0)$ & $17.0(0.1)$ \\
\hline 4R1.5 (25) & $55.4(0.0)$ & $11.5(0.0)$ & $75.5(0.0)$ & $2.9(0.0)$ & $11.2(0.0)$ \\
\hline 4R2.5 (26) & $55.4(0.0)$ & $14.8(0.1)$ & $76.8(0.0)$ & $3.4(0.0)$ & $14.4(0.1)$ \\
\hline $5 \mathrm{M} 1$ (27) & $50.3(0.1)$ & $9.9(0.0)$ & $74.2(0.0)$ & $2.7(0.0)$ & $9.5(0.0)$ \\
\hline $5 \mathrm{M} 2(28)$ & $51.6(0.0)$ & $14.8(0.0)$ & $75.0(0.0)$ & $3.8(0.0)$ & $14.3(0.0)$ \\
\hline $5 \mathrm{M} 3(29)$ & $53.9(0.0)$ & $19.7(0.0)$ & $75.8(0.0)$ & $4.8(0.0)$ & $19.1(0.0)$ \\
\hline
\end{tabular}

Tabla 81: Coordenadas de L, C y $h^{236}$ 
Fijándonos en la diferencia de color entre las tablillas, Ahn JS. y Lee YK. publicaron que la diferencia de color entre las diferentes tablillas oscilaba entre 0,9 unidades y 18,6 unidades de $\Delta \mathrm{E}$. Entre los 325 pares de tablillas comparados, resuelven que el $6.8 \%$ (22 pares) la diferencia de color fue inferior a 2.6 unidades de $\Delta \mathrm{E}$, umbral perceptible según Douglas en el año $2007{ }^{237}$. El 29.8\% (97 pares) obtuvo una diferencia de color que estuvo entre 2.6 y 5.5 unidades de $\Delta \mathrm{E}$. El resto de los pares de tablillas comparados (206 tablillas) poseían una diferencia de color entre las tablillas superior a 5.5 unidades de $\Delta \mathrm{E}$ (ver tabla 82$)$.

En este estudio la diferencia de color de 2.6 unidades para medir la diferencia entre dos colores $(\Delta \mathrm{E})$, fue considerada el límite perceptible porque el $50 \%$ de los dentistas pueden percibir esta diferencia de color. La diferencia de color $(\Delta \mathrm{E})$ de 5.5 unidades de $\Delta \mathrm{E}$, el $50 \%$ de los dentistas consideran que esta diferencia de color como clínicamente inaceptable ${ }^{237}$. Como sabemos, estos umbrales de discriminación de $(\Delta \mathrm{E})$ no son rígidos y dependiendo del autor que consultemos el rango de la horquilla puede variar.

En nuestros resultados, desarrollados en la tabla 72 , se puede apreciar que la diferencia de $\Delta \mathrm{E}$ mínima fue de 2.44 y se registró entre el color $2 \mathrm{~L} 2,5$ y $2 \mathrm{M} 2$, y la diferencia máxima fue de 44.26 y se registró como cabía esperar entre los colores extremos de la guía 3D Master, 1 M1 y 5 M3.

Entre los 325 pares de colores resaltamos, en tan solo 4 pares una diferencia de $\Delta \mathrm{E}$ inferior a 2.6 (1.24\%). El 9.54\% de las comparativas entre todos los colores de la guía 3D Master es encontraba con un $\Delta \mathrm{E}$ entre 2.6 e inferior a 5.5, el resto de las comparaciones poseían un $\Delta \mathrm{E}$ superior a 5.5 , que según Douglas $\mathrm{RD}$, era inaceptable clínicamente $^{237}$.

En el estudio publicado por Hassel A. en el año 2007, cuantificó la diferencia que existe entre las tres dimensiones del color. Un $\Delta \mathrm{L}$ de 5 unidades para los diferentes valores, un $\Delta \mathrm{C}$ de 5 unidades para las distintas intensidades y un $\Delta \mathrm{h}$ de 2 para los tres tipos de tinte $L, M$ y $R$. Por poner un ejemplo entre el valor 2 y 3 , y entre la intensidad 1,5 y 2,5 de la guía 3D Master, existe una diferencia de 5 en las correspondientes variables ordinales continúas ${ }^{190}$. 
Vamos a aplicar dichas distancias a los resultados encontrados en este estudio. Con referencia al valor, vemos que sí que existe un orden entre el valor dado en la guía $3 \mathrm{D}$ Master y el parámetro $\mathrm{L}$. Respecto a si cumple la diferencia de $\Delta \mathrm{L}$ igual a 5 unidades, tenemos que afirmar que no lo cumple según nuestros resultados.

Para la intensidad, evaluando nuestros resultados, no existe una relación ordenada entre las diferentes intensidades de la guía 3D Master y el parámetro C, ni tampoco una diferencia de $\Delta \mathrm{C}$ de 5 unidades entre ellas. De manera análoga interpretamos nuestros resultados para el tinte, no se encuentran agrupados según $L, M, y R$ y su correspondiente coordenada de color $\mathrm{h}$, ni tampoco existe una diferencia entre los tres tintes de 2 unidades.

Damos por supuesto que si no existe ordenación según criterios matemáticos entre las 26 tablillas reales de la guía de color 3D Master, los denominados colores o tablillas intermedias tampoco se van a encontrar entre sus correspondientes tablillas reales. Por ejemplo, el 4,5M3, no estará correctamente ubicado entre el valor o luminosidad 4 y 5. De forma similar analizaríamos la intensidad y no el tinte al no tener esa posibilidad y ser una variable cualitativa no ordinal.

No hemos podido encontrar artículos donde se relacione y se represente tridimensionalmente cada uno de las coordenadas de color polares ( $L, C, h)$ y su relación correspondiente entre el valor o luminosidad, intensidad y tinte de la guía de color 3D Master para poder compararlos.

Por eso, en nuestra opinión consideramos que dentro de la dentición natural existen colores que no están representados dentro de la guía de color 3D Master, y que si el espectrofotómetro Vita Easyshade compactes capaz de registrar un color por debajo de los umbrales marcados por el fabricante los engloba en el color más similar, por eso el color extremo inferior de la guía 3D Master es el $5 \mathrm{M} 3$.

En la parte superior de la guía 3D Master, es decir colores menos saturados y con mayor valor no ocurre lo mismo porque el fabricante ha confeccionado la guía 3D Master con un suplemento para "bleaching teeth" o dientes blanqueados. De tal manera que si el valor $(L)$ fuese claramente superior a 90, ese color no lo englobaría en el valor 1 , sino en el valor 0 , destinada a dientes blanqueados, según la distribución aportada por la casa comercial. 
DIFERENCIA DE COLOR ( $\triangle E$ E) ENTRE LAS MEDIAS DE CADA PAR DE TABLILLAS (AHN Y LEE 2008)

\begin{tabular}{|c|c|c|c|c|c|c|c|c|c|c|c|c|c|c|c|c|c|c|c|c|c|c|c|c|c|}
\hline Shade & 1M2 & 2 L1.5 & 2L2.5 & 2M1 & 2M2 & $2 \mathrm{M3}$ & 2R1.5 & 2R2.5 & 3L1.5 & $3 L 2.5$ & 3M1 & $3 \mathrm{M} 2$ & 3M3 & 3R1.5 & 3R2.5 & 4L1.5 & 4L2.5 & 4M1 & 4M2 & $4 \mathrm{M} 3$ & 4R1.5 & 4R2.5 & 5M1 & 5M2 & $5 \mathrm{M} 3$ \\
\hline $1 M 1$ & 3.4 & 4.5 & 8.9 & 4.3 & 5.6 & 9.5 & 4.4 & 7.2 & 9.9 & 12.0 & 8.3 & 8.8 & 12.3 & 9.2 & 12.0 & 12.3 & 14.2 & 12.0 & 12.9 & 15.8 & 11.4 & 13.4 & 15.3 & 16.4 & 18.2 \\
\hline $1 \mathrm{M} 2$ & & 3.3 & 6.1 & 4.9 & 3.6 & 6.6 & 3.1 & 4.6 & 8.9 & 9.9 & 8.7 & 7.4 & 9.6 & 8.9 & 10.0 & 11.3 & 12.4 & 11.9 & 11.5 & 13.8 & 10.3 & 11.7 & 15.0 & 15.1 & 16.0 \\
\hline $2 L 1.5$ & & & 4.9 & 2.6 & 1.6 & 5.7 & 0.9 & 3.3 & 5.8 & 7.6 & 5.6 & 4.5 & 8.1 & 5.7 & 7.7 & 8.2 & 9.8 & 8.6 & 8.7 & 11.5 & 7.3 & 9.1 & 11.8 & 12.2 & 13.9 \\
\hline $2 \mathrm{~L} 2.5$ & & & & 7.1 & 3.5 & 0.9 & 4.9 & 2.1 & 5.8 & 4.3 & 8.3 & 4.2 & 3.7 & 7.1 & 4.7 & 7.4 & 6.9 & 9.4 & 6.9 & 8.1 & 6.7 & 6.5 & 11.8 & 10.3 & 10.2 \\
\hline 2M1 & & & & & 3.8 & 7.9 & 2.7 & 5.6 & 5.9 & 9.0 & 4.0 & 5.3 & 9.9 & 4.9 & 8.9 & 8.2 & 10.7 & 7.8 & 9.2 & 12.5 & 7.4 & 9.9 & 11.0 & 12.5 & 15.0 \\
\hline $2 \mathrm{M} 2$ & & & & & & 4.2 & 1.5 & 2.0 & 5.4 & 6.5 & 6.2 & 3.8 & 6.7 & 5.7 & 6.6 & 7.7 & 8.8 & 8.6 & 7.9 & 10.3 & 6.7 & 8.1 & 11.6 & 11.5 & 12.7 \\
\hline $2 \mathrm{M} 3$ & & & & & & & 5.6 & 2.6 & 6.5 & 4.3 & 9.1 & 4.8 & 3.2 & 7.9 & 4.7 & 7.9 & 7.0 & 10.1 & 7.2 & 7.9 & 7.1 & 6.6 & 12.3 & 10.4 & 9.8 \\
\hline 2R1.5 & & & & & & & & 3.2 & 5.9 & 7.7 & 5.8 & 4.6 & 8.0 & 5.8 & 7.6 & 8.3 & 9.9 & 8.8 & 8.7 & 11.4 & 7.3 & 9.1 & 11.9 & 12.2 & 13.8 \\
\hline 2R2.5 & & & & & & & & & 5.6 & 5.4 & 7.3 & 3.8 & 5.1 & 6.4 & 5.5 & 7.6 & 7.9 & 9.1 & 7.4 & 9.2 & 6.6 & 7.2 & 11.8 & 10.9 & 11.4 \\
\hline 3L1.5 & & & & & & & & & & 4.4 & 3.9 & 1.8 & 6.4 & 2.0 & 4.1 & 2.5 & 5.2 & 3.7 & 3.4 & 7.1 & 2.0 & 4.6 & 6.3 & 6.7 & 9.7 \\
\hline 3L2.5 & & & & & & & & & & & 8.1 & 3.8 & 2.4 & 6.3 & 1.0 & 4.5 & 2.7 & 7.3 & 3.3 & 4.0 & 4.2 & 2.6 & 8.8 & 6.2 & 6.4 \\
\hline $3 \mathrm{M} 1$ & & & & & & & & & & & & 4.6 & 9.9 & 2.1 & 7.9 & 5.5 & 9.0 & 4.1 & 6.9 & 10.9 & 5.1 & 8.2 & 7.2 & 9.7 & 13.4 \\
\hline 3M2 & & & & & & & & & & & & & 5.3 & 3.1 & 3.7 & 3.9 & 5.5 & 5.4 & 4.2 & 7.3 & 3.0 & 4.7 & 8.0 & 7.7 & 9.8 \\
\hline $3 \mathrm{M} 3$ & & & & & & & & & & & & & & 8.2 & 2.8 & 6.8 & 4.5 & 9.5 & 5.5 & 4.9 & 6.2 & 4.3 & 11.1 & 8.0 & 6.7 \\
\hline $3 R 1.5$ & & & & & & & & & & & & & & & 5.9 & 3.6 & 7.0 & 3.0 & 5.0 & 8.9 & 3.1 & 6.2 & 6.2 & 7.8 & 11.3 \\
\hline $3 R 2.5$ & & & & & & & & & & & & & & & & 4.1 & 2.4 & 6.8 & 2.7 & 3.8 & 3.6 & 1.9 & 8.3 & 5.7 & 6.3 \\
\hline 4L1.5 & & & & & & & & & & & & & & & & & 4.0 & 3.1 & 1.8 & 5.8 & 1.4 & 3.4 & 4.4 & 4.4 & 8.2 \\
\hline 4L2.5 & & & & & & & & & & & & & & & & & & 6.9 & 2.3 & 2.0 & 4.1 & 1.3 & 7.3 & 3.7 & 4.5 \\
\hline 4M1 & & & & & & & & & & & & & & & & & & & 4.7 & 8.6 & 3.5 & 6.3 & 3.2 & 6.3 & 10.9 \\
\hline 4M2 & & & & & & & & & & & & & & & & & & & & 4.0 & 2.0 & 1.7 & 5.6 & 3.6 & 6.5 \\
\hline 4M3 & & & & & & & & & & & & & & & & & & & & & 5.9 & 2.7 & 8.6 & 4.0 & 2.6 \\
\hline 4R1.5 & & & & & & & & & & & & & & & & & & & & & & 3.2 & 5.4 & 5.1 & 8.3 \\
\hline 4R2.5 & & & & & & & & & & & & & & & & & & & & & & & 7.1 & 3.9 & 5.2 \\
\hline $5 \mathrm{M} 1$ & & & & & & & & & & & & & & & & & & & & & & & & 5.1 & 10.4 \\
\hline $5 \mathrm{M} 2$ & & & & & & & & & & & & & & & & & & & & & & & & & 5.4 \\
\hline $5 \mathrm{M} 3$ & & & & & & & & & & & & & & & & & & & & & & & & & \\
\hline
\end{tabular}

Tabla 82 
Sobre este aspecto, tenemos que reseñar que hemos encontrado 4 sujetos que sin haber sido sometidos a blanqueamiento dental han obtenido un color de la guía "bleaching teeth" por el método objetivo. Un sujeto con el color $0 \mathrm{M} 1,5$, dos sujetos con color de $0 \mathrm{M} 3$, y otro con el color 0,5M2, todos pertenecientes al grupo de edad de menores de 30 años.

No podemos terminar sin señalar la importancia que tiene realizar estudios con muestras grandes de pacientes de todas las edades y razas en diferentes países para poder definir con seguridad el espacio cromático dental natural y observar la evolución del mismo y así, sobre esta base, poder fabricar guías de color con rigor, que cubran en su totalidad el espacio de color dental. 
7.- CONCLUSIONES 



\section{7.- CONCLUSIONES}

Según los objetivos planteados, con la muestra seleccionada, el método aplicado y las limitaciones del estudio, podemos concluir:

1.-No podemos afirmar con rigor que nuestros resultados sobre el color dental esten en concordancia con los publicados en otros países, ya que existe una falta de uniformidad metodológica y muestral entre el presente trabajo y los estudios similares.

2.-En este estudio, los resultados indican que el valor o luminosidad es la dimensión del color donde hemos encontrado mayor relación entre el espectrofotómetro y el ojo humano, seguido por la intensidad y posteriormente el tinte.

3.-Los resultados obtenidos señalan que según aumenta la edad, el color dental disminuye su valor, mientras que la intensidad y el tinte aumentan de forma progresiva en cualquiera de los tres grupos de edad estudiados.

4.-Según la muestra seleccionada, el color más frecuente de la población de Castilla y León es el 3M1, seguido por el 1M1,5, y en tercer lugar el 2L1,5.

5.-Para todos los grupos de edad establecidos, las mujeres han presentado cifras medias ligeramente superiores a los hombres en la dimensión del color valor (L) y tinte (h), no así en la intensidad (C) donde las cifras medias en hombres son superiores.

6.-El valor o luminosidad es la dimensión del color que más claramente se encuentra ordenada en la guía de color dental 3D Master (Vita-Zahnfabrik), aunque no sigue un criterio matemático exacto. 

8.- REFERENCIAS
BIBLIOGRÁFICAS 



\section{8.- REFERENCIAS BIBLIOGRÁFICAS}

1. http://www.tesisenxarxa.net/TDX/TDX_UB/TESIS/AVAILABLE/TDX-0525106131854//01.ICM_PARTE_1.pdf

2. $\quad$ http://www.tesisenxarxa.net/TESIS_UV/AVAILABLE/TDX-0521107143606/urtubia.pdf

3. http://www.jfrutosl.es

4. CIE (Commission Internationale de IÉclairage). Improvement to industrial colour-difference evaluation. 2001 Viena CIE Central Bureau Public 142.

5. Bridgeman B. Psychology and neuroscience: mind and brain. Science 1987 Jan 16;235(4786):373-4.

6. Joiner A. Tooth colour: a review of the literature. J Dent 2004;32 Suppl 1:3-12 Review.

7. http://www.gusgsm.com

8. Sproull RC. Color control. Part III. J Prosthet Dent 1974; 31: 146-155.

9. Romeo Rubio M, Martínez Vazquez de Parga JA. Estudio compartivo de la intensidad lumínica reflejada entre diferentes cerámicas dentales. Revista Interncional de Prótesis Estomátologica 2002;4(3):211-217.

10. Martínez Vázquez de Parga JA., Nieto Alcalde S, Romeo Rubio M, Cañada Madinazcoitia L. Factores que determinan la percepción del color en Odontología. Revista Internacional de Prótesis Estomatológica 2004 Volumen 6, nำ3, 218-225.

11. http://www.tsevanrabtan.wordpress.com

12. Miller A. Shade selection and laboratory communication. Quintessence Int 1993;24:305-309.

13. Fondriest J. Shade matching in restorative dentistry: the science and strategies. Int J Periodontics Restorative Dent 2003 Oct;23 (5):467-79.

14. Valor Priego M, Martínez Vazquez de Parga JA, Romeo Rubio M. Revisión biliográfica de las alteraciones en la percepción el color según el sexo del receptor. Revista Internacional de Prótesis Estomatológica 2007 Vol 9, №2: 145154.

15. Rainwater C. Light and color. Racine, WI:Golden Press, 1971:100-118.

16. Touait B. Esthetic dentistry and ceramic restorations. London: Martin Dunitz, 1993.

17. http://www.pv-primero.blogspot.com

18. Martinez Vazquez de Parga JA., del Rio Highsmith J., Vela Ramón L. Principios 
Básicos del color. Revista Europea del Odontoestomatología 1994;6(3):151154.

19. http://www.campusvirtual.unex.es

20. http://www.radabeauty.com

21. http://www.lenorecraft.blogspot.com

22. http://www.giglykits.com.ar

23. http://www.proyectacolor.cl

24. McLaren EA. Luminiscent venners. J Esthet Dent 1997,9:3-12.

25. CIE (Commission Internationale de l'Eclairage). 1976. Annuaire, Roster, Register, Annexe au Bulletin CIE (París: Bureau Central de la CIE). (PROCLUS, patrimonio Conicet).

26. Cho BH, Lim YK, Lee YK. Comparison of the color of natural teeth measured by a colorimeter and Shade Vision System. Dent Mater 2007 Oct;23(10):130712.

27. http://www.mimoriarty.wordpress.com

28. Kuehni RG, Marcus RT. An experiment in visual scaling of small color differences. Color Res Appl 4 (1979), pp. 83-91.

29. Johnston WM, Kao E.C. Assessment of appearance match by visual observation and clinical colorimetry. J Dent Res 68 (1989), pp. 819-822.

30. Ragain JC, Johnston WM. Color acceptance of direct dental restorative materials by human observers. Color Res Appl 2000;25:278-85.

31. Douglas RD, Brewer JD. Acceptability of shade differences in metal ceramic crowns. J Prosthet Dent 79 (1998), pp. 254-260.

32. Melgosa M, Pérez MM, Hita E. Chromaticity-discrimination thresholds with aperture and object colors: experimental results and predictions of some recent color-difference formulas. Appl Opt 1996 Jan 1;35(1):176-87.

33. Wyszecki G. Color matching and color-differences matching. J Opt Soc Am 1972; 62:117-128.

34. CIE Proc. 8th Session, Cambridge 1931; $19-29$ (recomendations 1, 2, 3, 4), Cambridge University Press, Cambridge 1932.

35. http://www.daltonize.org

36. Morley $\mathrm{J}$. The role of cosmetic dentistry in restoring a youthful appearance. $\mathrm{J}$ Am Dent Assoc 1999; 130: 1166-72.

37. Goldstein RE. In-office bleachig: where we came today. J Am Dent Assoc 1997; 128: 11-5.

38. Lambert DL. Motivación estética y blanqueamiento dental vital. Signature Int 2000;5: 5-10. 
39. Clark EB. Tooth color selection. J Am Dent Assoc 1933; 20:1065-1073.

40. Hall NR. Tooth colour selection: the application of colour science to dental colour matching. Aust Prosthodont J 1991; 5: 41-46.

41. Hattab FN, Qudeimat MA, Al-Rimawi HS. Dental discoloration: an overview. Journal of Esthetic Dentistry 11 (1999), pp. 291-310.

42. Qualtrough AE, Burke FJT. A look at dental esthetics. Quintessence International 25 (1994), pp. 7-14.

43. Hernández Rodriguez Z, Celemín Viñuela A. Estudio del color en la población española según sexo y edad. Gaceta Dental: Industria y Profesionales 2009 № 203 Pág 160-175.

44. Clark EB. An analisys of tooth color. J Am Dent Assoc 1931;18: 2093-2103

45. Touati B, Miara $P$, Nathanson D. Transmisión del color y de la luz. En: Odontología estética y restauraciones cerámicas. Barcelona: Masson S.A., 1999:39-60.

46. Llamas Cadaval R, Villa Vigil A. Biología de la Pulpa y de los Tejidos Periapicales. Endodoncia: Técnicas Clínicas y Bases Científicas. Barcelona; Madrid. Masson. 2001. Pag. 4-13.

47. http://www.solutions.productos3m.es

48. Ten Bosch JJ, Coops JC. Tooth color and reflectance as related to light scattering and enamel hardness. Journal of Dental Research 74 (1995), pp. 374-380.

49. Boyde A. Microestructure of enamel. Ciba Found Symp 1997;20:19-31.

50. Geller W. Polishing porcelain makes a crown smoother, more translucent, and improves the color. Quintessence Dent Technol 1983;7: 384-384

51. Devigus A. La medición del color en Odontología. Quintessence (ed. Esp) 2004; $17: 281-6$.

52. Carballo Tejeda V, Martinez Vazquez de Parga J.A. Influencia del metamerismo en la percepción del color dentario. Rev Int de Prótesis Estomatológica 2008, volumen 11 número 3; 213-219.

53. Overheim D. Light and color. New York: John Willey, 1982.

54. Winter R. Visulizing the natural dentition. J Esthet Dent 1993;5:103-117.

55. Orban BJ. Oral histology and embryology. Ed6. St Louis; Mosby, 1976.

56. Cornell $D$, Winter $R$. Manipulating light with the refractive index of an allceramic material. Pract Periodontics Aesthet Dent 1999;11.913-917.

57. Spitzer D, Bosch JT. The absorption and scattering of light in bovine and human dental enamel. Calcif Tissue Res 1975;17(2):129-37.

58. Fujimoto D. Isolation and characterization of a fluorescent material in bovine 
achilles tendon collagen. Biochem Biophys Res Commun 197720 de junio; 76 (4) :1124-9.

59. Booij M, Bosch JJ. A fluorescent compound in bovine dental enamel matrix compared with synthetic dityrosine. Arch Oral Biol 1982;27(5):417-21.

60. Ten Bosch JJ. General aspects of optical methods in dentistry. Adv Dent Res 1987 Oct;1(1):5-7.

61. Sundar V, Amber PL. Opals in nature. J Dent Technol 1999;16:15-17.

62. Ten Bosch JJ, Coops JC. Tooth color and reflectance as related to light scattering and enamel hardness. Journal of Dental Research 74 (1995), pp. 374-380.

63. Garber DA. The quest for the all-ceramic restoration. Quintessence Dent Technol 2000;23:27-36.

64. Zena R. Evolution of dental ceramics. Compendium of Continuing Education in Dentistry 2001;21:1068-74.

65. Ko CC, Tantbirojn D, Wang T, Douglas WH. Optical scattering power for characterization of mineral loss. J Dent Res. 2000 Aug;79(8):1584-9.

66. Sproull RC. Color matching in dentistry. Part 1. The three dimensional nature of color. J Prosthet Dent 1973; 29:416-424.

67. Lemiere PA, Burk B. Color in dentistry. Hartford, CN: JM Ney 1975.66-74.

68. Goodkind RJ, Keenan KM , Schwabacher WB. A comparison of Chromascan and spectrophotometric color measurements of 100 natural teeth. J Prosthet Dent 1985 Jan;53(1):105-9.

69. Ishikawa $\mathrm{T}$, Ishiyama $\mathrm{T}$, Ohsone $\mathrm{M}$, Sekine $\mathrm{N}$. Trial manufacture of photoelectric colorimeter using optical fibers. Bull Tokyo Dent Coll 1969 Nov;10(4):191-7.

70. Hosoya Y, Goto G. Primary tooth color I. Chromatic measurement using a color and color difference meter 1001 DP. Shoni Shikagaku Zasshi. 1985;23(1):69-77.

71. Goodkind RJ, Schwabacher WB. Use of a fiber-optic colorimeter for in vivo color measurements of 2830 anterior teeth. J Prosthet Dent 1987;58: 535-542.

72. Rubiño ., García JA, Jimenez del Barco L, Romero J. Colour measurement of human teeth and evaluation of a Colour guide. Color Res Appl 1994 Vol 19 ํㅜ1: 19-22.

73. http://www.bustamantelab.blogspot.com

74. Zelanski P, Fisher MP. Elementos básicos del color. Madrid: H. Blume, 2001:13-21.

75. Bergen SF. Color in esthetics. NY State Dent J 1985; 51:470-471. 
76. Van der Burgt TP, ten Bosch JJ, Borsboom PCF. Kortsmit WJ. A comparision of new and convencional methods for quantification of tooth color. J Prosthet Dent 1990;63: 155-62.

77. Yap AU, Sim CP, Loh WI, Teo JH. Human eye versus computerized color matching. Oper Dent 1999; 24: 358-63.

78. Ragain JC, Johnston WM. Color acceptance of direct dental restorative materials by human observers. Color Res Appl 2000;25: 278-85.

79. Preston JD. Current status of shade selection and color matching. Quintessence Int 1985 Jan; 16(1): 47-58.

80. Watts $A$, Addy $M$. Tooth discolouration and staining: a review of the literature. British Dental Journal 190 (2001), pp. 309-316.

81. Seghi RR, Hewlett ER, Kim J. Visual and instrumental colorimetric assessments of small color differences on translucent dental porcelain. $\mathrm{J}$ Dent Res 1989 Dec; 68 (12):1760-4.

82. Paul S, Peter A, Pietrobon N, Hämmerle $\mathrm{CH}$. Visual and spectrophotometric shade analisys of human teeth. J Dental Research 2002, vol81, no8:578-582.

83. Mayekar SM. Shades of a color illusion or reality?. Dental Clinics of North America 45 (2001), pp. 155-172.

84. Okubo SR, Kanawati A, Richards MW, Childress S. Evaluation of visual and instrument shade matching. J Prosthet Dent 1998; 80: 642-8.

85. Sproull RC. Color matching in dentistry. Part II. Practical applications for the organization of color. J Prosthet Dent 1973;29: 556-566.

86. O'Brien WJ. A new small-color difference equation for dental shades. Journal Dent Res 1990 (69)11:1762-1990.

87. Culpepper WD. A comparative study of shade-matching procedures. $J$ Prosthet Dent 1970; 24: 166-173.

88. Donahue JL. Shade color discrimination by men and woman. Journal of Prosthetic Dentistry 1991 (65) 5: 699-703.

89. Van der Burgt TP, ten Bosch JJ, Borsboom PCF. A new method for matching tooth colors with color standard. J Dent Res 1985;64:837-841.

90. Miller LL. Organizing color in dentistry. J Am Dent Assoc 1987 (social issue):26E-40E.

91. Yap AU. Color attributes and accuracy of Vita-based manufacturers' shade guides. Oper Dent 1998 Sep-Oct;23(5):266-71.

92. Mokhlis GR, Matis BA, Cochran MA, Eckert GJ. A clinical evaluation of carbamide peroxide and hydrogen peroxide whitening agents during daytime use. J Am Dent Assoc 2000 Sep;131 (9):1269-77. 
93. Kihn PW, Barnes DM, Romberg E, Peterson K. A clinical evaluation of $\mathbf{1 0}$ percent vs. 15 percent carbamide peroxide tooth-whitening agents. J Am Dent Assoc 2000 Oct;131(10):1478-84.

94. Heymann HO, Swift EJ Jr, Bayne SC, May KN Jr, Wilder AD Jr, Mann GB, Peterson CA. Clinical evaluation of two carbamide peroxide tooth-whitening agents. Compend Contin Educ Dent 1998 Apr;19(4):359-62.

95. Meireles SS, Demarco FF, Ida dos Santos S, Dumith SC, Bona AD. Validation and reliability of visual assessment with a shade guide for tooth-color classification. Oper Dent 2008 Mar -Apr ; 33 (2) :121-6.

96. http://www.vita-zahnfabrik.de

97. Priest G, Lindke L. Tooth color selection and characterization accomplished with optical mapping. Pract Periodontics Aesthet Dent 2000 Jun-Jul;12(5):497503; quiz 504.

98. Hammad IA. Intraroral repeatability of shade selections with two shade guides. J Prosthet Dent 2003; 89: 50-3.

99. Chu SJ. Digital shade análisis and verification: a case report and discussion. Pract Proced Aesthet Dent 2001;13:129-36.

100. Nuñez Díaz P, del Rio Highsmith J. Estudio comparativo entre sistemas de medición del color en Odontología. Gaceta Dental 2007 mar; 179.

101. Li Y. Tooth color measurement using Chroma Meter: techniques, advantages, and disadvantages. J Esthet Restor Dent 2003; 15: 33-41.

102. Tung FF, Goldstein GR, Jang S, Hittelmann E. The repeatability of an intraoral dental colorimeter. J Prosthet Dent 2002;88:585-590.

103. Wee AG, Kang EY, Johnston WM, Seghi RR. Evaluating porcelain color match of different porcelain shade-matching systems. J Esthet Dent 2000; 12: 27180.

104. Brook $\mathrm{AH}$, Smith RN, Lath DJ. The clinical measurement of tooth colour and stain. Int Dent J 2007 Oct; 57 (5):324-30.

105. Bolt RA, Bosch JJ, Coops JC. Influence of window size in small-window colour measurements particularly of teeth. Phys Med Biol 1994;39:1133-1142.

106. Douglas RD. Precision of in vivo colourimetric assessment of teeth. $\mathrm{J}$ Prosthet Dent 1997;77:464-470.

107. Joiner A, Jones NM. Raven SJ. Investigation of factors influencing stain formation utilizing an in situ model. Advances in Dental Research 9 (1995), pp. 471-476.

108. Goldstein GR, Schmitt GW. Repeatability of a specially designed intraoral colorimeter. J Prosthet Dent 1993; 6:16-9. 
109. Amengual-Lorenzo J, Llena-Puy MC, Forner-Navarro L. Reproducibilidad en la medición del color in vitro e in vivo mediante colorímetros específicos para uso dental. RCOE 2005; 10 (3):263-267.

110. Wang X, J Ge, RM Fay, Lu H, Gao C, Powers JM.Comparison of the color of ceramics as measured by different spectrophotometers and colorimeters. Int $\mathrm{J}$ of Prosthodontics 2005, vol 18, nำ1: 73-74.

111. Horn DJ, Bulan-Brady J, Lamar Hicks M. Sphere spectrophotometer versus human evaluation of tooth shade. J Endod 1998;24:786-790.

112. Trushkowsky RD. How a spectrophotometer can help you achieve esthetic shade matching. Compendium, Enero de 2003, vol24,ํ1: 60-66.

113. Carrillo JS, Álvarez C. Estudio preliminar de dos sistemas de blanqueamiento con tecnologías innovadoras en una sola sesión. Gaceta Dental, marzo 2001, ำ116:48-60.

114. Carrillo JS, Álvarez C. Blanqueamientos en Odontología: algunos aspectos de su aplicación y posibilidades de medición en clínica. Gaceta Dental, noviembre 2002, nำ132: 54-72.

115. Kourtis SG, Tripodakis AP, Doukoudakis AA . Spectrophotometric evaluation of the optical influence of different metal alloys and porcelains in the metalceramic complex. J Prosthetic Dentristry noviembre 2004, vol 92,n5: 477-485.

116. Cefaly DF, Seabra BG, Tapety CM, Taga EM, Valera F, Navarro MF. Efectiveness of surface protection of resin modified glass ionomer cements evaluated spectrophotometrically. Operative Dentistry, 2001, no 26:401-405.

117. Ortengren U, S Langer, Göransson A, T Lundgren. Influence of pH and time on organic substance release from a model dental composite: a fluorescence spectrophotometry and gas chromatograph/mass spectrophotometry analisys. European J of Oral Sciences, 2004, no 112:530537.

118. Paravina RD. Investigation of certain commercial dental shade guides by digital image analysis (thesis). Yugoslavia: University of Nis College of Medicine, 1998

119. Bargui N. Effects of bath variation on shade of dental porcelain. J Prosthet Dent 1985;54:625-627.

120. Davison SP. Shade selection by color vision defective dental personnel. J Prosthet Dent 1990;63:97-101.

121. Bergen SF. Color education for the dental profession. (thesis) New York: University of New York College of Dentistry, 1975.

122. Preston JD. Light and lighting in dental offices. Dental Clin North Am 
1978;22:431-451.

123. O'Brien WJ. Sources of color variation of firing porcelain. Dent Mater 19917 : 170-173.

124. Prieto Alvarez M, Mariana Cadorín Martínez, Celemín Viñuela A, Martínez Vázquez de Parga J. Estado actual del método de la toma de color en prótesis dental. Gaceta dental 2008 , no 193 págs. 114-133.

125. Saleski CG. Color, light and shade matching. J Prosthet Dent 1972;27:263-268.

126. Paravina RD. Shademat Visual +. Stom Prot YU 2000;2:25-28.

127. Aragoneses $R$. Definir y transmitr los colores de las piezas dentales y sus matices. Gaceta Dental, Diciembre 2007, 146-159.

128. O'Brien W. Double layer effect and other optical phenomena related to esthetic. Dent Clin North Am 1985;29:667-673.

129. Burton JF. Presbyopia and the dentist: The effect of age on clinical vision. Int Dental J 1990;40:303-312.

130. Pizzamiglio E. A color selection technique. J Prosthet Dent 1991;66:592-596.

131. Chu JS. Clinical Steps to Predictable Color Management in Aesthetic Restorative Dentistry. Dent Clin North Am 2007 Apr;51(2):473-85.

132. Jimenez Rubio-Manzanares A., Segura Egea JJ. Valoración del color dentario en 87 pacientes utilizando las guías Vita Y Chromascop. Archivos de Odontoestomatología 1998;14(12):665-674.

133. Cal E, Güneri $P$, Kose $T$. Comparison of digital and spectrophotometric measurements of colour shade guides. J Oral Rehabil 2006 33; 221-228.

134. Paravina RD. Evaluación del un nuevo aparato desarrollado para la determinación del color. Revista Internacional de Prótesis Estomatologica, 2003; 5(2): 137-144.

135. http://www.bustamantelab.blogspot.com

136. Karamouzos A, Papadopoulos MA, Kolokithas G, Athanasiou AE. Precision of in vivo spectrophotometric colour evaluation of natural teeth. $J$ Oral Rehabil 2007 Aug;34(8):613-21.

137. Pohjola RM. Evaluation of a stander shade guide for color change after desinfection. Quintessence International 2007(38)8: 671-676.

138. CIE Commission International de I'Eclairage (CIE): Colorimetry (ed. 3). CIE publication No.15. Vienna, Austria, Central Bureau of the CIE, 2004.

139. Melgosa M, Pérez MM, Hita E. Chromaticity-discrimination thresholds with aperture and object colors: experimental results and predictions of some recent color-difference formulas. Appl Opt 1996 Jan 1;35(1):176-87.

140. Luo MR, Cui G, Rigg B. The development of CIE 2000 colour-difference 
formula CIEDE 2000. Color Res App 2001 26, 340-350.

141. CIE Publication 116-1995, Industrial colour-difference evaluation (Thecnical Report) CIE Bureau Central, Vienna 1995.

142. Vallittu PK, Vallittu ASJ, Lassila VP. Dental aesthetics-a survey of attitudes in different groups of patients. Journal of Dentistry 24 (1996), pp. 335-338.

143. Seghi RR, Johnston WM, O'Brien WJ. Spectrophotometric analysis of color differences between porcelain systems. J Prosthet Dent 56 (1986), pp. 35-40.

144. Goodking RJ, Loupe MJ. Teaching of color in predoctoral and postdoctoral dental education in 1988. J Prosthet Dent 1992;67:713-717.

145. Paravina RD, Powers JM. Esthetic color training in dentistry. St Louis, MO, Elvervier-Mosby, 2004.

146. Kim-Pusateri S. Brewer JD. Reliability and accuracy of four dental shade matching. Journal Prosthetic Dentistry 2009; 101: 193-199.

147. Barrett AA, Grimaudo NJ, Anusavice KJ. Influence of a tab and disk design onn shade matching of dental porcelain. J Prosthet Dent 2002;88:591-597.

148. Odioso LL, Gibb RD, Gerlach RW. Impact of demographic behavioral, and dental care utilization parameters on tooth color and personal satisfaction. Compend Contin Educ Dent 2000; 29(suppl):S35-S41.

149. Xiao J, Zhou XD, Zhu WC, Zhang B, Li JY, Xu X. The prevalence of tooth discolouration and the shelf-satisfaction with tooth color in a chinese urban population. Journal of Oral Rehabilitation 2007 (34): 351-360.

150. Kershaw S, Newton JT, Williams DM. The influence of tooth colour on the perceptions of personal characteristics among female dental patients: comparisons of unmodified, decayed and 'whitened' teeth. Br Dent $\mathrm{J} 2008$ Mar 8; 204(5):E9; discussion 256-7.

151. O'Brien WJ. Hemmendinger H, Boenke KM. Color distribution of three regions of extracted human teeth. Dental Material 1997 13: 179-185.

152. Goodkind RJ, Schwabacher WB. Use of a fiber-optic colorimeter for in vivo color measurements of $\mathbf{2 8 3 0}$ anterior teeth. J Prosthet Dent 1987;58:535-542.

153. Schawabacher WB, Goodkind RJ, Lua MJ. Interdependence of the hue, value and chroma in the middle site of anterior human teeth. J Prosthodont 1994 Dec; 3(4)188-92.

154. Odaira C, Iskibashi K, Nagai S. Comparison of color gradation for natural dental incisors and corresponding shade tabs (abstract). J Dent Res 2003;82:B-249.

155. Tsuchiya K. A colorimetric study of anterior teeth. Shilkwa Gakuho 1973;73:87-120. 
156. Zhao $\mathrm{Y}$, Zhu J. In vivo color measurement of $\mathbf{4 1 0}$ maxillary anterior teeth. Chines J Dent Res 1998,1(3):49-51.

157. Hasegawa A, Ikeda I, Kawaguchi S. Color and translucency of in vivo natural central incisors. J Prosthet Dent 2000 Apr;83(4):418-23.

158. Kato A, lbusuki M. Color of the first bicuspid crown and maxillary anterior gingiva of the maxilla. Kokubyo Gakkai Zasshi. 1976 Sep;43(3):362.

159. Eiffler C, Cevirgen E, S Helling, Zornek J , M Pritsch, Hassel AJ. Differences in lighness, chroma, and hue in the anterior teeth of quinquagenarians and septuagenarians. Clin Oral en Investig. 2010 Oct; 14 (5) :587-91.

160. Dozic A, Kleverlaan CJ, Aartman IH, Feilzer AJ. Relations in color among maxillary incisors and canines. Dental Materials 2005; 21(3):187-91.

161. Hasegawa A. Motonomi A. Color of natural tooth crown in Japanese people. Color Research Application 2000 Feb, vol 25, n1; 43-48.

162. Schawabacher WB, Goodkind RJ. Three-diemnsional color coordinates of natural teeth compared with three shades guides. J Prosthet Dent 1990;64:425-431.

163. Amaechi BT, Higham SM. Quantitative light-induced fluorescence: a potential tool for general dental assessment. J Biomed Opt. 2002 Jan;7(1):7-13.

164. Morley J. Tricks for matching shades: the color match game. Dent Today 2000 May;19(5):70-3.

165. Hassan AK. Effect of age on colour of dentition of Baghdad patients. East Mediterr Health J. 2000;6:511-513.

166. Jahangiri L, Reinhardt SB, Mehra RV, Mathenson PB. Relationship between tooth shade value and skin color :an observacional study. J Prosthet Dent 2002 Feb;87(2): 149-52.

167. Morley J. The esthetics of anterior tooth aging. Curr Opin Cosmet Dent 1997;4:35-9.

168. Xiao J, Zhou XD, Zhu WC, Zhang B, Li JY, Xu X. The prevalence of tooth discolouration and the shelf-satisfaction with tooth color in a chinese urban population. Journal of Oral Rehabilitation 2007 (34): 351-360.

169. Gozalo-Diaz D, Johnston WM, Wee AG. Estimating the color of maxillary central incisors based on age and gender. J Prosthet Dent 2008 Aug;100(2):93-8.

170. Nyström M, M Kononen, Alaluusua S, M Evälahti, Vartiovaara J. Development of horizontal tooth wear in maxillary anterior teeth from five to 18 years of age. J Dent Res 1990 Nov;69(11):1765-70.

171. Kato A, Ibusuki M. Color of the first bicuspid crown and maxillary anterior 
gingiva of the maxilla. Kokubyo Gakkai Zasshi. 1976 Sep;43(3):362.

172. Zhu H, Lei Y, Liao N. Color measurements of 1944 anterior teeth of people in southwest of China discreption. Zhonghua Kou Qiang Yi Xue Za Zhi 2001 Jul;36(4):285-288.

173. Curd FM, Jasinevicius TR, Graves A, Cox V, Sadan A. Comparison of the shade matching ability of dental students using two light sources. J Prosthet Dent 2006 Dec;96 (6): 391-6.

174. Esan TA, Olusile AO, Akeredolu PA. Factors influencing tooth shade selection for completely edentulous patients. J Contemp Dent Pract 2006 Nov 1;7 (5):80-7.

175. Martínez Vazquez de Parga JA, Del Rio Highsmith J. Terapeútica integrada de las alteraciones estéticas odontológicas. Ed.Pues, SL 1999.

176. Martínez Vazquez de Parga JA, Del Rio Highsmith J, Vela Ramón L. Técnicas de determinación del color. Una nueva propuesta. Revista Europea de Odontoestomatología 1994;6(4):211-214.

177. Smith PW, Wilson $\mathrm{NH}$. Shade selection for single-unit anterior metal ceramic crowns: a 5 year retrospective study of 2500 cases. Int J Prosthodont 1998 Jul-Aug; 11(4):302-6.

178. Bayindir F, Kuo S, Johnston WM. Coverage error of the tree conceptually different shade guide systems to vital unrestored dentition. J Prosthet Dent 2007 Sep; 98(3): 175-85.

179. Berns RS. Billmeyer and Saltzman's principles of color technology. 3rd ed. New York: John Wiley and Sons; 2000. p.88-92.

180. Azer SS, GM Ayash, Johnston WM , Khalil MF, Rosenstiel SF. Effect of esthetic core shades on the final color of IPS Empress all-ceramic crowns. J Prosthet Dent 2006 Dec;96(6):397-401.

181. Wyszecki G, Stiles WS. Color science: Concepts and methods. Quantitatinve Data and Formulae, 2nd ed., Wilwy, New York, 1982, pp. 83-116.

182. Hunter RS, Harold RW. The measurement of appearance. New York:1987 Wiley, pp.3-68.

183. Rhoads JE, Rudd KD, Morrow RM. Procedimientos en el laboratorio dental. Edit Salvat 1998.

184. Segura Egea JJ, Jiménez Rubio-Manzanares $A$, Valle Rodríguez $M$. Fundamentos de colorimetría aplicados a la toma de color subjetiva en Odontología. Quintessence (ed.esp.)1999;12(2): 75-83.

185. Scharer P, Rinn LA, Kopp FR. Principios Estéticos de la Odontología. Ed. Doyma, 1981. 
186. Vega del Barrio JM. Materiales en odontología fundamentos biológicos, clínicos, biofísicos y fisicoquímicos. Edit Avances Madrid 1996.

187. Rey KA, deRijk WG. Variations of $L^{*}, \mathbf{a}^{*}, \mathbf{b}^{*}$, values among Vitapan Classical Shade Guides. J Prosthodont 2007; 16: 352-356.

188. Bentley C, Leonard RH, Nelson CF, Bentley SA. Quantitation of vital bleaching by computer analysis of photographic images. $J$ Am Dent Assoc 1999;130:809-816.

189. Horn DJ, Bulan-Brady J, Hicks ML. Sphere spectrophotometer versus human evaluation of tooth shade. J Endodontics, diciembre 1998 vol 24 ,n12: 786790.

190. Hassel AJ, Grossmann AC, Schmitter M. Interexaminer reliability in clinical measurement of $L^{*}, C^{*}, h^{*}$ values of anterior teeth using a spectrophotometer. International Journal Prosthodont 2007; 20: 79-84.

191. O’Keefe KL. Improving shade matching techniques. Part 2. J Houston Dist Dent Soc 1988; 59-28.

192. Lee YK, Lu H, Powers JM. Optical properties of four esthetic restorative materials after accelerated aging. Am J Dent 2006 Jun;19(3):155-8.

193. Paravina RD, Powers JM, Mariefay $R$. Comparación colorimétrica de dos guías tonales. Rev int de prótesis estomatologica 2002; 4 (4): 274-279.

194. Oh WS, Koh IW, O'Brien WJ. Estimation of visual shade matching errors with 2 shade guides. Quintaesence Int . Nov - Dec 2009 ; 40 (10):833-6.

195. Klemetti E, Matela AM, Haag P, Kononen M. Shade selection performed by novice dental professionals and colorimeter. J Oral Rehabil 2006;33: 31-5.

196. Wee AG, Lindsey DT, Kuo S, Johnston WM. Color accuracy of commercial digital cameras for use in dentistry. Dent Mater 2006 Jun;22(6):553-9.

197. Chamberlain GJ, Chamberlain DG. Color-its measurement. Computation and application .1st ed. London: Heyden 1980.

198. Haddad HJ , Jakstat HA, G Arnetzl, Borbely J , Vichi A, Dumfahrt H, Renault P, and cols. Does gender and experience influences shade matching quality?. J Dent 2009; 37 Suppl1:e40-4 Epub 2009 May 22.

199. Rodriguez Carmona M, Sharpe LT, Harlow JA, Barbur JL. Sex-related differences in chromatic sensitivity. Visual Neuroscience 2008;25:433-40.

200. Anusavice KJ. Reducing the failure potential of ceramic-based restorations. Part 1: Metal-ceramic crowns and bridges. Gen Dent 1996 NovDec;44(6):492-4.

201. Winkler S, Boberick KG, Weitz KS, Datikashvili I, Wood R. Shade matching by dental students. J Oral Implantol 2006;32(5):256-8. 
202. Ethell J, Jarad FD, Youngson CC. The effect of colour defective vision on shade matching accuracy. European Journal of Prosthodontics an Restorativr Dentistry, 2006; 14(3): 131-136.

203. Capa N, Malkondu O, Kazazoglu E, Calikkocaoglu S. Evaluating factors that affect the shade-matching ability of dentists, dental staff members and laypeople. J Am Dent Assoc 2010 Jan;141(1):71-6.

204. Horn DJ, Bulan-Brady J, Lamar Hicks M. Sphere spectrophotometer versus human evaluation of thhth shade. J Endod 1998;24:786-790.

205. Corcodel N, Helling S, Rammelsberg P, Hassel AJ. Metameric effect between natural teeth and the shade tabs of a shade guide. Eur J Oral Sci 2010 Jun;118 (3):311-6.

206. Corcodel N, Rammelsberg P, Moldovan O. Effect of external light conditions during matching of tooth color an intraindividual comparison. Int $\mathrm{J}$ Prosthodontic 2009; 22:75-77.

207. Jasinevicius TR, Curd FM, Schilling L, Sadan A. Shade-matching abilities of dental laboratory technicians using a commercial light source. J Prosthodont 2009 Jan;18(1):60-3.

208. Cha HS, Lee YK. Difference in illuminant-dependent color changes of shade guide tabs by shade designation relative to three illuminants. Am J Dent 2009 Dec; 22(6):350-6.

209. Gokce HS, Piskin B, Ceyhan D, Gokce SM, Arisan V. Shade matching performance of normal and color vision-deficient dental professionals with standard daylight and tungsten illuminants. J Prosthet Dent 2010 Mar;103 (3):139-47.

210. Meyenberg KH. Estética dental: una perspectiva europea. Journal of Esthetic Dentistry (version en castellano). Mayo Junio 1995;5(3):11-18.

211. Goldstein RE. Estética odontológica. Argentina .ED intermedica, 1980.

212. Paravina RD. Possibilities for improvement of the shade matching clinical procedure (thesis). Yugoslavia: University of Nis College of Medicine, 2000.

213. Vanini L. Light and color in anterior composite restorations. The International Aesthetic Chronicle 1996,8: 673-682.

214. Russell MD, Gulfraz M, Moss BW. In vivo measurement of colour changes in natural teeth. Journal Oral Rehabil 2000; 27: 786-792.

215. Paravina RD, Majkic G, Imai FH, Powers JM. Optimization of tooth color and shade guide design. J Prosthodont. 2007 Jul-Aug;16 (4):269-76. Epub 2007 Apr 23.

216. Analoui M, Papkosta E, Cochran M, Matis B. Designing visually optimal shade 
guides. J Prosthet Dent 2004 Oct;92 (4):371-6.

217. Boenke KM, O'Brien WJ .Coverage error of a new three dimensional shade guide (abstract). J Dent Res 1999;78:382.

218. Carossa S. Influencia de las espigas-muñones en la trasnsmisión de luz a través de diferentes coronas de porcelana: valoración clínica y espectrofotométrica. Rev Int de Prótesis Estomatológica 2001, vol3, n4:260265.

219. Da Silva JD, Park SE, Weber HP, Ishikawa-Nagai S. Clinical performance of a newly developed spectrophotometric system on tooth color reproduction. $J$ Prosthet Dent 2008 May;99(5):361-8.

220. Braun A, Jepsen S, Krause F. Spectrophotometric and visual evaluation of vital tooth bleaching employing different carbamide peroxide concentrations. Dental Materials 200723 (2):165-169.

221. Khurana R, Tredwin CJ, Weisbloom M, Moles DR. A clinical evaluation of the individual repeatability of three commercially available colour measuring devices. Br Dent J 200722 Dec, 203 (12) :675-80.

222. Dozić A, Kleverlaan CJ, El-Zohairy A, Feilzer AJ, Khashayar G. Performance of five commercially available tooth color-measuring devices. J Prosthodont 2007 Mar-Apr;16(2):93-100.

223. Lagouvardos PE, Fougia AG, Diamantopoulou SA. Repeatibility and interdevice reliability of two portable color selection devices in matching and measuring tooth color. J Prosthet Dent 2009;101:40-45.

224. Joiner A, Hopkinson I, Deng Y, Westland S. A review of tooth colour and whiteness. J Dent 2008;36 (suppl):S2-S7.

225. Witkowski S, Yajima ND, Wolkewitz M, Strub JR. Reliability of shade selection using an intraoral spectrophotometer. Clin Oral Investig 2011 Aug 10, (Epub ahead of print).

226. Seghi RR. Effects of instrument-measuring geometry on colorimetric assessments of dental porcelains. Journal Dental Res 1990; 69:1180-1183.

227. Jung RW, Jung WD. Vita Easyshade, Doc 200309151.http://www.vident.com/assets/downloads_cloak/Easyshade_Technology_paper. pdf, accessed Mar 2007.

228. Guan $\mathrm{YH}$. The measurements of tooth whiteness by imagen and spectrophotometry: a comparison. Journal of Oral Rehabilitation 2005 (32):715.

229. Derdilopoulou FV, Zantner C, Neumann K. Evaluation of visual and spectrophotometric shade analyses: A clinical comparison of 3758 teeth. Int 
J Prosthodont 2007;20:414-416.

230. Hugo B, Witzel T, klaiber B. Comparison of in vivo visual and computer-aided tooth shade determination. Clin Oral Investig 2005; 9: 244-250.

231. Myers ML, Browning Wd, Chan DCN, Blalock JS, Callan RS. Intra-rater agreement of easyshade and three practitioners. J Dent Res 2005;84:(Spec Iss A):403.

232. Judeh A, Al-Wahadni A. A comparison between conventional visual and spectrophotometric methods for shade selection. Quintessence Int 2009 Oct; 40(9):e69-79.

233. Horn DJ, Bulan-Brady J, Hicks ML. Sphere spectrophotometer versus human eye of tooth shade. J Endod. 1998 Dec; 24(12): 786-90.

234. Shillinburg $\mathrm{H}$, Hobo S, Whitsett LD. Fundamentals of fixed prosthodontics. 3rd ed, Chicago: Quintessence 1997;437.

235. Landis JR, Koch GG. The measurement of observer agreement for categorical data. Biometrics 1977; 33(1): 159-174.

236. Ahn JS, Lee YK. Color distribution of a shade guide in the value, chroma, and hue scale. J Prosthet Dent 2008 Jul; 100(1):18-28.

237. Douglas RD, Steinhauer TJ, Wee AG. Intraoral determination of the tolerance of dentist for perceptibility and acceptability of the shade mismatch. $J$ Prosthet Dent 2007;97:200-8. 

9.- ANEXO I 



\section{1.- ANEXO I}

El Análisis Cluster, también conocido como Análisis de Conglomerados, Taxonomía Numérica o Reconocimiento de Patrones, es una técnica estadística multivariante cuya finalidad es dividir un conjunto de objetos, o individuos, basándose en las características que estos poseen, en grupos (cluster en inglés) de forma que los perfiles de los objetos en un mismo grupo sean muy similares entre sí (cohesión interna del grupo) y los de los elementos de los conglomerados diferentes sean distintos (aislamiento externo del grupo). Es decir, que los grupos resultantes deben mostrar mucha homogeneidad entre los elementos del grupo y un alto grado de heterogeneidad entre los diferentes grupos. A partir de ahora a cada uno de estos grupos los denominaremos conglomerados

El Análisis de Conglomerados es una técnica exploratoria de datos de la que conviene destacar que la solución no es única y que se puede obtener distintas soluciones dependiendo del procedimiento seleccionado.

Previo a un análisis de conglomerados ascendente jerárquico (método de Ward) se realiza un análisis de componentes principales a las tablillas en las variables $L$ (valor 0 luminosidad), C (Intensidad o croma) y h (tinte o tono) tomando como valores de estas variables las medianas de los pacientes que fueron observados en cada una de las tablillas. Este análisis permite representar en un espacio bidimensional las interrelaciones entre las tablillas y las variables $\mathrm{L}, \mathrm{C}$ y $\mathrm{h}$, así como los representantes de los conglomerados que se obtienen.

Se han realizado dos análisis que consideran o no, el número de pacientes de cada una de las tablillas, refiriéndonos en el primer caso a análisis de conglomerados "con peso" y en el segundo caso a análisis de conglomerados "sin peso". 
Este Anexo I, se debe a que no nos hemos podido resistir a aplicar un Análisis de Conglomerados a las varibles ordinales continuas L, $\mathrm{C}$ y $\mathrm{h}$ para poder realizar un estudio en profundidad de como se relacionan y se agrupan las 26 tablillas de color de la guía dental 3D Master, así como los colores intermedios proporcionados por el espectrofotómetro. Además los gráficos ubican espacialmente está relación para visuliazarla de forma inequívoca.

Como veremos a continuación se aplican dos tipos de estudio, uno, denominado "con peso" donde cada color viene respaldado por su n, es decir, por el número de sujetos cuyo color dental se corresponde con el mismo. Otro estudio "sin peso" donde cada color es independiente sin tener en cuenta el número de sujetos que lo representa.

\subsubsection{Análisis de todas las tablillas de color con peso}

Antes de comenzar la exposición es conveniente señalar que cuando hablamos de todas las tablillas de color incluimos las 26 tablillas de color de la guía Toothguide 3D Master y los colores intermedios, datos que aporta el espectrofotómetro dental sin correspondencia física de tablilla de color.

La proporción de varianza entre cluster con respecto a la varianza total es de 0.8243 , es decir, el porcentaje de varianza inter-cluster con respecto a la varianza total es del $82.43 \%$, para los seis grupos de conglomerados en los que hemos dividido las tablillas estudiadas.

A continuación vamos a describir cada uno de los cluster, definiendo las características propias de cada grupo, sus componentes y las diferencias con respecto al centroide. El centroide es el promedio de las tablillas en las componentes L, C y h.

Vamos dar unas nociones básicas para la interpretación de las representaciones gráficas de los análisis de componentes principales de conglomerados. El eje horizontal representa un $81.94 \%$ de la inercia o varianza total de los datos mientras que el eje vertical representa un $16.24 \%$. La primera representación gráfica que se expone está reflejada a escala real y la segunda representación gráfica se amplía el eje vertical para poder apreciar mejor la situación de las tablillas en la gráfica. 
El centroide de todas las tablillas se representa en el punto de intersección de estos dos ejes. Además del centroide parten tres flechas, "Direcciones de Crecimiento" de cada una de las tres variables estudiadas, L, C, h que nos sirven para agrupar el conjunto de tablillas. Según se aleja la flecha del centroide significa que las tablillas que siguen dicha dirección tienen cifras altas, con respecto al valor del centroide de la variable que dicha flecha represente. Las tablillas que siguen la dirección opuesta a la flecha tienen cifras bajas con respecto al valor del centroide, tanto más bajas cuanto más alejadas estén del valor central de los ejes.

Los círculos amarillos representan los centroides de los conglomerados y su tamaño es proporcional al tamaño del cluster o número de sujetos que esa agrupación determinada representa.

Estas nociones que acabamos de explicar, son trasladables al resto de estudios de conglomerados en los tres análisis siguientes, salvo que en el análisis de todas las tablillas sin peso, el tamaño de los representantes de los grupos es proporcional al número de tablillas que forman los conglomerados.

La caracterización de los cluster se realiza mediante un contraste de hipótesis que compara los valores promedios de L, C, h, dentro del conglomerado (media de medianas) con respecto a los promedios globales para estas variables. Se toma en consideración los pesos de los conglomerados.

\section{Conglomerado 1}

Se caracteriza porque los componentes de este grupo poseen en promedio un valor más alto (82.87) que el centroide (76.25) ( $p<0.0001)$. El valor promedio de tinte también es más alto, 95.23 frente a 90.88 correspondiente al promedio de las tablillas $(p<0.0001)$. Un contraste similar sobre la intensidad nos dice que también es significativamente menor que el promedio de las tablillas, un valor de 14.68 frente a un valor de $19.89(p<0.0001)$.

Está compuesto por 10 tablillas que representan un número de 357 pacientes de un total de $1.361(26,23 \%)$, y es el cluster con mayor peso de los seis.

Las tablillas que engloba:

0,5M2 - 0M1,5 - OM3 - 1,5M1 - 1,5M1,5 - 1M1 - 1M1,5 - 2L1,5 - 2M1 - 2M1,5 
Conglomerado 2

Las características de este grupo se basan en un valor superior al global, 83.72 frente a 76.25 ( $p<0.0001)$ del centroide. La intensidad media del grupo es ligeramente superior a la intensidad de referencia pero sin diferencia estadísticamente significativa, 20.44, con respecto a $19.89(p=0.105)$. En el tinte existen diferencias estadísticamente significativas, encontramos una cifra promedio que engloba todas las tablillas de 92.11, y la referencia de este grupo 2 es de 90.88 ( $p<0.0001)$.

Este grupo está compuesto por ocho tablillas, que representan un peso de 156 sujetos dentro de la muestra total es decir, el $11.43 \%$ del total.

Sus componentes son:

1,5M2 - 1,5M2,5 - 1M2 - 2L2 - 2L2,5 - 2M2 - 2M2,5 - 2R2

\section{Conglomerado 3}

Los valores medios de las medianas de las tablillas de referencia empleadas para comparar son los siguientes, para el valor o luminosidad 76.25, para la intensidad 19,89, y para el tinte 90.88. En comparación los valores promedio de esta grupo número tres son para la luminosidad o valor, 74.98, para la intensidad, 16.61, y para el tinte 92.18. Resumiendo, el valor es ligeramente superior, la intensidad inferior, y el tinte superior, los tres presentan diferencias en promedio estadísticamente significativas $(p<0.0001)$.

Los componentes de este cluster son nueve:

$$
\text { 2,5L1,5 - 2,5L2 - 2,5M1- 2,5M1,5 - 2,5R1,5 - 2R1,5 - 3,5M1 - 3L1,5 - 3M1 }
$$

Este es el segundo conglomerado en importancia según el peso, representa a 339 individuos, en porcentaje, un $24.90 \%$. Si sumamos el peso correspondiente al cluster 1 , y al cluster 3, observaremos que superan ligeramente el $50 \%$, ello nos da la información de que representan a más de la mitad de la muestra total de sujetos incluidos en este estudio estadístico.

\section{Conglomerado 4}

Los valores promedio de este cluster con respecto a la luminosidad o valor, tinte e intensidad son por este orden, 75.45, 87.88, 26.03. Existen diferencias en promedio 
estadísticamente significativas para el tinte que es menor, para la intensidad que es mayor, y también para el valor que disminuye de un 76.25 para el conjunto de todas las tablillas a un promedio de $75.45(\mathrm{p}=0.040)$.

El Cluster número 4, es el cluster más numeroso en cuanto a número de tablillas que le pertenecen, 23:

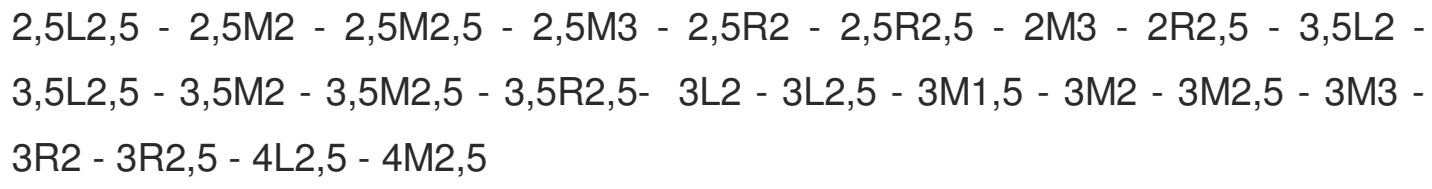

A pesar de ser el cluster más numeroso en cuanto al número de tablillas vemos que su peso de 200 sujetos ocupa el cuarto lugar, con un porcentaje de $14.69 \%$.

\section{Conglomerado 5}

Este grupo de tablillas presenta un promedio de valor y de tinte menor con cifras de 67.55 , y 87.37 respectivamente $(p<0.0001)$, por el contrario la intensidad media es ligeramente superior, $21.65(p<0.0001)$.

Su peso es de 219 sujetos (16.09\%), y contiene 16 tablillas:

$$
\begin{aligned}
& \text { 3,5L1,5 - 3,5M1,5 - 3,5R1,5 - 3,5R2 - 3R1,5 - 4,5M1 - 4,5M1,5 - 4,5M2 - 4L1,5 - } \\
& \text { 4L2 - 4M1 - 4M1,5 - 4M2 - 4R1,5 - 4R2 - 5M1 }
\end{aligned}
$$

\section{Conglomerado 6}

Por último el cluster número 6, con el peso menor de los cinco cluster ya descritos, está compuesto por 90 individuos (6.12\%) y por nueve tablillas:

3,5M3 - 4,5M2,5 - 4,5M3 - 4M3 - 4R2,5 - 5M1,5 - 5M2 - 5M2,5 - 5M3

Los valores medios de valor y tinte son inferiores al promedio de todas las tablillas, respectivamente con números de 64.81 y 81.73 respectivamente $(p<0.0001)$, por el contrario la intensidad media es claramente superior con cifras de $33.99(p<0.0001)$.

A continuación en la tabla resumen 1 resumimos los datos anteriormente expuestos. En el gráfico 1 representamos todas las tablillas agrupadas en conglomerados con su peso, en las dimensiones a escala real En el gráfico 2, se representa lo mismo que en 
gráfico 1, pero se amplía el eje vertical para la mejor visualización de las tablillas correspondientes.

En la tabla resumen de Ánálisis de Conglomerados 1, hemos colocado una flecha para indicar el sentido de la variación de L, C, y h si aumenta o disminuye, donde no hay cambio estadísticamente significativos, se mantiene la celda en blanco. También se puede valorar la media y las desviaciones estándar junto con el $p$ valor.

De manera análoga a esta explicación se pueden leer e interpretar las tablas y gráficos del estudio de Conglomerados o Cluster.

\begin{tabular}{|c|c|c|c|c|c|c|c|}
\hline \multicolumn{8}{|c|}{ ANALISIS DE CONGLOMERADOS } \\
\hline \multicolumn{8}{|c|}{ TODAS LAS TABLILLAS DE COLOR } \\
\hline & & $\mathbf{L}$ & C & h & Peso (n) & Porcentaje & Componentes \\
\hline CENTROIDE & & 76.25 & 19.89 & 90.88 & 1361 & $100 \%$ & \\
\hline \multirow{3}{*}{ Conglomerado 1} & Variación & $\uparrow$ & $\uparrow$ & $\downarrow$ & \multirow{3}{*}{375} & \multirow{3}{*}{$26.23 \%$} & \multirow{3}{*}{$\begin{array}{c}0,5 \mathrm{M} 2-\mathrm{OM} 1,5-\mathrm{OM} 3-1,5 \mathrm{M} 1- \\
1,5 \mathrm{M} 1,5-1 \mathrm{M} 1-1 \mathrm{M} 1,5-2 \mathrm{~L} 1,5-2 \mathrm{M} 1 \\
-2 \mathrm{M} 1,5\end{array}$} \\
\hline & media $\pm S D$ & $82.87 \pm 2.95$ & $14.68 \pm 1.75$ & $92.11 \pm 1.18$ & & & \\
\hline & $p$ valor & $\star$ & $\star$ & * & & & \\
\hline \multirow{3}{*}{ Conglomerado 2} & Variación & $\uparrow$ & & $\uparrow$ & \multirow{3}{*}{156} & \multirow{3}{*}{$11.43 \%$} & \multirow{3}{*}{$\begin{array}{c}1,5 \mathrm{M} 2-1,5 \mathrm{M} 2,5-1 \mathrm{M} 2-2 \mathrm{~L} 2-2 \mathrm{~L} 2,5- \\
2 \mathrm{M} 2-2 \mathrm{M} 2,5-2 \mathrm{R} 2\end{array}$} \\
\hline & media $\pm S D$ & $83.72 \pm 2.14$ & $20.44 \pm 1.03$ & $92.11 \pm 1.18$ & & & \\
\hline & p valor & \# & 0.105 & \# & & & \\
\hline \multirow[t]{3}{*}{ Conglomerado 3} & Variación & $\uparrow$ & $\downarrow$ & $\uparrow$ & \multirow[t]{3}{*}{339} & \multirow[t]{3}{*}{$24.90 \%$} & \multirow[t]{3}{*}{\begin{tabular}{|} 
2,5L1,5 - 2,5L2 - 2,5M1 - 2,5M1,5 - \\
$2,5 \mathrm{R} 1,5-2 \mathrm{R} 1,5-3,5 \mathrm{M} 1-3 \mathrm{~L} 1,5-3 \mathrm{M} 1$
\end{tabular}} \\
\hline & media \pm SD & $74.98 \pm 2.50$ & $16.61 \pm 2.03$ & $92.18 \pm 0.99$ & & & \\
\hline & p valor & * & * & * & & & \\
\hline \multirow[t]{3}{*}{ Conglomerado 4} & Variación & & $\uparrow$ & $\downarrow$ & \multirow[t]{3}{*}{200} & \multirow{3}{*}{$14.69 \%$} & \multirow{3}{*}{$\begin{array}{c}2,5 \mathrm{~L} 2,5-2,5 \mathrm{M} 2-2,5 \mathrm{M} 2,5-2,5 \mathrm{M} 3- \\
2,5 \mathrm{R} 2-2,5 \mathrm{R} 2,5-2 \mathrm{M} 3-2 \mathrm{R} 2,5-3,5 \mathrm{~L} 2 \\
-3,5 \mathrm{~L} 2,5-3,5 \mathrm{M} 2-3,5 \mathrm{M} 2,5-3,5 \mathrm{R} 2,5 \\
\text { 3L2 - 3L2,5 - 3M1,5 - 3M2 - 3M2,5 - } \\
\text { 3M3 - 3R2 - 3R2,5 - 4L2,5 - 4M2,5 }\end{array}$} \\
\hline & media $\pm S D$ & $75.45 \pm 3.42$ & $26.03 \pm 3.09$ & $87.88 \pm 1.70$ & & & \\
\hline & p valor & 0.040 & * & * & & & \\
\hline \multirow{3}{*}{ Conglomerado 5} & Variación & $\downarrow$ & $\uparrow$ & $\downarrow$ & \multirow{3}{*}{219} & \multirow{3}{*}{$16.09 \%$} & \multirow{3}{*}{$\begin{array}{c}\text { 3,5L1,5- 3,5M1,5 - 3,5R1,5 - 3,5R2 - } \\
\text { 3R1,5 - 4,5M1 - 4,5M1,5 - 4,5M2 - } \\
\text { 4L1,5 - 4L2 - 4M1 - 4M1,5 - 4M2 - } \\
\text { 4R1,5 - 4R2 - 5M1 }\end{array}$} \\
\hline & media $\pm S D$ & $67.55 \pm 3.35$ & $21.65 \pm 2.52$ & $87.37 \pm 2.09$ & & & \\
\hline & p valor & * & * & * & & & \\
\hline \multirow{3}{*}{ Conglomerado 6} & Variación & $\downarrow$ & $\uparrow$ & $\downarrow$ & \multirow{3}{*}{90} & \multirow{3}{*}{$6.12 \%$} & \multirow{3}{*}{$\begin{array}{c}\text { 3,5M3 - 4,5M2,5 - 4,5M3 - 4M3 - } \\
\text { 4R2,5 - 5M1,5 - 5M2 - 5M2,5 - 5M3 }\end{array}$} \\
\hline & media $\pm S D$ & $64.81 \pm 5.48$ & $33.99 \pm 4.59$ & $81.73 \pm 2.87$ & & & \\
\hline & p valor & 夫 & 夫 & $\star$ & & & \\
\hline
\end{tabular}

Nota: P-valores $<.0001$, serán identificados con un asterisco

Tabla resumen Análisis de Conglomerados 1 


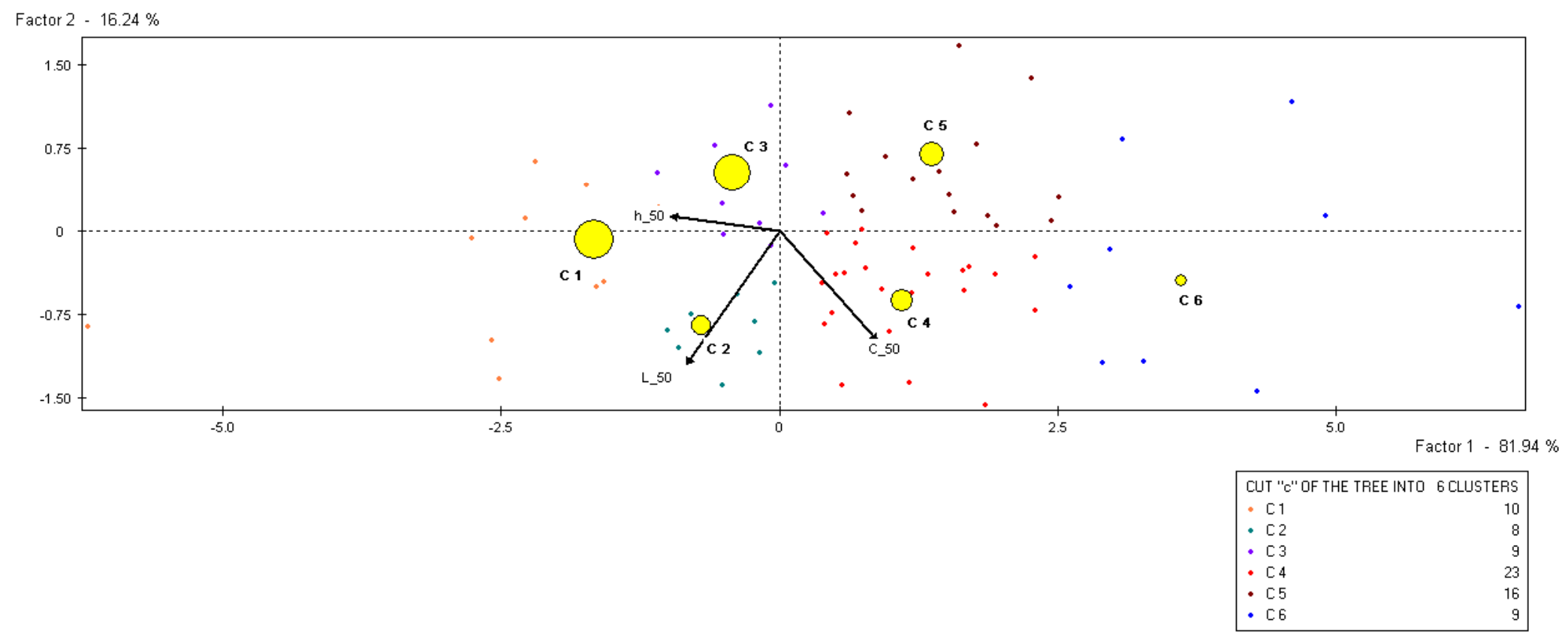

Gráfico Análisis de Conglomerados 1 


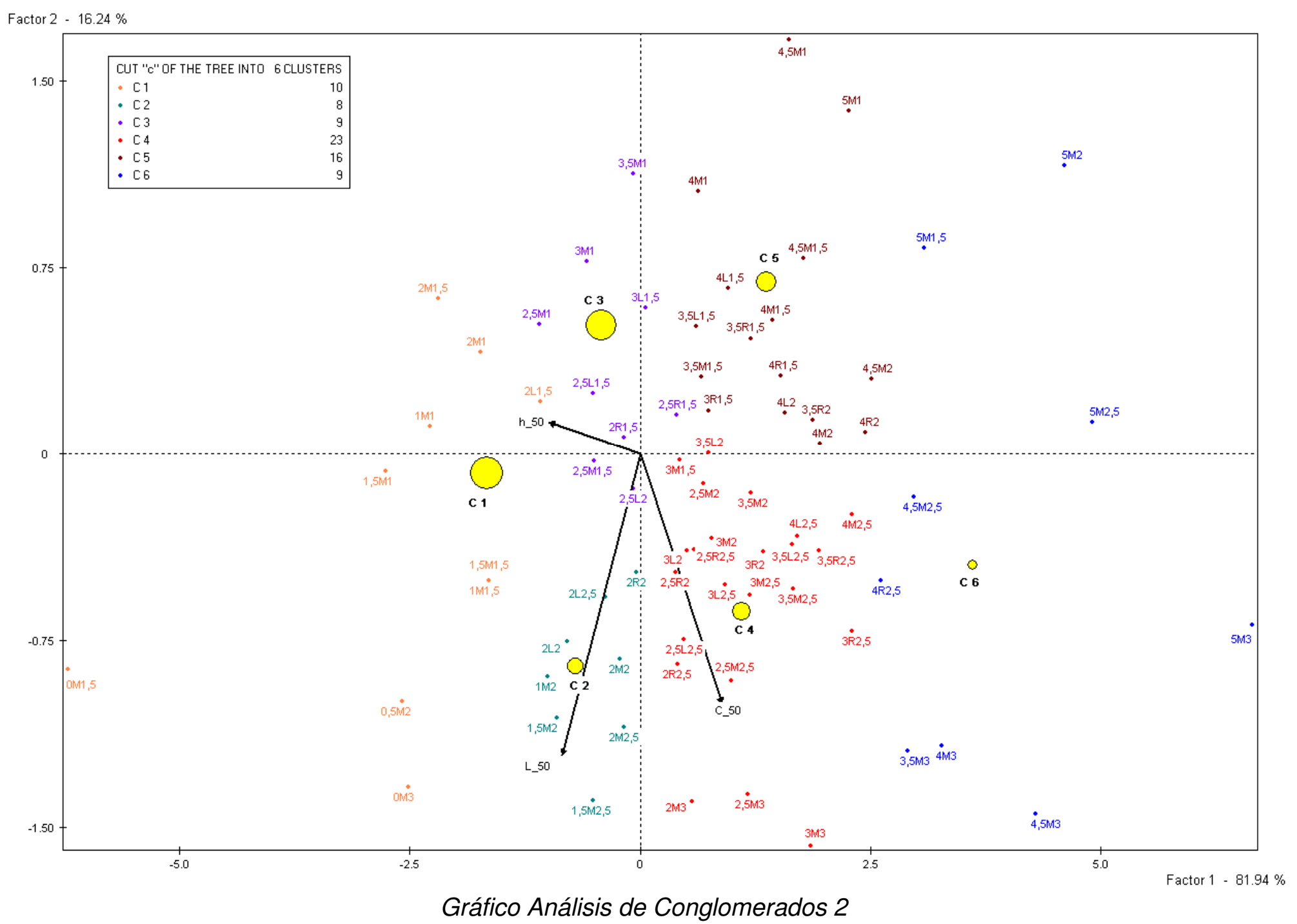




\subsubsection{Análisis de todas las tablillas de color sin peso}

La proporción de varianza entre conglomerados con respecto a la varianza total es de 0.7664 , es decir, se encuentra representado un $76.64 \%$ de la información, para los cinco grupos de conglomerados en los que hemos dividido las tablillas estudiadas, sin tener en cuenta el número de individuos que representa dentro de la totalidad de sujetos estudiados; con esto queremos decir, que todas las tablillas tendrán la misma importancia, sin considerar el número de repeticiones.

A continuación vamos a describir cada uno de los conglomerados definiendo las características propias de cada grupo, sus componentes y las diferencias con respecto al centroide.

Para la interpretación de las representaciones gráficas del Análisis de Conglomerados diremos que la línea discontinua horizontal representa un $83.75 \%$ de la información, mientras que el eje vertical representa un $12.61 \%$. Denominamos Centroide al punto de intersección de estas dos líneas. Además de este punto centroide parte tres flechas, "Direcciones de Crecimiento" de cada una de las tres variables estudiadas, L, C, h que nos sirven para agrupar el conjunto de tablillas según sus medianas. Según se aleja la flecha del centroide significa que las tablillas que siguen dicha dirección tienen cifras altas de la variable que dicha flecha represente.

En este caso el promedio de las 75 tablillas con respecto al valor o luminosidad es de 74.64, para la intensidad es de 22.87 y para el tinte es de 88.85 .

Hemos resumido a través de la tabla resumen 2, y de las representaciones gráficas expuestas posteriormente, las características de este análisis de conglomerados.

\section{Conglomerado 1}

Aparecen diferencias estadísticamente significativas $p<0.0001$ en todos los casos, tanto para el promedio valor o luminosidad que se ve aumentado 83.65 , para la media de la intensidad que se ve disminuida a 15.40, por el contrario el promedio del tinte se ve aumentado hasta llegar al 95.02.

Lo componen 14 tablillas que suponen el $18.66 \%$ de todas las tablillas:

0,5M2 - 0M3 - 1,5M1 - 1,5M1,5 - 1,5M2 - 1M1 - 1M1,5 - 1M2 - 2,5M1 - 2L1,5 - 2L2 $2 \mathrm{M} 1$ - 2M1,5 - 3M1 


\section{Conglomerado 2}

Este conglomerado solo representa a una tablilla (1.33\%): 0M1,5. Sus coordenadas son para el valor 100.00 , para la intensidad 7.7 y para el tinte $112.2^{\circ}$.

\section{Conglomerado 3}

Este es el grupo más numeroso con un porcentaje del $45.33 \%$ con 34 tablillas:

1,5M2,5 - 2,5L1,5 - 2,5L2 - 2,5L2,5 - 2,5M1,5 - 2,5M2 - 2,5M2,5 - 2,5M3 - 2,5R1,5 2,5R2 - 2,5R2,5 - 2L2,5 - 2M2 - 2M2,5 - 2M3 - 2R1,5 - 2R2 - 2R2,5 - 3,5L1,5 - 3,5L2 3,5M1 - 3,5M1,5 - 3,5M2 - 3,5R1,5 - 3L1,5 - 3L2 - 3L2,5 - 3M1,5 - 3M2 - 3M2,5 - 3R1,5 - 3R2 - 4L1,5 - 4M1

Sus valores promedios de L, C y h no difieren significativamente del centroide, siendo sus valores correspondientes por este orden $p=0.080, p=0.276, p=0.112$.

\section{Conglomerado 4}

El 28\% de las tablillas está dentro de este grupo de 21 elementos:

3,5L2,5 - 3,5M2,5 - 3,5M3 - 3,5R2 - 3,5R2,5 - 3M3 - 3R2,5 - 4,5M1 - 4,5M1,5 - 4,5M2 4,5M2,5 - 4L2 - 4L2,5 - 4M1,5 - 4M2 - 4M2,5 - 4R1,5 - 4R2 - 4R2,5 - 5M1 - 5M1,5

El valor media es significativamente menor 68.41 y el tinte promedio también 85.37 ambos con un $p<0.0001$ En cambio la intensidad media se ve aumentada del 22.87 valor del centroide a 26.75 de este conglomerado $(p<0.0001)$.

\section{Conglomerado 5}

El $6.66 \%$ de las tablillas están dentro de este grupo de cinco elementos:

4,5M3 - 4M3- 5M2 - 5M2,5 - 5M3

Caracterizados por unos valores medios de valor y tinte significativamente menores y una intensidad media significativamente mayores todos con un $p<0.0001$. Dando cifras, este grupo se encuentra definido por unos promedios de luminosidad o valor de 60.35, una intensidad de 37.57 y un tinte de 78.78. 
Representa un $11.75 \%$ del total y tiene una representación en sujetos de 64 .

Posteriormente en la tabla resumen 2 resumimos los datos pertenecientes a este análisis de conglomerados y a continuación en el gráfico 3 , se podrá observar su representación con escala real, y en el gráfico 4 se podrá ver con más detalle al ampliar el eje vertical.

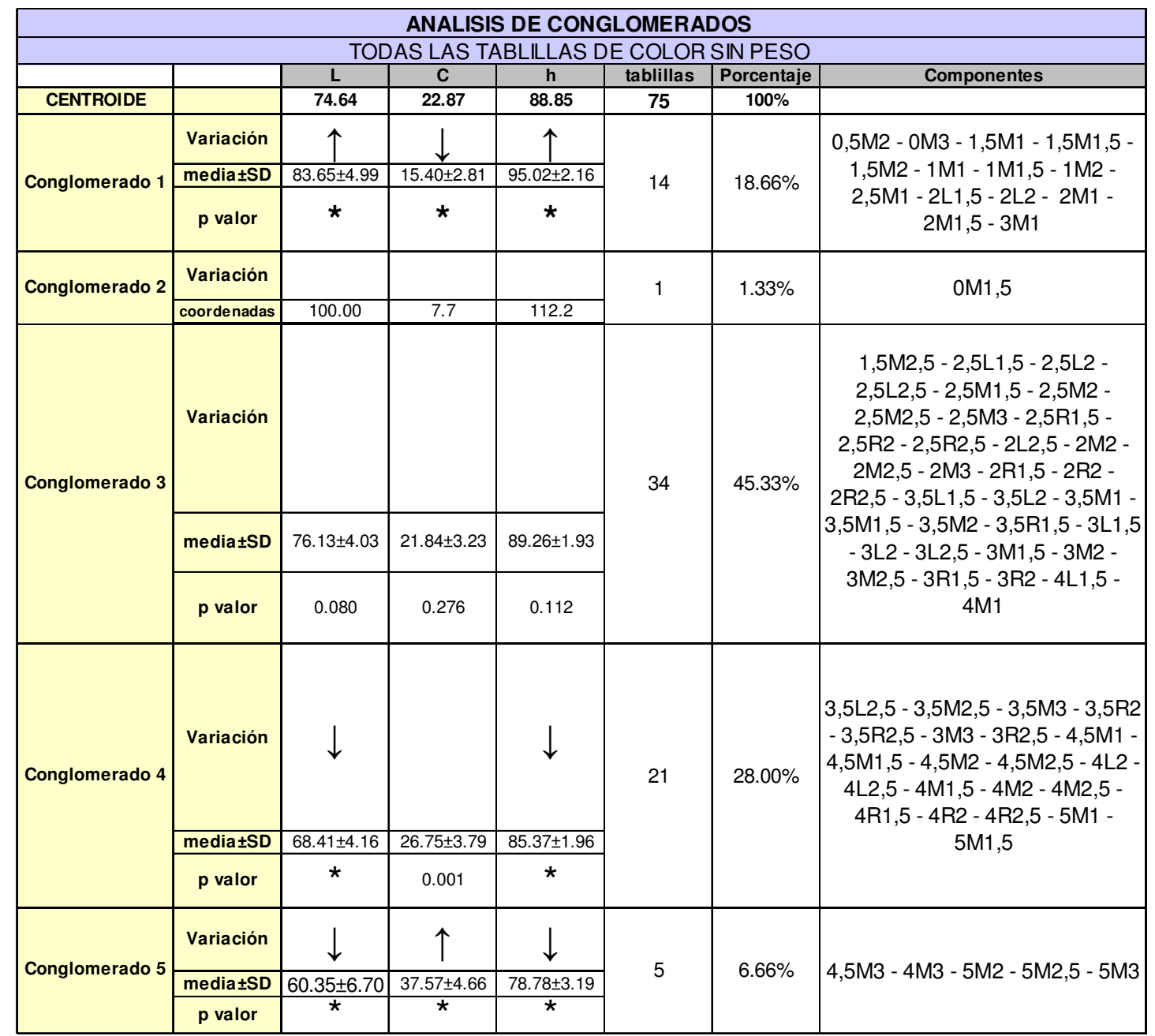

Nota: P-valores <.0001, serán identificados con un asterisco*

Tabla resumen Análisis de Conglomerados 2 


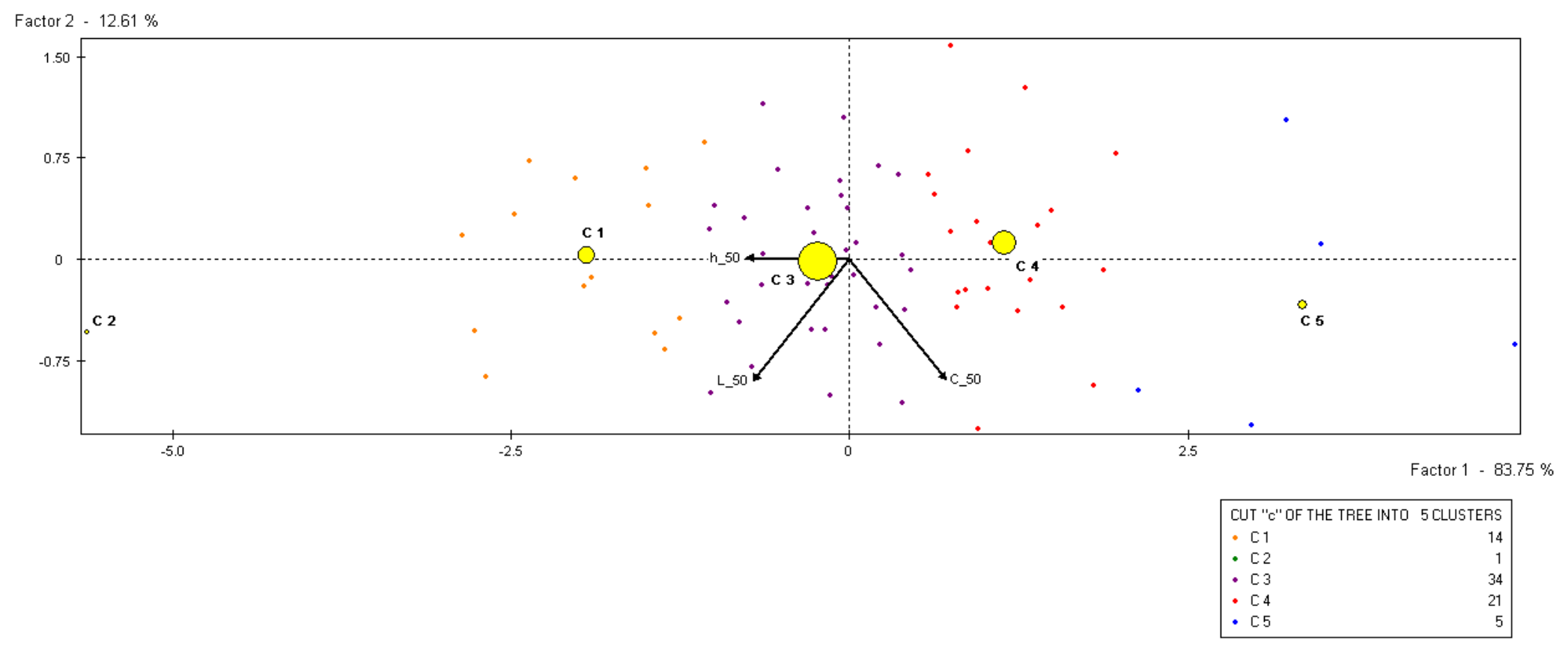

Gráfico de Análisis de Conglomerados 3 


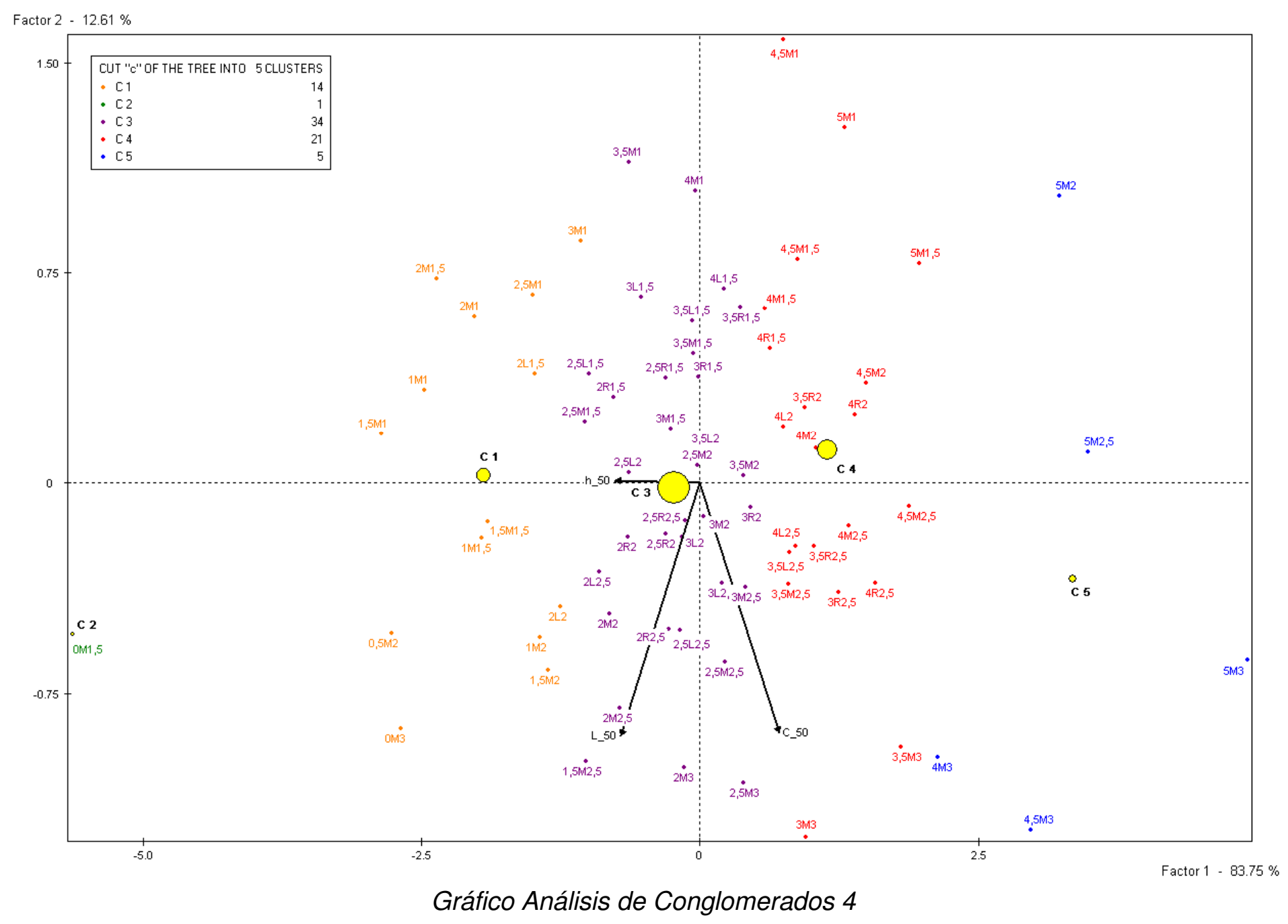




\subsubsection{Análisis de las tablillas 3D Master con peso}

Analizamos, dentro de este epígrafe, solo las 26 tablillas de la guía de color 3D Master, que simbolizan a 545 pacientes, es decir, un $40.04 \%$ del global.

Al agrupar dichas tablillas por similitud, se resuelve con 4 grupos diferentes, que representan un $74.13 \%$ de toda la varianza interconglomerado.

El promedio de las 26 tablillas de color con respecto al valor o luminosidad es de 77.13, con respecto a la intensidad es de 18.71 y por último el tinte de 91.86 .Vamos a describir cada uno de los grupos comparándolos con los promedios de referencia, es decir, con el centroide. La imagen correspondiente representa como factor 1 el $79.62 \%$ de la información en el eje vertical, y el 19.19\% de la información en el eje horizontal, denominado factor 2 .

\section{Conglomerado 1}

Se compone de tres elementos, 1M1 - 2L1,5 - 2M1, y tiene un peso de 192 individuos $(35.22 \%)$ y es el suprior de los cuatro. Sus características más importantes concentran un valor medio superior (80.67), un tinte promedio superior (95.27) y una intensidad media menor (13.84), todas con diferencias estadísticamente significativas y $\mathrm{p}<$ 0.0001 .

\section{Conglomerado 2}

Sus siete elementos son: 1M2 - 2M2 - 2R2,5 - 2L2,5 - 3M2 - 3L2,5 - 2M3. Su peso representa el $22.56 \%$ (123 sujetos) de los individuos cuyo color objetivo se encontraba dentro de las 26 tablillas de color presentes en la guía de color 3 D Master. El valor medio es superior (82.19), la intensidad media es superior (18.71) ambos con $p$ valores $<0.0001$ y el tinte promedio es ligeramente inferior (91.23) con un $p$ valor de 0.025 .

\section{Conglomerado 3}

El segundo en importancia por su peso, concierne a 166 individuos que significa un porcentaje de $30.45 \%$. Las seis tablillas que le pertenecen son: 2R1,5 - 3R1,5 - 3L1,5 $3 \mathrm{M} 1$ - 4M1 - 4L1,5. 
El dato medio del tinte es muy similar, 91.30 ( $p$ valor 0.028) sin diferencias estadísticamente significativas, el promedio de la intensidad es inferior (16.70) así como el promedio de la luminosidad o valor, éstas si se ven respaldadas por diferencias estadísticamente significativas $(p<0.0001)$.

\section{Conglomerado 4}

Engloba el mayor número de tablillas, sus 10 elementos son los siguientes: $3 \mathrm{M} 3$ 3R2,5 - 4M2 - 4L2,5 - 4R1,5 - 4R2,5 - 4M3 - 5M1, 5M2 - 5M3.

Tanto la luminosidad o valor medio, como el tinte promedio, son inferiores a los valores del centroide correspondientes. El valor tiene una cifra de 68.04 y el tinte de 83.51, ambos con diferencias estadísticamente significativas $(p<0.0001)$. Por el contrario la intensidad media se ve aumentada a 32.14, y está marcada con un $p<$ 0.0001 .

A continuación y siguiendo con la sistemática del análisis de conglomerados anterior, hemos realizado la tabla resumen 3 y la representación gráfica a en escala real de las 26 tablillas de color de la guía 3D Master en el gráfico 5.

\begin{tabular}{|c|c|c|c|c|c|c|c|}
\hline \multicolumn{8}{|c|}{ ANALISIS DE CONGLOMERADOS } \\
\hline \multicolumn{8}{|c|}{ TABLILLAS 3D MASTER CON PESO } \\
\hline & & $\mathbf{L}$ & C & $\mathbf{h}$ & Peso (n) & Porcentaje & Componentes \\
\hline CENTROIDE & & 77.13 & 18.71 & 91.86 & 1361 & $100 \%$ & \\
\hline \multirow{3}{*}{ Conglomerado 1} & Variación & $\uparrow$ & L & $\uparrow$ & \multirow{3}{*}{192} & \multirow{3}{*}{$35.22 \%$} & \multirow{3}{*}{$1 \mathrm{M} 1-2 \mathrm{~L} 1,5-2 \mathrm{M} 1$} \\
\hline & media $\pm S D$ & $\frac{1}{80.67 \pm 1.87}$ & $13.84 \pm 1.60$ & $\frac{1}{95.27 \pm 1.33}$ & & & \\
\hline & p valor & * & * & $\star$ & & & \\
\hline \multirow{3}{*}{ Conglomerado 2} & Variación & $\uparrow$ & $\uparrow$ & & \multirow{3}{*}{123} & \multirow{3}{*}{$22.56 \%$} & \multirow{3}{*}{$\begin{array}{c}1 \mathrm{M} 2 \text { - } 2 \mathrm{M} 2-2 \mathrm{R} 2,5-2 \mathrm{~L} 2,5- \\
3 \mathrm{M} 2-3 \mathrm{~L} 2,5-2 \mathrm{M} 3\end{array}$} \\
\hline & media \pm SD & $82.19 \pm 3.39$ & $22.04 \pm 2.75$ & $91.23 \pm 2.10$ & & & \\
\hline & p valor & * & * & 0.025 & & & \\
\hline \multirow{3}{*}{ Conglomerado 3} & Variación & d & L & & \multirow{3}{*}{166} & \multirow{3}{*}{$30.45 \%$} & \multirow{3}{*}{$\begin{array}{c}2 \mathrm{R} 1,5-3 \mathrm{R} 1,5-3 \mathrm{~L} 1,5-3 \mathrm{M} 1- \\
4 \mathrm{M} 1-4 \mathrm{~L} 1,5 .\end{array}$} \\
\hline & media $\pm S D$ & $72.78 \pm 2.72$ & $16.70 \pm 2.15$ & $91.30 \pm 1.37$ & & & \\
\hline & $p$ valor & & & 0.028 & & & \\
\hline \multirow{3}{*}{ Conglomerado 4} & Variación & 1 & $\uparrow$ & 1 & \multirow{3}{*}{64} & \multirow{3}{*}{$11.75 \%$} & \multirow{3}{*}{$\begin{array}{c}3 M 3-3 R 2,5-4 M 2-4 L 2,5- \\
4 R 1,5-4 R 2,5-4 M 3-5 M 1- \\
5 M 2-5 M 3\end{array}$} \\
\hline & media \pm SD & $68.04 \pm 7.61$ & $32.14 \pm 6.13$ & $83.51 \pm 3.83$ & & & \\
\hline & p valor & & & & & & \\
\hline
\end{tabular}

Nota: P-valores <.0001, serán identificados con un asterisco*

Tabla resumen Análisis de Conglomerados 3 


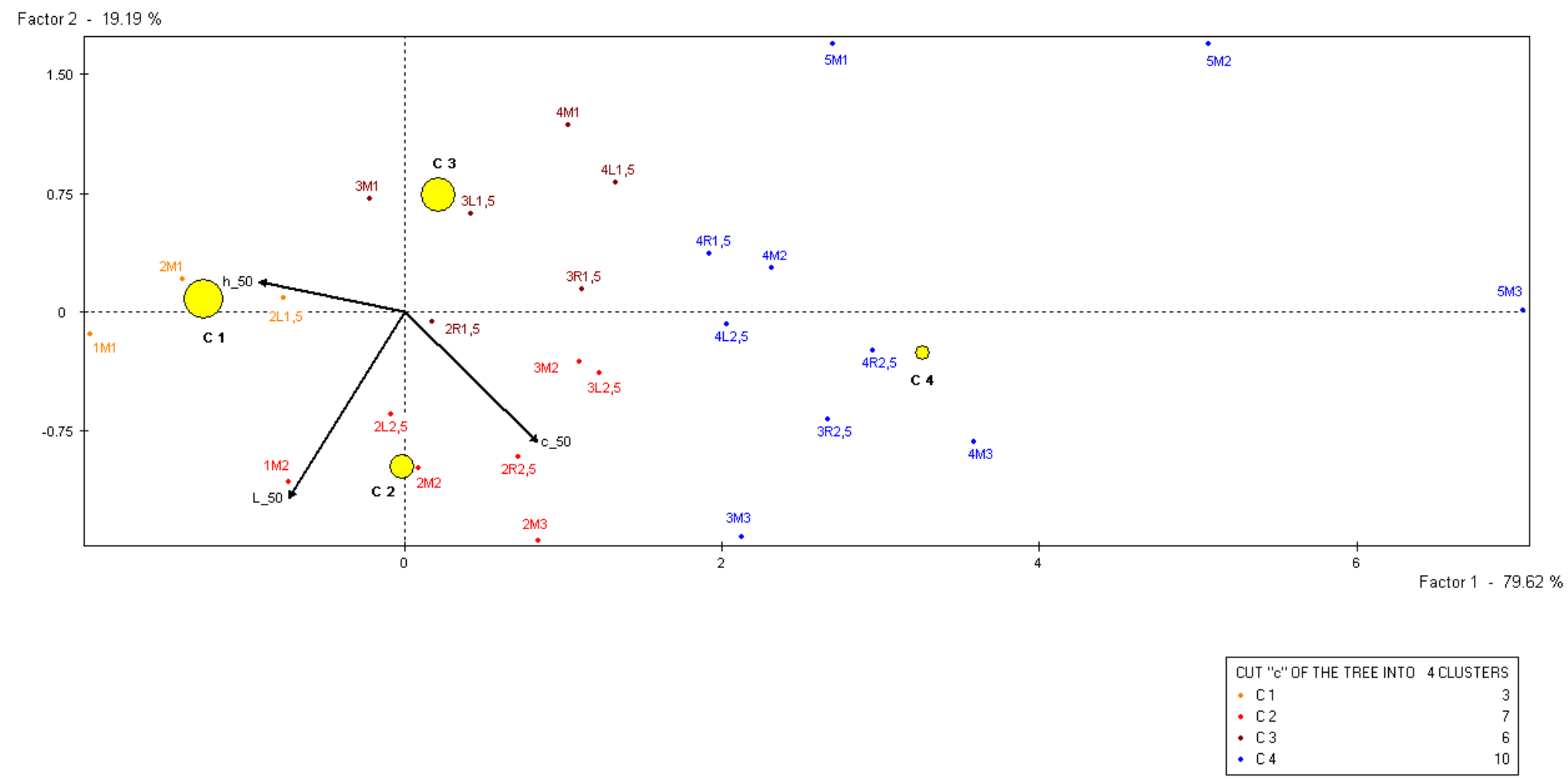

Gráfico de Análisis de Conglomerados 5 


\subsubsection{Análisis de la las tablillas 3D Master sin peso}

La proporción de varianza entre conglomerados con respecto a la varianza total es de 0.8049 , es decir, se encuentra representado un $80.49 \%$ de la información, para los cinco grupos de conglomerados en los que hemos dividido las tablillas estudiadas, sin tener en cuenta el número de individuos que representa dentro de la totalidad de sujetos estudiados; con esto queremos decir, que todas las tablillas tendrán la misma importancia, sin considerar el número de repeticiones.

A continuación vamos a describir cada uno de los conglomerados, definiendo las características propias de cada grupo, sus componentes y las diferencias con respecto al centroide.

Vamos dar unas nociones básicas para la interpretación de las representaciones gráficas del Análisis de Conglomerados. La línea discontinua horizontal representa un $82.33 \%$ de la información, mientras que el eje vertical representa un $14.35 \%$. Denominamos Centroide al punto de intersección de estas dos líneas. Además de este punto centroide parte tres flechas, "Direcciones de Crecimiento" de cada una de las tres variables estudiadas, L, C, h que nos sirven para agrupar el conjunto de tablillas según sus medianas. Según se aleja la flecha del centroide significa que las tablillas que siguen dicha dirección tienen cifras altas de la variable que dicha flecha represente.

En este caso el promedio de las 26 tablillas con respecto al valor o luminosidad es de 73.30, para la intensidad es de 23.58 y para el tinte es de 88.02 .

Hemos resumido a través de la tabla 4, y del gráfico 6 expuestos posteriormente, las características de este análisis de conglomerados.

\section{Conglomerado 1}

Engloba seis elementos de 26, es decir un $23.07 \%$ del total. Sus elementos son los siguientes, $1 M 1$ - 2L1,5 - 2M1 - 2R1,5 - 3L1,5 - 3M1. Sus características más importantes concentran un valor medio superior (78.03), un tinte promedio superior (93.58) y una intensidad media menor (15.20), todas con diferencias estadísticamente significativas para $p<0.005$, excepto la luminosidad o valor $(p=0.054)$. 
Conglomerado 2

El valor promedio es de 80.04 , la intensidad de 23.02 y el tinte de 89.94 . No se aprecian según sus $\mathrm{p}$ - valores diferencias estadísticamente significativas ni en la intensidad ni en el tinte. Está representado por siete elementos que aportan un porcentaje de $26.92 \%$.

\section{Conglomerado 3}

Al igual que en el grupo anterior lo forman siete elementos, que son: 3R1,5 - 4L1,5 4L2,5 - 4M1 - 4M2 - 4R1,5 - 5M1.

No encontramos diferencias estadísticamente significativas para los valores medios del tinte, ni de la intensidad ni de la luminosidad o valor.

\section{Conglomerado 4}

Está compuesto por cuatro elementos, 3M3 - 3R2,5 - 4M3 - 4R2,5 que equivalen al $15.38 \%$ de las 26 tablillas analizadas. Solo la intensidad media se desmarca con diferencias estadísticamente significativas de los datos promedio del centroide, con una media de 31.65 y un $p$ valor de 0.009 .

\section{Conglomerado 5}

Es el grupo con menor número de elementos, dos, 5M2 - 5M3 y representa un porcentaje de $7.69 \%$ de las 26 tablillas. Los valores medios de la luminosidad o valor y del tinte encuentran disminuyen de manera estadísticamente significativa con respecto al dato medio correspondiente del centroide. El promedio de la intensidad aumenta, diferenciándose estadísticamente del valor promedio del centroide, 
ANALISIS DE CONGLOMERADOS

\begin{tabular}{|c|c|c|c|c|c|c|c|}
\hline \multicolumn{8}{|c|}{ ANALISIS DE CONGLOMERADOS } \\
\hline \multicolumn{8}{|c|}{ TABLILLAS DE COLOR GUÍA 3D MASTER SIN PESO } \\
\hline & & L & C & h & (n) & Porcentaje & Componentes \\
\hline CENTROIDE & & 73.30 & 23.58 & 88.02 & & $100 \%$ & \\
\hline \multirow{3}{*}{ Conglomerado 1} & Variación & & . & $\uparrow$ & \multirow{3}{*}{6} & \multirow{3}{*}{$23.07 \%$} & \multirow{3}{*}{$\begin{array}{c}1 M 1-2 L 1,5-2 M 1-2 R 1,5- \\
3 L 1,5-3 M 1\end{array}$} \\
\hline & media \pm SD & $78.03 \pm 3.77$ & $15.20 \pm 2.22$ & $93.58 \pm 2.59$ & & & \\
\hline & p valor & 0.054 & 0.001 & 0.002 & & & \\
\hline \multirow{3}{*}{ Conglomerado 2} & Variación & $\uparrow$ & & & \multirow{3}{*}{7} & \multirow{3}{*}{$26.92 \%$} & \multirow{3}{*}{$\begin{array}{c}1 \mathrm{M} 2-2 \mathrm{~L} 2,5-2 \mathrm{M} 2-2 \mathrm{M} 3- \\
2 \mathrm{R} 2,5-4 \mathrm{M} 1-4 \mathrm{M} 2-4 \mathrm{R} 1,5- \\
5 \mathrm{M} 1\end{array}$} \\
\hline & media \pm SD & $80.04 \pm 3.52$ & $23.02 \pm 2.45$ & $89.94 \pm 1.81$ & & & \\
\hline & p valor & 0.006 & 0.407 & 0.126 & & & \\
\hline \multirow{3}{*}{ Conglomerado 3} & Variación & $\uparrow$ & & & \multirow{3}{*}{7} & \multirow{3}{*}{$26.92 \%$} & \multirow{3}{*}{$4 \mathrm{~L} 1,5-4 \mathrm{~L} 2,5-4 \mathrm{M} 1$ - 4M2 - 4R1 } \\
\hline & media $\pm S D$ & $68.51 \pm 3.99$ & $22.73 \pm 3.43$ & $87.36 \pm 1.83$ & & & \\
\hline & p valor & 0.036 & 0.361 & 0.347 & & & \\
\hline \multirow{3}{*}{ Conglomerado 4} & Variación & & $\uparrow$ & 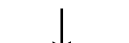 & \multirow{3}{*}{4} & \multirow{3}{*}{$15.38 \%$} & \multirow{3}{*}{ 3M3 - 3R2,5 - 4M3 - 4R2,5 } \\
\hline & media $\pm S D$ & $72.44 \pm 3.39$ & $\frac{1}{31.65 \pm 3.40}$ & $83.70 \pm 1.88$ & & & \\
\hline & p valor & 0.409 & 0.009 & 0.036 & & & \\
\hline \multirow{3}{*}{ Conglomerado 5} & Variación & 1 & $\uparrow$ & 1 & \multirow{3}{*}{2} & \multirow{3}{*}{$7.69 \%$} & \multirow{3}{*}{$5 \mathrm{M} 2-5 \mathrm{M} 3$} \\
\hline & media $\pm S D$ & $\frac{\downarrow}{54.05 \pm 1.05}$ & $37.55 \pm 6.95$ & $\frac{\Downarrow}{76.13 \pm 2.88}$ & & & \\
\hline & p valor & 0.000 & 0.003 & 0.000 & & & \\
\hline
\end{tabular}

Nota: P-valores <.0001, serán identificados con un asterisco*

Tabla resumen Análisis de Conglomerados 4 


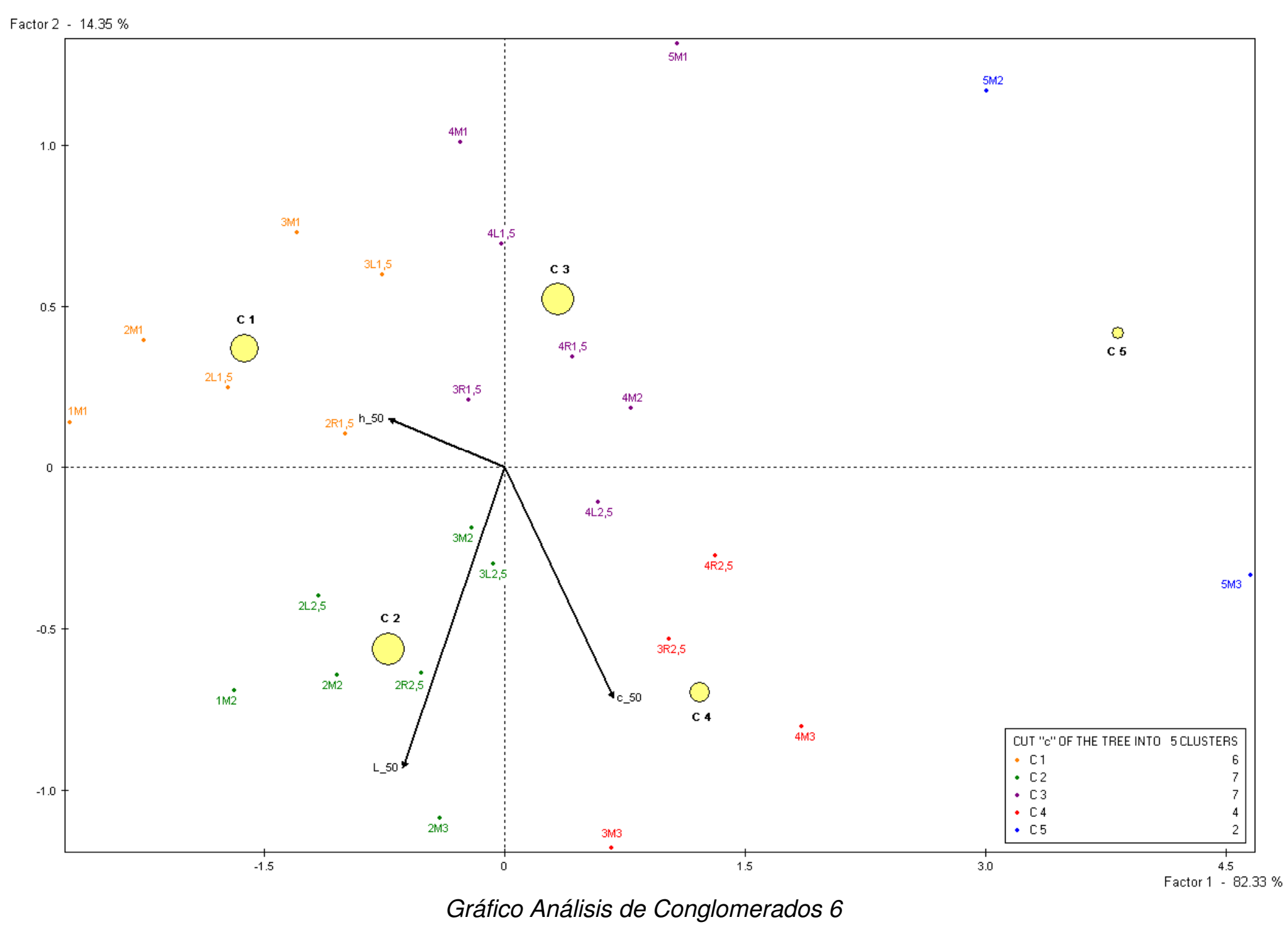



ANEXO II

ANEXO III

(CD ADJUNTO) 